\title{
TED HUGHES: ENVIRONMENTALIST AND ECOPOET
}

Yvonne Reddick 


\section{Dedication}

In memory of C. E. A. Reddick. 


\section{Acknowledgements}

I am grateful for the support of an Early Career Fellowship at the University of Warwick's Institute for Advanced Study, and a Research Fellowship at the University of Central Lancashire, which made it possible for me to write this book.

Many thanks to Jonathan Bate, Emma Francis, Robert Macfarlane and David Morley for their advice and support for this project. Bate offered incisive comments at multiple stages in the process that led to this book. Terry Gifford, Neil Roberts and Alan Rice have provided invaluable encouragement. I also wish to acknowledge the comments of anonymous peer reviewers who evaluated drafts of the manuscript. 


\section{TABLE OF CONTENTS}

CHAPTER I. INTRODUCTION

CHAPTER II. HUGHES, ECOCRITICISM AND ECOPOETRY

CHAPTER III. FROM MYTHOLMROYD TO MEXBOROUGH: ORIGINS OF HUGHES'S ENVIRONMENTAL AWARENESS

CHAPTER IV. 'LONG LIVE THE WEEDS AND THE WILDERNESS': HUGHES'S 'GREEN' LITERARY INFLUENCES

CHAPTER V. ANIMAL AGENCY, AMERICA AND EARLY ENVIRONMENTAL VIEWS

CHAPTER VI. THE ENVIRONMENTAL REVOLUTION

CHAPTER VII. HUGHES’S FARMING

CHAPTER VIII. 'JOIN WATER': HUGHES'S RIVER-POETRY

CHAPTER IX. GREEN LAUREATE

CHAPTER X. GLOBAL ENVIRONMENTS

CHAPTER XI. HUNTING, SHOOTING, FISHING - AND CONSERVATION? CONCLUSION 


\section{$\underline{\text { List of Abbreviations }}$}

Add MS: Additional manuscripts

BL: British Library

Cam TS: Cambridge University Library typescript

CPH: Ted Hughes: Collected Poems. London: Faber \& Faber 2003.

CPP: Sylvia Plath: Collected Poems. London: Faber \& Faber 1981.

DB: Difficulties of a Bridegroom. London: Faber \& Faber 1995.

Emory MARBL: Emory University Manuscripts, Archives and Rare Books Library

FTNB: Folktale notebook

PC: Ted Hughes and Keith Sagar, Poet and Critic: The Letters of Ted Hughes and Keith Sagar. London: British Library Publishing 2012.

PM: Poetry in the Making. London: Faber \& Faber 1967.

SGCB: Shakespeare and the Goddess of Complete Being. London: Faber \& Faber 1992. SPJ: The Unabridged Journals of Sylvia Plath. New York: Anchor 2000.

WP: Winter Pollen. London: Faber \& Faber 2004. 


\section{Chapter I. Introduction}

In 1993, Ted Hughes wrote to the critic Terry Gifford that his 'greening' began 'with everything that lay about [him] in [his] infancy.' 1 This book places his 'greening' - the development of his environmental consciousness - within its historical context, showing how it shapes his writing. Hughes won acclaim early in his career thanks to his famous poems about animals. A polymath who read avidly, he researched environmentally conscious farming practices, pollution, climate change and species extinction. He was a prominent public intellectual who co-founded the West Country Rivers Trust and supported bodies such as the Torridge Action Group, the Countryside Commission and the Royal Society for the Protection of Birds. Scholars have researched Hughes's active engagement in environmental issues before, and yet the opening of the British Library's Ted Hughes archive in 2011 revealed a far greater breadth of material than had previously been accessible. These materials transform our understanding of Hughes as an environmentalist and environmental writer by providing a far more detailed account of his activities. This study of Hughes as an environmental writer has never been more timely, since cultural interest in Hughes's work is also growing apace. Carol Ann Duffy inaugurated the Ted Hughes Award for new work in poetry in 2010, the Ted Hughes Society was formed in 2011, and Jonathan Bate's major biography of Hughes was published in 2015. Indeed, it was Bate’s interest in Hughes's environmentalism that first inspired him to write Ted Hughes: The Unauthorised Life.2 Since then, a new Ted Hughes Project has been founded at the University of Huddersfield, headed by South Yorkshire poet, scholar and hunter Steve Ely.

Meanwhile, the environmental issues that so preoccupied Hughes remain pressing problems in our time. In a letter of 1997, Hughes wrote to a fellow member of the West Country Rivers Trust that in the future, the struggle between commerce and environmental husbandry would be 'overtaken on the grandest scale by global warming' (qtd. in Douglas 10). His words were prescient. Concern about climate change has generated international initiatives such as the Intergovernmental Panel on Climate Change, founded in 1988, which seeks to influence policy via the UN Framework Convention on Climate Change's annual conferences (IPCC 2013 1). The Intergovernmental Panel on Climate Change’s 2014 report begins, 'Human interference with the climate system is occurring' (2). The adverse effects that it lists - an impact on marine and freshwater ecosystems (8), detrimental consequences for agriculture (10), the impact of deforestation (21) - recall many of Hughes's own environmental concerns. The report stresses the need for climate change mitigation as well as adaptation (17), and its warnings about the potential economic damage that global warming could bring resonate with Hughes's statement about its probable impact on commerce (19). In spite of such warnings, President Donald Trump’s administration has attempted to prevent data on climate change from being accessible to the public (Weiser), and tried to deny that carbon

${ }_{1}$ BL Add MS 88988/2, Ted Hughes to Terry Gifford, 17th December 1993.

2 Neil Roberts, conversation with Jonathan Bate, 'Ted Hughes: Dreams as Deep as England' conference, University of Sheffield, $10^{\text {th }}$ September 2015. 
dioxide causes climate change (Milman). With environmental issues at the forefront of many people's minds, cultural responses to environmental problems continue to proliferate. Artists, writers, musicians and filmmakers are focusing their attentions on environmental issues. Practitioners from performance artist Joseph Beuys to contemporary video artist Edwina Ashton consider our relationship with other species. 3 Artist Eduardo Kac creates controversial, transgenic animals to raise unsettling questions about our management of animal lives (Wolfe 2010 158-67). Musical engagements with environmental issues range from Daniel Crawford's compositions inspired by climate change data (Reubold) to Richard Skelton and Autumn Richardson's laments for Britain's lost wolves and forests. 4 Outdoor installations by artist Andy Goldsworthy and poet David Morley, created from organic materials, examine the environmental implications of creating culture products in the first place.5 The past fifteen years have seen a wealth of publications deploying ecocriticism, 'the study of the relationship between literature and the physical environment' (Glotfelty and Fromm xviii) and ecopoetics (the study of poetry that rejects outmoded forms of nature writing and replaces them with a significant environmental focus). Scholarly interest in environmental poetry is growing apace, while cultural interest in Hughes's work is burgeoning: there has never been a more opportune time to explore Hughes's environmentalism.

The attention that Hughes's work commands from ecocriticism testifies to his pre-eminence as an environmental writer. Pioneering ecocritics such as Terry Gifford, Jonathan Bate and Leonard Scigaj have analysed Hughes: Gifford in three monographs, edited essay collections, many book chapters and a large corpus of articles, Bate in a seminal ecocritical book and a major biography, and Scigaj in two monographs, an array of articles and an edited essay collection. It was Gifford's work that first brought Hughes's environmental campaigns to the attention of the scholarly community. Keith Sagar has written a book on Hughes's writing about nature. More recently, Susanna Lidström has devoted several articles, and a recent monograph, to an examination of Hughes and Heaney's work in the light of ecocritical theories such as environmental sign-systems and ecopoetics. Sam Solnick's 2016 monograph analyses how Hughes's poetry resonates with recent ideas about the Anthropocene: our current era when human beings have become a geological force. Meanwhile, Plath studies suggest new perspectives on environmental poetry that can be applied to Hughes's work. Plath's environmental concerns have been analysed by Gifford (2011 165-7), the Plath expert Tracy Brain (2001 84-140) and the ecopoetics scholar Scott Knickerbocker (123-158). Since Hughes and Plath both informed themselves about chemical pollutants and mobilised to protest against nuclear technology, insights on Plath's work add to our understanding of the two poets' knowledge of environmental problems.

\footnotetext{
3 For more information about the way visual art engages with animals, see Steve Baker, 'Sloughing the Human' in Wolfe 2003 147-64.

4 These appear in their albums Wolf Notes (2011) and Succession (2013).

5 For further artists who create such installations, and the implications of such artistic practices for the crossover between literature and art, see Skinner 2004128.
} 
This book builds on the foundations laid by many earlier critics. Craig Robinson's 1989 monograph Ted Hughes as Shepherd of Being, which provides a Heideggerian reading, adumbrates later ecocritical readings of Hughes by stressing Hughes's 'acutely sensitive attunement to the environment' (2). However, Robinson's book does not engage with the recently available archival material that now enriches our understanding of Hughes's environmentalism. Keith Sagar's Ted Hughes and Nature: 'Terror and Exultation' (2009) gives a thorough account of Hughes's writing about nature, yet it leaves out important theoretical insights and does not engage with poetry after River. Owen Johnson complained in an unpublished thesis of 1991 that literary scholarship was yet to reflect contemporary concern about environmental problems (22), but four years later, Leonard Scigaj's article 'Ted Hughes and Ecology: A Biocentric Vision', contributed significant groundwork to critical work on Hughes's environmental writing.

Missing from Hughes studies to date are a full examination of Hughes's environmental writing in its historical and political contexts, and a detailed analysis of the way his poetry engages with the environment at lexical and formal levels. The field as it stands requires a closer engagement with the international dialogue that is occurring among ecopoetics scholars. Another notable lacuna is a detailed problematisation of Hughes's defence of blood sports. It is equally surprising that there has been no earlier discussion of the way in which prominent women poets have celebrated Hughes's environmental writing and activism. Of course, 'green' issues have been an important feature of previous work on Hughes - but this book's engagement with the above issues broadens the ambitions of the field. It was Gifford's work that placed Hughes among the 'green' poets (2011 132-56). Many studies of Hughes's work comment on writings that are obviously 'green': protest poems such as ‘1984 on 'The Tarka Trail'” and 'If' (Gifford, Ted Hughes 57-58), high-profile environmental statements such as 'Rain-Charm for the Duchy' (Gifford, Ted Hughes 64; Roberts 2006 155) and ecological laments such as 'The Black Rhino' (Gifford, Ted Hughes 63; Scigaj 1994 178). Gifford has also produced an innovative analysis of the link between extinction and industrial decline in Hughes's poetry about Elmet ('Hughes's Social Ecology' 81-2); but Hughes's perception of human beings' immersion in their environment, and the extent to which they have altered it, goes even deeper than this.

New work in ecopoetics shows how the shape and sound of poetry can echo natural sounds and animal vocalisations. It demonstrates how the lyric I can be superseded by a consciousness that acknowledges its connection to the more-than-human world. It examines how addresses to animals and landscapes, rhetorical though they may be, take nonhuman entities as valuable interlocutors. A poem does not have to carry an overt message of environmentalist protest to be an ecopoem. This book shows, via close textual analysis of published works and unpublished drafts, how much of Hughes's poetry is ecopoetry in all of these ways. Hughes's poetry even suggests innovative new developments for the field of ecopoetics. Some ecocritics have put forward theories that account for recent literature's preoccupation with toxicity, contamination, pollution and environmental devastation in the Anthropocene. Yet scholars of ecopoetry were only just beginning to do comparable work in 2015 and 2016, despite the wealth of ecopoetry that demands such interpretations. Chapter V 
shows how Hughes's Crow-project creates a distinctive ecopoetic mode to describe pollution, rubbish, war-zones and radiation: a poetics of waste for the Anthropocene waste lands of the late twentieth century. Meanwhile, postcolonial ecocriticism6 complements ecopoetic theories about indigenous peoples by deepening our understanding of Hughes's (sometimes problematic) presentation of Native Americans, and environments in developing countries. Hughes is remembered primarily for his poetry, but he was also an interdisciplinary author, capable of working across genres and creating hybrid literary works. Some ecopoetics scholars, such as John Felstiner (2009 4), contend that poetry, better than any other form of speech, articulates the warning signs in our environment. Such theorists would do well to remember that Hughes was an accomplished writer of environmental fiction, drama, polemics, campaign letters, speeches, articles, broadcasts, nature-diaries and fishing-diaries; he was also an important editor of environmental writing.

Moreover, Hughes's environmental awareness begins earlier than most critics except Gifford and Ely have acknowledged. Keith Sagar and Leonard Scigaj, for example, find Hughes's early poems to be anthropocentric. Yet Hughes was aware that silage pollution killed fish in the 1940s, while newly available archival materials show that his reading of Jungian psychoanalysis before he went to University, and during the late 1950s, 7 was shaping his conception of how our inner nature is connected to the natural world surrounding us. There was a tendency in early Hughes criticism to view Hughes's early animal-poems as wholly violent, or as revealing more about human beings than about animals themselves. Sagar finds 'The Hawk in the Rain', 'The Thought-Fox' and 'The Horses' to be 'at least as much about the narrator as the animal' (Sagar 2009 80), while Scigaj finds Hughes's early animal poems to be 'anthropocentric, and to some extent concerned with exerting patriarchal control'; the anthropocentrism of the early poetry 'vanishes abruptly in Wodwo' (1994 165). Paul Bentley has questioned how animals with 'trapsprung' heads and a seemingly automatic purpose can be 'assimilated with the organic' (3). Sagar has commented that many of Hughes's early animal-poems describe animals as 'machines' (2009 90) - but some of the animals in 'The Hawk in the Rain' have more creaturely agency than these thinkers would allow. Susanna Lidström's monograph is one of the first studies to propose that Hughes's poems are antianthropocentric (2015 141-44), and she finds early, 'violent' poems such as 'Thrushes' to illustrate such thinking (144). Jonathan Bate's highly influential study The Song of the Earth rightly stresses Hughes's graphic presentation of nature 'red in tooth and claw', although Bate does reiterate the old stereotype of Hughes's poetry as 'relishing the violence of nature's own processes' (2000 27). Bate later nuances this judgement by writing that Hughes is a poet '[o]f fresh water but also of polluted places. Of living life to the full, but also of death. And

\footnotetext{
${ }_{6}$ For more information about how the relationship between ecocriticism and postcolonialism has developed from mutual suspicion to cooperation, see Rob Nixon's chapter ‘Environmentalism and Postcolonialism' in Ania Loomba, Suvir Kaul, Matti Bunzi, Antoinette Burton, and Jed Etsy, eds, Postcolonial Studies and Beyond. Durham NC: Duke University Press, 2005, 233-51. See also Nixon’s book Slow Violence and the Environmentalism of the Poor (2011).
}

7 BL Add MS 88918/129/2 notes taken from folder, 20-22. These notes are undated, but they are situated between diary entries dating from 1959 and 1960. 
among his creatures are those not only of light but also of violence' (2015 5). This book seeks to appreciate the rich and nuanced symbolic possibilities of Hughes's famous poems about animals - creatures such as the jaguar have metaphorical depth as 'beautiful, powerful nature spirit[s]' and 'symbol[s] of man's baser nature', as Hughes told Faas (199) - while also illustrating their author's sensitivity to the agency, perception and suffering of real animals.

Hughes does not write of violent natural processes with unmixed relish. Lidström and Garrard astutely argue that 'what Hughes is trying to describe is not violent behaviour per se, but the instinctual behaviour of animals that he sees as the opposite to human self-awareness; actions that are free from any interventions by consciousness and therefore, in Hughes's view, essentially different from social and cultural human behaviour' (38). This is frequently the case; but it becomes more complicated in poems such as 'Pike', where the pike's predatory violence also symbolises impulses within the human unconscious. Moreover, some of Hughes's human characters, such as Jack Orchard in 'Hands' and the Native American headman in 'The Gulkana', have creaturely traits, which Hughes usually sees as extremely positive. Hughes's writing helped to jolt British poetry out of the urbane, 'fixed' atmosphere of The Movement, 8 channelling his anger about the class war (Bentley 9-10) and environmental destruction. Yet if the early Hughes often celebrates nature's violence, he sometimes problematises it - and he is deeply critical of human violence. Insights from the archives into texts that Hughes read suggest that while writing the poems of predation in Lupercal, he was reading Schopenhauer's views on the 'will of the species', but also the 'peace of the species', which survives violence.s Hughes's presentation of the ethical treatment of animals is multifaceted, and it sometimes seems contradictory. Gifford has analysed Hughes's fishing (1999) and Sagar and Roberts have begun some enquiries into the apparent contradictions surrounding his hunting. This book is the first critical work to problematise his defence of bloodsports, in the light of documents in Hughes's archive. The archives reveal how Plath permanently altered Hughes's attitude towards shooting game. They provide his correspondence with the Conservative philosopher and foxhunting man, Roger Scruton. They reveal that he also defended angling on conservationist grounds during a public inquiry in 1997, show how he attempted to negotiate the difficult issue of animal suffering as he farmed, campaigned, shot and fished. Discussions with Boyanowsky and Pero focus on the necessity of blood sports to the health and sanity of human beings. Hughes's environmental awareness began during his boyhood, and permeated much of his written output - and it originated with Hughes's enjoyment of blood sports. His (problematic) defence of hunting in the last years of his life attempts to reconcile progressive environmentalism with country practices that had by then begun to look extremely conservative.

It is Hughes's apparent conservatism, or his perceived reluctance to engage with politics, that many politically-minded critics have found objectionable. Yet new insights into Hughes's

\footnotetext{
8 For Hughes's admiration of the Movement poets, and his difference from them, see Skea’s Asia Festival interview transcription.
}

9 BL Add MS 88918/129/2 notes taken from folder 16-17. 
engagement with green politics and ideology complicate both of these viewpoints. When Seamus Heaney wrote of Hughes as a poet of the elemental, 'primeval landscape' (1983 15), he set the tone for many later critical opinions. Sean O’Brien finds that Hughes's poetry 'is uninterested by the developing social and political reality of the British Isles in his adult lifetime' (37), although he does admit that Hughes engages with the Great War (39). Tom Paulin accuses Hughes of wishing to 'escape into a dreamtime before history' (254) - a 'dreamtime' that actually conceals his allegiance with the political right. Since then, a newer strain of criticism has identified overt political and historical ideas in Hughes's work, but it has not yet paid sufficient attention to his engagement with environmentalist ideology and politics. Bentley has characterised the younger Hughes as an angry young man (46-9), while Ely finds that in his older years, he became a 'maverick 'small c' conservative' with strains of 'patrician environmentalism' (2015 55). A glance at Hughes's library corroborates this gradual shift in his political views: he begins with an occasional interest in Marxism, then researches 'green' economics, and finally looks up a critique of the Conservatives' supposed centralisation of power.10 His friend Roy Davids believed that he voted for the Green Party (Davids 2), although he admired Thatcher in his later years (Morpurgo n.p). 'Politically, he was never exactly consistent' (Bate 2015 482). He was not - yet Hughes thought that like the Royal Family, the Poet Laureate was required to remain above the level of party politics ( $L T H 530$ ). It is unsurprising that he was reluctant to circulate his political views publicly, although he did not hesitate to criticise those in power if they were not doing enough for the environment. Hughes frequently finds it impossible to escape into an apolitical nature, a 'dreamtime before history'. When he goes in search of the goddesses of Devon's rivers, his mythic vision is rapidly overturned by knowledge of polluting agricultural policies and nuclear waste dumps in the sea (CPH 841-4). Hughes may well yearn for a 'new and natural world that predates society' (Paulin 254), but his longing for it is a product of his critique of late capitalism, humans' dependence on destructive technology, and widespread environmental damage. Even when it does not engage overtly with politics, Hughes's ecopoetry is redolent of the environmentalist ideology that drives green politics, and it responds to contemporary developments in environmental thinking.

The recent flourishing of scholarly work deploying ecopoetry and ecocriticism makes this study of Hughes's environmentalism all the more necessary. Writers as early as Shakespeare 11 and Chaucer 12 have been the subjects of ecocritical readings, although Greg

\footnotetext{
10 In 1962 or 1963, Hughes acquired C. Wright Mills’s The Marxists, perhaps early enough for it to influence his writing about the 'class war' in his article 'The Rat under the Bowler Hat': Emory MARBL: HX40.M53 1963 HUGHES. Later books demonstrate his interest in 'green’ economics: Emory MARBL archive. Edward Goldsmith. The Great U-Turn: De-industrializing society. Bideford: Green Books, 1988. HC21. G65 1988 HUGHES. David W Pearce, Anil Markandya and Edward Barbier. Blueprint for a Green Economy. London: Earthscan, 1989. HD75.6.P427 1989 HUGHES. Frances Cairncross. Costing the Earth. London: Business Books, 1991. HC79. E5 C26 1991 HUGHES. Emory MARBL archive. In later years, he was researching critiques of Thatcher and Major's policies: Simon Jenkins. Accountable to None: The Tory Nationalization of Britain, Emory Woodruff library HD 4145. J46. 1995 HUGHES. The books on environmental issues far outnumber those on Marxism or Conservatism.
}

11 See for example Lynne Bruckner and Daniel Brayton, eds. Ecocritical Shakespeare. Farnham: Ashgate, 2011. 
Garrard shows how western literature becomes explicitly and self-consciously engaged with environmental issues after the publication of Silent Spring in 1962 (2004 1-2). William Rueckert was the first thinker to coin the term 'ecocriticism', in his 1976 essay 'Literature and Ecology: An Experiment in Ecocriticism' (Glotfelty and Fromm xix). It took until the 1990s for the movement to gain the scholarly momentum it has now. A wealth of publications engaging with ecocriticism, ecopoetics and animal studies has come out over the past few years. In the scholarship of ecopoetics, a sub-field of ecocriticism, Terry Gifford's Green Voices (1995), Leonard Scigaj's Sustainable Poetry (1999), David Gilcrest's Greening the Lyre (2002), Angus Fletcher's A New Theory for American Poetry: Democracy, the Environment, and the Future of Imagination (2004), Jonathan Skinner's 'Statement on "New Nature Writing”' (2005) in his ecopoetics journal, John Felstiner's Can Poetry Save the Earth? A Field Guide to Nature Poems (2009), Forrest Gander and John Kinsella's Redstart: An Ecological Poetics (2012), Scott Knickerbocker's Ecopoetics (2012) and Ann FisherWirth and Laura-Gray Street's The Ecopoetry Anthology (2013) raise questions about nature and humanity, debate what constitutes ecopoetry, and analyse its intricate relationship to the nonhuman world. This study of Hughes's work builds on the foundations of their scholarship. What is striking, though, is that all of these books, the first to focus on ecopoetics, were published in the United States, except Green Voices.13 Terry Gifford wrote in the 2011 second edition of Green Voices that there had been a lack of dialogue between American and British ecopoets and ecopoetics scholars before the publication of Neil Astley's 2007 anthology Earth Shattering: Ecopoems (9). With Skinner's appointment to an academic post in Britain, his ecopoetics journal has also crossed the Atlantic, and the transatlantic dialogue on ecopoetics continues to develop apace. British critic Sam Solnick's 2016 monograph takes the important step of analysing Hughes's ecopoetry as a response to the Anthropocene. British ecocritics such as John Parham, Robert Macfarlane and Matthew Jarvis have all explored the ways in which poetry engages with Britain's environments. British poets Neil Astley, Alice Oswald and Harriet Tarlo have written incisive prose essays on ecopoetry, which are analysed in Chapter I; all three have edited significant ecopoetry anthologies. This book seeks to develop and contribute to the growing dialogue about ecopoetry, which is now a global field. Australian ecocritic Kate Rigby, who has recently moved to a post in Britain, has written a book chapter on ecopoetry and the Anthropocene (2014), while Australianbased critic Tom Bristow has written a monograph on The Anthropocene Lyric (2015). Greg Garrard (a British ecocritic now based in Canada) and Susanna Lidström (a Swedish expert on British ecopoetry) have created a nuanced critique of Fletcher and Felstiner's views (48). Lidström and Garrard's article, Lidström’s 2015 monograph, and Solnick’s 2016 book, are among the first studies to use ideas from ecopoetics and apply them to Hughes's work,

12 See for example Gillian Rudd. Greenery: ecocritical readings of late medieval English literature. Manchester: Manchester UP, 2010.

13 It is worth mentioning that Kinsella is Australian, although he has worked in the United States and Britain. His collaboration with Gander, and the global scope of Astley's book, show that new, global dimensions are emerging in ecopoetics. 
although the second edition of Green Voices had adumbrated this development. Meanwhile, complementary publications on Plath's environmentalism, in Knickerbocker's Ecopoetics (2012) and Tracy Brain’s The Other Sylvia Plath (2001), suggest new ways in which Hughes's work could be interpreted, while Hughes's reading of Plath's work, and her reading of his, are elucidated in Heather Clark's The Grief of Influence (2010). Knickerbocker and Brain's reclamation of Plath as an ecopoet suggests that Hughes, too, deserves an ecopoetic reading of his work.

Of course, it is Hughes's relationship with Plath that has been the source of well-known hostility between him and some prominent feminist scholars and writers.14 Feminists have also objected to the imaginary goddesses in his work, and ecocritics need to be aware of the problems that Hughes's nature-goddess causes for them. One of the most important critics to take Hughes to task for his goddess-worship is Jacqueline Rose, who is troubled by Hughes's image of a repressed feminine principle that becomes destructive, provoking the 'retaliatory violence' of the male (151). Hughes's abstract Mother Nature is not invariably identified with real women (WP 129), but she certainly does struggle violently with Mankind until the invention of 'green' technologies (132-3). Late in his career, Hughes significantly complicated an essentialist identification of woman with the organic, the natural and the pretechnological. His children's environmental fable The Iron Woman goes some way towards deconstructing the stereotype perpetuated in 1970s counterculture and early 1990s ecofeminism, of woman as 'close to the earth' and man as technologically superior. As Chapter VIII shows, Hughes's idealistic children's book seeks to end both the battle of the sexes and the war against nature. It is also significant that since Hughes's death, some of Britain's most important women poets have celebrated his legacy. In 2010, major feminist writer and Poet Laureate Carol Ann Duffy inaugurated the Ted Hughes Award for New Work in Poetry. When Alice Oswald's collaboration with the artist Jessica Greenman won the first Ted Hughes Award, Duffy commented that the judges' choice was fitting, as 'Alice Oswald of all poets working today is probably the most like Hughes' (Flood). Oswald’s 2005 memorial speech for Hughes, and her editing of A Ted Hughes Bestiary in 2014, implied that poetic affiliation transcends the problems that feminist scholars objected to in Hughes's work. It is telling that Oswald celebrates Hughes's animal-poems, their environmental implications (2005), and the way he shows people 'what they have in common' with animals (2014 xiii).

\section{The Development of Hughes’s Environmentalism}

14 Feminist critiques of Hughes range from scholarly objections to the way he dealt with Plath's literary legacy, to stingingly personal attacks. Linda Wagner objected to Hughes's destruction of Plath's last diary (Wagner 308); Marjorie Perloff attacked him for his supposed 'desertion' (295) of her; poet Robin Morgan's incendiary poem ‘Arraignment' accuses him of murdering her. Scholarly opinion has undergone some important changes since the feminist backlash against Hughes, with Nathalie Anderson (1995), Tracy Brain (2011) and Jane Stigen Drangsholt (2015) considering his engagement with gender. Scholars are now able to read Hughes's fragmented, but revealing, diaries in the British Library, which tell his side of the story of his marriage to Plath. Jonathan Bate has examined these diaries to give Hughes's account of Plath's final weeks (2015 208), and has contextualised the origins of the 'feminist backlash' against him within in the early days of the feminist movement (346). 
In a forthcoming book chapter, Terry Gifford posits a six-stage model detailing the phases Hughes's 'greening'. Gifford's model is valuable as a pioneering analysis of the development of Hughes's environmentalism, but perhaps the idea of 'stages' is too programmatic to encompass the gradual shifts in thinking that happen during the course of a life. This book proposes instead that Hughes's environmentalism developed with the twentieth century's green movement - but that did not prevent him from occasionally exemplifying reactionary thinking, as in his defence of hunting. Currents of thought appear in his writing, only to resurface decades later; this can be seen in the way the international focus of 'The Environmental Revolution' in 1970 anticipates Hughes's environmental engagement in African and Canadian conservation in the 1980s and 1990s. He sketched out the development of his environmental awareness, decade by decade. A draft of a speech about farming that Hughes gave after he took up the Laureateship is filed with drafts of Season Songs in the British Library. The speech summarises the development of his knowledge:

The dying of the fish at Old Denaby.

Nothing more, till 1959 - Silent Spring

1960 - DDT

1970s - dying of the fish. Cancer etc.

1980s - the public turning against farms

Silage? Slurry? Nitrates?

Farming is the most dangerous occ.

R. Ash the [illegible] in land

'What you throw into the ditch, appears in your child's cup'.15

Yet Hughes's published work, and his vast archive, suggest that his environmentalism was more complicated, international, politicised, and contradictory than his summary suggests.

\section{Ecopoetic Strains in the Poetry of Contemporary and Recent Poets}

Hughes's environmental awareness kept pace with developments in the environmental thinking of the twentieth century. Yet his compendious knowledge of contemporary poetry also encompassed the poetic movement that would come to be known as 'ecopoetry'. Hughes's work has been productively placed within the context of his environmentally aware contemporaries from Britain and Ireland: in Green Voices, Gifford devotes chapters to Norman Nicholson (1914-87), George Mackay Brown (1921-96), John Montague (1929 - ), R. S. Thomas (1913-2000), his Irish predecessor Patrick Kavanagh (1904-67), Gaelic poet Sorley MacLean (1911-96), and his great friend in poetry, Seamus Heaney. Lidström and Garrard (2014) and Lidström (2015) have also analysed Hughes’s ecopoetry alongside

15 BL Add MS 88918/1/55, notebook containing drafts of Season Songs 2. 
Heaney's, while Solnick has examined Hughes within the context of poetry appropriate to the Anthropocene, by Derek Mahon (1941 - ) and J. H. Prynne (1936 - ) (2016). While Chapter III analyses Hughes's relationship to some important poetic predecessors from his 'sacred canon', recent poets and near-contemporaries also shared preoccupations that would inform his poetic development and the specific thematic and formal features of his ecopoetry. The canon of British ecopoetry is vast, and some brief examples that feature prominently in Hughes's anthologies and his library are considered here. Among the (then) recent poems to consider human beings' relationship with animals that Hughes and Heaney anthologise in their children's anthology The Rattle Bag are MacCaig's 'Praise of a Collie' (RB 351), an elegy for a working dog and the traditional work of crofters, and Norman Nicholson's 'Cowper's Tame Hare', with its eldritch suggestion of inter-species eroticism (114). A significant predecessor for the poetry of Moortown Diary was R. S. Thomas. Hughes did not subscribe to Thomas's Anglican religious beliefs, and his Laureate-poems that attempt to unify Britain go against the grain of Thomas's opposition to the Anglicisation of Wales (Merchant 25). Yet the two men shared concerns about industrialisation and the decline of traditional farming. Hughes and Heaney anthologise Thomas's 'The Ancients of the World', which celebrates animals from The Mabinogion as embodiments of a past as deep as Wales. Thomas preserves the wisdom of 'the toad of Cors Fochno' and 'the owl of Cwm Cowlyd' (RB 29),16 their sonorous Welsh names deployed in defiance of encroaching English influence. Thomas's 'Lore', which celebrates traditional Welsh agriculture in the era of the 'scythe' and warns that the 'machine | Whose fuel is human souls' (RB 253) risks eroding such rural practices, is particularly important for Hughes's farming-poetry and his critique of environmentally damaging technology. Poems such as Thomas's 'Depopulation of the Hills' also foreshadow Hughes's elegies for the decline of traditional Devon farming in Moortown Diary.

The dispossession of rural folk from their lands is yet more acutely felt in two poems by Sorley MacLean and Norman MacCaig, which Hughes and Heaney select. 'Hallaig' is Maclean's lament for a Raasay village deserted after the Clearances (The School Bag 262, see also Heaney 2002). MacCaig mourns the decline of both Gaelic language and the traditional crofters' practices of spinning and peat-cutting in 'Aunt Julia' (RB 51). This history of dispossession and changing land use would inform Hughes's poetry of declining industry in Remains of Elmet. Yet this collection has more in common with contemporary writing that engages with landscapes closer to home: what Heaney would term 'Englands of the mind'. In 1971, the year that Hughes had the idea for the project that would become Remains of Elmet (LTH 376), Geoffrey Hill (1932-2016) delved into memories of his boyhood and called up the presiding spirit of the Saxon King Offa in Mercian Hymns. Hill's distinctive prosepoetry creates a clashing of new 'Gasholders, russet among fields' and older 'Milldams, marlpools that lay unstirring' with organic 'Eelswarms' (VII np). These remains of industrial Mercia, and Hill's evocation of declining economic practices such as the work of his

16 The tale of these venerable creatures is recorded in Jeffrey Gantz, trans. The Mabinogion. London: Penguin, 1976, 164-5. 
grandmother, who worked 'in the nailer's darg' (XXV, np), 17 would help to inspire Hughes's likening of loom-shuttles to leaf-loam and ant-warfare to mill-workers in poems such as 'Hardcastle Crags'. Yet Hughes's engagement with landscapes on both sides of the North/South divide would prevent him from creating a mythical England as unified as Hill's, despite his efforts to do so in some of the Laureate-poems.18 Hughes's involvement in international literary business, such as Modern Poetry in Translation, and his later engagement in environmental issues abroad, open his work to further transnational influences.

The early work of Seamus Heaney19 is often shown to have been influenced by Hughes (Ingelbien 627), but their later friendship was one of poetic dialogue and collaboration. Important overlappings and convergences can be seen between their poetry, although Heaney acknowledged that he was 'a different animal from Ted' (Heaney and Haffenden 74). Heaney had been observing creatures wild and tame in poems such as 'Serenades' from Wintering Out (1972) and 'Badgers' from Field Work (1979), which echoes Hughes’s nearcontemporaneous 'Coming Down through Somerset' but transforms a roadkilled badger into a painful political emblem of 'the murdered dead' (Heaney 1998 150). Heaney's growing distance from the traditional rural practices of his childhood runs as a recurring strain from poems such as 'Digging' and 'Churning Day' in Death of a Naturalist (1966) to 'The Harvest Bow' in Field Work (1979), published in the same year as Hughes's Moortown Diary, and through to more recent work such as Seeing Things (1991), in which field labourers become 'Apparitions' from the 'country of shades' (Heaney 1998 359).

1981 would see a surprising convergence between Hughes's poetry and that of the very writer who would later mock him as 'Laureate Hughes'.20 Although he is better known for criticising social and political injustices 21 than for writing about environmental justice, Tony Harrison (1937 -) published a series of extinction elegies in in 1981.22 This was the year that Hughes published a lament for an endangered macaw; five years later, Wolfwatching would juxtapose Hughes’s personal elegies for family members with extinction elegies.

\footnotetext{
17 Hughes owned Hill’s Canaan (1998), Tenebrae (1978), King Log (1968), Preghiere (1964) and Collected Poems (1985). The latter is kept at Emory Rose library MARBL DANOWSKI 20121938.
}

18 Tom Paulin has lambasted Hill's collection for 'labour[ing] to produce an image of ye old England covered by the ruins of the welfare state' (282), and for its lack of cultural and racial diversity (283). Hughes creates emblems of British racial diversity such as 'peacock', 'Hoopoe' and 'African violet' in the Laureate-poem 'The Ring', but the Devon focus of his Moortown-poems and the West Yorkshire of his Elmet-poems evokes an England more complex, diverse and divided than Hill's England unified under Offa, Rex Totius Anglorum Patriae (XIII).

19 The ecopoetic elements of Heaney’s work are analysed by Gifford (1995 Chapter 5), Bate 2000 (202-04), Lidström and Garrard (2014), and is the subject of Chapters 2, 46 and 7 of Lidström's 2015 monograph.

20 See Harrison’s poem ‘A Celebratory Ode on the Abidcation of King Charles III’ (Harrison 320-3).

21 Among Harrison's most famous poems to grapple with issues of social division are 'Them \& [uz]' (1974) and $V$. (1985). His anti-Laureateship poems include 'Laureate's Block' (1999), in which he mourns Hughes's death while celebrating his own freedom ‘to blast and bollock Blairite Britain’ (Harrison 332).

22 ‘Art \& Extinction’, PN Review 8.2, December 1981. 
Hughes's poetic interests from the USA included 'Shapiro, Lowell, Merwin, Wilbur and Crowe Ransom' (Faas 203). Both Wilbur and Merwin have been analysed from an ecopoetic perspective (Knickerbocker Chapter III, Scigaj 1999 Chapter 5), and Hughes's library contains volumes that were milestones in the development of ecopoetry in the States. W. S. Merwin was part of Hughes's literary circle in both Boston and London, and Hughes was well acquainted with his work; significantly, his library includes collections that chart Merwin's turn towards the environment as a major poetic focus (Scigaj 1999 xiii): The Rain in the Trees (1988) and The Vixen (1996).23 Hughes owned writer and activist Gary Snyder's Turtle Island (1973);24 Puckett credits Snyder with making 'some of the most definitive contributions to [American] ecopoetics' (76), while Selby characterises Turtle Island as his most 'vehemently ecological' work (134). These two poets are among the four American ecopoets whom Scigaj analyses: A. R. Ammons (1926-2001), Wendell Berry (1934 -), W. S. Merwin (1927 - ) and Gary Snyder (1930 - ), all of them born within a few years of Hughes. In an interview in 2012, Merwin spoke about knowing Hughes and Plath (Merwin 199), the problems of anthropocentric thought, and rainforest conservation (192); Hughes also knew of Merwin's activism to defend Hawaii's forests (see p. 198 of this book). From farther afield, Hughes read the work of Australian poet Les Murray (1938 - ),25 whose ecopoetry and environmental prose are analysed by Bate (2000 237-42). Of course, a far wider array of work by Hughes's contemporaries displays ecopoetic strains; 26 the writers mentioned here are the proto-ecopoets and ecopoets whose work he knew especially well.

It would be foolish to suggest that reading Hughes's work through the lens of his environmentalism is the only way of reading it. Hughes's images are richly polysemous, and he himself acknowledged that 'it is the reader's own nature that selects' the meaning of his poetic symbols (Faas 199). Not all of Hughes's poetry can be interpreted convincingly as ecopoetry, despite some critics' attempts to find environmental strains in any form of text. Morton creates a half-flippant ecocritical reading of Charles Bernstein's one-liner 'this poem intentionally left blank' as 'ecological in several ways' because it is 'organic', although not 'strictly environmental' (2009 4-5). He asserts that 'All poems are environmental, because they include the spaces in which they are written and read - blank space around and between words, silence within the sound' (2009 2). Of course, there is no escaping the materiality of

23 These two volumes are kept at the Emory MARBL archive, PS3563.E75 R35 1988 and PS3563.E75 V58 1996 respectively. Hughes acquired a wide range of Merwin's work: ten volumes of his poetry and translations are archived at Emory University.

${ }_{24}$ Gary Snyder. Turtle Island. Boston: Shambhala, 1993. Emory MARBL PS3569 .N88 T8 1993 DANOWSKI.

25 Hughes’s library at Emory University contains Lunch \& Counter Lunch (1974) PR9619.3 .M83 L8 1974 HUGHES, The Vernacular Republic: Poems 1961-1981 (1982), PR9619.3 .M83 V47 1982 HUGHES, The Rabbiter's Bounty: Collected Poems (1991) PR9619.3.M83 A17 1991B HUGHES, and Subhuman Redneck Poems (1993) PR9619.3 .M83 S83 1996 HUGHES.

${ }_{26}$ For a broader range of ecopoets from the USA, see Ann Fisher-Wirth and Laura-Gray Street's The Ecopoetry Anthology, San Antonio: Trinity UP, 2013 and Puckett 75-7. A more international range of ecopoetry is represented in Astley's Earth Shattering: Ecopoems (Newcastle-upon-Tyne: Bloodaxe, 2007) and Alice Oswald's The Thunder Mutters: . 
the poem as an artifact reproduced on woodpulp or disseminated digitally via an electronic device; likewise, the reader is complicit in altering the environment around her by the banal acts of switching on an e-reader or purchasing a print copy. Yet Morton's emphasis on the space on the page forces all poetry to conform to a single paradigm, ignoring the other effects - visual patterning, Luftpausen, erasures, lacunae - that blank spaces and silences create. An ecopoetic reading of, say, Hughes's Alcestis might well be possible, but it would be equally strained; an analysis that deployed translation theory or biographical criticism would be more successful. Hughes's most strident poems of environmental protest are rarely his best. His most experimental and challenging ecopoetry is found in Crow, which is nevertheless somewhat occluded by Hughes's inability to complete its narrative trajectory. His most satisfyingly balanced and unified ecopoetic volume is River. Four other collections stand out in his diverse body of work for articulating distinctive intellectual and emotional considerations with particular technical skill and thematic integrity, but their primary preoccupations are not ecological. Lupercal is notable for its fearless channelling of the forces that shape nature, man and woman. Remains of Elmet is among Hughes's most structurally balanced, visually evocative and subtly mournful books. Tales from Ovid is his most successful translation for keeping faith with the source-text while deploying a Hughesian poetic voice, and for drawing out Ovid's relevance to contemporary concerns. Birthday Letters is the most emotionally moving and poetically significant of the personal collections that Hughes published late in his life. There are significant and occasionally surprising ecopoems in all of these, Hughes's six strongest collections, but their merits are richly diverse. This book also pays attention to some of Hughes's collections that are not always his most famous or poetically successful, but which succeed in capturing the environmental preoccupations of his age: Season Songs, Moortown Diary and Wolfwatching.

The present book aims to explore the environmental and ecopoetic richness of Hughes's work, while also paying attention to the intersection of environmental preoccupations with other themes. Hughes's commitment to conservation was deeply bound up with his boyhood enjoyment of hunting, his occupation as a farmer for many years, and his lifelong love of fishing: he was a champion of country life as well as an environmentalist. His love of 'wild' places, from Old Denaby and Crookhill to remote salmon-rivers in Alaska and Iceland, sprang as much from his rejection of popular cultural values and materialistic modernity as from his environmentalism. His poetry responds to the work of a wealth of earlier writers, and his poetic dialogue with Plath's poetry spans a great part of his writing career, as Heather Clark has argued (2010). Postcolonial and racial issues were not a central preoccupation for his poetry, but they come to the fore when he includes black characters in his unpublished prose drafts to accompany Crow, when he orientalises Assia Wevill in Capriccio, and in his sometimes controversial remarks about Africa (Morpurgo np; see also p. 195 of this book). Yorkshire, the First World War, issues of class and gender, and the Devon farming and fishing community play crucial roles in his writing. This book focuses more closely on Hughes as a public figure than on his personal life, but of course personal matters influenced his poetry - not least the autobiographical project that gave rise to Capriccio, Birthday Letters and Howls and Whispers. Much of his writing, whether environmental, mythical or personal, seeks to atone for 'masculine guilt' (Roberts 2006 99). As a writer and 
environmentalist, Hughes strives to re-establish 'a right relation with the source, that is, with Nature and the female' (Sagar 2009 xiv). One of the main reasons he became an environmentalist in the first place, was to restore mankind's broken relationship with 'the source'. Yet Hughes sought to restore this disrupted relationship via writing as well as environmental campaigns - and it is ecocriticism, ecopoetry and his idea of nature that we must first explore in order to find out how he does this. 


\section{CHAPTER II. HUGHES, ECOCRITICISM AND ECOPOETRY}

\section{Ecocritical Interpretations of Hughes}

Hughes has long been recognised as a prominent environmental poet. Jonathan Bate finds in his poetry 'the hot stink of animal flesh' (2000 203). When Seamus Heaney calls him 'a guardian spirit of the land and language', a view quoted on the back cover of the hardback edition of Hughes's Collected Poems, he evokes Hughes's roles as national bard, preserver of ancient rhythms, and defender of wild places. In a 2009 newspaper article and radio broadcast, Simon Armitage pays tribute to Hughes as a 'poet and eco warrior'.

One of the earliest ecocritical interpretations of Hughes's work was Owen Johnson's unpublished PhD thesis Ted Hughes: Speaking for the Earth (1991). At that point, ecocriticism had not developed sufficiently for Johnson to be able to draw on an existing body of scholarship (23). Evoking deep ecology and Gaia theory (10-11), Johnson writes that Hughes calls for the reinstatement of the earth as a divinity (11). He sees Hughes progressing from being unable to 'speak for the Earth' in Lupercal (127) to articulating a convincing 'religion of the earth' (275) in River, yet he views some of the conservation-poems in Wolfwatching as uninspired (279). The thesis was written before ideas of 'speaking for the earth' had been advocated by scholars such as Bate (2000 93), and problematised by scholars such as Tarlo (2008 17); yet in many ways it is ahead of its time. Johnson's analysis of birdsong in 'Evening Thrush' and 'The Skylark came' encapsulate an idea that has gained headway from Bruno Latour to posthumanism: 'Poetry, culture, might seem only another part of nature's exuberance' (28). As we shall see, Hughes's presentation of how nature, humans and culture are related is the source of important subsequent debates.

In 1994, Leonard Scigaj published 'Ted Hughes and Ecology: A Biocentric Vision', one of the first studies of Hughes's biocentrism. Biocentrism is 'the view or belief that the rights and needs of humans are not more important than those of other living things' (Oxford English Dictionary); its opposite is anthropocentrism, or human-centred thinking. Scigaj writes that 'The early animal poems of the confident young adult are nevertheless anthropocentric' (165) and that

One can see in his early poetry an emphasis upon kinship with animals and a longing to fuse with Nature's vital energy, in Wodwo a questioning of anthropocentrism, in Crow a comprehensive critique of anthropocentrism, and from Gaudete through Wolfwatching a gradual development of a biocentric vision that often incorporates a mystical grasp of the 'inner spiritual unity of Nature' that he admired in Nicholson. (164) 
Hughes's nascent desire to fuse with 'Nature's vital energy' can be glimpsed in poetry from his juvenilia onwards. It is not the case that 'most of Hughes's poetry since Crow offers this [spiritually] positive ecological vision' (162) - Hughes writes many elegies for extinct species, and protest pieces about polluted landscapes, after Crow. However, Scigaj’s assessment that 'Hughes's poetry shares a basic premise with ecologists and environmentalists: the only way to save this planet is to change the perceptions of its human inhabitants about Nature' (2001 160), is one that is borne out in Hughes's writing.

Terry Gifford's seminal book Green Voices: Understanding Contemporary Nature Poetry followed in 1995, and was reprinted in 2011. Gifford contends that 'Hughes began as an antipastoralist' (Green Voices 133), although contradictions arise in his first two collections because 'Hughes writes "cleansing" anti-pastoral poems at the same time as "seeing" celebratory poems' (135). As will be demonstrated in this book, Gifford’s ideas about 'nature's processes of decay and re-creation' (142) and the 'interactive whole' of 'culture, human life, animal and bird life, and the workings of weather upon landscape' (145), are especially significant for other ecopoetics scholars as well. Hughes's involvement in nature, via activities such as farming, shows him to be a 'sensitive inhabitant of the natural world' (145). In a later essay, Gifford returns to Hughes’s supposed meshing of 'nature' with 'culture' in his later work, identifying his ecological sensibilities with Murray Bookchin's concept of 'social ecology' ('Hughes's Social Ecology' 82). This book offers a detailed problematisation of the ways in which Hughes views nature, culture, humans and other animals, arguing that his views are not always consistent; the next section will pursue this in further detail.

The ecocritic Richard Kerridge, on the other hand, takes a different view from Gifford. Kerridge aligns Hughes not with 'social ecology', but with the more fundamental thinking of Arne Naess's Deep Ecology.

Hughes's environmentalism is clearly a variant of the kind known as Deep Ecology. Soon after ['The Environmental Revolution'], that term was introduced to environmental debate by the Norwegian philosopher Arne Naess, who defined Deep Ecology against what he saw as the 'shallow' environmentalism concerned only with pollution, damage and depletion as specific problems. 'Shallow' environmentalism sought particular solutions without making a general challenge to industrialization and consumerism. Naess saw this as inadequate. [...] The environmental movement had to be concerned with philosophy, morality, psychology and spirituality, as well as ecological science and tactical politics. It had to envision a transformed culture. Hughes comes at environmentalism from a particular set of literary and anthropological preoccupations, but his vision is one of the same radical kind. (187-88)

Kerridge bases this argument on an analogy between the ideas of Naess and the views Hughes expressed in 'The Environmental Revolution'. While these similarities are pertinent, Naess's essay on Deep Ecology was published three years after Hughes's article, and there are no books by Naess in Hughes's library at the Emory archive. It is more likely that Hughes's holistic view of the globe as a single living organism (or goddess), and his desire to 
transform culture by returning to a lost set of values, was initially formed by the 'anthropological preoccupations' that Kerridge mentions. It was later shaped by his knowledge of Gaia theory, which he did research.27 Hughes's desire for a fundamental change in values was profoundly radical, but his activities cannot all be aligned with the values of Deep Ecology. He had an uneasy relationship with industrialisation and consumerism, as he lambasted those who would 'cash in the world' (WP 130) - but he was certainly in favour of environmentally conscious enterprises, from organic farming to rod and line fishing. Hughes's environmentalism was ideologically committed and responsive to contemporary politics; Naess would no doubt dismiss societal and political engagement as 'shallow environmentalism'. Hughes, who argued that farm pesticides poisoned people as well as otters, and that sewage ruined a river for both salmon and fishermen, would see 'social ecology' as of equal importance to Deep Ecology.

Two other major ecocritics, Lawrence Buell from the United States and Jonathan Bate from Britain, have also written on Hughes. Bate's influential 2000 monograph The Song of the Earth engages with Hughes at several points. As well as commenting on Hughes's presentation of violence, Bate makes a perceptive link between Hughes's review of Max Nicholson's The Environmental Revolution (27-28), and the way Hughes 'ecologises' Ovid (29). Bate links Hughes to an earlier, proto-environmentalist Laureate, Wordsworth, when he explores both writers' West Country poetry about the interconnected lives of rivers and human beings. Of course, Wordsworth could not have anticipated the river-pollution that Hughes criticises in his poetry (222). Bate's later biography of Hughes gives further information on Hughes's angling and campaigns against water pollution (2015 399-412). Buell, meanwhile, analyses Hughes's 'In the Dark Violin of the Valley'. Buell comments that Hughes's metaphor of the violin 'works both for and against this poem's representation of riverness' (2001 251) and that the metaphor of the needle provides a 'delicately fateful rendering of the ecological web of life' (250). Yet, 'for the ecopoet, metaphor is both indispensable tool and occupational hazard' (251). Metaphor is so indispensible to literary creation that ecopoets can hardly be blamed for deploying it. Buell's judgement that this metaphor is an 'occupational hazard' needs to be replaced with a more thorough examination of how Hughes negotiates the relationship between nature, artifacts and art, which this chapter will provide.

Alice Oswald's 2005 memorial address for Hughes, which was published as a newspaper article, argued that Hughes's writing demands that we change our attitudes towards the environment. Other publications in a similar vein soon followed, including Simon Armitage's 2009 championing of Hughes as a 'poet and eco warrior'. Armitage portrays Hughes as an activist who lobbied 'Michael Heseltine, John Gummer and Margaret Thatcher on the themes of pollution and poison' ('Poet and Eco Warrior' 2). More recently, Armitage has written that one of Hughes's letters to a fellow fisherman 'speaks of someone not just in touch with the landscape around him but in tune with it' (2012). Armitage's article nevertheless begs the

\footnotetext{
27 Hughes acquired several books by James Lovelock, including Gaia: A New Look at Life on Earth (Emory MARBL QH313 .L68 1982 HUGHES), and other theories about Gaia such as Peter Bunyard and Edward Goldsmith, eds. Gaia, the thesis, the mechanisms and the implications. Emory MARBL QH540.C36 1987 HUGHES.
} 
question of whether a fisherman who eats salmon can be 'in tune' with the fish he kills; this critical question is posed in Chapter $\mathrm{X}$ of this book.

Keith Sagar's book Ted Hughes and Nature: 'Terror and Exultation' (2009) argues that '[t]he centrality of nature in Hughes' work has been obvious from the publication of The Hawk in the Rain' (xi). Sagar thinks of Hughes's work as a 'struggle to get into a right relation with the source, that is, with Nature and the female' (xiv) - hence the religious tenor of many of Hughes's River-poems. Sagar writes that 'in River, Hughes found the end of his poetic journey, from a world made of blood to a world made of light' (2006 168). Yet poems about extinction and predatory violence come after River. Violence inflicted on vanishing species is especially visible in Wolfwatching, and the poems examining it bring us back to the 'world of blood'. Hughes's protest poems evoke not a 'world of light', but an environment that is irreversibly damaged and polluted. Sagar's progression from 'blood' to 'light' is unrealistically neat, and the environmental dimensions of Hughes's poetry after River should not be dismissed.

Lidström’s 2015 monograph creates an apposite comparison of Hughes and Heaney's ecopoetry. Drawing on the work of Serpil Opperman, Timothy Clark, Timothy Morton and others, she traces the emergence of a 'postmodern ecocriticism' (2015 5-6) - which makes a welcome change from older studies of Hughes that shunned lengthy engagement with literary theory. She examines Crow and non-anthropocentric religions (22-46) and technology in Elmet (67-83). She evaluates his poems from the perspective of ecosemiotics - the study of sign-systems in the environment (103-118). She finds that even Hughes's early animal-poems can be viewed as anti-anthropocentric. She finds that 'While many of the early poems depict acts of violence or destruction, as in many of the animal poems, the later collections focus on processes of renewal' (144). She examines Hughes's supposed engagement with deep ecology, posits the innovative view that his work questions humanism's focus on our species as superior to other creatures (140-45), and deploys ecopoetic theory by Angus Fletcher, John Felstiner and Timothy Clark (147-150). Yet Lidström's book does not engage with important new insights from the archives, which give a fuller picture of Hughes's environmental campaigns and illuminate exactly which philosophical, scientific and ideological views were most important to him.

More recently, scholars of the environmental humanities have turned their attentions to the Anthropocene, our human-dominated age in which human-caused environmental change is inscribed into the very bedrock, climate and oceans. Scholarship on Hughes has recently begun to follow suit. The term 'Anthropocene' was proposed by atmospheric scientists Paul Crutzer and Eugene Stoermer in 2000. Crutzer and Stoermer traced human beings' lasting effects on the atmosphere back to the Industrial Revolution (17) and commented on how our species has become 'a major geological force' (18). Yet the point at which the Anthropocene begins, and the concept itself, continue to provoke debate. Estimations for its commencement range from 1610, when changes resulting from the conquest of the Americas had taken hold, to as late as 1964, the peak in fallout from nuclear testing (Solnick 4-7). The term was coined two years after Hughes's death, and his late twentieth-century environmental awareness could only adumbrate the magnitude of the concerns that researchers such as Crutzer and Stoermer 
raise. Yet he was clearly extremely worried about irreversible alterations that human beings have made to our planet, as his comments about climate change show (qtd. in Douglas 10).

The ecocritic Timothy Clark has offered one of the most provocative critical studies of writing in the Anthropocene. He argues that the term 'Anthropocene' has become a 'shorthand term for all the new contexts and demands - cultural, ethical, aesthetic, philosophical and political - of environmental issues that are truly planetary in scale, notably climate change, ocean acidification, effects of overpopulation, deforestation, soil-erosion, overfishing and the general and accelerating degradation of ecosystems' (2015 1). As a concept, it 'blurs and even scrambles some crucial categories by which people have made sense of the world and their lives. It puts in crisis the lines between culture and nature, fact and value, and between the human and the geological or meteorological', manifesting itself as 'a bewildering and often destructive contamination of human aims and natural causality' (9). Individual human beings are obliged to think and act 'as if already citizens of a world polity' (9), in an age that demands 'a new kind of eco-cosmopolitanism capable of uniting people across the world without erasing important cultural and political differences’ (17). He offers the sobering view that the Anthropocene is 'independent of or indifferent to social, cultural, or political will or intent' (13), and that its scale defies human conceptualization and representation (187). These are the grounds for his challenge to scholars who over-claim the efficacy of cultural criticism - and indeed poetry - as a force for cultural change. For Clark, ecocriticism can help us to 'comprehend ecological problems', not to resolve or mitigate them (21). He offers an important challenge to scholars such as Bate (2000 283) who have made the hyperbolic claim that poetry can save the earth (Clark 2015 195). Of course it cannot. Yet Clark is too nihilistic in his appraisal of the capabilities of ecological art and literature. There is no doubt that poetry is capable of encouraging ecological awareness in individuals, but as a genre that is nowhere near as popular as fiction or creative nonfiction, its literary reach is limited. Faced with the scale of human alterations to the planet, the combined contributions that all the ecologically aware arts can make to mitigating our impact on our surroundings is infinitesimally small. Yet literary and artistic works need to take their place alongside environmental technology, politics and activism as one of many tools that can help our species to conceptualise the vastness of problems such as climate change. Arts for Nature, which Hughes co-founded, argued for the advantages of environmental art to appeal 'directly 
to the heart'; the emotional and aesthetic appeal of art does indeed offer an important alternative to scientific and political environmental discourse.

Sam Solnick’s 2016 monograph offers both a rigorous consideration of Hughes's archive and a refreshing application of theories about literature in the Anthropocene to his work.

Solnick's posthuman literary criticism posits that for Hughes, technologies such as language are developments of evolutionary processes: language has a prehuman evolutionary origin (70), while Hughes presents the myths that we develop from language as having an evolutionary function (72). Thus, the 'extension of the evolutionary adaptive into the cultural and technological is crucial to Hughes's thinking' (72). According to Solnick's reading of him, for Hughes, the human being is a 'prosthetic creature' (72) and frequently a 'technological animal' (12). This often holds true in Hughes's work - but he also presented Neanderthals as technological animals ('Baboons and Neanderthals' 161), further deconstructing a humanist privileging of the primacy of the human primate. Solnick's is one of the most nuanced considerations of Hughes's deployment of the language of technology in his attempts to reconnect with the living world: 'Hughes's challenging of the rational human by foregrounding its animal impulses is matched by a technological rupturing' (12). However, his ideas that Hughes 'uses violence as a means of reasserting a lost sense of corporeality' (76), and that hunting is 'a technologically mediated engagement with the animal' (69) are complicated in this book. Hughes's writings about violence towards animals - especially hunting - are more contradictory and ethically compromised than a simple 'engagement' with nonhumans. Hughes undoubtedly wished to repair what he saw as humankind's broken connection with nature, the 'source' - but he also acknowledged that 'nature' had been fundamentally changed by human activity.

\section{Hughes and the Idea of Nature}

Any ecocritical study must engage with the complex idea of how human beings perceive and relate to 'nature'. This is particularly important for Hughes, as his presentation of nature generates a broad array of critical debates. No earlier scholarship has yet given a full account of the shifts and inconsistencies that occur in Hughes's presentation of nature, at different times. Yet there are differing views about humans and nature among ecocritics as well. Early ecocriticism acknowledged that one of environmentalism's central dilemmas was that 'the act of identifying the presumption of human apartness from nature as the problem is itself a symptom of that very apartness' (Bate 2000 37). Bate writes that there are three senses of the word 'nature'. The first is 'the concept of the non-human' through which humanity visualises its difference from other species - although this definition acknowledges that the categories of 'human' and 'nonhuman' are being revised continually. The second relates to the inescapable 'structures, processes and causal powers that are constantly operative within the physical world' - and which of course affect humans. The third is the 'lay' term which refers to 'landscape', 'wilderness' or 'countryside'. These three senses of the term cannot be held apart fully (2000 33-4). However, many environmental thinkers have problematised such views of nature, subjecting the first definition's proposal of a divide between human and nonhuman to intense critical scrutiny. Bill McKibben's seminal book on climate change, The

28 Emory MARBL archive collection 644, box 155, folder 7, statement about Arts for Nature by Prince Philip. 
End of Nature (1989), was highly significant in alerting the public to the possibility that human-caused climate change might be responsible for extreme weather events. McKibben also proposed the idea that what we call 'nature', in all of Bate's senses, is fundamentally altered and changed by human influence (McKibben 51). The historian of science Bruno Latour has argued that the distinction between human beings and nature is not clear-cut, as modern civilisation has created a proliferation of hybrids (1993 10-11). Timothy Morton has deconstructed the term 'Nature' (2007, 2010), arguing for it to be superseded by a new form of thinking about ecological interconnection that 'includes all the ways we imagine how we live together' (2010 4). Ecological thought, for Morton, negotiates our connection to everything from great apes to corals and artificially intelligent machines (71-3). Cary Wolfe's work on animal ethics (2003) and posthumanism (2010) further complicates a hierarchical view of humans and nonhumans. Posthumanism, for Wolfe, questions humanism's central assumption that our species is separate from, and superior to, other species. It strives for a 'decentring of the human' (2010 xv). He shows that 'one study after another' shows how " "reason", then tool use, then tool making, then altruism, then language [...] flourish quite reliably beyond the species barrier' (2003 2). Not only posthuman criticism, but also cultural theories that examine the Anthropocene, destabilise binary or dialectical views of 'nature' and 'culture'. In the Anthropocene, for Timothy Clark, the perceived boundary between the two is challenged: 'The notion of nature as the other to culture has been giving way in environmental thought to more blended conceptions of the two as forming one perhaps bafflingly complex entity (as in Donna Haraway's earlier coinage 'natureculture')'. For Clark, human alterations to ecosystems render the idea of a pristine nature 'escapist'. Meanwhile, 'human cultures are always entirely part of natural systems of energy exchange in the biosphere' (2015 56-7). It is this new thinking in ecocriticism that informs a new generation of Hughes scholars such as Susanna Lidström, Samuel Solnick and Iris Ralph. It is also an important theoretical concept for the present book.

Early criticism tended to view Hughes as espousing a binary view of nature and human beings as essentially separate. Sagar thinks that Hughes initially rejects nature, implying that he sees it as separate from human beings (2009 36); although Hughes longs to reunite them (xiv). More recently, Lidström and Garrard's article - surprisingly - perpetuates this dichotomy between human civilisation and nature: 'Hughes's poems usually draw a clear line between nature and culture, and strongly favour the former' (38). ('Culture,' here, appears to be used in Bruno Latour's sense of 'technologically advanced western civilisation.') Paul Bentley nuances such views by arguing that Hughes sees the relationship between 'nature' and 'culture' as dialectical: neither can exist without the other. In his view, 'the Other of nature is projected from the social world which becomes its underside [...] This is why Hughes's poetry returns us in the end not to nature, but to its formative intersection with culture' (16). Hughes certainly presents nature as a sundered Other in a letter of 1990 to Moelwyn Merchant, but as will be argued shortly, he shows the enmeshing of 'nature' and 'culture' as far more complex in his writing about evolution and in many of his poems. Indeed, in Lidström's view, Hughes is anti-anthropocentrist and posthumanist because he 'undermines the humanist human/animal dichotomy', and because his work creates a 'recognition and portrayal of nature’s own agency, apart and independent from humans' 
(2015 144). This is a more radically 'green' take on Hughes. Critics who wish to claim Hughes's poetry as posthumanist need to negotiate the problem that Hughes's library suggests that he did not research posthumanism, 29 and that during his lifetime, it was not as well known in the humanities as it is now. It is certain, though, that Hughes's radically 'green' statements about other species challenge anthropocentrism and anticipate posthumanism.

\section{Human, Animal and Machine}

Earlier debates about Hughes's view of 'nature' have not acknowledged that what he writes about the relationship between nature, humanity and culture is highly complex, and is not always consistent. From Paul Bentley's Marxist perspective, Hughes's nature and culture are locked in a dialectical relationship (14): neither can exist without the other. Yet even 'TigerPsalm,' a Crow-poem first published in 1969, presents a dialectical relationship between military technology and natural violence, only to question and complicate it. Hughes contrasts the tiger's 'exalted', blameless kill with the 'to-fro dialectic' of machine guns - but the two categories blur when the tiger's face is likened to a military 'banner' ( $C P H$ 578). The tiger becomes imbricated within Hughes's discourse of human, martial imagery - and needless to say, the poem that examines the tiger is itself a cultural artefact. Any critical attempts to keep 'nature' and 'culture apart are now complicated by scholarship that indicates that 'culture' is not the exclusive preserve of human beings. Many biologists now accept that '[c]ultural phenomena have been identified in a growing number of animal species, ranging from primates to cetaceans' (Koops et al 1). It is this mode of thinking that informs the cultural criticism of Helena Feder, who argues for ecocriticism and posthumanism to challenge 'the humanist ideology of culture'. She calls for '[a] radically expansive idea of culture, a non-speciesist multiculturalism' capable of intervening 'in forms of subjugation that function precisely by excluding some from the realm of culture' (228). Hughes, who wrote that baboons' 'intuition' is impoverished by an excess of rational intellect ('Baboons and Neanderthals' 164) and who reviewed C. J. Lilly’s controversial experiments to teach human language to dolphins ('Man and Superbeast'), knew of scientific research that foreshadowed such perspectives. 'Nature' cannot be kept apart from 'culture' as a pure category. We live in an age where the earth's climatic, oceanic, terrestrial and biological systems have been permanently affected by human activities; and as we have seen, for Timothy Clark, human culture products inevitably form part of earth's systems of energy exchange. Remains of Elmet, with its 'Lumb Chimneys' that must fall to earth if they are to flower again, resonates with this idea. Applying posthumanist and Anthropocene theories to Hughes, Solnick argues that human technology, for Hughes, is an extension of evolutionary adaptation (72); in turn, 'the animal affects the technological' (67).

Hughes’s famous early animal-poems, such as ‘Pike’ and 'Thrushes', smash together organic and industrial images. Bentley perceptively argues that Hughes’s characteristic animals described in industrial terms are an affront to traditional ideas of nature and culture (14), but

29 A search for 'posthuman', or 'anthropocentrism', or ‘cyborg', or 'hybrid' does not reveal anything in his library at Emory. 
this is undermined by his later assertion that 'There is nothing organic about Hughes's most memorable animals' (133). Sagar, too, argues that Hughes's 'hawks, pike, thrushes, sharks, were all machines' (2009 90). Arguments that Hughes’s part-industrial animals are merely mechanical, risk misrepresenting the poems and restricting the richness of their symbolic range. It is precisely because some of Hughes's animals combine organic and inorganic imagery, that they are so unsettling. In 'Thrushes', the thrush has a 'Dark deadly eye' and 'delicate legs' as well as a coiled steel purpose. When Hughes describes the worm that the thrush eats, the thrush's offspring, Mozart's brain and the shark snapping at its own side ( $C P H$ 82), his frame of reference cannot be anything other than living, organic flesh. Mozart has 'animal brain tissue', and he and the animals represent 'divine activity in something fleshly' (WP 258). The pike's eye stares 'as a vice locks - The same iron in this eye | Though its film shrank in death' (85). The simile comparing eye to vice evokes figurative likeness, but the move to metaphor in the following line confounds metal and beast in a complex meshing of the organic and the artificial. Hughes was influenced by his childhood in industrial Yorkshire, by the association of organic flesh with machines in the literature of the Great War,30 and also by part-artificial animals in contemporary science fiction.31 Although he may create provocative combinations of organic and artificial, Hughes's writing still frequently searches for an unspoiled, original, paradisal nature. Yet he finds that the only way he can attempt to access it, is via culture. Hughes wrote to Moelwyn Merchant that his childhood fascination with animals, 'when I became conscious', was 'a natural gravitation towards whatever life had escaped the cultural imprint' (LTH 579). In this letter, nature, for Hughes, is everything 'which culture tortures \& destroys' (580). Yet it was only by torturing and destroying them - by killing them 'in vast numbers' (579) - that he was initially able to reconnect with animals. The 'cultural imprint' on a damaged nature would later become manifest as a different symbol of violence done to both inner and outer nature: the bloodprint of the burnt fox. However hard Hughes may try to reunify the mind with an originary nature, his poetry acknowledges that it has been culturally modified - and that the techniques of poetry can never capture its unmediated crowiness, foxiness and ferality (PM 119). Some of his writings do present nature as an Other which culture destroys, and from which humankind has attempted to separate itself. Yet, as the next section shows, Hughes sees this as a disastrous evolutionary maladaptation - one that brings him back to a concept that anticipates Clark’s ‘bafflingly complex’ web of nature and culture.

\section{The Fall: From Baboon to Homo sapiens}

\footnotetext{
so When wounded, Sassoon's character George Sherston reflects that he once again became 'part of the war machine which needed so much flesh and blood to keep it working' (Sassoon 241). Animals played their part in the conflict, working to transport war-machines alongside the soldiers; in Hughes's 'A Dream of Horses', the horses that 'cannoned the world from its place' evoke horse-drawn field guns (CPH 66).

31 He bought Ray Bradbury’s 1951 science fiction novel The Silver Locusts, which mentions a battle fought with 'metal insects and electric spiders' (12), although the novel would also have resonated with his concerns about nuclear warfare and an altered climate. Emory MARBL archive, PS3503 .R18 S5 1975 HUGHES. In 1964, he acquired a science fiction anthology: Brian Aldiss, Yet more Penguin science fiction: an anthology. Harmondsworth: Penguin, 1964. Emory MARBL archive, PN6120.95 .S33 A42 1964 HUGHES.
} 
In his 1990 letter to Merchant, Hughes notes that his attempts to (re)connect with animals began when he became 'conscious'. To gain a sense of how Hughes approaches the origins of the divorce of humankind from nature, we must first look at what he has to say about consciousness and human beings' inner nature. This informs what he writes about baboons, Neanderthals and human evolution. Back at the end of the 1950s, Hughes noted down the following summary of Jung's idea of the Fall:

Jung's interpretation of the Fall: - the act of becoming conscious (ye will become like God), guilt in that spirit is robbed \& subordinated to conscious control. His new consciousness alienates him from men32

This corresponds to the beginning of Jung's 1930 essay 'The Stages of Life', in which Jung argues:

It is just man’s turning away from instinct - his opposing himself to instinct - that creates consciousness. Instinct is nature and seeks to perpetuate nature, whereas consciousness can only seek culture or its denial. Even when we turn back to nature, inspired by a Rousseauesque longing, we “cultivate” nature. As long as we are still submerged in nature we are unconscious, and we live in the security of instinct which knows no problems. (1960, loc. 7021)

It is this alignment of consciousness with culture and instinct with nature that will inform Hughes's prose about how human beings have attempted to view the two categories as separate. Even an attempt to turn back towards nature 'cultivates' it, for Jung - an idea that has become more acutely pressing in our Anthropocene age of agribusiness, overgrazing and extensive environmental modification, and one that is important to Hughes's cultural mediation of the forces of nature in his writing. Jung continues: 'It is the sacrifice of the merely natural man, of the unconscious, ingenuous being whose tragic career began with the eating of the apple in Paradise. The biblical fall of man presents the dawn of consciousness as a curse' (loc. 7045). Here is the core of Hughes’s argument in his essay 'Baboons and Neanderthals: a reading of The Inheritors'.

In this essay, Hughes interprets William Golding's novel as a fable of humankind's 'fall' into the rational intellect. He draws on the work of South African naturalist Eugene Marais, who studied baboons and concluded that the more 'intelligent' his simian subjects were, the less instinctive their behavior became. The more intelligent baboons were less able to function as 
well-adjusted primates. When Marais hypnotised human subjects, he found that their repressed instincts were restored (164). Hughes concludes: 'without saying that his smarter baboons had suffered something like The Fall, he had brought zoological evidence to the argument that the free intelligence is man's original enemy' (164): here is the link to Jung's idea of the Fall. However unorthodox it might be for Hughes to apply Jungian psychanalysis to baboons and early hominids, this essay offers important information about how Hughes sees humans, animals and evolution. The rational intelligence that comes with consciousness is what separates us from Neanderthals and from other animals, for Hughes. Homo sapiens sapiens' ancestor was 'a round-eyed, pongoid, innocent dawn creature of no particular name' rather resembling a Yeti, (162), who existed in 'the lost, natural Paradise, where the lack of intellectual enquiry and adaptive ingenuity coincided with a perfect awareness of being alive in the moment, and inreality, (an awareness approaching, maybe, a state of blessedness)' (164). This is why sea-trout experience 'the real samadhi' (CPH 659), and why relaxing animals can seem to be 'in a religious daze, the state of steady bliss' that is '[o]ur lost birthright' (1208-9). But for human beings to reattain a state of Samadhi, the ultimate blessedness, they require cultural narratives. As Hughes wrote to Merchant, 'The animals, who were created exactly as they are by this Creation, are therefore in a state of 'bliss' - they live a divine life in a divine world. They live in perpetual 'Samadhi', and have never fallen from it into ego-consciousness, into the acculturating, detatched [sic] cerebration which removes us from it - separates us from the 'bliss' of our animal/spiritual being' (LTH 580). Hughes goes on to explain the process of how consciousness evolved among early hominids, as he did in 'Baboons and Neanderthals', and states that 'culture appeared, as I say, as a substitute for what we had lost - religion appeared as a technology to regain it' (581). Poetry, too, is a cultural method for attempting to regain that lost state of animal blessedness - but capturing animals in poems damages them ('An Otter') as often as it symbolically releases them ('The Jaguar').

Hughes's letter to Merchant, and the essay 'Baboons and Neanderthals' also give important insights into the way Hughes sees the question concerning technology. Solnick proposes that Hughes's violence is 'not a poetics of unmediated reconnection but a subtler figuration of humans' various technologically mediated engagements with the environment and their own, and other animals', embodiment' (198). Yet there is a broad spectrum of 'technologically mediated' engagements for Hughes, and the nuances between them need to be drawn out. 
Hughes praises the Neandethals for creating 'exquisitely dainty flints', and for performing funeral rites that indicated that they had religious beliefs ('Baboons and Neanderthals’ 161). These are the technologies of early hominids whom Hughes does not see as possessing an excessively rational intellect; they are thus not separate from other animals. (There is some inconsistency between Hughes’s idea that Neanderthal religion belongs to a blessed, precultural state, and his later letter to Merchant, which proposes human religion as a technology for reconnecting with this state). The bloody handprint in the dream of the burnt fox, which resembles cave art, and the wolf-mask in 'February', which echoes pre-Christian ritual, attempt to repair humankind's damaged relationship with nature, although this cannot be done without harming individual animals: the fox ends up bloodied and the mask suggests a trophy wolf-muzzle. These primitive technologies risk harming isolated individuals, but they contrast with technologies that create more widespread destruction: for example, the 'concrete bunker', 'shotgun' and 'bombs' in 'Crow Goes Hunting'. Poetry is presented as a positive way of mediating the connections between human and nonhuman, in the early Hughes of 'The Thought-Fox'; by the time of Crow's 'Notes for a Little Play' and 'Crow's Undersong', the representational act of literary creation becomes more problematic. Solnick argues that hunting is frequently 'a technologically mediated engagement with the animal' (69) for Hughes, yet in 'Crow Goes Hunting', this 'engagement' is disrupted and ineffective. The guilt that shooting provokes in 'A Solstice', means that the kill is fraught with contradictions and ethical tensions (see Chapter X). Indeed, in the short story 'The Head', the elder brother kills a Yeti-like, 'pongoid, innocent dawn creature' (DB 149): here, technology gives human beings an evolutionary advantage over their predecessors, but it clearly sunders human beings from a more animal-like ancestor. For Hughes, technologies associated with hyperrationality and environmental destruction are the ones that cause the most problems for humankind, and for Nature, humankind's creator. However, he sees environmentally responsible technology as offering a potential solution.

It is not the Fall into consciousness, but 'Reformed Christianity' in its ecocidal and misogynistic forms that Hughes blames for destructive technologies and environmental damage in 'The Environmental Revolution' (WP 129). In the book that Hughes reviews here, Max Nicholson implied that humankind and nature had been separated when he argued that 'Harmony between man and nature is no longer a mystical and abstract but a practical and pressing matter' (19). Here, Nicholson presents a binary view of 'man' and 'nature', which Hughes nevertheless nuances and problematises in his review. Hughes takes up Nicholson's idea of 'the monstrous anti-Nature that we have created, the now nearly-autonomous 
Technosphere' (WP 128) but he undermines Nicholson’s binary relationship between technology and nature when he proposes that 'a crash programme of legislation and subsidies, of applying technological means already well researched' (131), as a culturally mediated solution. The computer is '[Nature's] oracle, speaking the language to which everybody, even Technology itself, has agreed to listen' (133). Here, then, human beings have attempted to separate themselves from nature - but the very technologies that they employ to do this will bring them back to their creator, their evolutionary origin. The reason why environmentalists have struggled to communicate their message is that 'We have a biologically inbuilt amnesia against the fears of extinction' (129): even technologically advanced civilisation is invariably part of the wider system of evolution, which it cannot control. Hughes's idea of 'amnesia' about the possibility of human extinction was prescient: referring to Kari Norgaard's study of villagers' unwillingness to act on their knowledge of climate change in their everyday lives, Clark notes that climate change proves too disturbing and too vast a phenomenon for many people to attempt to take action (2015 167). Hughes writes that, 'When something abandons Nature, or is abandoned by Nature, it has lost touch with its creator, and is called an evolutionary dead end. According to this, our Civilization is an evolutionary error' (129). However hard human beings may try to deny their imbrication in biological processes and systems, they are inevitably an integral part of them.

\section{‘Fusion’ with nature}

Hughes places increasing emphasis on how humans are linked to other organisms and take their place in ecosystemic processes from 'Wodwo' onwards, and this mode of thinking begins to introduce important new dimensions to the presentation of nature in Crow. It paves the way for the ecstatic poems of union with nature in Gaudete, and the more grounded, realistic poems of human beings' place in the ecosystem in Moortown Diary and River. He learnt from his reading of Dylan Thomas that 'The force that through the green fuse drives the flower' also drives blossoming youth (see Chapter III). Even early in his career, his imagination creates hybrid thought-animals and mythical creatures: the fox-man confounds the traditional boundaries between species, the jaguar functions as a symbol of humankind's baser nature, while the Wodwo cannot decide whether he is earth, animal or wild man. This book devotes less space to the mythic poetry of Gaudete than to the more realistic ecopoetry of Moortown Diary and River. Yet the poetry of Gaudete's verse-epilogue is particularly illuminating here: it illustrates how the Hughes of the 1970s, fascinated by non-Western views of nature, strives towards complete unity with the nonhuman.

I watched a wise beetle

Walking about inside my body

I saw a tree

Grow inward from my navel ( $\mathrm{CPH} 359)$. 
suggests complete fusion with nonhuman creatures, a human body consumed by other organisms after death. Here is a view that anticipates the uncanny interconnections of Morton's 'ecology without nature', of which human beings are always-already a part. However, in 'Trying to be a leaf', the speaker only manages to become a leaf 'For a moment'; a revelation from the Goddess returns him abruptly to his human 'face and hands' (360). The human speaker of the poem may be completely enmeshed in biological processes, but an attempt to experience the life of a completely different species - and one as radically different from a human as a leaf - proves impossible. A few years previously, Hughes had shown how Crow seeks to achieve unity with the nature-goddess, who represents a pure and unaltered nature - a quest that is frequently frustrated. When he sings his undersong, Crow knows that if it had not been for her, there would have been no crying in the city, for 'There would have been no city' ( $\mathrm{CPH} 237$ ). These mythical poems strive towards an ecstatic monism, for a 'fusion' with nature and the elusive goddess. Of course, such a goal is frequently problematic: here, Hughes presents nature as an untouched category, but it will prove to have been utterly defiled by human actions in poems such as 'Nymet'. A less mystical form of nondualistic thinking about humans and nature occurs in Hughes's work when, a little later in his career, he considers our relationship and kinship with other species.

Nowadays, some ecocritics would take Hughes to task for giving his nature-goddess a human face: Joyce Kilmer's image of trees lifting their arms to pray is branded as 'an egregious example of anthropocentrism' in the Ecopoetry Anthology (loc. 485). Experts who have combined queer theory with ecocriticism, such as Catriona Sandilands, would question why Hughes envisages his nature-goddess as female and heterosexual when living organisms display an entire spectrum of asexual, bisexual and intersex characteristics: 33 'intersexuality is common in too numerous forms to document; many organisms move from one kind of sexed body to another' (Sandilands 306). Nevertheless, Hughes's image of the goddess was an important, if problematic, feature of 1970s counterculture and later of Gaia theory.

\section{Kinship and fellowship with other species}

When Hughes is at his most prescient of posthumanist theories, he deconstructs a humancentred sense of our species as superior to others. His emphasis on the common traits that humans share with other organisms claims animals as our distant relatives, our fellow creatures - and sometimes even our equals. By turns humorous, unsettling and radically green, these thoughts have potentially profound implications for the way we treat other species. One prose piece fundamentally re-evaluates our place in the world, stating that 'man is a virtuoso bacteria' when seen from the 'objective reality of the world' (qtd in Scigaj 1986 1). By the time he writes River, he sometimes characterises the human's inner self as animallike: a fisherman's inner self becomes a 'larva from prehistory' ( $\mathrm{CPH} 667)$. Here is his Jungian picture of a primordial unconscious, the innocent dawn creature that persists within the minds of modern human beings. He goes beyond this idea to show that not just the inner self, but animals themselves, are 'fellow' sentient beings: he calls fish 'fellow aliens from

33 For an important study of sexual and reproductive diversity, see Joan Roughgarden, Nature's Rainbow: Diversity, Gender and Sexuality in Nature and People. Berkeley: California UP, 2004. Print. 
prehistory' (654), reminding us of our connection to them through our earliest vertebrate ancestors. In a slightly later protest-poem, the human becomes a 'Monkey Mutant'. Hughes again acknowledges our evolutionary kinship with creatures such as baboons and

Neanderthals, but he does so in this poem in the hope that we will evolve to 'bear a brain with brains' (731) that we can use to combat the pollution thought to be damaging human brains at the time (730). This poem is a far cry from Hughes's desire to reconnect with a primordial nature in the letter he wrote to Merchant: its frustrated rhetoric carries its environmentalist message.

In his writing about pollution, environmentalism and other animals, Hughes continues to refine and develop his critique of anthropocentrism as his career progresses. He emphasises the shared dangers to human and nonhuman life in his 1993 interview about The Iron Woman. When commenting on those who challenged his campaigns against water pollution, Hughes said, 'They think you're defending fish or insects or flowers. But the effects on otters and so on are indicators of what's happening to us. It isn't a problem of looking after the birds and bees, but of how to ferry human beings through the next century' (Morrison). This statement gives a Lovelockian sense of the ecosystem as a whole, of human beings as sharing the plight of fellow creatures, and also an acknowledgement of how extensively human beings have altered their environment and themselves. Hughes was a persuasive rhetorician, but this argument ranks among his most compelling statements for environmentalism. Here are thoughts that anticipate Morton's 'ecological thought', which emphasises extensive ecological interconnection; here, too, he anticipates Clark's writing on the pervasiveness of human alterations to the environment in the Anthropocene. However, towards the end of his life, Hughes makes one statement that is 'greener' still. One of Hughes's musings to Sagar pushes the idea of 'fellowship' significantly further: 'For years I've kept having an idea that I daren't quite formulate: why aren't wild animals simply given the legal status of fellow citizens' (PC 257). He does not seem to have thought through the implications of his whimsical comment to Sagar: giving animals citizenship would mean that he could no longer shoot them, fish for them or eat them. It would lead to absurd consequences such as foxes being required to respect the rights of their fellow citizens the chickens. Some scholars of animal ethics might criticise the idea of applying a human term such as 'citizenship' to nonhumans, pointing out that it keeps them within a human frame of reference (see for example Wolfe 2003 192). Yet Hughes's idea of giving animals citizenship would have been seen as provocative by his hunting and fishing associates at the time; here is an important comment that anticipates posthumanism's project to decentre the human.

Hughes's views of the relationship between nature and human are highly complex, and occasionally contradictory; yet it is possible to draw out four main strands of thought. He examines humankind's 'fall' into rational consciousness, a theme which begins early in his career and to which he returns at several points; deploying insights by Jung, he argues for human beings to be put back into contact with their 'primitive' selves. He opposed reformed Christianity's perception of humankind as separate from, and superior to, other species; and he questioned Nicholson's (perhaps unwitting) perpetuation of a divide between nature and human technology. His more mystical poetry strives towards an ecstatic fusion with an 
unspoiled nature, although this becomes particularly fraught in collections such as Crow. He later develops searching statements that analyse environmental interconnection, expose human alterations of the environment, and challenge humanism's perception of the primacy of the human species. So far, this chapter has demonstrated how he does this in a sample of his poetry and prose. Yet Hughes's writing examines human beings' relationship to the environment at an even more intrinsic level. His examination of environmental connections and dilemmas is embedded within the lexical, formal and sonic features of his poetry itself. He is a multidisciplinary writer, and deploys such methods in other literary genres as well. It is to theories about ecopoetry that we must turn, in order to gain a full sense of how Hughes's poetry articulates the wonders, challenges and tensions of our imbrication in the living world.

\section{$\underline{\text { Ecopoetry and Ecopoetics }}$}

Ecopoetics is a special branch of ecocriticism, devoted to the study of how poetry articulates our connection to our environment. 'Nature poetry' is a problematic term because it risks reinforcing the human/nonhuman binary that Bate identifies in his first definition of 'nature'. The term environment, however, includes the 'physical surroundings or conditions in which a person or other organism lives’ (OED), and is a more suitable term for articulating our place in the living world. Some scholars see poetry as uniquely qualified to do this. Bate's postRomantic concept of a poetry that 'may effect an imaginative reunification of mind and nature' (2000 245) depends on Heidegger's idea that 'poetry is the original admission of dwelling because it is a presencing not a representation, a form of being not of mapping' (2000 262). Later scholars follow this line of thought, but do so somewhat uncritically. Fletcher argues for a turn away from Romanticism in American poetry (1-2), stating that 'poetry, our imaginative making, seems to participate in nature' (4) because it expresses uniquely 'close personal involvements' with the environment (3). Felstiner does not substantiate his claim that 'poetry more than any other form of speech reveals the vital signs and warning signs of our tenancy on earth' (4). These theories ignore important developments in contemporary experimental writing, which blurs the boundaries between poetry and prose. They also fail to recognise the importance of environmental prose genres such as 'the new nature-writing', as it was called in the summer 2008 issue of Granta. Poetry is not uniquely qualified to examine our relationship to our environment: prose nature-writing, ecotopian fiction, and the Sacred Earth dramas whose creation Hughes oversaw, can contain the 'experiential not descriptive' components that Bate sees as unique to ecopoetry (2000 266). Hughes's own hybrid collections Wodwo and Gaudete, which juxtapose prose and poetry, significantly complicate Bate, Fletcher and Felstiner's assertions. His short story 'The Rain Horse' evokes the experience of being among South Yorkshire landscapes and animals, as brilliantly as his Elmet-poems map West Yorkshire. Environmental writing provides many other challenges to this privileging of poetry. Kathleen Jamie's lyrical essays in Sightlines (2012) are as personal and as evocative of wild presences as her poetry in The Tree House (2004). John Muir's prose of experience and of dwelling inspired Roosevelt to participate in nature's making by inaugurating national parks and forest reserves (Macfarlane 2015). Max Porter's Grief is the Thing with Feathers (2015) re-imagines Hughes's Crow in a genredefying blend of poetry, prose and playscript; his work is redolent of Hughes's incipiently 
ecological hybrid play, Eat Crow. A great breadth of non-literary art engages with environmental issues; a very small selection includes the work showcased at the Rachel Carson Center and Deutsches Museum's Welcome to the Anthropocene: The Earth in our Hands exhibition (2014-16) and Cape Farewell's Art \& Climate Change exhibition (200610). Lidström and Garrard do not wholly subscribe to Felstiner and Fletcher's view, but they note that '[p]oems depend on unique formal qualities, and are perhaps even more than other literary genres animated by and able to contain open-ended, multiple and even contradictory levels of meaning. This makes them especially interesting to look to for images that challenge established patterns of environmental thought and address complex, labyrinthine twenty-first century human-environment relations between local and global, social and ecological, perception and imagination' (37). If we are to examine what makes modern ecopoetry one of the best genres for exploring ecological issues, we need to venture beyond revivals of Romantic thinking, beyond Heidegger's hut in the Black Forest, and engage with insights into twenty and twenty-first century poetry such as this.

Ecopoetry takes various forms: as Gifford notes, “ "Ecopoetry is now broadly used for what used to be called "nature poetry", much of which is now included in anthologies of ecopoetry, whilst "green poetry" has come to refer to narrowly propagandist environmental poetry' (Green Voices 8). Hughes himself distinguished between his own 'protest pieces' and ecopoetry that he felt was the 'real thing' (Green Voices 149). Lidström and Garrard draw a similar distinction between two forms of ecopoetry. The first begins with the individual's experiences, and focuses on descriptions and appreciation of non-human nature, with roots in Romantic and deep ecology traditions. It aims to heighten individual readers' awareness of their natural surroundings. The second tries to 'grapple with the changing relationship between human societies and natural environments' (37). Fisher-Wirth and Street follow a similar line of enquiry, bracketing off transcendental, individual encounters with the morethan-human as 'nature poetry' and arguing that there are two forms of ecopoetry: an 'environmental' form displaying an explicit engagement with 'politicized environmentalism', and an 'ecological' variety more willing to enact ecological processes by deploying experimental form (locs 476-500). These are useful categories for some poets, but in Hughes's case, they are not always clear-cut. Hughes's poems of individual experience appreciate non-human nature, but they are often rooted in his knowledge of the changing relationship between human societies and the environment. The poems in River in particular suggest that the two categories often overlap, and may be present side by side in the same poem. 'The Gulkana' focuses on individual epiphany when Hughes describes his communion with the river and fish, and on society and the environment when he grapples with the problems that Western consumerism has brought to a Native American village. Hughes's ability to deploy both modes in the space of a single poem, testifies to his ecopoetic subtlety and skill.

There is largely a consensus among ecopoets and ecopoetics scholars that 'nature poetry' is outmoded as a genre. As Andrew Schelling puts it, 'most examples commonly cited cling to painfully outdated, neo-Victorian assumptions regarding both self and nature’ (90). Marcella Durand agrees: 'We ourselves are the wilderness destroying the very systems of which we are a part' (59). Although Romantic poetry marks a turning point in the depiction of nature (Gilcrest 2), and Wordsworth displays an early form of environmentalism (Bate 1991), environments form an important part of literature as old as The Epic of Gilgamesh.34 Indeed,

34 For more information on forests in Gilgamesh, see Pogue Harrison 13-18. 
Gilcrest argues that all poetry is environmental in a sense, because 'every poem implies a place' (3). Gilcrest does overgeneralize here, especially across literary periods, and it is important to note that premodern literature can only anticipate our current understanding of environmental processes. For Greg Garrard (1), literature becomes fully aware of environmental problems with the publication of Silent Spring in 1962. The book was also a major literary milestone in Hughes's environmental awareness.35 Although mythological metamorphoses and animist beliefs foreshadow environmental thinking, Timothy Morton views the 'ecological thought' as 'unavailable to nonmodern humans' (2010 4). It is the task of literature in the late twentieth century and beyond to articulate the 'theory and praxis of deliberate earthlings', as Jonathan Skinner puts it (2001 2).

Ecopoetry is diverse in focus and form. Skinner has identified some major themes, but his list of possible subjects is far from exhaustive, as he himself acknowledges:

For some readers, ecopoetics is the making and study of pastoral poetry, or poetry of wilderness and deep ecology. Or poetry that explores the human capacity for becoming animal, as well as humanity's ethically challenged relation to other animals. For others, it is poetry that confronts disasters and environmental injustices, including the difficulties and opportunities of urban environments. For yet others, ecopoetics is not a matter of theme, but of how certain poetic methods model ecological processes like complexity, non-linearity, feedback loops, and recycling. Or how "slow poetry" can join in the same kind of push for a sustainable, regional economy that "eating locally" does. Or how poetic experimentation complements scientific methods in extending a more reciprocal relation to alterity - ecopoetics as a "poethics". Or even how translation can diversity the "monocrop" of a hegemonic language like English. "Greener than thou" claims finally are the least interesting dimension of ecopoetics, especially given the ease of "greenwashing." Rather than locate a "kind" of writing as "ecopoetic, it may be more helpful to think of ecopoetics as a form of site-specificity to shift the focus from themes to topoi, tropes and entropologies, to institutional critique of "green" discourse itself, and to an array of practices converging on the oikos, the planet earth that is the only home our species currently knows (Skinner 2011).

It is rather surprising to see the pastoral listed here, when theorists such as Gifford have revealed it to be largely irrelevant to recent and contemporary poetry (2012). Yet Hughes complicates the pastoral, examines humankind's relationship to animals, evokes disasters, mimics the cycle of the seasons, enters into dialogue with scientific theory, and performs some formal experiments. He is fascinated by the alterity of non-western cultures. In his poems of Yorkshire, Devon and rivers in particular, he creates work that is site-specific.

How should poets live in, use and inhabit the environment? Skinner's early manifesto for ecopoetics reads thus:

"Eco" here signals - no more, no less - the house we share with several million other species, our planet Earth. "Poetics" is used as poesis or making, not necessarily to emphasize the critical over the creative act (nor vice versa). Thus: ecopoetics, a house making. (2001 7) 
The 'house' metaphor is not entirely appropriate to Skinner's ecopoetic project: it evokes something constructed out of bricks and mortar, possibly at the expense of local ecology. His evocation of a 'home' in his 2011 essay (see above) is more apt. Yet it is more appropriate to think of ecopoetry as evoking habitats instead of houses. Robert Pogue Harrison has dismissed the notion of habitat as opposed to valued place (200) - but he misses the fact that a habitat can mean 'The locality in which a plant or animal naturally grows or lives' or 'the geographical area over which it extends' or 'the particular station or spot' it occupies. Importantly for humans, habitat also means 'Dwelling-place; habitation' (OED). Ecopoetry is poetry of habitat: appropriate for evoking a world that encompasses local, global, biotic, abiotic, human and nonhuman elements; and, critically, the ways in which we have irreversibly altered our habitat.

Place and habitation are critical to one theorist of ecopoetry. Scott Bryson argues that ecopoets value the interaction between 'two interdependent and seemingly paradoxical desires, both of which are attempts to respond to the modern divorce between humanity and the rest of nature'. These desires are 'to create place, making a conscious and concerted effort to know the more-than-human world around us' and 'to value space, recognizing the extent to which that very world is ultimately unknowable' (8). Drawing on the work of anthropologist Keith Basso, Scott Bryson argues for ecopoets to be regarded as being like Western Apache storytellers: 'place-makers' who evoke 'visions of how things have been, and, implicitly, how things might be' (10). He contends that ecopoetry encourages us to move from considering our surroundings as abstract spaces, to seeing them as valued places with which we can form an affective bond: a move towards the geographer's Yi-Fu Tuan's ‘topophilia' or love of place (11). This helps us to form an understanding of our interrelationship with our environment (12), and to consider it as worthy of protection rather than exploitation (16). Yet Scott Bryson's focus on place and space needs to be opened up to include a more nuanced discussion of local and global. Ecocriticism has long privileged the importance of the local, Scott Bryson's 'place', as an important tool to enable us understand global environmental issues (38-40). Hughes was deeply rooted in the English landscape and language - but there are many instances when his writing reminds us that a global environmental consciousness needs to acknowledge that identities are made up of 'mixtures, fragments, and dispersed allegiances to diverse communities' (Heise 2008 43), and indeed diverse localities.

'Ecocriticism', 'ecopoetry' and 'ecopoetics' are by no means uncontested terms (see Buell 2005 viii, Tarlo 2011 11, Gifford Green Voices 8.) However, scholars such as Jonathan Skinner, and contributors to his ecopoetics journal, cautiously employ the term, although it may not be perfect. To analyse Hughes's ecopoetics, one needs to find more general information about the process of ecopoetic 'making', its relationship to environmental concerns, and its deployment of linguistic features. Most ecopoets and ecocritics agree that ecopoetry must refashion language in a way that is appropriate to its engagement with the environment. The poet Marcella Durand summarises this view: 'Experimental ecological poets are concerned with the links between words and sentences, stanzas, paragraphs, and how these systems link with energy and matter - that is, the exterior world' (62). Timothy Clark states that ecopoetry combines formal experimentation with a focus on environmentally engaged thinking: 'At issue is an aesthetic interested in formal experimentation and the 
conception of the poet or poem as forming a kind of intellectual or spiritual frontier, newly coupled with a sense of the vulnerability and otherness of the natural world, distrust of a society dominated by materialism and instrumental reason, and sometimes giving a counteraffirmation of non-western modes of perception, thought or rhetorical practice. The poem is often conceived as a space of subjective redefinition and rediscovery through encounters with the non-human' (2011 139). As we shall see, the idea of the individual human's 'subjectivity' is challenged in poems by Hughes such as 'Wodwo' and 'Go Fishing' Kinsella and Gander's experimental volume Redstart upholds Durand and Clark's ideas about the formal qualities of ecopoetry: they raise the question of how 'syntax, line break, or the shape of the poem on the page express an ecological ethics'. Since 'our perceptual experience is mostly palimpsestic or endlessly juxtaposed and fragmented', events have 'layers' that reflect a biosphere composed of 'interdependency' (2). Their book contains a long ecopoem that deploys forms ranging from Greek choric odes (19) to pared-down amygdalas of meaning (29) and open-form pages whose words cluster like nests, groves or baskets of food (44). From Britain, Tarlo's anthology The Ground Aslant focuses on the formal and sonic features of ecopoetry and landscape poetry, primarily on writers 'whose formal techniques are exploratory and experimental enough to be called radical' (2011 8). There is 'a relationship between the spatial arrangement of the poem and the landscape'; such formal experiments 'affect the reading, the sounding of the poem on the air, and this is central to the philosophy of the open form poem' (9). When one thinks of experimental British ecopoets, Ian Hamilton Finlay, Mario Petrucci or indeed Tarlo herself might spring to mind. Hughes is not renowned for the radicalism of his poetic forms. However, he is daringly innovative in his own way. In experimental poems such as 'Milesian Encounter on the Sligachan' and 'A Kingfisher,' environmental sound answers environmentalist sense, rhythm is stripped down to its powerful elementary parts, and the form of the exterior world shapes stanzas, line breaks and mise en page. The works that Hughes created in collaboration with many artists also testify to an important visual dimenstion in his ecopoetry. It is undeniable that the sound of recited ecopoetry is also critically important. Skinner summarises it pithily: 'We have filled the atmosphere with our stories, and still we cram in more. The delicacy of our planet makes its own noise. Can we listen, to listen?' (ctd in Sweeney). Yet elsewhere, he accords too much importance to the auditory: 'sound may be the "true north" of ecopoetics: thinking about how poems interact with their sonic environments may be the quickest (if most literal) way to check in with the environment, whether urban, "wild," or in-between' (2011). This narrow judgement is not borne out by the visually experimental ecopoetry that Skinner himself publishes in ecopoetics. Ecopoets may choose to deploy visual devices to sculpt the form of their poetry; they may opt to echo and respond to the non-human world with sound; they may evoke taste, smell, touch. Quite often, they deploy all of these sensory strategies.

Elsewhere, Skinner identifies four main 'species' of ecopoetry. The first species, the 'topological', can be identified as 'the literature and poetry of place, but more generally any referring "outside" the poem to a "natural" topos. This is a commonplace that plants at least one foot within the themes and motifs of pastoral tradition, as it cannot help referencing literary convention'. Skinner borrows a term from Jed Rasula, 'tropological', to describe the second species. Creating 'tropological' ecopoetry involves 'casting poems as somehow functioning like ecosystems or complex systems, troping on language and ideas from the environmental sciences.' Gary Snyder's description of the poet as detritus feeder is the most famous example. Skinner draws on the work of land artist and writer Robert Smithson for a term for the third species: 'entropological' poetics. This is 'a practice engaged at the level of materials and processes, where entropy, transformation and decay are part of the creative 
work. Any "concrete" writing focused primarily on the procedures and materiality of the letter might fall into this category [...] but also other kinds of "writing" that involve marking the land or natural processes and that might more properly be considered under the rubric of the visual arts' (2005 128). Skinner is prescient in his inclusion of the fourth species, the 'ethnological', which foreshadows later critical interest in postcolonial environments. Here is how Skinner identifies it:

Learning about the landscapes our "nature" has obscured necessarily entails tasks of translation outside Western languages and cultures; it also means becoming more selfconscious about our own ethnic projections. In this sense, an ecopoetics is always already an ethnopoetics. (2005 129)

Hughes's poetry contains specimens of three of these 'species' and elements of a fourth. The groundedness of many of the poems in Remains of Elmet, for example, is topological. River can be seen as a collection that encapsulates aquatic ecosystems: it is tropological. Hughes's work does not have the entropological radicality of, say, Ian Hamilton Finlay's land installations. Nevertheless, the seasonal cycles of Moortown Diary, Season Songs and River echo natural processes on the page and strive towards the entropological. Even in the most traditional book of poems, the growing, felling, cutting, pulping, printing and binding entailed in making the volume, and the volume's eventual decay, are inevitable entropological processes.

'Ethnological' ecopoetry should be written with care: Gander and Kinsella state that it is 'hypocrisy to use indigenous knowledge, to co-opt it, as a way of affirming one's own connection to the place that one has directly or indirectly helped oust indigenous people/s from anyway.' It is indeed problematic for a white writer to appropriate indigenous knowledge to him or herself. Stereotyping non-white races as ecological indigenes is almost as troubling to modern readers as calling them 'primitive', as Hughes's Cambridge anthropology textbooks did. One can allow indigenous knowledge to 'become a positive part of a nonindigenous discourse' (Gander and Kinsella vii), but Gander and Kinsella are right to caution that 'so often it's a veneer of connection and respect hijacked to validate one's own presence and disturbance of land' (viii). If Hughes's concept of indigenous people living in palaeolithic Edens seems naïve to readers nowadays, we must remember that the texts by Haig-Brown and C. M. Bowra that he was reading in the early 1960s were current in their time. Indeed, Hughes's very nostalgia for aboriginal ways of life is a function of his dismay at modernity, with its consumerist values and sterile artificiality. As Bate notes, 'Idealization of the supposed organic communities of the past, like idolization of the aboriginal peoples who have supposedly escaped the ills of modernity, may often serve as a mask for the oppressions of the present' (Bate 2000 25). This book shows that Hughes's 'ethnological' writing is permeated with sensitive references to the mythologies of shamanic and animist cultures - and often the 'oppressions' that have threatened their belief-systems. In works such as The Tiger's Bones and 'The Head', Hughes shows the power-struggles that threaten both their ways of life and the environments on which they depend. However, he remains unusually reluctant to describe Native Americans in his published work, and if there are any 'ethnological' anxieties in his ecopoetry, they relate to his boyhood identification of himself as a Native American hunter and fisherman. 


\section{$\underline{\text { Hughes and ecopoetic language }}$}

Any attempt to evoke the environment in art raises complex questions about representation. Presuming to speak for a voiceless entity is problematic: the poet who does so anthropomorphizes nature. David Gilcrest is skeptical: 'the attempt to recognize the nonhuman subject as linguistically competent strikes one as an essentially colonizing move' (53). Drawing on the work of Catriona Sandilands, Kenneth Burke and others, he states that the poet should 'eschew the nonhuman speaking subject in favor of a rhetoric of alinguistic agency' (59). Gilcrest's denial of language to nonhumans would be seen as problematic by Wolfe (2003 2) and Morton (2010 71). The trouble with the 'voice for nature' is rather that it places human language into the mouths of nonhumans, rather than evoking their own systems of communication. A potential solution is John Clare's transcription of the nightingale's song (qtd in Oswald, 'The Thunder Mutters' 36), or Les Murray's method of creating Translations from the Natural World (1992): both acknowledge the otherness of animal communication and the potential for meaning to be lost in translation. Moreover, it is sometimes necessary for an environmentally engaged author to speak on behalf of nature in some capacity. Buell finds that personification and the pathetic fallacy are essential in some degree to environmental writing: 'The rhetoric of nature's personhood speaks merely to the nominal level; what counts is the underlying ethical orientation implied by the troping [....] [T]o ban the pathetic fallacy - were such a thing possible - would be worse than to permit its unavoidable excesses. For without it, environmental care might not find its voice' (1996 217218). As we have seen, he makes a case for the difficult necessity of metaphor (2001 251). A voice for the environment might resemble the 'voice for Ariel' called for by Jonathan Bate: 'The ecocritical project always involves speaking for rather than speaking as its subject' (2000 72). The idea of a 'speaking for' an entity that cannot communicate via language remains problematic, but not entirely impossible. Hughes speaks for the Earth in his Tales from Ovid, translating and ecologising Ovid's voice for the earth-goddess. Particularly exciting developments in ecopoetry occur when poets give voice to hybrids - creatures that are analysed in the criticism of Latour, Haraway, Wolfe and Morton. Hughes's Wodwo is one such hybrid, able to express his part-wild existence with a human voice. Rather than imagining hybrids, Hughes creates a 'hybrid' voice in 'Curlews' and 'Grouse-Butts', which incorporate bird-calls and sound back to the voices of nature. These 'hybrid' poems avoid appropriating nonhuman subjectivity, and instead allow our interrelationship with our environment to shape their meaning and their form.

There is also debate about how ecopoets should deploy the lyric I, if at all. Harriet Tarlo rejects nature poetry because 'the inner self/outer world distinction so dear to nature poetry through the ages has become outdated' (2008 15). Although this dualism is obsolete, it is still possible for the persona of an ecopoem to use the lyric I to situate himself or herself within, say, a local bioregion, the global context, the processes of evolution, or his/her complicity in processes such as climate change and overconsumption. Gander and Kinsella also do not oppose the lyric I per se, as it 'is always hidden away there by varying degrees of separation.' They state it should be put under pressure, in terms of 'what constitutes the self' and 'how it operates as messenger and witness' (viii). Hughes's poem 'Wodwo' begins 'What am I?' (CPH 183). There follows a catalogue of elements of the landscape that complicate and ultimately dissolve the Wodwo's identity. Hughes's work shows that the lyric I can be problematised sufficiently for it to remain relevant to modern ecopoetry.

Indeed, some theorists view poetry's use of the pathetic fallacy, personification and the artifice of language as not just inevitable, but appropriate and desirable. Scott Knickerbocker 
makes a case for the artifice of poetic language as 'a way to relate meaningfully to the natural world' (2012 2). Knickerbocker sees various poetic devices as highlighting humankind's close relationship to nature. Citing John Berger, he argues that metaphor is at the heart of representation, and humankind's relationship to animals. Not only did language itself begin with metaphor, but the 'first subject matter for painting was animal.' For Berger, 'Probably the first paint was animal blood' and 'the first metaphor was animal'. Even if what 'distinguished man from animals was the human capacity for symbolic thought', the 'first symbols were animals' (qtd in Knickerbocker 2012 4). This primitivist reading of the creation of signs and symbols resonates with Hughes's poetic engagement with so-called 'primitive' chants and poems, for example the animal symbolism in his poem 'Amulet'. Knickerbocker defends apostrophe because it accords agency to non-sentient beings: 'Apostrophe and personification overtly claim that we take note of the nonhuman world; yet they also imply the possibility that the nonhuman world takes note of us, as they rhetorically place the nonhuman in the position of interlocutor, even if silent' (2012 6). Knickerbocker's scholarship is valuable as one of the first monographs on ecopoetics, and amid a backdrop of earlier ecocritical arguments about the way that poetry brings human beings closer to the natural world, its arguments in favour of poetic artifice give ecopoetics scholars an instructive reminder to pay attention to the potential pitfalls and narcissism of attempts to represent the environment via a linguistic medium. However, with its subtitle The Language of Nature, the Nature of Language, one would expect Knickerbocker's book to engage more thoroughly with philosophical debates on language, deconstruction and semiotics; ecocritics such as Serpil Opperman (2008) and Timothy Clark (2010) have long been examining the former, while Timo Maran (2010, 2014, 2016) and Timothy Morton (2010 66-7) have been analysing the latter for many years.

Nevertheless, all this theorization about 'capturing animals' without killing them, a voice for nature, the delicacy of our planet making its own noise, and open-form poetry where form echoes landforms, risks making ecopoetry sound naïve to the complexities of environmental representation, and blind to the changes that humans themselves have made to the nature that it purports to examine. Ecopoetics needs to enter into dialogue firstly with literary theories that are aware of the challenges of representing nature, and secondly with critical material about writing in the Anthropocene, if it is to keep pace with developments in ecocriticism. Timothy Morton deconstructs nature writing, which he terms 'ecomimesis', in Ecology without Nature: Rethinking Environmental Aesthetics (2007). He urges ecocritics to beware of the 'compelling illusion' of nature-writing that disguises its textual and aesthetic dimensions (2007 54), which he terms ‘ecomimesis’. Reacting to prose nature-writing such as 
Thoreau's Walden, he writes, 'when ecomimesis renders an environment, it is implicitly saying: "This environment is real; do not think that there is an aesthetic framework here"” (3), but of course, '[t]he inherent instability of language, and of the human and nonhuman worlds, ensure that ecomimesis fails to deliver' (78). There are elements of narcissism in 'ecomimesis', for 'Some nature writers think that they are receiving a direct transmission from nature, when in fact they are watching a mirror of the mind' (68). Kate Rigby's work on ecopoetry builds on Morton's criticism, and cautions against a fetishisation of the text: 'The ecomimetic insistence on the capacity of really good writing to truly render the embodied experience of nature, far from bringing us any closer to the other-than-human, simply seduces us into an idolatry of the text: while claiming to celebrate nature, ecomimesis actually celebrates the human capacity to capture the other-than-human in writing' (116). Of course, 'the text does not deliver what it promises, if that promise is an embodied experience of the more-than-human world' (117). Hughes did wish the immediacy of his 'ecomimetic' mode of composition in Moortown Diary to bring his reader closer to the experience of farming that he describes. Yet he was, of course, aware that words are 'unnatural, in a way, and far from being ideal for their job', unable 'to capture the infinite depth of crowiness in the crow's flight' (PM 119). Rigby continues to argue for the importance of ecopoetry to turn our gaze towards the external environment: 'as Yves Bonnefoy puts it, to "lift our eyes from the page" (117). For Rigby, ecopoetry that celebrates the more-than-human world is important, but a more negative form of ecopoetry that 'bears prophetic witness, in grief and anger, to the violence of objectification, instrumentalization, and commodification' of nature (127), is equally necessary. Rigby's idea of ecopoetry that pays attention to the commodification of nonhumans resonates with Hughes's concerns about the desacralised objectification and commodification of nature in 'The Environmental Revolution,' which will be analysed further in Chapter V.

Tom Bristow's The Anthropocene Lyric is one of the first monographs to put ecopoetic theory into dialogue with critical debates on the Anthropocene. Analysing the poetry of John Kinsella, Alice Oswald and John Burnside, he argues that 'Anthropocene lyricism does not aim at synchronicity, harmony or holism'. Instead, it aims at 'erasing human-centredness' and engaging with 'disconnection' and 'breakdown' (112). This resistance to 'harmony and holism' offers an important complication of Skinner's paradigm of tropological and entropological ecopoetics, suggesting that poetry for the Anthropocene needs to pay attention to the way that human beings alter environmental processes and systems. Hughes was interested in the 'holism' of Gaia theory, and his poetry of the 1980s reflects this; although his work is also aware that planetary systems are disrupted by human activities. Via a 
geocritical method that relies on 'the relationship between cultural practice and physical geography' (4), Bristow sets up productive ideas of 'connection and disconnection, diaspora and exile, union and division, harmony and discord' (6), putting the local into dialogue with global environmental issues. It is these disconnections and divisions that become particularly significant when Hughes's poetry of place interacts with his awareness of global environmental issues. Yet while he highlights the importance of breaking down holism and harmony, Bristow's focus on place-making occasionally steers perilously close to Bate’s focus on the imaginative reunification of the mind with nature: 'When coupled with Anthropocene lyricism, place is felt as it is encountered as being lived out by others, by more than ourselves, by our situatedness in history and ecology. It is the space in which we best witness the fragility, beauty and indifference of flora and fauna, climate and season - the more-than-human world' (7). Such analyses of situatedness and place also become complicated when cultural artifacts engage with Anthropocene phenonmena that are so vast as to be placeless: for example, Timothy Morton's idea of climate change as 'nonlocal' (2013, loc. 104), or Timothy Clark’s argument that the environmental effects of overpopulation impact upon all areas of the earth, even sparsely populated regions (2015 86).

Solnick’s Poetry in the Anthropocene (2016) brings theories of ecopoetry into dialogue with scientific paradigms such as systems theory and the theory of evolution. Arguing that the arguments put forward by Bate were relevant to the Romantics, but are no longer applicable to our current age of more advanced environmental change, Solnick proposes that 'Poetry can no longer 'sing the song of the earth'. In the Anthropocene, poetry is forced to find new ways of rendering, recalibrating and mutating the complex relationships between human organisms and the environments that their behaviours and technologies have shaped' (15). Importantly, he also explores how poetry draws attention to its own referentiality and self-referentiality (57). He envisages an important role for environmentally aware art: 'ecologically orientated art does not simply consist of ornamenting an environmentalist message; it helps explore why and how communication about ecology, biology and technology might be affecting or (in)effective' (57). This is an important consideration for Hughes, who questioned the success of his environmentalist 'semi-protest pieces'. As chapter IX will show, it is the effectiveness of such modes of communication - a battle of the sciences where environmental science vied with the polluting interests of large corporations - that Hughes targeted in one of his campaigns and in his article 'If' (1992). This book aims to pay yet closer attention to the precise scientific theories that Hughes knew, and to contemporary developments in environmentalism in which he was involved. 
Poetry in the Anthropocene must acknowledge the extensive and insidious changes that human beings have made to our planet, and how these changes affect us. It is when Hughes engages with the detritus, wreckage, fallout and remains that human beings create, that his poetry becomes especially aware of this. Ecopoetic engagement with filth, rubbish, toxicity, decay, radiation, ashes and relics requires a particular poetic mode: one that Hughes perfected in Crow. In exploring such super-simple, super-ugly, garbage-strewn and vermin-infested literature, ecocritical theory remained ahead of ecopoetics for a long time. Buell's idea of toxic discourse (1998 645), Gifford’s concept of the anti-pastoral (2012 18-19) and Dana Phillips's theory of 'excremental ecocriticism' (2014) began to suggest an alternative way of looking at writing about environmental destruction, pollution and filth, although they are too narrow to encompass the full range of ideas in Hughes's Crow-project. From ecopoetics theorists, Skinner's idea that ecopoetry 'confronts disasters and environmental injustices' (2011) is helpful, as is Gary Snyder's view of the poet as detritivore (71). But again, these theories are not sufficiently expansive to be fully applicable to Crow; nor do they explore exactly how ecopoetry accomplishes such tasks via its formal, lexical and auditory features. Publications on waste studies, such as Susan Signe Morrison's The Literature of Waste: Material Ecopoetics and Ethical Matter (2015), provide new insights for the study of ecopoetry. As will be argued in Chapter V, Crow exemplifies a poetic mode that focuses on waste, from the local waste of a littered moor to the planet laid waste by nuclear conflagration. Indeed, this is a poetic mode adequate to the Anthropocene: any attempts to effect an imaginative re-unification of the mind with nature end up illustrating the extent to which 'nature' is modified by climate change, human predation, nuclear technology, habitat loss and species extinction.

Ecopoetry, then, is a poetry of habitat: it explores our relationship to the environments and ecologies that surround us, the alterations that we have made to them, and our imbrication within their systems. It can no longer present the supposedly untouched landscapes of earlier nature poetry. The places that it presents can include toxic wastelands, cityscapes, intensively farmed countryside, managed 'wildernesses', digital networks and parts of the solar system beyond the Earth. Ecopoetry engages with animals and plants: how we meet them, how we use them, and whether it is right to prioritise our needs over theirs. The visual form and sonic qualities of their poems embody their environmental engagement. If the lyric ' $I$ ' is used, it is not deployed in the solipsistic way earlier nature poets used it. Even personal meditations on the individual's connection to the more-than-human world, can imply an ecological ethics. For the Romantics, nature poetry necessarily predated 'green' politics. In the twentieth century, environmental agendas became integrated into the politics of a spectrum of parties, 
ranging from National Socialism in Nazi Germany ${ }_{36}$ to the environmental Marxism of the 1970s and 1980s. With the rise of Green Parties in the USA and Britain, The Greens in Germany, and movements such as Buen Vivir in Latin America, environmental poets may choose to align their work with an array of ideological agendas. Ecopoetry of the last fifty years is sometimes apolitical, but its creator's other writings, views and activities need to be taken into account before such a judgement is made. Ecopoetry can dramatise ecological interconnection; or demonstrate what happens when ecosystemic processes are altered by human actions; or explore the complicated moral dilemmas of western contact with huntergatherers who live off the land. Ecopoets can tackle issues that affect human beings and their environments equally: struggles for land ownership; the fight for environmental justice in less developed countries; modernity's pernicious appetite for natural resources; the adequacy or inadequacy of different modes of environmental communication. Ecopoetry of waste can contemplate the horrific prospect of pollution and destruction on a global scale. Ecopoetry will continue to develop many further thematic and formal strategies in the future, and this synopsis is far from exhaustive. But for it to be 'the real thing', as Hughes put it, poets must combine aesthetic and critical judgements with ecological ethics to avoid writing 'semiprotest' green propaganda. From his early years in Mytholmroyd and Mexborough, through to his years in America, his many trips abroad, his farming, his fishing and his engagement with endangered environments, Hughes's writing is often a poetics of living with and disrupting local and global ecologies: a poetics of habitat.

36 For further information, see Bramwell 1989. 


\section{CHAPTER III. FROM MYTHOLMROYD TO MEXBOROUGH: ORIGINS OF HUGHES'S ENVIRONMENTAL AWARENESS}

\section{Myths of Mytholmroyd and Capturing Animals}

Hughes's early understanding of the environment can be traced as far back as his years in Mytholmroyd, where he lived from his earliest childhood to the age of eight. The events of his childhood contribute to a foundational myth that lies behind much of Hughes's poetry, and which provided the deepest impetus for his environmentalism: the idea of leaving behind a paradisal age in an Edenic place, and the endless quest to return. As we shall see, environmental destruction, conflict and historical events almost invariably thwart this quest. Hughes's understanding of animals, plants and human beings' use of them developed in two important ways during his childhood and early adolescence. Firstly, hunting and fishing with his older brother gave him a close relationship with animals; after his brother's departure, he began to kill fewer species, and to learn to value certain types of creature. Secondly, he became aware of environmental pollution due to farming. Contrary to some of his own assertions, however, there was no neat progression from capturing animals to capturing animal-poems. Hughes shot vermin, and occasionally game animals and predators, for most of his adult life.

The 1940s saw an increasing awareness of several issues that we would now see as protoenvironmental: food security, the sustainable supply of timber (McCormick 1995 32-3), and conservation. The Nature Conservancy was founded in Britain was founded in 1949 (37). This was not 'environmentalism' as we know it now, and such movements were focused on resource management, conservation and preservation. Hughes does not mention these developments in his reminiscences about his childhood. But as we shall see, he did read two key writers who exposed him to early conservationist thinking, and a book in his library suggests that he was aware of the laws protecting predatory birds.

Hughes's commentary on his childhood develops at different stages in his writing career. In 1961, the BBC broadcast an interview with Hughes and Plath. When asked about his animalpoems, Hughes replies that his earliest memories were of toy 'lead animals' and a 'thick animal book' bought for him when he was four, and which became 'a sort of bible' for him for the next five years. He drew animals and made them out of Plasticine. He remembers his proximity to the countryside, and acting as a 'retriever' when his brother went shooting. He stresses that his early childhood was 'sealed off' in his mind, when he moved to Mexborough, and found the town 'industrial, depressing and dirty' and living there an 'unhappy' experience ('Two of a Kind'). This interview clearly communicates the importance of Hughes's working-class early childhood in a largely rural landscape, which he describes as formative for his poetry about animals and nature.

An essay that was first published a little later, broadcast in 1963 with revisions made in 1964, returns to Hughes's boyhood landscape. Scout Rock is described thus: 
The most impressive early companion of my childhood was a dark cliff, or what looked like a dark cliff, to the South, a wall of rock and steep woods half-way up the sky, just cleared by the winter sun. This was the memento mundi over my birth: my spiritual midwife at the time and my godfather ever since - or one of my godfathers. From my first day it watched. If it couldn't see me direct, a towering gloom over my pram, it watched me through a species of periscope: that is, by infiltrating the very light of my room with its particular shadow. (1974 122)

The rock is a solemn presence. Yet Hughes's description of it as his 'companion', his 'spiritual midwife' during his childhood, and his 'godfather', accords it tremendous agency. He is 'watched' by the rock - even to the point where it peers at him 'through a species of periscope'; this idea resonates with Morton's idea of uncanny, pervasive ecological interconnection. The great importance and agency that Hughes gives to place in is poetry especially in the sequences relating to Elmet - originates in his boyhood encounters with the landscape.

Scout Rock contrasts with the moors, which are 'a gentle female watery line', 'friendly' (125) and 'exultant' (126). Hughes even writes that 'If any word could be found engraved around my skull, just above the ears and eyebrows, it would probably be the word 'horizon'” (125). The horizons mark the poet to the point where they have a textuality that metaphorically inscribes itself onto his mind and body. It is here that Hughes heard the 'dry and so similar voices of grouse and sheep, and the moist voices of curlews': sounds that informed his later poetry. Moreover, Yorkshire people 'are not detached enough from the stone, as if they were only half-born from the earth'. Hughes evokes their deep groundedness in place, but also their engagement in farm labour, and their later toil in gritstone mills. Wide horizons, the voices of curlews and sheep, the earthbound people of stony towns: these will become foundational images in Hughes's later Elmet-poetry. Hughes ends with the descent back into the valley, back towards human habitation: 'This was where the division of body and soul, for me, began' (126). The division of body and soul is akin to the divorce of humankind from nature that Hughes examines in 'Baboons and Neanderthals' and his 1990 letter to Merchant: a deeply destructive experience. Gifford's analysis of drafts of this essay show that boyhood walks from valley to moorland marked an important initial development in Hughes's environmental awareness (Gifford 2014 2). When he returned to the valley, Hughes thought of it as 'the pit' (126). The 'pit' is the pit of hell; but it is also a miners' term. The young Hughes would learn more about pollution, industry and the 'pit' when he moved to South Yorkshire at the age of eight.

Hughes's early environmental knowledge cannot be separated from his interest in capturing animals. His childhood hunting and fishing expeditions with his brother Gerald are well documented, and are explained in greater detail in 'Capturing Animals':

There are all sorts of ways of capturing animals and birds and fish. I spent most of my time, up to the age of fifteen or so, trying out many of these ways and when my enthusiasm began to wane, as it did gradually, I started to write poems. 
Hughes also states that his interest in animals began when he began (WP 10). This corroborates what he later wrote to Gifford: his 'greening' began with everything that lay about him in his infancy. In some moving draft poems archived with the drafts of Remains of Elmet, Hughes describes some of his earliest encounters with hunters and hunted. At this stage in their drafting, they are presented as early memories. He writes of an old gamekeeper showing the wings of snipe to him and to Gerald. 37 He recalls the time he saw and knew a hawk for the first time - holding a small bird in its claw, with another bird flying after it and crying. 38 This particular image was later published in 'What's The First Thing You Think Of?' (CPH 695-6).

Gerald taught Ted to fish in the local canal from the age of three (Scigaj 1991 5). When Ted was about two, he fell into the water at Stub Dam; his mother summoned him back from a later camping expedition with Gerald because she was concerned about his fascination with water. He would 'gravitate to water wherever there [was] the possibility of fish' (Ted Hughes: Dream Time). Gerald also had more to do with Hughes's passion for capturing animals than anyone else, thanks to his passion for creeping about on the hills with a rifle:

He took me along as a retriever and I had to scramble into all kinds of places collecting magpies and owls and rabbits and weasels and rats and curlews that he shot. He could not shoot enough for me. At the same time I used to be fishing daily in the canal, with the long-handled wire-rimmed curtain mesh sort of net.

[...] When I was eight, we moved to an industrial town in south Yorkshire. [...] I soon discovered a farm in the nearby countryside that supplied all my needs, and soon after, a private estate, with woods and a lake. [...] I still have some diaries that I kept in those years: they record nothing but my catches. (WP 11)

Gerald does not remember their shooting as quite so indiscriminate: he recalls Ted's fascination with 'hawks and owls', which they never shot. The species that Gerald remembers shooting are traditionally seen either as game or pests: 'rats, wood pigeons, rabbits' 'stoats' and 'grouse' (27). All childhood memories are coloured by our adult views: Ted might emphasise the young hunters' bloodthirsty shooting of owls, weasels and curlews to contrast it with his later focus on 'capturing' poems. An alternative reason for this was that they actually did shoot owls, because short-eared owls hunt the game birds39 that Ted and Gerald enjoyed poaching for the pot. Owls were actually protected in Yorkshire at the time (Eric Parker 67-8), and it is possible that both brothers later wished to conceal their boyhood killing of rarer birds. Controlling predators that prey on game would emerge as a significant problem in Hughes's conservationist defence of shooting (see Chapter X). He also does not mention his gin traps in Poetry in the Making; they were a source of unease in his later life

\footnotetext{
37 BL Add MS 88918/1/52 'It’s a quiet place. I sit, or I stroll’

38 BL Add MS 88918/1/52 'There they lie, I watch them’

39 Lister-Kaye notes that a gamekeeper in Scotland was prosecuted for shooting a short-eared owl as late as 2004 (136).
} 
(LTH 579). Yet hunting expeditions allowed the boys to become immersed in local ecology, and to begin to understand their impact upon it.

Native American culture interested both Gerald and Ted when they lived in Mytholmroyd and at the beginning of their time in Mexborough, to the point where Native American myths seemed to them to overlay the landscape. The boys were also aware of the importance of hunting and animals to Native Americans. Poems such as 'Black Hair' (1996) describe Hughes's mother, Edith, as Native American in appearance. Ted would follow Gerald 'pretending to be a Red Indian hunter' (Gerald Hughes 24). Gerald taught him about the creatures around him - 'That's a magpie; they are egg stealers' (25). It was Gerald who, when Ted was about nine, taught him a (supposedly) Native American war-song about the woodpecker:

I am the woodpecker,

My head is red,

To those that I kill

With my little red bill,

Come wolf, come bear and eat your fill,

Mine’s not the only head that's red. (Sagar 2006 104)

The war-song about the woodpecker has an 'unmediated violence', according to Sagar (2006 104). The choice of a woodpecker is unusual: they are rarely aggressive, but the woodpecker is able to drum loudly on tree trunks when it is drilling a nest-hole, and both British and North American species have blood-red cockades. Gerald Hughes recalls the route the two of them took through Redacre Wood, 'where Ted had a tom-tom drum hidden' (26). Hughes's identification of Yorkshire people with Native Americans became more anachronistic later in his career.

Ted and Gerald Hughes look back on killing animals during their youth with nostalgia, sometimes mingled with traces of guilt. To some extent, the boys' hunting was for subsistence and to supplement their household's income. Ted set traps for mice, cured the skins under the lid of his school desk, and sold them (Pero 54) - a shrewd way for a young boy to make extra pocket money. Gerald recalls that a gamekeeper 'would often pay us a shilling for a good rabbit [...] which helped with the family budget' (Gerald Hughes 34) and that rabbits supplemented the family's diet (64). A farmer also rewarded Ted with eggs for shooting a rat (37), so their hunting contributed to the pest control that always forms a part of rural life. However, they also hunted because they enjoyed it: Hughes describes his brother's shooting as a 'pastime' that was unusual at the time (Pero 54). Gerald recalls that he and Ted saw a fox crushed by a deadfall trap, and remembers that Ted had a dream featuring an old lady and a fox cub orphaned by the trap. He links 'the beginning of Ted's great interest in the fox', his horror of deadfall traps and his later short story 'The Deadfall' to this incident (56). Gerald also recalled that Hughes was 'very upset' by the deadfall, and that he once said, "When you take a life [...] what about its partner, what about its offspring, and what about its 
relationship with the creatures around it? [...] I don't want any part in that. It's totally wrong” (Dream Time). Gerald's memory of Ted's words would suggest the very earliest stirrings of an awareness of ecological interconnection, although the young Hughes would not have known to label it as such. Indeed, when the Hughes family moved from Mytholmroyd to Mexborough, and after Gerald had moved to Devon to become a gamekeeper, Hughes's attitude towards animals underwent a gradual change. 'Capturing Animals' describes an important phase in Hughes's early awareness of animals and environments: 'at about fifteen my life grew more complicated and my attitude to animals changed. I accused myself of disturbing their lives. I began to look at them, you see, from their own point of view' (WP 11). A growing sensitivity to the suffering of hunted creatures during his adolescence was an important step in the development of Hughes's environmental knowledge. However, it is significantly complicated by Hughes's continued passion for hunting, which will be examined more fully at the end of this chapter.

The writing of Henry Williamson helped Hughes to develop his boyhood interest in the lives of animals, and an awareness of animal suffering. He encountered Tarka the Otter in the school library at Mexborough Grammar (PC 276). He was eleven when he found it, and he reread it for two years (WP 4). Hughes describes how Williamson's book shaped his interest in animals and writing:

My own bond with Henry Williamson was made through that book [...] [A] world I was already given to completely - my world of wild creatures in the South Yorkshire countryside - became a world of Henry's radiant language. In this way, Tarka put my life under an enchantment that lasted for years, and that gradually crystallised into an ambition to write for myself. (1980 160-161)

In Tarka, Hughes read that wild creatures were 'the small and persecuted kinsfolk of man' (Williamson 18). He encountered Williamson's spirited criticisms of hunting, such as the following:

Once hunted himself, then hunting for necessity, man now hunts in the leisure of his time; but in nearly all those who through necessity of life till fields, herd beasts, and keep fowls, these remaining wildlings of the moors have enemies who care nothing for their survival. The farmers would exterminate nearly every wild bird and animal of prey, were it not for the landowners, among whom are some who care for the wildlings because they are sprung from the same land of England (126-27).

Tarka introduced the young Hughes to Williamson's brand of conservation. The above passage smacks of 'patrician environmentalism' - an ideological tinge that Ely finds in Hughes's adult politics (2015 55). Hughes had no time for the green-tinged fascism that Williamson developed after writing Tarka. Yet in Tarka, Hughes glimpsed how private land ownership could aid conservation, how hunting creates class-related tensions, and what a hunted animal endures physically. Paradoxically, Williamson followed the otter hunt (Williamson xi), much as Hughes would later defend foxhunting. Here, too, was a precursor for Hughes's conflicted attitude towards hunting with dogs. Much later, from his early thirties, Hughes lived 'on Tarka’s river, the Taw’ (1980 163) and got to know Williamson, 
although they never became very close.40 Hughes’s 1949 edition of Williamson's Salar the Salmon $_{41}$ deepened his fascination with the creatures that live under the surface of Devon's rivers, and provided a model for the salmon's journey from source to sea and back in River. Gerald's time among the 'wildlings' of Devon, and the appeal of fishing Tarka's 'Two Rivers', would contribute to Hughes's later desire to move to the West Country.

The following year, Hughes encountered a book that made him and Gerald dream of landscapes much farther afield than Tarka's 'Two Rivers'. Their reading of hunter, fisherman and frontiersman Roderick Haig-Brown awakened a desire to 'emigrate together to British Columbia’ (Boyanowsky 3) and emulate Haig-Brown’s trapping and angling lifestyle. Hughes owned two of Haig-Brown's books on the British Columbian salmon run, books that formed his desire to fish there in later life. Ely writes that Hughes read hunting-stories such as Panther (1934) (2015 24). Panther begins with its author's defence of violent passages: 'Ki-yu [the panther] was not cruel - no wild animal is cruel, or kind either for that matter. When Ki-yu killed he did so, as do all animals, for one or other of three reasons - because he was hungry, because he was in fear of his life, or because his right to a female was challenged [...] only man is cruel' (Haig-Brown 1934 7). As we shall see, Hughes's own essay 'Poetry and Violence' expands upon these very themes. In this early book, the reader's sympathies are with the cougar protagonist rather than the hunters who never manage to outwit him, even though details of the narrative were provided by British Columbia's greatest cat hunter (9). Ely notes that Haig-Brown was 'an early environmentalist' whose works 'wrestled with the theme of how to live in and exploit the natural world without destroying it' (2015 24). But Haig-Brown did not merely wrestle with these themes in his writing: he was an environmental campaigner from the 1940s to his death (Keeling 246), his first major campaign targeting dams on the salmon-rich Fraser River. Return to the River: a story of the Chinook run, is a nature-story that incorporates Haig-Brown's 'growing awareness of ecological interdependence and the threat to natural systems posed by industrial development' (Keeling 250); Hughes's 1942 edition of this book is old enough for him to have read it at grammar school. Hughes later acquired A River Never Sleeps and The Whale People.42 Haig-Brown's conservationist ideas developed through a 'modern sportsman ethic' to 'utilitarian conservation' and ultimately 'a humanistic and ecological critique of North American attitudes toward the land' (Keeling 244), a progression not unlike Hughes's own development. Haig-Brown was already beginning to develop the latter mode of thinking in Return to the River. There, the young Hughes read the extraordinary views of the conservationist angler, Senator Evans, who is concerned that he is partly to blame for the 'rape of America' (1942 26). The book exposed Hughes to Haig-Brown's descriptions of a river polluted by sewage and industry (68), a decrease in the salmon run (74), criticisms of dams (164) and the running of a commercial hatchery (176-77) - ideas that would be highly

\footnotetext{
40 For information on the ideologies in Williamson's nature-writing, and the ways in which Hughes enters into dialogue with his work, see Reddick 2013.

41 Emory Rose Library PR6045 .I59 S3 1949 HUGHES.

42 Emory MARBL QL795 .F7 H29 1942 HUGHES, SH441 .H15 1948 HUGHES and PR9199.3 .H29 W4 1962 HUGHES.
} 
important to Hughes's environmental protest-poems and to River. Hughes's 1962 edition of The Whale People would later shape his concept of Native Americans' understanding of the creatures of their seas. Haig-Brown evokes a civilization where a prayer is a lure (1962 42), where a whale-chief comes of age by shamanising to the spirits of wolves and whales (6983). Ely credits Haig-Brown and Williamson with 'narrating vividly and brutally how humans interfere with the lives of animals, bringing death, pain and suffering'. Such writers made Hughes feel 'empathy and guilt', and would ultimately 'challenge his trigger-happy approach to shooting' (2015 102). Yet Haig-Brown is greener than Ely acknowledges, and the earlier writer provided an important role model for Hughes's adult campaigns on behalf of rivers. As late as 1990, Hughes said to Boyanowsky, “"Remember, Haig-Brown said: 'Rivers need friends'” (120-21).

Yet earlier scholars have almost completely ignored an important British influence on Hughes's boyhood attitude towards animals: the Victorian nature-writer Richard Jefferies. Hughes owned multiple copies of The Gamekeeper at Home and The Amateur Poacher; 43 two of these are old enough for him to have read them with Gerald in Mytholmroyd. Previous critical engagements with Jefferies' influence on Hughes are confined to a few cursory references by Robinson (1989 24, 74, 79), who does not check whether or not Hughes read him. In The Gamekeeper at Home, Jefferies describes the killing of rabbits, mice, weasels, stoats and rooks (84-96): the edible and verminous species whose numbers the gamekeeper must reduce. The keeper wages 'ceaseless war' against hawks, plentiful in Jefferies' time (99); kills magpies, although these were becoming 'much less common' (99); and 'destroys owls', even though Jefferies is not convinced that they kill game (100): here are most of the species that Hughes recalls targeting. Jefferies's gamekeeper secretly dislikes the hounds and horsemen who break his fences, even though they tip him for blocking up foxes' earths (40). This ambivalence towards hunting paved the way for Hughes's later, conflicting opinions of the hunt. From The Gamekeeper at Home, Hughes (paradoxically) learnt everything from how to poach with snares (119) and conceal the poaching of birds (118) to the tricky art of noosing ‘jack’ pike (142-3); The Amateur Poacher describes the use of such stratagems from the poachers' perspective. These books joined the magazines The Shooting Times and The Gamekeeper (WP 4) in Hughes's repertoire of writings about hunting and the management of animal populations for shooting. Jefferies' writing about both gamekeeping and poaching influenced Ted and Gerald's rather contradictory pursuit of both game and vermin: they were at once amateur poachers and aspiring gamekeepers. Originally serialized in 1878 and 1879, when wild animals were plentiful and when farming was far less intensive than it was in Hughes's time, Jefferies' books informed Hughes's traditional views of how wild animals should be treated. Jefferies' idealised rural community of eccentric gamekeepers and cunning poachers partly explains why Hughes displayed nostalgia for his boyhood hunting expeditions very late in life (Pero) - even though his environmentalist principles informed

43 These include a 1935 edition of The Gamekeeper... with an introduction by Henry Williamson, old enough for Hughes to have read it as a young boy (Emory MARBL SK505.J44 1935 HUGHES). It is possible that his 1881 edition of The Amateur Poacher (SK31.J46 1881 HUGHES) was an expensive antique, acquired later in Hughes's life. 
him that such hunting was unsustainable. Jefferies’ influence on Hughes early knowledge of the environment is ambiguous: the nostalgia that Jefferies' writing displays was at odds with the more clearly 'green' influence of Haig-Brown's progressive campaigns to defend fish habitats.

But of course, Hughes's respect for animals developed mainly via direct encounters with them. At the age of thirteen or fourteen, Hughes remembers setting out alone, very early one morning, on the south side of the River Don. He was on the lookout for rabbits. He followed an animal path up the riverbank, and as he peered over the top, he came face to face with a fox coming up the other side, 'doing exactly what I was doing, but in the opposite direction'. They stared at each other in amazement for a second, and then the fox fled, leaving behind a reek of musty smell.44 This experience partly informed 'The Thought-Fox'. The ecopsychology of this encounter with a wild animal is striking: Hughes finds his gaze and his amazement mirrored in the astonishment of the fox. As will be discussed later, animal gazes show us our deep, intrinsic link to other species by mirroring our own. At Mexborough, Hughes also experienced a connection to the land through farming. He remembers that in the summer of 1945, when he was fifteen, he helped to build stacks of wheat, barley and oats on a South Yorkshire farm, alongside German prisoners of war. 45 These encounters would inspire significant works such as 'Sunstroke' and 'The Harvesting'. Ely mentions surprisingly little about how Hughes's attitude towards polluting heavy industry was formed by Mexborough. Ely describes a pit town 'at the zenith of its prosperity' with 'colliery spoil heaps spreading across the countryside and the atmosphere still distinctly sooty and smoky' (189). Hughes did not only react against the resulting 'aesthetic and environmental blight' (184) at the time, but remembered the polluted Don, Manchester's rotten lung and the Bessemer steelworks' upglare in far later writings. The young Hughes would certainly have been aware of the importance of industry to South Yorkshire's economy: his brother worked briefly at the Bessemer factory. Yet his adolescent escapes to hunting grounds unspoiled by the surrounding heavy industry anticipate his later, acute awareness of the contrast between post-industrial landscapes and the supposedly unspoiled 'wild' places of Alaska and British Columbia. This view of 'wild' places as set apart from industrialised landscapes contributed to his view of human life and nature as having undergone a disastrous severance.

Mexborough was located near a pristine hunting-ground that Hughes and Gerald initially shared. Hughes's change from killing animals to capturing poems was not as clear-cut as he makes out in Poetry in the Making. Gerald gained permission from the farmer, Oats, to shoot at Manor Farm, Old Denaby. Hughes 'succeeded to' this permission to shoot there after Gerald left Mexborough to become a mechanic in Barnet and later a gamekeeper in Devon (Ely 2015 60). Ely notes that at Manor Farm, Hughes began his later preoccupation with a 'retreat from the town into a 'private' countryside', continued his 'shooting, trapping, fishing and the observation of nature' and viewed the landscape through the lens of 'folklore, myth, adventure stories [and] the practices of 'Red Indians' (59). Hunting with dogs and ferrets, snaring rabbits, 'poaching, ratting and similar pursuits were common' in Mexborough but not at Manor Farm (2015 68-69, 71), and so there was a local culture of hunting for sport and subsistence, with or without 'permission' from farmers. This atmosphere of working-class

44 BL Add MS 88918/7/2, MS notes 13-14.

45 BL Add MS 88918/1/55, ruled blue school notebook 1-2 
poaching and shooting contrasts with Hughes's later involvement with elite conservationists, and his anxieties about upper-class bloodsports, which will be analysed in Chapter X.

Yet by 1944, Hughes was fishing at Crookhill Park (Ely 2015 76, and his attitude towards wild creatures was changing. Ely comments on an incident, recorded by Hughes's friend Edna Wholey, when John Wholey and Hughes threw a live hedgehog into the Crookhill pond. The boys were 'ashamed' and Hughes 'wrapped it in his jumper', took it home to the Wholeys' house and placed it 'in front of the range' to dry out (LTH 11). 'Is it too much to see in this empathy for a wild animal the early stirrings of an ecological conscience?' (Ely 2013 30). Ely is right to frame this statement cautiously, but Hughes's treatment of animals was changing. In a draft of a letter in which he answers questions about his environmental awareness, Hughes states that he does not know whether his interest in environmental protection dated back to Mexborough. He partly counteracts his own uncertainty, by stating later that when he moved from Mytholmroyd to Mexborough, he relocated from a village whose canal held giant trout to a town where one drink from the river would kill an elephant.46 Yet in that letter of December 1993 to Terry Gifford, Hughes stated that his 'greening' had been developing from his early childhood. He was bound to develop an admiration of animal life: he watched badgers at play in the early hours of the morning. After Ted and John Wholey caught frogs and spiked them on barbed wire around Crookhill Pond, they were so sorry that they 'held animal funerals as atonement' (Bate 2015 58). Ely also analyses a striking event that occurred when Hughes was thirteen, and which he related in a letter to Keith Sagar. Hughes was 'looking up into a holly tree' at the Crookhill pond, where there was 'sometimes a tawny owl' (PC 181). As Ely writes, '[t]he younger Hughes would have wasted no time in shooting the owl, but by his mid-teens, he was content merely to observe (and to imbue the owl and the holly tree with significance, deciding for an apparently arbitrary, but deeply felt personal reason, to orient his whole life around the striking date (4/4/44) he was 'looking up' into the tree)' (2013 30). He found an injured owl by the roadside, and looked after it at Crookhill; he would 'talk to it for hours' (Bate 2015 58). He also caught a 'dormouse' to surprise Edna Wholey, but 'took pains to release it into the wild in a habitat that would be suitable' - a 'step-change in attitude from the Hughes of only a few years earlier', who used to trap and slaughter mice (Ely 2015 103). Thus, '[i]t was during his 'Crookhill period' that Hughes began to conceive of nature as having intrinsic value - and therefore something to be conserved independent of its utility’ (Ely 2013 30). Ely later nuances this statement by writing that 'It was not at Crookhill that Hughes gave up shooting, but it was at Crookhill where he effectively began to consider the rights of animals and challenge his behaviour towards them' (2015 103).

Yet it was not just 'nature' or 'animals' generally that Hughes learnt to value - it was certain animals specifically. It was Hughes's 'Crookhill period' that inspired adolescent versified fantasies of gaffing an enormous pike, and shooting ducks with a frost-chilled snap; this significantly complicates Ely’s idea that he was considering animal rights. Hughes’s interest

46 BL Add MS 88918/7/2, TS answers to a reader’s questions 2. This is probably a draft of the letter to Gifford in which Hughes comments on the development of his 'greening' during his infancy. 
in shooting animals to be used and traditional game animals did not wane until long after Crookhill: there, he grew maggots for fishing on the corpses of birds that 'he had shot specifically for that purpose' (Ely 2015 86), he 'shot hares and partridges' as late as his National Service in the 1950s, and sent the 'dressed corpses' to friends while meat was rationed (LTH 705). During his national service, he also disturbed animals' lives by pitting spiders against each other, to watch their 'intricate and vicious' fights (Boyanowsky 155). He was aware of early conservation measures concerning raptors; his 1949 edition of Predatory Birds of Great Britain, published by the British Field Sports Society, showed him the protection offered to different species in different counties.47 The book put forward the idea that gamekeepers were conservationists, protecting rarer birds' eggs from collectors (Eric Parker 3). As late as 1962, Hughes shot jackdaws, a species usually considered to be vermin by farmers and gamekeepers (Ely 2015 102). He did not, as Gifford suggests, quickly move from killing animals to 'capturing' them in poems. The incidents with the owls and the hedgehog show that his earlier fascination with the kill was becoming tempered with a concern for the lives of particular species: specifically, rare or infrequently seen nocturnal animals (owls, dormice, hedgehogs). He continued killing common animals, species that could be used (game, birds for growing maggots), and animals that are often seen as repulsive or verminous (jackdaws and spiders). He treated his own domestic animals, or wild animals that he kept, with a gentleness that would evolve into the kind animal husbandry of his later years. He did not yet have a fully formed 'ecological conscience', but he had begun to develop a sense of how to treat certain animals ethically. We can already see important tensions emerging in Hughes's attitude towards animals: his favouring of particular species will be echoed in his support of shooting practices that risk damaging predator populations (see Chapter X).

During his years at grammar school, Hughes sometimes wrote animal poems, despite what he says to the contrary in 'Poetry in the Making' (WP 11). Keith Sagar owned several photocopies of unpublished poems given to him by Hughes's English teacher, John Fisher. One of them imagines catching a pike. Sagar writes:

In a poem he wrote at the time, 'On catching a 40lb pike', Ted described it as 'a sinister fish in a sinister lair'. With perhaps a little exaggeration he wrote:

I felt I'd hooked 3 parts of hell ...

And then he leapt and shook his head

His jaws clashed loud his eyes burned red ...,

Again he rushed, the reel screamed fast.

I only hoped this was his last,

But no he leapt, he smashed, he bored

47 Emory MARBL QL690 .G7 P25 1949 HUGHES 
Or four feet high in curves he soared.

For fourteen hours I fought that fight... (2009 248-9)

Elsewhere in this boyhood tale of fishing, the pike is imagined as full of pent-up anger, like Hughes's jaguar and macaw, while the details of the fish's flanks, the spoon lure and the fear of a snag presage his mature river-poetry and fishing-diaries. Yet the poem also ends with the gaffing of the fish.48 It is one of the most violent fishing-poems that Hughes ever wrote, and is surpassed in violence only by the 'gaffing' and 'clubbing' of fish in Hughes's later story 'The Head' ( $D B$ 139). He only killed fish in later life if he wanted to eat them. Equally significant among the poems written during Hughes's boyhood is a beautiful poem about hunting wildfowl, which describes the curlew's call (later mentioned in poems about Elmet), and which contains the famous 'frost-chilled snap' 49 praised by Hughes's teacher Pauline Mayne (LTH 722). Other childhood poems - Hughes’s humorous 'The Zeet Saga or Pale Tale I' and 'Hiawatha' 50 - hint at his later interest in landscapes (including imagined North American landscapes) and his preoccupation with Native Americans.

Hughes wrote to Terry Gifford that he was aware of water pollution during his boyhood: 'I was aware that silage killed fish ever since the 1940s - when I saw its effects on a farm in South Yorkshire'.51 Hughes writes in an introduction to Three Books, which contains River, that when he was a boy, one of his favoured fishing spots was an old oxbow of the Don, 'Vinah's Pond' (Ely 2015 62) teeming with fish and waterfowl. One day in the early 1940s, he was concerned to see the fish bobbing their mouths at the surface of the water, as fish do when they are desperate for oxygen. He continues,

That same day I noticed a strange ruddy vein in the ditch water that drained from the farm buildings, two or three hundred yards away. And I registered a new smell. I traced the vein to a big stone shed, packed with sodden, dark-stained grass - reeking the new smell. It was the first silage. (CPH 1211)

This is the dying of the fish at Old Denaby that Hughes mentioned in his speech, quoted in the introduction. Old Denaby lies on the opposite bank of the River Don to Mexborough, and the village was part of Hughes's paper round (LTH 693-94). Hughes wrote that he thought of the Don itself as composed of 'solid chemicals - bubbling, fuming, multicoloured' (LTH 694) and 'steaming, foaming poisons' (CPH 1211). Mexborough was responsible for his nascent awareness of environmental pollution: a crucial step in his understanding of environmental issues. Early experiences of working on the land, and observing environmental damage, strengthened Hughes's sense of connection to his local area and the creatures that dwelt there.

\footnotetext{
48 Keith Sagar’s private archive, photocopy of ‘On Catching a 40lb Pike’, 1-2.

49 Keith Sagar’s private archive, photocopy of 'The long mudflats are calling me’, 1-2.

50 Examples of unpublished poetry written during Hughes’s adolescence, which his teacher Pauline Mayne owned, are described in Barrington, Bennet and Wymer 120.
}

51 BL Add MS 88988/2, letter from TH to Gifford, 17. 12. 93. 
Hughes's early childhood in Mytholmroyd was foundational to his knowledge of landscapes, animals and plants. West Yorkshire was so important to him that he devoted the entirety of Remains of Elmet (1979) to mapping the landscapes of his boyhood, and charting the historical and personal memories that they called up. His poetry would revisit Elmet many times afterwards as he reworked the collection and wrote new West Yorkshire poems. But it is his unpublished notes to Remains of Elmet that give us a particularly significant key to one of the reasons why his awareness of environmental issues developed during his boyhood. He mentions that he felt estranged from the 'industrial depression' of the towns.52 He continues:

That feeling of it being my parents' world - but in no way mine. My alienation from the earliest days. My searching out the wild creatures - as allies of my feelings. My dream of a wild natural world behind that world. 53

Hughes's memories are tinged with the explicitly environmentalist preoccupations of his adulthood; he wrote that he first had the idea for his Elmet-project around 1971 (LTH 376), and these notes are likely to date from the 1970s, after he had heralded the birth of the 'environmental revolution'. Yet this important passage in Hughes's working notes tells us that it was actually his reaction to industry that set him apart from the older generation, and sent him off looking for wild creatures. From his boyhood, Hughes presents himself as an outsider: individualistic, neo-primitive, a child of nature. Here are the origins of his critique of modernity, his nostalgic longing for lost landscapes, his identification with certain kinds of animal, and also his sense of alienation from the working class. It is interesting that he does not mention here that he also killed the animals that were his 'allies'.

Hughes's memory for dates may not be entirely accurate, but we can build up a picture of his understanding of animals and environments thus far. Gerald 'could not shoot enough' animals for him (WP 11); his reading of Jefferies on gamekeeping and poaching, and HaigBrown's early hunting books such as Panther (1934), inspired a passion for trapping that continued even after Gerald had left. He shot with John Wholey, and they 'killed absolutely everything'; at the age of eleven, his diaries recorded indiscriminate shooting (Pero 54). Yet also at the age of eleven, Hughes started to read Tarka the Otter, which contained Williamson's diatribe against indiscriminate hunting. At twelve, he read Return to the River, which exposed him to early conservationist thought and further fuelled his passion for fishing. As he reread Tarka, his attitude towards hunting began to change. He celebrated wildfowling and revelled in the gaffing of a huge pike in his adolescent poetry. Yet at thirteen or fourteen, he came face to face with a fox, which was out hunting for rabbits just as he was; this strengthened his sense of identification with it. At thirteen, too, he spared a tawny owl; around this time he rescued a dormouse and a hedgehog that he had used in pranks, and cared for an injured owl. The decline of industry in Mytholmroyd, and polluting industry in

52 BL Add MS 88918/1/52, page torn from notebook labelled 59 by Hughes, 'The massacre at the farm above Peckett'

53 BL Add MS 88918/1/52, page torn from a notebook and labelled 59 by Hughes, titled 'The massacre at the farm above Peckett'. 
Mexborough, drove him to seek out unspoilt hunting-grounds and to think of certain animals as his allies. He witnessed silage pollution killing fish. At nineteen, his reading of a book about birds of prey increased his awareness of the conservation issues surrounding shooting. He did not stop shooting entirely, but he began to challenge his own earlier obsession with the kill. He was beginning to value rarer species and to understand the need to preserve them. 


\section{IV. 'LONG LIVE THE WEEDS AND THE WILDERNESS': HUGHES'S 'GREEN' LITERARY INFLUENCES}

In Hughes’s personal mythology, Mytholmroyd, Old Denaby, Crookhill and his 'wild life' roaming the moors feature more prominently than his reading during his adolescence and early adulthood. Yorkshire's wild places are central to early interviews such as 'Two of a Kind', essays such as 'Poetry in the Making' and 'The Rock,' and later interviews for The Paris Review and Wild Steelhead and Salmon. Yet to Drue Heinz, Hughes said that shooting, fishing and his preoccupation with animals 'were pretty well my life, apart from books' (Heinz, my emphasis). Hughes was encouraged to read voraciously by his mother Edith and his sister Olwyn. For him, 'Chaucer, Shakespeare, Marlowe, Blake, Wordsworth, Keats, Coleridge, Hopkins, Yeats, Eliot’ were a ‘sacred canon’ (Heinz) of poets from whom he drew foundational inspiration. The poetry that he anthologised in The Rattle Bag (1982) and The School Bag (1997), the children's poetry anthologies that he co-edited with Seamus Heaney, afford insights into additional formative influences: Keats, Clare, Dylan Thomas, Edward Thomas, Robert Graves, D. H. Lawrence.

The poets of his 'sacred canon' influenced Hughes’s poetics, his concept of the Muse, his idea of the literary life, his critical prose - and also the way in which he wrote about nature. He declared that his poetic ear was 'spellbound' by a metrical style that he called the 'unorthodox tradition' (WP 365). The 'unorthodox tradition' broke free from the constraints of Continental metres and drew on the 'alliterative, accentual line' (366) of Old English verse. Hughes saw the tradition as a poetic lineage, running from Sir Gawain and the Green Knight through to Chaucer (367), Wyatt, Marlowe and Shakespeare (369). He thought it was then inherited by Blake and Coleridge, whom he viewed as anticipating Hopkins's 'sprung rhythm' (WP 327); they were followed by Clare and Keats (371). Hughes heard Hopkins's influence on Yeats's The Wanderings of Oisin (328), a poem that was important to him (58). Among twentieth-century poets, Hughes admired ‘Graves’s own style of ordinary speech in free verse' (WP 323) as an inheritor of the tradition. These poets shaped Hughes's ideas about the poet's role in society. He was interested in Blake as a revolutionary and in Yeats's reaction against 'the spiritless materialism’ of modern civilization (Faas 200). Hughes identified with Lawrence as 'a northern, working-class voice with a sensitivity to the raw forces of nature, an interest in myth and archetype [and] an unashamed openness of sexual energy’ (Bate 2015 148). Graves's writing about mythology, poetic inspiration and the Muse was a foundational influence: when Hughes read The White Goddess he even resented Graves for 'taking possession of what I considered to be my secret patch' ( $L T H$ 679). Eliot, the last member of the 'sacred canon' whom Hughes mentioned to Heinz, was known to Hughes first 
as a major canonical figure, and later as his mentor at Faber and Faber.

Of Hughes's most important poetic influences, several were particularly crucial for shaping his writing about how human beings relate to animals, landscape and the environment. In 1973, three years after he had heralded the birth of the 'environmental revolution', Hughes would write of Shakespeare as recording 'the declaration of war against the natural (real) world and natural fellowship with it’. For Hughes, Shakespeare’s heirs were Blake, Wordsworth, Keats, Hardy, Yeats, Eliot and Hopkins: they represented a continuation of 'Nature's attempt to correct the error'. Poetry, in Hughes's view, was 'nature healing'; in its popular form, this idea would develop into 'the conservation movement' in the 1960s and 1970s (LTH 336). The most important poets to leave their mark on Hughes's ecopoetry were Blake, Yeats, Wordsworth, Hopkins, Lawrence and Dylan Thomas; he saw the first four as offshoots of a Shakespearean rootstock. Hughes told Heinz that '[m]y dominant passion in poetry up to and through university was Yeats, Yeats under the canopy of Shakespeare and Blake.' He was also 'fascinated by Rilke' and rejected all modern poetry except that of 'Dylan Thomas and Auden’ (Heinz). The Rattle Bag speaks of Hughes’s passion for folksongs, mythology, the Muse and 'unorthodox' metre, and his preoccupation with the poetry of war - but the anthology has a distinctly 'green' tinge in places. From Heaney's translation of 'The Names of the Hare' to Yoruba hunting poems, even the ancient and anonymous poetry explores humankind's relationship with the natural world. Donne's 'The Baite,' which invests fishing with a powerful erotic undertow, influences some of the gender relations that would be represented in Hughes's fishing-poetry. The Rattle Bag features poems one might expect to read in an anthology of twentieth-century ecopoetry, such as the poems by Nicholson, MacCaig and MacLean mentioned in the Introduction. Eberhard's 'putrid lamb | Propped up with daisies' (RB 160) ushers in Hughes's unflinchingly realistic poetry of livestock husbandry. The School Bag draws deeply on Hughes and Heaney's knowledge of Irish, Welsh and Scottish poetry,; it contains a long section devoted to animalpoems (205-224). Blake, Clare, Hopkins, Lawrence, Dylan Thomas, Edward Thomas, Wordsworth and Yeats are given pride of place. These are the poets of Hughes's 'green' canon.

\footnotetext{
54 Eliot's enthusiastic response to a letter about the possibility of publishing Hughes was, 'I'm inclined to think we ought to take this man now'. Image of a letter to T. S. Eliot, dated 09.04.1954. Faber and Faber archive. http://www.faber.co.uk/archive/asset/121559/ accessed on 17th Aug 2012.

55 This letter also uses the term 'nature' in political, historical and psychoanalytical contexts. Hughes's concurrent involvement in the environmental movement partly explains his enthusiastically 'green' glossing of these poets at this time; yet they had clearly sown the seeds of his preoccupation with humankind's exile from 'nature'.
} 
Hughes's 'sacred canon' is a poetic one, but if he had a 'sacred canon' of prose writers, it would include Jung, Lawrence's novels, Dostoevsky and Tolstoy, which he remembers having read by the time he reached university ( $L T H$ 679). By the time he graduated, it would also include James Frazer, whose esoteric anthropological study The Golden Bough had an important place in his notebooks and his library. If Hughes's 'green canon' is expanded to include prose writers, Jung and Frazer would take their places alongside Williamson and Haig-Brown. Hughes read all of Jung's translated volumes (Faas 37), and Jung influenced his fascination with the unconscious, archetypes, the Great Mother, and some of his more esoteric interests in the occult. Jung also informed Hughes's ideas about humans' 'inner nature' and our need for a connection to the physical environment. Frazer provided the young Hughes with a wealth of mythical imagery, which he would quote in poems such as 'The Green Wolf' and 'Rain-Charm for the Duchy'; but most importantly for Hughes's environmental thinking, Frazer shaped his conception of pre-Christian and precolonial societies' supposed closeness to the vegetation gods. Folktales and the songs and stories of preliterate societies were also formative influences on Hughes - but it was the Romantics who helped to shape Hughes's interest in such 'children of nature' in the first place.

\section{Hughes and the Romantics: Children of Nature}

Although the term 'ecology' postdates the Romantic era (Hutchings 176), theorists such as Morton (1995) and Bate (1991) have located the origins of elements of the modern environmental movement in Romanticism. Hughes was no Shelleyan vegetarian radical. But his friend Roy Davids called him 'Coleridge-cum-Wordsworth' (qtd in Bate 2015 13). His choice of Romantic poems in children's anthologies, especially The Rattle Bag, shows that he was interested in the Romantics' relationship to landscape, plants and animals. The poems suggest that he would probably have sympathised with the following critical statement: 'If the French Revolution was one great root of Romanticism, then what used to be called 'the return to nature' [...] was surely the other' (Bate 1991 7). Hughes held unorthodox views about the Romantics: he thought that the shamanic flight was 'the basic experience of the poetic temperament we call 'romantic', citing some of 'Keats's longer poems' as examples (WP 58). The shaman's flight enables the shaman to reconnect with the world of the spirits and the domain of the animals (see Chapter IV). For Hughes, the Romantic poet's imaginative flight often brings him back down to earth in nature. Hughes is likely to have anthologised Keats's 'La Belle Dame Sans Merci' in The Rattle Bag because he viewed it as shamanic, because it was important to Graves's conception of the Muse (Graves 418-23), but also because the poem was significant for Rachel Carson, a critical influence on the next chapter in Hughes's environmentalism. 'The sedge is wither'd from the lake | And no birds sing' is an epigraph of Carson's Silent Spring (1963 v). In The Rattle Bag, Hughes and Heaney select John Clare's nature-poems 'The Badger', 'The Flood', 'Hares at Play', 'Little

${ }_{56}$ Notes on Frazer are kept at BL Add MS 88918/9/13 unnumbered page inserted into folktale notebook, 'Chap I: King of the Wood'. His multiple editions of The Golden Bough are kept at Emory MARBL, BL310.F72 1949B HUGHES. 
Trotty Wagtail', 'Mouse's Nest' and 'The Vixen', giving Clare more space than Byron, or even Coleridge, whose 'new principle' of metre clearly interested Hughes (WP 391). Clare's status as a farmer-poet, his careful observations of wild animals, and his meditations on foxhunting and badger-baiting, resonated with Hughes's own preoccupations. We shall return to Clare's influence on Hughes in Chapter VI. Yet Blake and Wordsworth were the most important Romantic influences on Hughes's understanding of landscape, animals, weather and his nascent environmental thinking.

Some of Hughes's writing about the ethical treatment of animals echo views expressed by Blake, who profoundly influenced Hughes (Faas 202) and with whom he identified in his student writing. 57 Hughes anthologised Blake's 'Auguries of Innocence', in which Morton sees a 'developing sense of the cry of nature' (1995 42). Hughes probably agreed with Blake that 'A Robin Breadbreast in a Cage | Puts all Heaven in a Rage' (RB 47): Hughes's 'Macaw' makes similar criticisms of caging birds. Hughes's farming poetry resonates with Blake's view that abusing livestock is abhorrent, but eating them is acceptable: 'The Lamb misus'd breeds Public strife | And yet forgives the Butcher’s Knife' (48).

Blake's interest in potent energies and powerful predators was even more important to Hughes's view of animals, and specifically to animal-poems such as 'The Jaguar'. Blake, for Hughes, was a poet of violence (Faas 198), who taught him how to deploy powerful animal symbols without letting their predatory energies go unchecked:

Blake’s great poem “Tyger! Tyger!” is an example, I think, of a symbol of this potentially dangerous type which arrives with its own control - it is yoked with the Lamb, and both draw the Creator. [....] Behind Blake's poem is the upsurge that produced the French Revolution, the explosion against the oppressive crust of the monarchies [...] the symbol itself is unqualified, it is an irruption, from the deeper resources, of enraged energy (200).

Hughes's poems about powerful predators represent both real animals and potent forces within society (201). The revolutionary fervour that Hughes saw in Blake's Tyger helped Hughes to shape this dual perspective. A similar 'crazy, revolutionary, and poetic' energy (WP 132) would erupt as the 'vital, somewhat terrible spirit of natural life' (130) to create the ideological force behind the 'environmental revolution'. The images of 'hammer', 'chain' and 'furnace' that forge the Tyger also partly explain Hughes's characteristic use of industrial imagery to evoke natural power. Any children's anthology of major canonical poets would contain 'The Tyger', but when Hughes and Heaney anthologise it, they provide an important clue to the origins of Hughes's iconic poems about predators.

Yet it is one of Hughes's 'green' protest poems, published only in partial form, which most clearly bears the hallmark of Blake’s influence.

We'll march along some vacant lanes

To where the speechless mouths make stand

While Leukaemia doubles its gains

57 The satirical typescript that Hughes wrote while he was at Cambridge is modelled on Blake's An Island in the Moon (LTH 681). 
Throughout North Wales and Cumberland ('If' 33).

We shall return to this poem later, but its most important predecessor is Blake's 'London':

I wander thro' each charter'd street

Near where the charter'd Thames does flow,

And mark in every face I meet

Marks of weakness, marks of woe. (Blake 88)

Hughes voices his discontent about nuclear issues: while protestors march from London to Aldermaston to ban the Bomb, the Official Secrets Act silences protest against the marine nuclear waste dumps that are causing cancer in North Wales and Cumberland. To create a voice of 'green' protest, Hughes affiliates himself with a powerful predecessor whose 'enraged energy' he harnesses.

In mythical works such as Crow and Cave Birds, we could see Hughes as writing about animals in the visionary, Coleridgean mode of The Rime of the Ancient Mariner, which is anthologised in The School Bag. Coleridge's creatures provoke guilt and set ordeals in motion; they also inspire blessing. Yet in some of Hughes's 'greenest' moments of communion with nature, he is distinctly Wordsworthian. Bate sees Hughes as writing 'between Coleridgean vision and Wordsworthian authenticity' (2015 15). Authenticity, rather than myth, is at the core of some of Hughes's most ecologically engaged poems. Hughes's descriptions of the earliest stirrings of his environmental awareness - his 'wild life' on the moors among the animals - are influenced by his reading of Wordsworth's idea of the 'Child of Nature' (Wordsworth 218). All of the selections from Wordsworth that Hughes and Heaney anthologise in The Rattle Bag are from The Prelude. Bate considers Hughes's largely unpublished Black Coat: Opus 131, which forms part of the drafts of Birthday Letters, as the later Laureate's response to The Prelude (2014 13-14). Hughes published Prelude-like pieces in Birthday Letters and also in earlier writings, and they offer important insights on his perception of his earlier connection with the Yorkshire environment. When selecting 'Was it for this' from The Prelude for their first children's anthology, Hughes and Heaney recall Hughes's boyhood fascination with rivers and streams. The Derwent was Wordsworth's 'playmate'; Wordsworth's Rousseauian fantasy of himself as 'A naked savage, in the thunder shower' (RB 457) would have resonated with Hughes's vision of himself as a Native American boy hunter. In the anthologised section 'Boat Stealing', a huge cliff has 'voluntary power instinct' to rear up and follow Wordsworth ( $R B$ 84). This image inspired Hughes's image of Scout Rock watching him in his prose essay 'The Rock' (see Chapter II). Yet more significant for Hughes's incipient ecological awareness is 'Nutting', in which the young Wordsworth 'forc'd' his way into 'A virgin scene', inflicting 'merciless ravage' on a hazel grove (RB 314-15). Hughes’s ‘Daffodils’ (1986) might bring Wordsworth's 'I wandered lonely as a cloud' to mind; yet 'Nutting' is a more significant proto-environmentalist predecessor. When Hughes describes the 'soft shrieks | Of their jostled stems' (CPH 1126), he echoes the 'imagery of sexual violence' that Hutchings finds in 'Nutting' (185). Wordsworth's poem ends with an evocation of a feminine genius of place:

Then, dearest Maiden! move along these shades

In gentleness of heart with gentle hand

Touch, - for there is a Spirit in the woods (RB 315). 
If Wordsworth's speaker experiences 'remorse as a result of his environmentally destructive behavior', then his poem imbues nature with a spirit to affirm 'the inherent value of the nonhuman world' (Hutchings 185). Equally Wordsworthian is Hughes's 'The Owl', in which Plath's amazement at Hughes's close relationship with British animals 'woke up my dumb, ecastatic boyhood'. Hughes deliberately plays the child of nature. His 'masterpiece' is when he lures a tawny owl in Grantchester:

I sucked the throaty thin woe of a rabbit

Out of my wetted knuckle, by a copse

Where a tawny owl was enquiring.

Suddenly it swooped up, splaying its pinions

Into my face (CPH 1064).

The boy in Wordsworth's Prelude had elicited responses from Windermere's tawny owls when, through joined fists, he 'Blew mimic hootings to the silent owls | That they might answer him' (RB 419).

However, a very different relationship with nature emerges in Hughes's selection of Wordsworth’s ‘Resolution and Independence’ for The School Bag. The poem’s speaker sees a hare and a skylark on the moor - totem animals of some of Hughes's poems, in the moorland setting that recalls his West Yorkshire childhood. 'Even as these blissful creatures do I fare’ (46), Wordsworth reflects. Yet this sense of a shared life with animals is quickly disrupted. The old leech gatherer stirring the mud can no longer find enough leeches to make a living: 'Once I could meet with them on every side; | But they have dwindled long by slow decay' (49). Wordsworth was probably unaware of why 'slow decay' might have reduced the number of leeches - but Hughes, with his knowledge of environmental problems, would have seen this poem as a forerunner of his own writing about dwindling aquatic life. A paradisal Northern childhood, exploring spots of time, confessing regret for deflowering daffodils, communing with owls, depleted aquatic life: Hughes the child of nature is Wordsworth's heir.

\section{Hughes and Hopkins: The Weeds and the Wilderness}

Hopkins, like Coleridge, was a critical influence on Hughes's perception of 'unothodox' metre (WP 326-41), and he read him ‘very closely' (Faas 203). Hopkins’s idea of 'sprung rhythm’ was important for shaping Hughes’s poetic ear. It is their rhythm that makes Hughes's early war-poems such as ‘Bayonet Charge' so compelling - and this distinctive deployment of rhythm is also behind some of Hughes's most accomplished evocations of natural forces. Hughes quoted Hopkins's idea that 'sprung rhythm' was ' “fetched out” by the stressing', marked partly by the stress of speech, partly by 'contextual suggestion', and partly by 'alliteration and assonance' (Hopkins, qtd in WP 339). It was also from Hopkins that Hughes learnt the technique of allowing the scansion to 'rove over' from one line to another (Hopkins 7), a form of rhythmic enjambement that Hughes deploys in 'The Hawk in the Rain'. If one takes Hopkins's 'The Windhover' as one of the canonical predecessors of 'The Hawk in the Rain', one finds a multiplicity of Hopkinsian devices. There is the ghost of a 
pentameter in this poem, and its most 'orthodox' line, if scanned to pick out its strong stresses, reads: 'While bán | ging wínd | kílls these | stúbborn | hédges|'. Here are two iambs, followed by a reversal of the foot to create a Hopkinsian counterpoint rhythm (Hopkins 8), so that the line ends with three trochees. Yet Hughes fully unleashes the 'unorthodox tradition' in the urgent rhythm of these lines:

Blóodily grábbed dázed lást-móment-cóunting

Mórsel in the éarth’s móuth, stráin towards the máster-

Fúlcrum of víolence (CPH 19).

Here is Hopkins's alliteration of the letter M, to pick out stress. Here too, Hughes allows the stress on the word 'master' to 'rove over' to the following line. The result piles up breathless, hyphenated stressed syllables as the speaker strains to soar with the hawk. There are also telling lexical parallels between Hughes's analysis of this poem, and his own: the windhover lifting off the page 'like a hallucination' (WP 340) mirrors the 'hallucination'-like steadiness of the hawk in Hughes's poem. It is through his use of Hopkinsian poetics that Hughes conveys the brunt force of the struggle between bird and wind. Hopkins's 'sprung rhythm' is behind some of Hughes's most rhythmically forceful poems, but it also creates an ecopoetry which Hughes saw as more closely reflecting animal movement than its more orthodox metrical counterparts. For Hughes, Hopkins's metre 'reproduces the forceful, slicing parabola of the small falcon's body, tensed and compacted by the pressure of the wind against it' (WP 340).

Hopkins helped Hughes to develop an ecopoetics that was 'natural' in its speech-rhythms and its subject matter. When Hughes quotes Hopkins's view that 'sprung rhythm' is 'the most natural of things' (WP 326), the word 'natural' takes on new connotations when one examines the Hopkins poems that Hughes chose to analyse and anthologise. Hughes praises 'Inversnaid' for 'the brilliant kinaesthetic dance and immediacy, the energetic abundance of living voice' that resemble 'natural speech rhythms' (333). The 'Victorian ecology' (Parham 98) of 'Inversnaid' and 'Binsey Poplars' are important for Hughes's developing 'green' ideology. When Hughes anthologised 'Binsey Poplars', he perpetuated Hopkins's lament for a very specific stand of trees in a specific spot. Hopkins's proto-ecological elegy moves from the specific locality of the poplars to a general meditation on what human beings do to their woodlands: ' $\mathrm{O}$ if we but knew what we do | When we delve or hew - | Hack and rack the growing green!', and then move back to the 'Sweet especial rural scene' (RB 77). Hughes would take up the cause of Britain's endangered hardwood trees in his first environmental 
campaign. Hopkins repeats this movement from a specific spot to a general environmental reflection in 'Inversnaid', ending with, 'Long live the weeds and the wilderness yet' ( $R B$ 215). Parham finds that Hopkins combines 'a deep ecological poetic, designed to re-convey the phenomenological moment', that progresses 'towards a social ecopoetic in which we might feel, experience and understand the transformations wrought by society on its human and nonhuman inhabitants’ (98). Both currents of thought clearly influenced Hughes.

\section{Swallowed Alive by Yeats}

Hughes said that he was 'swallowed alive by Yeats' (LTH 625), who 'spellbound' him for six years, although his point of access to Yeats's work was 'not so much through his verse as through his other interests, folklore, and magic' (Faas 202). Yeats influenced Hughes's passions for 'unorthodox' metre, myth and magic, and the interest in his rebellious Irish forebears that is evident in poems such as 'Crag Jack's Apostasy'. He shaped Hughes's awareness of the environment because 'my animal kingdom, the natural world, the world of folktales and myth, and poetry, became a single thing - and Yeats was my model' (LTH 625). Yeats's nature-poetry also provides a metrical and thematic model for Hughes's ecopoetry. When Hughes quotes Yeats's 'The Falling of the Leaves', which he finds to be the voice of the 'unorthodox tradition', he shows us a source-text of his own early poem 'October Dawn', which echoes its metre and which has a similarly autumnal focus. Yeats uses a form that begins with a dactylic tetrameter line, followed by a line consisting of an unstressed syllable, two dactyls, a trochee and a single ictus. Here are the lines that Hughes quotes, scanned to show their strong stresses and their feet:

Áutumn is | óver the | lóng leaves that | lóve us

And óver the | míce in the | bárley | sheaves;

Yéllow the | léaves of the | rówan a | bóve us,

And yéllow the | wét wild-| stráwberry |léaves (qtd in WP 328).

And here are three lines in which Hughes echoes the pulse of Yeats's metre:

From the níght be | fóre, and the | whístling | gréen [...]

Squéezes the | fíre at the | córe of the | wórld,

Squéezes the | fíre at the | córe of the | heart, ( $\mathrm{CPH} 37$ ).

The first line by Hughes reads like a more flexible, 'unorthodox' version of part of Yeats's 'The Falling of the Leaves', complete with its evocation of natural time and falling foliage. In the next lines quoted, the forceful lexis of Hughes's invocation of the coming winter sets it apart from Yeats, but the repetition that opens the lines, the dactyls, the ictus at the end, and the turning of the year are distinctly Yeatsian. 
Yeats also helped to influence Hughes's rejection of materialistic modernity; this is significant for his environmentalism because, as he wrote in 1970, he was concerned that multinational corporations would 'cash in the world' (WP 130). Hughes thought that '[b]ehind Yeats' poem ['The Second Coming'] is the upsurge that is still producing our modern chaos - the explosion against civilization itself, the oppressive deadness of civilization, the spiritless materialism of it' (Faas 200). The antidote to this 'spiritless materialism' is to unleash Yeats's 'rough beast', as Hughes did in his animal-poems, or to try to reconnect with an enchanted wild of pre-Christian mythology, as Yeats attempted to do in The Wanderings of Oisin. Hughes saw The Wanderings of Oisin as shamanic (WP 58). In The Rattle Bag, he and Heaney anthologise the song of the Immortals at the end of Book I. '[A]part in the grassy places', Oisin and Niamh are protected from the passage of time that destroys animal life: “"My speed is a weariness," falters the mouse | And the kingfisher turns to a ball of dust' (RB 321). The Yeatsian link between animals, poetry and myth is present throughout Hughes's career, but it becomes particularly noticeable in one particular instance late in his life. His working title for Birthday Letters, The Sorrows of the Deer, is taken from his reading of the mythology behind The Wanderings of Oisin. The 'sorrows of the deer' are deer-hunting by the men of Ulster, the marriage of the sidhe-hind Sadhbh to a human hunter, the loss of her son Oisín to the mortal world and the displacement of ancient Irish religion by Christianity. Hughes and Heaney's selections from Yeats also reflect their interests in Irish mythology, their critique of organised religion, and Heaney's concern about the Troubles but Yeats shaped Hughes's ecopoetry by helping him to link his 'wild life' among the animals to mythology and poetry.

\section{H. Lawrence: Hunting The Fox}

Hughes read Lawrence ‘at an impressionable age’ (Faas 203). Sagar (2009 64), Moulin (16) and Ely (2015 99) have noted parallels between Hughes's biography and that of the earlier writer. Lawrence's prose and poetry were highly important influences: Hughes openly affiliates his work with Lawrence's Birds, Beasts and Flowers (1923) in his 1986 collection Flowers and Insects. After Hughes had absorbed the 'unorthodox', but still regular, metres of predecessors such as Wordsworth and Hopkins, Lawrence was one of the twentieth-century poets who showed him how to deploy experimental verse-forms. 'Man and Bat', which is anthologised in The Rattle Bag, helped Hughes to use a markedly variable line-length to convey animal movement. Lawrence's lines in this poem vary in length from fifteen words to one. The following lines use ragged, irregular line-lengths to capture erratic, zigzagging flight:

Now out, out from my room!

So to drive him out, flicking with my white handkerchief: Go!

But he will not. (RB 262)

Critically for contemporary ecopoetry, this is hardly a harmonious encounter with another species: it is an example of the 'ethically challenged' treatment of other species that Skinner analyses. Hughes's response to this poem is 'The Kingfisher'. Its lines vary in length from 
eight words to one, its mise en page conveys rapid, staccato movement, and Hughes borrows Lawrence's method of echoing the observer's utterances:

And look! He’s

- gone again.

Spark, sapphire, refracted (CPH 663).

Lawrence shaped the ideas behind Hughes’s ecopoetry by showing him the ideal of a primordial, pre-human world; sublime predators; and the relationship between humankind and beasts. Several critics also view Lawrence as a proto-environmentalist writer. Salter argues that Lawrence's critique of capitalism springs from its effects on nature; his 'understanding of the threats that man brings to the natural world' is apparent 'long before the environment became the universal issue it is now' (175). Becket finds that Lawrence presents us with 'the spectre of species loss' (33). Hughes and Heaney anthologise no fewer than twelve of Lawrence's animal-poems in The Rattle Bag. 'Eagle in New Mexico' clearly influences the terrifying predatory energy of Hughes's 'Hawk Roosting' (see Chapter IV). In 'Humming-Bird', Lawrence imagines

$$
\begin{aligned}
& \text { some otherworld } \\
& \text { Primeval-dumb, far back } \\
& \text { In that most awful stillness ( } R B \text { 197) }
\end{aligned}
$$

Hughes's fascination with 'primeval' environments and supposedly 'primitive' peoples was partly fostered by his reading of Lawrence. 'Mountain Lion' suggested that rare hunted creatures should have as much right to live as humans, even putting forward the extreme thought, 'how easily we might spare a million or two of humans'. The 'frost-face' (RB 299) of Lawrence's cat is clearly echoed in Hughes's 'Puma': 'the Moon frosts her face' ( $C P H$ 591). But Lawrence's 'Snake' is a yet more significant influence on Hughes: Lawrence's 'earth-brown' snake from the 'bowels of the earth' ( $R B$ 395) is the origin of Hughes's 'earthbowel brown' serpent in 'A Horrible Religious Error' ( $C P H 231)$. Becket finds that 'Snake' 'anticipates ecological consciousness because it raises the question of human agency, and human conscience, in relation to the non-human Other' (31): the speaker throws a log at the snake to show his power over it, but does not kill it.

Hughes does not anthologise 'Love on the Farm', a highly significant poem to which both he and Plath would react, and the source of some strains in his writing that modern readers might find most troubling. In Lawrence's poem, the (female) creatures of the farm cower in fear as the farmer passes; his killing of a rabbit in a snare is paralleled by the dominant embrace that ensnares his wife.

The rabbit presses back her ears,

Turns back her liquid, anguished eyes

And crouches low: then with wild spring

Spurts from the terror of his oncoming

To be choked back, the wire ring

Her frantic effort throttling:

Piteous brown ball of quivering fears! [...] 
With his hand he turns my face to him

And caresses me with his fingers that still smell grim

Of the rabbit's fur! God, I am caught in a snare! (Lawrence 1994 1011).

It was partly through Lawrence that Hughes was exposed to the idea of hunting as a particularly masculine activity, and the metaphor of women as prey. Lawrence's 'Love on the Farm', and also 'Rabbit Snared in the Night', are immediate predecessors of Plath's 'The Rabbit-Catcher' and influences on Hughes's response in a poem that borrows her title. Yet it is Lawrence's novella The Fox (1922) that provides a particularly important key to interpreting Hughes's fascination with foxes, his mythology of hunting and fishing, and the powerful sexual charge of some of his writing about pursuit and angling in particular. After his boyhood encounters with foxes, Hughes would have been struck by Lawrence's novella, in which a fox fascinates and possesses the tomboyish young woman March. In Lawrence's words, the fox 'entered her brain' and 'dominated her unconsciousness' (12); here we have the prototype of Hughes's thought-fox entering the dark hole of the head. The fiery fox-brush that singes March's mouth in a dream (20) is the archetype behind Hughes's burnt fox. The solider Henry is 'identified with the fox' (18): his cunning, vulpine sexuality pushes the unmarried women, March and Banford, to adopt conventional gender roles. Drawing on the anthropological theory of Walter Burkert, Doherty comments that hunting is an exclusively male activity for premodern peoples (7). It is by hunting the fox that Henry manages to 'bring down' (Lawrence 24) March as if she were a prey animal: 'the sacrificial economy that secures Henry's masculine identity consigns March to the role of animal victim' (Doherty 11). Henry's killing of the fox to usurp its mesmeric power over March also provides a clue about why Hughes sometimes emulated Henry by shooting foxes ('A Solstice') or taking the fangs of dead ones ('Autumn Nature Notes') - although, as we shall see, killing a totemic creature also provoked no small amount of guilt. Lawrence clearly helped to shape Hughes's views of gender, sexual liberation, class and the place of the individual writer in society - but most importantly for his environmental awareness, Lawrence deepened Hughes's interest in hunting, 'primeval' creatures, farming and the value of rare animals.

\section{Dylan Thomas: the force through the green fuse}

Hughes read Thomas, thanks to John Fisher (Bate 2015 54), 'at an impressionable age.' In fact, he was one of the few contemporary poets whom Hughes read in early adulthood, apart from Eliot and Auden (Faas 203). Hughes called Thomas a 'genius' (Ely 2015 42). Hughes's early 'Here in the Green and Glimmering Gloom' revises the 'mussel pooled and heron | Priested shore' of 'Poem in October' with 'At the mussel-pool's edge, the heron's bones' (Ely 2015 159). Yet the most important poem for Hughes's ecopoetry is 'The force that through the green fuse drives the flower', a striking meditation on how human bodies respond to, and form part of, natural cycles. The poem was anthologised in The Rattle Bag. Hughes's poetry about polluted water contaminating the human body is an environmentally aware revision of lines such as the following: 'I am dumb to mouth unto my veins | How at the 
mountain spring the same mouth sucks' ( $R B$ 161). If early environmentalists such as Max Nicholson saw human beings and nature as largely separate categories, Thomas's sense of natural processes working through us offers a presciently intricate view of environmental interconnection. James Keery has noticed Hughes's debt to Thomas in several poems from The Hawk in the Rain. The poised, predatory stillness of Hughes's 'The Hawk in the Rain' echoes Thomas's 'hawk on fire hangs still'; Hughes reworks Thomas's 'up the rays of his eyes' into 'The Jaguar's' 'down the drills of his eyes' (Keery 59). Barbara Hardy calls Thomas a 'green poet [...] anticipating our present wishes and efforts to care for the globe' (132). In Thomas too, Hughes also found a poetic predecessor who wrote of the horror of nuclear warfare. In 'Poem on his birthday', the 'rocketing wind' that blasts bones from the hills communicates Thomas's fear of the Bomb (Goodby 402). One of Hughes's most overtly political, collected protest-poems against nuclear warfare is 'A Woman Unconscious'. An important poetic predecessor of it is Thomas's 'The hand that signed the paper felled a city', which Hughes anthologises in The Rattle Bag.

Here is the first stanza of Thomas's poem:

The hand that signed the paper felled a city;

Five sovereign fingers taxed the breath,

Doubled the globe of dead and halved a country;

These five kings did a king to death. (RB 182).

Here, Hughes updates Thomas’a poem for the Cold War era:

Russia and America circle each other;

Threats nudge an act that were without doubt

A melting of the mould in the mother,

Stones melting about the root, $(\mathrm{CPH} 62)$.

Hughes creates a looser version of Thomas's alternation between iambic pentameter, tetrameter and trimeter, his alternate full rhymes and half-rhymes, modernising both form and content. Hughes's deployment of a less regular metre augments his poem's sense of tension and uncertainty: the reassuring patterns of natural cycles are profoundly disrupted. Nuclear technology was a major social and environmental concern for Hughes, and he would explore it more fully in Crow.

Another Thomas entered Hughes's sacred canon during his youth. Hughes's interest in Edward Thomas was partly due to his grandmother's taste in poetry, and it was deepened by Thomas's writing about the First World War (Ely 2015 19). Yet in The Rattle-Bag, we glimpse Hughes and Heaney's interest in Thomas's nature-poetry. Thomas's 'Cock-Crow', with its opposing cockerels in the dawn, is a theme taken up by Hughes in his own 'CockCrows'. 'The Combe' laments the death of a badger, 'That most ancient Briton of English beasts' (RB 111) - a line that Hughes cited to Daniel Huws (LTH 135) and which is the origin of his idea of foxes and grouse as ancient Britons in poems such as 'A Solstice' and the 1985 version of 'Grouse Butts'. 
Hughes's awareness of environmental problems is an important difference between his work and the works of many writers in his 'sacred canon'. In his anthologies, Keats's lake without birdsong and Wordsworth's struggling leech-gatherer adumbrate environmental thinking that their authors could not fully have understood. Hughes was, in part, an heir to the 'neoRomanticism' (Goodby 11) of Dylan Thomas, but he did not straightforwardly launch a 'romantic revolt against the dry, cerebral verse of the Movement' in British poetry (Alvarez 23). Keery writes that instead of revolting against the Movement, Hughes 'preceded it, then simply carried on', unconcerned by 'literary fashion' (59). Elements of Hughes's poetry are neo-Romantic; others seem to 'precede' the poetry of his own time; yet others keep pace with contemporary developments in the poetic movement that would come to be called ecopoetry. Drawing on his 'sacred canon' was an important way for him to achieve his distinctive method of sounding by turns ancient and uniquely modern. Yet his efforts to develop his awareness of environmental issues make his writing 'greener' than that of any member of his 'sacred canon'. His work responds fully to the intellectual and ecological preoccupations of his age - and one thinker whose work was particularly influential to both the intellectual life of the 1950s and Hughes's early 'green' thinking was Jung.

Hughes, Jung and Ecopsychology: 'Inner Nature'

Hughes's concept of poetic language was deeply bound up with his views on psychology. When describing language as an indicator of the unknowable depths of the unconscious, he uses a striking animal metaphor:

That little phrase is like the visible moving fin of a great fish in a dark pool: we can see only the fin: we cannot see the fish, let alone catch or lift it out. Or usually we cannot. Sometimes we can. And some people have a regular gift for it. (WP 21)

One of those people with a gift for drawing meaning from the deep was Jung (22), whose view that water is the commonest symbol for the unconscious suggests the metaphor of the fish in the dark depths (Jung 1957 18). Of course, Hughes's love of fishing and his interest in dreams shape this image as well, and the idea of phrase as fin hints at a confluence of inner psychological meaning and outer environment. Hughes’s sister Olwyn introduced him to Jung's Psychological Types just before he went up to Cambridge, ${ }_{58}$ and the book 'confirmed [his] feelings about the supreme holiness of animals and the natural world'. The Emory archive shows that Hughes owned at least seventeen volumes of Jung's translated work, and three books to which Jung contributed. He read all of Jung's translated works (Faas 37). While living in Cambridge, he noted down the following extraordinary observations, drawn from his reading of Jung:

58 BL Add MS 88918/7/2, typescript page beginning ‘time, an anachronism’. 59 BL Add MS 88918/7/2, typescript page beginning ‘this preoccupation with animals in their wilderness'. 
The Primitive a closer observer of unnatural or irregular events - a better knowledge of their sequences. [...]

The natives of Mt Elgon did not dream - only their witch-doctor dreamed. But he said he had not dreamed since the British came - now the Governor had all the dreams. But his (the witchdoctor's) father had still had big dreams - had known where game was, where the cows calved, what trouble was coming.

The Papuans believe the crocodiles have gone over to the British Govt.60

Jung thought that indigenous peoples understand their environments better than westerners; colonialism disrupts this deep connection. Such reading clearly helped Hughes to formulate his ideas about the exile of the western mind from nature.

He made further detailed notes on Jung, between 1959 and 1960, based on Jolande Jacobi's Jung anthology Psychological Reflections. Jung helped to shape Hughes’s view of the environment by proposing the importance of our connection to the earth, and to the most ancient strata of our unconscious mind - the parts of the mind that children and 'primitive' people can supposedly still access. As we have seen, Jung's idea of the 'fall' into conscious, rational thinking was a profound influence on Hughes's conception of what separates human beings from animals. When Hughes wrote to his editor that the 'inner nature' of Leonard Baskin's work was akin to the 'inner nature' of his own, he was of course discussing their artistic practices (LTH 149). Yet his term ‘inner nature’ also evokes Hughes’s Jungian interest in the animalistic, primordial self that he thought persists within us. In his writing about fishing, it was this inner, primitive, animal-like self that Hughes would celebrate.

Hughes became aware of ecopsychology towards the end of his literary career.

Ecopsychology is 'The psychology of animals or humans in relation to their social, physical, or natural environments; esp. (in later use) psychology in interaction with considerations of integrating human and ecological concerns’ $(O E D){ }_{62}$ In January 1994, Terry Gifford wrote to Hughes that he had just read Roszak's The Voice of the Earth: An Exploration of

\footnotetext{
60 TH, unpublished prose and research notes, BL MS Add 88918/9/12, small coverless notebook, 4 recto. The notes are likely to date from his time living next to a converted chicken coop in the garden of St Botolph's Rectory, Cambridge, with Michael Boddy, as 'Michael' and a 'hut' are mentioned. 61

BL Add MS 88918/129/2 undated prose research notes 20-22. These prose notes are archived between a diary account of catching a skate and a crab off Boston with Plath, which when checked against her diaries, was the $10^{\text {th }}$ of June 1959. The next is an entry from the $28^{\text {th }}$ of December, when the two of them walked to Blackdene and saw a recent grave dating from February 1959; this is likely to be during their visit to Yorkshire in
} December 1960.

62 For a critique that problematises ecopsychology, see Clark 201575. 
Ecopsychology, stating that it was 'nothing new' but might help the green movement to gather 'momentum'. Gifford had also asked Hughes about the ethics of fishing, and Hughes had responded that fishing was his Jungian way of reconnecting with the 'primitive' human:

Do you know Jung's description of his therapy as - a way of putting the human being back in contact with the primitive human animal? Meaning - most neuroses, of individuals and of our cultures - result from the loss of that contact.64

Hughes saw rod and line fishing as less destructive than commercial fishing, and as a useful way of containing destructive human impulses, as will be explained in the last chapter. It is striking that when asked if he knows about ecopsychology, Hughes implies that Jungian psychology has long been ecopsychology. Jung informed Hughes's views of the Great Mother, of tricksters, dreams and medicine-men - and most importantly for his environmental awareness, the way we attempt to reconnect with our 'inner nature'.

\section{The White Goddess}

Thanks to his English teacher John Fisher, Hughes was introduced to one of the foundational books of his poetic consciousness: Robert Graves's The White Goddess. Fisher presented a copy of this esoteric study of inspiration and the Muse to Hughes on the occasion of his 'going up' to Pembroke College, Cambridge. This book cannot be called explicitly ecological, but it introduced Hughes to some potent animal and plant symbolism that marked his ecopoetry.

The White Goddess contributed to the more mystical aspects of Hughes's ecopoetry by positing a connection between the Muse and various sacred creatures, trees and locations. The White Goddess is also the 'Lady of the Wild Things' (Graves 379). Graves's analysis of the Ogham alphabet, whose letters are named after trees, proposes a link between literacy and the non-human world. Hughes copied out Graves's description of the names of the trees and the Ogham alphabet in a notebook.65 Graves comments that '[I]n all Celtic languages trees means letters' (33). Moreover, particular trees have their own literary connotations: Graves proposes an etymological link between the words 'book' and 'beech' (34). Poetry is connected to trees, for Hughes records in his notes that Apollo was born under a palm-tree (FTNB 29), the willow is associated with Mount Helicon where the Muses live, and that apples are associated with 'Poets' immortality' (FTNB 30). Graves's evocation of the 'naturalness' of writing and poetry recalls much later ecocritical texts that analyse the writing process. Hughes's poem 'Trees’ has a speaker who whispers to a birch and a holly, two trees

BL Add MS 88988/2: Terry Gifford to TH, 11. 01. 94.

64 BL Add MS 88988/1 TH to Terry Gifford, 16. 01. 942

65 BL Add MS 88918/9/12, uncovered ruled and grid-marked manuscript folktale notebook. Henceforth abbreviated to 'FTNB'; page numbers will be given in parentheses in the text. The handwriting begins with the copperplate of Hughes's boyhood and adolescence. 
of the sacred grove of Graves's Ogham alphabet ( $\mathrm{CPH} 134)$; the 'weeping letters' of Gaudete's sycamore are clearly tree-letters (369). While David Abram derives the Hebrew alphabet from animal symbols - aleph symbolises an ox's head (101) - he argues that writing distances us from the 'natural' world when compared to the spoken word (79). For John Berger and Scott Knickerbocker, as discussed in Chapter I, writing does the opposite: it can bring us into closer contact with our environment. For Solnick, drawing on the work of Donna Haraway, language and writing are extensions of evolutionary processes anyway (70). Graves's evocation of the 'naturalness' of writing contributed to Hughes's environmental poetry, although Hughes's work is always aware of the gap between words and experience (PM 118-24). Meanwhile, Graves's concept of the Muse was to shape Hughes's ideas about poetic inspiration in important ways. As we have seen, Jacqueline Rose has taken Graves to task for depicting destructive relationships between poets inspired by the muse, and real women. Yet when Hughes's muse became the Iron Woman, he created an important response to criticisms such as hers (see Chapter VIII).

\section{Hughes at Cambridge: Meeting the Thought-Fox}

For Hughes, Cambridge was often 'wonderful'. But at other times, it was 'a bird without feathers', an 'old dry apple', a ditch 'where all the frogs have died' (LTH 12). Hughes presented himself as having written very little successful poetry while he was at university (PC 122). However, he submitted a satirical typescript, containing many poems, which could raise his grade at his Tripos examinations.66 It is surprising that this important document was neglected by scholarship on Hughes for so long. 67 The typescript contains striking poems about environments, landscapes and creatures. One of the characters voices the Jungian idea that human beings need to encounter their inner bestial impulses if they are to remain healthy and sane. If man tries to deny his bestial origins, they claim him; the solution is to 'meet the beast halfway and beat him back into a new obedience', otherwise we risk being 'devoured' (Cam TS 11). Far later in his life, in the last published interview he ever gave, Hughes was to comment on that very connection between modern human beings and the 'primitive' man or woman (Pero 56). Significant poems about moors (Cam TS 4), swallows, a woman 'slick and sliver as a whiting' (15), the moon (18) mountains (22), bats (22), dinosaurs (23), technology and hyperrationality (26) further illuminate our understanding of the importance of animals, the environment and the dangers of destructive technologies in Hughes's early writing. $68 \mathrm{~A}$ poem called 'The Industrial City' laments that the 'spring moon' can no longer 'lift the hackles of the blood', although the world's tides move for her. The city with its 'Machined' demands frustrates human beings' natural lust and augments their 'brute rage' (17). Here is Hughes's critique of industrialisation, capitalist modernity, and our alienation from our inner

66 'The ear-witness account of a poetry-reading in Throttle College, before the small poets grew up into infinitesimal critics'. Cambridge University Library, ENGL 1/155. Henceforth abbreviated to 'Cam TS'. Page numbers will be given in parentheses in the text.

67 Simon Pomery brought the typescript to the attention of more scholars at the 'Ted Hughes: From Cambridge to Collected' conference in September 2010.

68 For further information about how Hughes's poetry and intellectual interests developed at Cambridge, see Reddick 2015. 
nature. Here, too, he positions himself as a Gravesian moongazing Muse-poet. He is beginning to examine violence and the repression of natural instincts, although violence is not so deftly handled here as it will be in Lupercal. But the most exciting poem from his student typescript is the following one about autumn. It is reproduced here for the first time.

The year's dank rag is smouldering under the trees.

The shattered sunlight sleeps against a root

Where sunlight never alit all the green days.

Autumn comes touching at both heart and thought.

Now warm wind in the soft ache of the wood

Is melting the glinting crystals of decay.

The jewels of the small birds have melted away

In the music of the kind wind. Eyes turn inward.

And the gleaning skies afxter the wain of the wai summer

Sink onto the land as the land sinks out of sight.

The day trails a grey cloak to the hill like a dreamer,

Bright dagger of intellect hidden under it.

And daylong in warm ovens the kindling vixens

Quicken under wide eyesx, under pricked ears.

Till $a$ changed winds makes one crystal of the night,

Where the wise stars creep in the blown grass like insects,

And the blown grasses thresh themselves on the stars,

And the foxes scream like witches in their fires, 69

Hughes is beginning to deploy a more flexible verse-form than the strictly rhyming couplets he had favoured in boyhood poems, such as 'On Catching a 40lb Pike'. Supple half-rhyme

69 Hughes's handwritten emendations to his typescript are given in italics. Deletions are marked with an x. The original punctuation and spacing are preserved in this transcription. 
and assonance create the chiming between lines; quatrains are varied with a sestet at the end. Yet there are times when even this more supple form seems strained: stars likened to 'insects' are rather improbable when compared to the specificity of the language that describes the 'vixens', which they are designed to echo in assonance. The first line of this poem foreshadows the lit fox in the 'dripping ground' of 'Crow Hill' ( $\mathrm{CPH}$ 62). But of course, it is the association of foxes with fire that is most redolent of the famous totem animal of Hughes's creative life. The contrast between the foxes described here, and the pitiful state of the burnt fox in Hughes's dream, could not be starker. Vixens in earths as warm as ovens possess the vital spark of quickening life. Yet the cry of foxes does evoke the fiery torment of witches; these women interested Hughes because of their connection to the heretical and occult practices of Graves's Goddess, for their affinity with animal familiars, and for their shapeshifting powers; Lupercal's 'Witches' articulates men's suspicion of them. There is a note of Hughes's concern that our attempts to separate ourselves from the natural world also cut us off from everything heretical and creative within our own nature: the inspiring force that the burnt fox represents. But the vixens have a double function as emissaries of wild, vital life. The young Hughes would have learnt from Gerald that dog-foxes scream to assert territorial boundaries, and that the vixen screams during the breeding season. The vulpine behaviours in this poem are largely healthy and natural. At Cambridge, Hughes did not spend all of his time 'burning the foxes' (LTH 719) by writing stifling critical prose. Thought-foxes were already firing his imagination by suggesting incipiently ecological poetry.

While Hughes was reading - and writing - about folklore and mythology, some anthropological texts on the syllabus also shaped his understanding of animals, landscape and world religions. He owned several copies of James Frazer’s The Golden Bough: A Study in Magic and Religion, one of which bears the formal inscription 'Edward J Hughes', 70 suggesting that he read this copy while he was at university. He made careful notes on the first part of Frazer's book, which he inserted into his notebook on folklore.71 This book would have complemented his study of both English Literature and Anthropology. As one of the texts mentioned in Eliot's (perhaps mock-scholarly) notes to The Waste Land, Frazer's book was not only important to Hughes as an anthropological text, but because it was significant to a poet he greatly admired. Muriel Bradbrook humorously told Jonathan Bate that the purpose of the Cambridge English Tripos in Hughes's time was to enable students to read and interpret The Waste Land.72 Frazer's analysis of pre-Christian beliefs in a wide range of cultures provided Hughes with some significant insights into non-Christian views of nature.

Frazer's ambitious and esoteric analysis encompasses belief-systems drawn from Classical antiquity, from European folklore, and from a huge array of world mythologies. Among the most significant parts of Frazer's book for Hughes's ecopoetry are his accounts of sacrifice, sacrificial kings, and rain-making. Hughes's poem 'The Green Wolf' alludes to a chosen

\footnotetext{
70 MARBL, BL310.F72 1949B HUGHES.

71 BL Add MS 88918/9/13 unnumbered page inserted into folktale notebook, 'Chap I: King of the Wood’

72 Personal communication, December 2009.
} 
member of the Normandy Brotherhood of the Green Wolf (Frazer 754), who personified the tree-spirit and was burned in ancient times during midsummer celebrations (797). Kings were thought to be linked to nature and the fertility of the land (Frazer 128-30). Hughes, who became a friend of Prince Charles in later life, would never dream of writing poetry about the systematic regicidal sacrifice that Frazer describes. Yet, Hughes's 'Rain-Charm for the Duchy' suggests that he did draw on his early reading of ancient beliefs that connected the fertility of the monarchy with that of the land. Hughes's 'Rain-Charm for the Duchy' is also inspired by another kind of natural magic: rain-making. Frazer evokes the importance of rainmakers: 'in savage communities the rain-maker is a very important personage' (75). There are many ways of making rain, but the aspersion of places, people or sacred objects with wet branches is one that inspires an image in in Hughes's 'Rain-Charm': the 'drenched bush' ( $\mathrm{CPH}$ 803; see Frazer 75-6). The fertility of waterways is also important to Frazer, and his book informs some of Hughes's poetry about fishing. Frazer describes Native American ways of procuring fish in British Columbia. Hughes identified with Native Americans; he fished in British Columbia, and would have been struck by passages such as this:

If the fish do not come in due season, and the Indians are hungry, a Nootka wizard will make an image of a swimming fish and put it into the water in the direction from which the fish generally appear. This ceremony, accompanied by a prayer to the fish to come, will cause them to arrive at once. (Frazer 21)

Hughes did not believe in sympathetic magic, but he did write a poem inspired by Nootka prayers that are lures ('Earth-Numb'). By implication, Hughes's Laureate-poetry has the power to make the rain fall after drought, and to lure the salmon back to British rivers. His early study of Frazer furnished him with many potent nature-myths that inform his environmental poetry.

Hughes's study of Anthropology provided him with an in-depth view of multiple nonWestern perspectives on the environment. He himself makes the connection between his nostalgia for a 'Palaeolithic' hunting life, his interest in animals, and ancient religions. In an unpublished autobiographical prose draft, he wrote of 'primitive' religions in which animals and supernatural beings are 'interchangeable'. 73 Roberts notes that he had the opportunity to study texts that developed his interest in magical language and animism:

Students were required to choose one of two lists of monographs. One of these lists included E.J. and J. D. Krige's The Realm of a Rain Queen, and the other Malinowski's Coral Gardens and their Magic and R.F. Fortune’s Sorcers of Dobu. The portrayal of a matriarchal society in Krige and the discussion of magical language in Malinowski would both have appealed to the devotee of Graves, while the subject of Fortune’s book clearly anticipates his interest in shamanism. (2003 19)

Hughes owned a 1963 edition of Sorcerers of Dobu.74 It was not as important to his poetry as Graves and Frazer's texts, but his later acquisition of it suggests that it had been significant for his studies. The book exemplifies the belief-systems of just one people whose view of nature is profoundly different from - and arguably more respectful than - the West's. It would have deepened Hughes's knowledge of ideas of magical verse and humankind's

73 BL Add MS 88918/7/2, TS draft of prose piece (probably 'Poetry and Violence') beginning 'time, an anachronism. My life up to quite a late date was a wholly conscious’.

74 Emory MARBL DU580 .F6 1963 HUGHES. 
connection to the environment. The Dobuans' beliefs are totemic and animist, rather than shamanic. The ancestress of the Dobu people is imagined to be a bird (Fortune 31), and it is taboo to kill the totem animal of certain relatives. While this belief has the practical, ecological effect of preventing overhunting, 75 it suggests that Dobuans are so profoundly connected to their environment that they regard certain creatures as having agency and personhood. Significantly for Hughes, the incantations that allow one to perform magic are in verse - and are highly prized (Fortune 96). The songs and chants of pre-Christian peoples helped to inspire Hughes's later poetry, especially his environmental epic folktale Crow.

It is important to remember that Hughes was reading these texts at a time when Cambridge still offered a degree in Colonial Studies. A postcolonial scholar would no doubt criticise Frazer and Fortune for perpetuating stereotypes of indigenous people as close to nature, and therefore associating them with 'savagery' and irrationality. Hughes sometimes comes close to replicating such stereotypes, although he took those who wrote down precolonial beliefs to task for destroying the very belief-systems they set out to record (WP 73). His reading also exposed him to the effects that the erosion of traditional economic and agricultural practices had on non-western societies. He would have been aware of the argument of Ian Hogbin's Experiments in Civilization, even if he did not read it thoroughly (Bate 2015 78). Hogbin details how such 'experiments' in the Solomon Islands led to the decimation of indigenous peoples by introduced diseases (127), while the erosion of traditional culture caused profound psychological distress (133-34). Hogbin's book was written at a time when the Administration would be required to choose between the demands of 'the local planters' or to 'give consideration to the consequences of wage labour on native society and take steps, as Tanganyika has done, to obviate them' (242). This text from the Anthropology Tripos would 'contribute to [Hughes's] sense of modern civilisation's damaging alienation from nature' (Bate 2015 78), but its critique of colonial projects is more damning than Bate implies. Hogbin's book provides a precursor for Hughes's postcolonial environmental play The Tiger's Bones.

Yet the most important premodern belief-systems to shape Hughes's writing about creatures are animism and shamanism. 76 Hughes's concept of animist beliefs was informed by his reading of contemporary anthropological texts while he was at university. His reading of Eliade's later book helped to crystallise his ideas. The books he read at university date from late colonial times, while Eliade's Shamanism was published in 1951 and translated into English in 1961, during the long process that saw the British Empire’s former colonies gain their independence. These writers were not yet aware of the 'newly respectful postcolonial and post-Cartesian ethnography' that Brian Taylor finds in new formulations of animism (102). Hughes's dream of the burnt fox suggests the initiatory dream that shows a young shaman that he has been chosen to shamanise, and marks an important point in Hughes's development.

75 Far later in his life, Hughes corresponded with the right-wing ethicist Roger Scruton (see Chapter XI). Scruton views totemism as having an ‘ecological function’ (1996 152).

76 Brian Taylor sees Hughes's practice as more animistic than shamanic. For more information about the debates surrounding animism and shamanism in Hughes's work, see Taylor's article 'Shaman of the Tribe? Ted Hughes and Contemporary Animism.’ The Ted Hughes Society Journal 4.1 (2014) 101-114. 
Hughes's work presents an idiosyncratic fusion of primitivism and forward-thinking environmentalism. For him, the two are not necessarily in opposition. Gifford and Roberts state that 'It is clearly impossible for a modern English poet to be a shaman' (1981 20), and yet Anthony Libby considered that 'the role [Hughes] plays as poet must be understood literally in terms of the activity of the shaman' (391). Hughes considered Shakespeare (SGCB 87-92), Yeats and Eliot (WP 272) to be shamans: all three influenced him significantly. The critic Timothy Morton writes, 'Ancient animisms treat beings as people, without a concept of Nature. Perhaps I'm aiming for an upgraded version of animism' (2010 8). It is unlikely that Hughes actually believed in animism. Yet animism was important to him; almost as important as his passionate interests in astrology and religions of the nature-goddess. Animism helped to shape the more mythical aspects of his thinking about the environment.

\section{The Page is Blooded}

Let us return to Hughes's dream of the burnt fox. This dream, which took place during his second year at university, is a key episode in his personal mythos. In his published accounts of the vision of this creature, he is certain that he dreams it; in unpublished accounts, he is not always sure.77 Whether we interpret it as dream, hallucination, fantasy or slyly vulpine fabrication, it is tremendously significant. Of course, Hughes was already writing about fiery foxes at Cambridge. Studying the English Tripos was not tantamount to 'destroying' the creatures of his inner life completely, although the animal-poems he captured were rather more 'sickly' (PM 17) than the fully-fledged creatures of his collected poetry. His later critical essays, such as 'The Evolution of 'Sheep in Fog'” and 'Myths, Metres, Rhythms,' are very successful works of literary criticism. But in his later recollections of his time at University, his apprenticeship in literary criticism made him feel embattled. The first and second paragraphs of 'The Burnt Fox' are steeped in the language of warfare - he feels a 'resistance' to the Leavis-style dismantling of texts, he puts up a 'fiercely fought defence', he comes to a 'halt', he has 'retreated' (WP 8). He returns to the image of literary criticism as a war on creativity much later, in a letter to Nick Gammage, where he requires 'gasmasks, protective clothing, armour, weaponry' to survive the ‘culture police’ (LTH 617). The burnt fox can quite reasonably be interpreted as stepping from a trench or from the charred wreckage of Blitzed Sheffield. Yet the source of its injuries is very specific in this account: 'its body and limbs had just now stepped out of a furnace' (WP 9). This furnace did not forge the brain of Blake's Tyger, but it is the product of the scientific endeavours that created military technologies. This is the same hyperrational mindset that is behind the analytical drive of Cambridge Practical Criticism, for Hughes. After-images of Gerald's broken and lacerated hand at the Bessemer steelworks are in the background of this dream (Gerald Hughes 73). On one level, the burnt fox reflects Hughes’s critique of technological modernity and mechanised warfare, but the furnace that burns him also fuels 'the critical exhalations and toxic smokestacks and power stations of Academe’ (LTH 617). Images of warfare, injury

77 Hughes's account of this event in prose and letters states that he dreamed of the burnt fox - but in unpublished autobiographical notes he does question whether or not it was a dream (BL Add MS 88918/7/2 TS autobiographical notes 14). Whether it was a dream, a hallucination, or an experience that Hughes imagined, the encounter with the burnt fox remains a foundational aspect of Hughes's mythos. 
and pollution combine to focus Hughes's critique of multiple forms of hyperrationality, of the war against nature as a war against our inner nature.

The fox's placing of its (human) hand on the page is often seen as a creaturely act of writing (Faas 60), with good reason when in 'The Thought-Fox', the page is printed. Yet O'Connor links the handprint not just to literary creation, but to the rupestral art of cave-paintings (loc. 1619). Both of these interpretations are important. But there is more to it than this, and the fox's bloodloss and its part-human hybridity are particularly significant. The pronouns that Hughes uses in 'The Burnt Fox' display some telling discrepancies: the creature is referred to impersonally as 'it' five times, then changes to a gendered, more interlocutory 'he', then changes back to an 'it' (9). Hughes's prose hovers uneasily between identifying with the fox and keeping 'it' at arm's length: here is his hesitation between between viewing the foxhybrid as human self or animal other. But with creature's words 'Stop this - you are destroying us,' the 'us' in question refers to both Hughes's thought-animals and himself. As O'Connor has pointed out, the dream Ted Hughes and the fox are 'separate manifestations of a single entity' (loc. 1235). They are - but one is modern and the other premodern. Hughes blistered both hands in the fire at Mytholmroyd when he was small (Gerald Hughes 19). The burnt fox is Hughes's seared inner nature, his damaged inner link to his boyhood existence among the animals. It is connected to his urge to draw 'grotesque figures' on his walls at university (LTH 22), including life-sized pumas (Bate 2015 80): Hughes as neo-primitivist cave painter among Cambridge undergraduates. The fox's way of expressing himself is preliterate, but the process he initiates is Hughes's mediation of the natural world via the technology of writing. For writer and art critic John Berger, the first paint was animal blood, and the first subject for painting was animal (7). After his boyhood hand injuries, Hughes knew full well that burns do not bleed: they blister or exude fluid and plasma. This hardly matters in the dream, as it is the act of blooding the page that is as significant as the fox's burns. Blooding is an initiatory hunting-ritual. The blood of a hunter's first kill is daubed on his/her cheeks, and for Hughes's correspondent Roger Scruton, the animal thus becomes a 'totem' (72). The burnt fox risks becoming a hounded creature, and the price of initiating Hughes into poetry is that it is lucky to escape with its life. The burnt fox's preliterate mode of communication is presented as a more immediate, corporeal and visceral engagement with the poet's 'inner nature' than the hyperrational act of literary criticism; yet the imminent act of writing poetry means that Hughes's encounter with the animal is necessarily mediated by cultural processes.

A similarly complex and fractured relationship between totem animal and inner self is present later in Hughes's career, in an epilogue-poem from Gaudete:

The one I hunt

The one

I shall rend to pieces

Whose blood I shall dab on your cheek

Is under my coat. (CPH 363-4) 
Here is a wink to Henry Williamson's semi-autobiographical A Fox under my Cloak (1954). By this time, Hughes had also been offered a fox-cub concealed under a stranger's jacket; his failure to accept it is related in 'Epiphany', and the incident is remembered here. In this epilogue-poem, the fox is the quarry but also the shamanic self that must be rent to pieces; at once the concealed cub, but also Hughes's own inner nature, wrapped in his black coat. The 'you' who will receive the blooding is the Goddess, and the speaker accepts his necessary self-sacrifice here. Thought-foxes, the vulpine aspects of Hughes's poetic persona, and hunted foxes will continue to provoke complex and often contradictory literary responses. Poems such as 'Pike', 'The Jaguar' and especially the fishing-poems of River will continue to explore this uneasy tension between 'capturing' animals in poems, and sometimes destroying them in the process; between raw encounters with the natural world, and the technologies that complicate or even enable them; between unleashing the forces of nature, and caging them. 


\section{Animal Agency, America and Early Environmental Views}

Between his graduation from Cambridge and the early 1960s, Hughes deepened his understanding of animals in captivity, nuclear technology, food production and conservation. In the States, his interest in the environment began in earnest. After he graduated, he took up several odd jobs that enabled him to observe animals and plants at close quarters. One of the most important of these, for his poetry, was his experience washing dishes in Regent's Park Zoo. Poems begun during the early 1950s show that he was considering the repression of human beings' instincts and examining the experiences of caged animals. New technologies were broadcasting information about wild animals' lives, and perpetuating early conservationist views. Hughes would later comment that '[s]ince the late fifties [...] books and more recently television programmes about wildlife and natural history have become virtually a craze', and he credited them with changing people's attitude towards animals and the environment (WP 267). 1955, the BBC series Look, presented by naturalist Sir Peter Scott, launched with an episode about foxes. 'The Thought-Fox', that seminal evocation of poetic inspiration, was partly inspired by a Swedish nature film about foxes.

Hughes and Plath's passionate meeting in 1956, and their ensuing poetic partnership, were foundational for their lives and critical to their writing - but Plath also began to shape Hughes's attitudes towards the environment. He was exposed to her compassionate view of animals; fostered by her suburban upbringing, her ideas about them were somewhat different from the unsentimental opinions of Yorkshire's farmers and poachers. Her reaction to his killing of a sick grouse in Yorkshire in August 1956 permanently affected his attitude towards shooting. Hughes had been concerned about nuclear technology since he was a student; but Plath's well-developed knowledge of nuclear testing in America would have sharpened his concern. Russia and America were circling each other ( $\mathrm{CPH}$ 62), and the Suez Crisis of 1956 saw the Soviets threatening to unleash their nuclear firepower on Western Europe. Awareness of the impact of pollution in Britain was growing: also in 1956, Britain passed the Clean Air Act. This reduced London's terrible smogs; it also improved air quality in the industrial north, where the buildings of Hughes's childhood had been grimed by coal fire smoke and the burning of coalpit waste.

It was not until Hughes and Plath moved to America in 1957 that Hughes would begin writing about nuclear technology and the Cold War, and to gain a fuller understanding of the environmental implications of food production. Frustrated by the sterility of suburban life, he was developing his critique of the western mind exiled from nature. Yet he also experienced the magnificent national parks that would feature in Birthday Letters, and met the Native Americans he had long dreamed of encountering. He read that nuclear waste was being dumped off the coasts of Boston and Ireland. Upon his return to Britain, his reading of Silent Spring further sharpened his awareness. His interest in environmental issues began in earnest when he lived in the States, but it would not be until the mid 1960s that the term 'environmentalist' would come into use. By the early 1960s, he would have seen himself as an opponent of nuclear technology, an activist, and a conservationist. With the foundation of World Wide Fund for Nature in 1961, international awareness of conservation was also developing rapidly. Max Nicholson, an environmental thinker who would play a part in 
catalysing Hughes's explicitly environmentalist writing, chaired the committee that set up the Fund.

It was during this chapter in the development of his environmentalism that Hughes wrote what was probably his first environmental protest-poem. Hughes, Plath and their daughter attended an Aldermaston march in 1960, and their opposition to nuclear weapons would pave the way for Hughes's explicitly environmentalist activities from 1970 onwards. His first three poetry collections display the expansion of his poetic ambitions and the development of his thinking about animals; there is a progression from focusing on human cruelty inflicted upon animals ('Macaw and Little Miss'; 'The Jaguar') towards poems of symbiosis ('The ThoughtFox', 'February', 'The Bear'), through to poems about putting animals to justifiable use ('View of a Pig', 'Lupercal'). 'Wodwo', written in 1961 but collected in 1966, is a masterful rendition of a speaker's attempt at integration with the nonhuman; it paves the way for formally and sonically adventurous elegies that use animal symbols ('The Howling of Wolves', 'Skylarks'). In Lupercal, Hughes’s poetry becomes noticeably more engaged with environmental issues, with the result that by the time he publishes Wodwo, he has begun to create poems of intricate ecological interconnection.

\section{'A Widening, Deepening Greenness'}

After Cambridge, Hughes appears to have wanted to combine writing with work that would allow him to encounter animals. This contributed to his Heathcliff-like persona, but it was also symptomatic of his longing to connect to the 'wild, natural world' beyond lecture theatres and offices. An early idea for a money-making scheme had been mink farming - 'an extension of my trapping over Old Denaby', he told his brother ( $L T H 26$ ). He washed dishes at Regent's Park Zoo in the autumn of 1954, and got to know a particular jaguar that lived in a small cage near the kitchen window ( $L T H 586)$. His job as a rose-gardener in the summer of 1955 (Bate 2015 87) was somewhat tamer, but it nevertheless enabled him to work outdoors and to learn about cultivation. Crucially, his time at Regent's Park Zoo let him observe wild animals in captivity: this was one of the experiences that inspired his famous poem 'The Jaguar' and his descriptions of the inert creatures surrounding it. Hughes had begun to write about the pent-up energies of caged beasts and the caging of human beings' baser instincts; but it is contradictory that he would consider caging mink for profit. He would express conflicting views about the treatment of captive, farmed and hunted animals for the rest of his life.

Edwin Muir found that Hughes's 'The Jaguar' had an 'admirable violence'. There is no doubt that some of Hughes's strongest poems deal with violence: the sequence of war-poems that ends The Hawk in the Rain, the smouldering energy of Lupercal's 'Hawk Roosting' and the rapacious predation in 'Thrushes' show Hughes wielding violence to great poetic effect. Yet his early poems about animals have too often been reduced to their violent and anthropocentric elements. When Hughes writes of the 'legendary depth' of the pond in 'Pike', he hints at the depth and multiplicity of poetic meanings in his early animal-poems. In his interview with Faas, he evokes his animal poems' rich capacity for polysemy: 'The symbol opens all these things ... it is the reader's own nature that selects'. When commenting on his poem 'The Jaguar', he offered a range of interpretations: 
I prefer to think of [poems such as 'The Jaguar'] as first, descriptions of a jaguar, second ... invocations of the Goddess, third ... invocations of a jaguar-like body of elemental force, demonic force. [...] A jaguar after all can be received in several different aspects ... he is a beautiful, powerful nature spirit, he is a homicidal maniac, he is a supercharged piece of cosmic machinery, he is a symbol of man's baser nature shoved down into the id and growing cannibal murderous with deprivation, he is an ancient symbol of Dionysus since he is a leopard raised to the ninth power, he is a precise historical symbol to the bloody-minded Aztecs’' (Faas 199).

Among the 'several different aspects' of his jaguar that Hughes allows his reader to perceive, are the violent 'homicidal maniac', the potentially violent, human repressed 'baser nature', its significance in mythology - and also its far more positive role as a 'beautiful, powerful nature spirit'. His comments invite an ecocritical reading that is particularly rich and multilayered. Sagar finds that Hughes's early animals are 'machines', and that Wodwo marks an abrupt change towards biocentrism (2009 90). Yet as we have seen, his part-mechanical, partorganic animals deconstruct the idea of a binary relationship between 'nature' and 'culture'. His evocation of humankind's 'baser nature' suggests a link between human beings' animal instincts and our creaturely cousins; the structure of The Hawk in the Rain, which begins with a sequence of poems about the forces of nature and ends with a series of war-poems, invites a comparison of the two. Indeed, Lidström finds anti-anthropocentric strains in supposedly 'violent' poetry, which depicts 'acts of violence that are, in Hughes's poetics, wholly natural and amoral'. This was a view that Hughes had first encountered in Haig-Brown's work. One of Hughes's letters about Lupercal complicates Lidström's view of Hughes's animal violence as amoral; yet the poems that channel the energy of animals' positive violence are indeed 'expressions of a more-than-human nature', as Lidström puts it (2015 144). The vivid, realistic, violent lives of Hughes's animals invite us to consider the beastlier sides of human nature, and accord tremendous agency to the animals themselves. It is this creaturely agency, this sense of our intrinsic connection to animals, that need to be explored in greater depth.

Hughes's first poetry collection The Hawk in the Rain (1957) begins with a menagerie of animal-poems. 'The Hawk in the Rain', 'The Jaguar', 'Macaw and Little Miss', 'The Thought-Fox' and 'The Horses' signal their creaturely subject matter in their titles, while 'Famous Poet', 'Secretary' and 'A Modest Proposal' examine the creaturely aspects of human beings. At least three - 'The Jaguar', 'Macaw and Little Miss', and 'Famous Poet' draw on images of captive beasts that Hughes derived from his time working at London Zoo. Poems such as 'Wind' and 'Song' explore the connections between human beings and the wider environment. The collection's middle section transitions from this evocation of the Muse to several poems evoking difficult heterosexual relationships ('A Modest Proposal,' 'Incompatibilities') and achieves moments of resolution ('Fallgrief's Girlfriends'). 78 A particular asset to the collection is the series of powerful war-poems with which it ends, running from 'Casualty' to 'Two Wise Generals'. Most importantly for this analysis of his ecopoetry, Hughes devotes a great deal of space to creatures, weather and landscape. Hughes had written or begun some of the key poems in this collection, such as 'The Jaguar', 'The Thought-Fox', 'Wind' and 'Song', (PC 291-92) before he met Plath. Others were written after he had witnessed her reaction to his killing of the grouse in Yorkshire. He would not speak publicly about this incident until much later in his life. However, he had been exposed to two conflicting attitudes towards animals by the time his first collection was published. The hunting, poaching and trapping traditions of his Yorkshire childhood came into tension

78 This poem expresses Hughes’s pride in his girlfriend Shirley (Bate 2015 92). 
with Plath's sensitive impulse to spare pursued creatures (except fish - LTH 131). Hughes's early communion with animals, and his continuing affinity with them, shapes some striking poems of animal agency. The most ecological of the poems in The Hawk in the Rain, 'The Jaguar' and 'The Thought-Fox', show animal eyes expressing the wild force of will and creating a moment of creaturely communion. This is an important goal of ecopoetry: it 'explores the human capacity for becoming animal, as well as humanity's ethically challenged relation to other animals' (Skinner 2011). Derrida thought that to break down the barrier between human and animal, we must 'seen seen' by an animal whose eyes meet ours. Animal eyes can, without a word, 'address' us (2002 382; original italics). Hughes goes a step further: looking into an animal eye initiates a 'widening, deepening greenness' that creates a symbiotic poetic partnership with an inspiring animal.

The hawk of the collection's title poem is evoked vividly and with striking poetic force, and the poem intermittently turns the reader's focus towards its human speaker. There are some images that lock the poem's focus into a human viewpoint: the hawk is 'Steady as a hallucination'. The frustrated speaker yearns towards the 'master- | Fulcrum of violence' where the hawk hangs still. A discourse of mastery and omnipotence permeates this poem, although it is noteworthy that Hughes has inherited some of this discourse from Dylan Thomas's hawks, and that the poem ends with the hawk's vulnerability: he may fall and 'mix his heart's blood with the mire of the land'. The hawk can certainly be read as a richly symbolic thought-animal, a metaphor for the wings on which the powerful dare aspire. Yet the poem's visionary qualities are balanced by its realism, which is generated by its rootedness in a particular time and locality. The 'drumming ploughland' might be Old Denaby farm; the 'banging wind' that 'kills these stubborn hedges' ( $C P H 19$ ) evokes the wild Northern English weather that becomes the 'brunt wind' and drumming hills of 'Wind' (36), which was written mostly at Hughes's parents' house in Heptonstall.79 The hovering hawk is a specific individual, hunting over Hughes’s own South Yorkshire hunting ground. The poem rejects the abstraction of Hopkins's 'dauphin' with his 'wimpling wing', the improbability of Thomas's 'souls of slain birds sailing'. Here, two currents of thought that inform Hughes's environmentalism combine: the poem brings together his boyhood fascination with hawks and owls, and his growing acknowledgement of animals' perceptions, survival instinct, individuality and vulnerability.

Raptors fascinated Hughes from his childhood, and large predators haunt his adult poetry. He began to think about the cruelty that human beings inflict upon predators when he saw the fox in the deadfall (Dream Time); he would have further considered the treatment of predators when he worked in Regent's Park Zoo. Hughes evokes his dismay at seeing wild animals in confinement: parrots strut 'Like cheap tarts to attract the stroller with the nut', the captive lion and tiger are 'Fatigue with indolence', the boa constrictor is a coiled 'fossil' (CPH 19). These are the broken-spirited animals that one encountered in zoos of the mid-twentieth century, before the animal rights movement and the Zoo Licensing Act of 1981 placed greater emphasis on their welfare. They also function as symbols of human beings' repressed 'baser nature', longing to be unchained. Indeed, the early version of the poem that Hughes

79 BL Add MS 88918/7/2 MS autobiographical notes 2. 
published in Chequer described the crowds of onlookers as behind bars: 'And like lifeprisoners they through bars stare out' (1242). Hughes first saw a jaguar in a tiny cage in a zoo at Morecambe at the age of five. He tried to model it repeatedly, and remembered it for much of his adult life. This is the jaguar of the early version of his poem. At Regent's Park Zoo, in 1954, Hughes met that 'particular Jaguar' who lived in a 'transit' cage near the kitchen (LTH 586). His mind linked this animal to the jaguar that he had seen at Morecambe. He set about 'modelling' the jaguar in verse, trying to capture 'that irritated, black-lipped half-snarl' that big cats exhibit ‘when they're going to and fro in cages feeling pent-up' (LTH 587).

Leonard Scigaj writes that 'The jaguar's activity reinforces the premium Hughes places upon vitality in his fifties journey toward Reality’ (1980 48), while Michael Malay finds it to be 'symbolic' and 'visionary' $(93,97)$. Readings of this animal as a visionary have persisted. Bate sees the jaguar as Hughes's totem animal, and the poem that honours it as containing the central myth of Hughes's work: 'For Hughes, the role of the poet is to break the iron bars, to set free the spirit of the jaguar, to return humankind to its primal relationship with nature' (2015 94). From Hughes's own commentary on the poem, there is no doubt that he celebrates the jaguar as a nature-spirit replete with liberating, Dionysian energy. Yet his remarks call up more disturbing aspects of human beings' baser nature. He offers a reading of his jaguar as a 'homicidal maniac'. Some critics went a step further: 'Where I conjured up a jaguar, they smelt a stormtrooper' (Faas 201), and indeed Bentley has pointed out that the poem is a commentary on 'fascism, class, and the idea of natural superiority' (Bentley 52). Hughes takes pains to steer his conversation with Faas away from such troubling political affiliations, but his critics are right to catch a whiff of disturbing history amid the jaguar-stinks of this poem. In the essay 'Poetry and Violence', he invites readers to view his jaguar as a symbol of political trauma in the collective unconscious. Amid the dreams of his German patients, Jung reported, 'between the wars, a rapidly increasing population of lions, panthers, big dangerous cats' (WP 264). The short, fierce fuse of Hughes's jaguar that ignites the bang of blood in the brain, the fire-blind eyes, bring with them after-images of the detonating bombs that fell on South Yorkshire during the Blitz, and of the nuclear blasts that preoccupied Hughes and Plath during the 1950s. Despite his later claim in 'Poetry and Violence' that his predators are 'angels' (262), Hughes's animals do call up images of a human violence that is far more destructive than a predator's kill. Lidström's view that the violence of Hughes's predators is natural and amoral (2015 144) is complicated by their link to human beings' baser instincts which may prompt human beings to act in a morally reprehensible way.

Yet the poem is not exclusively preoccupied with using animal symbols to stand in for human affairs. It also attempts to capture the jaguar's perception of reality in a striking example of Hughes's early ecocentrism. Within the last two lines of the third stanza, there is a shift from the crowd's perspective to a closeup of the jaguar that focuses on its eyes: the jaguar is 'hurrying enraged | Through prison darkness after the drills of his eyes' (CPH 19). These words encapsulate the jaguar's rage at being imprisoned, and raise the ethical question of whether it is right to cage animals for human pleasure. Yet the 'drills of his eyes' evoke the jaguar's penetrating gaze, the pent-up violence of his predatory instincts - and his agency. 'His stride is wildernesses of freedom' releases the jaguar from his prison into the untameable 
world of his own subjectivity. The poem ends, 'Over the cage floor the horizons come' $(C P H$ 20). There is a moment of identification between poet and animal here: the word 'horizon' was, after all, the one that Hughes had said could be found engraved around his own skull (The Rock 125). The idea that nonhumans have consciousness and subjectivity - what Hughes would call an 'inner life' - is a central preoccupation for ecocritics. Thomas Nagel's famous 1974 essay 'What is it Like to be a Bat?' explored how we could envisage animal consciousness: bats have experience, although their perceptual apparatus is very different from our own, as they perceive their surroundings by using sonar (438) - which humans cannot use without the aid of technology. Even though bats' apprehension of common mammalian experiences such as pain and fear have 'a specific subjective character, which it is beyond our ability to conceive' (439), it is likely that their perceptual experiences are 'fully comparable in richness of detail to our own' (440).80 The jaguar is freighted with an intricate variety of metaphorical (and human-centred) meanings, but the poem also imagines the perceptual experiences of real, caged, suffering animals. One can only envisage what it is like to be a captive jaguar by extrapolating from the experiences of the visionary in his cell. But it is this partly successful creative act of empathy with the animal that shows how the poem functions as a celebration of a 'beautiful, powerful nature-spirit'. Here, an important discrepancy arises between Hughes's Jungian idea that animals lack consciousness, and the way he presents the jaguar's inner life. The jaguar in the poem is clearly conscious, and has perceptual experiences; but it is a 'visionary' because Hughes sees it as lacking a human, hyperrational intellect, and it is thus able to access a state of creaturely bliss.

If the jaguar paces its cage alone, unconcerned with the human beings watching it, the wild fox in 'The Thought-Fox' enters human habitation with a sharp, hot stink of poetry. This is an early poem that imagines symbiosis between human and nonhuman. The poem was written when Hughes was ‘sitting up late one snowy night in dreary lodgings in London' (PM 19) - it was 1955, he had spent the evening at a party with Thom Gunn, and returned to 19 Rugby Street at $1 \mathrm{am}$ to begin the poem while sitting in bed.81 Hughes wrote that his fox was 'both a fox and a spirit [...] [t]he words have made a body for it and given somewhere to walk' ( $P M$ 20). It is a force of poetic inspiration, but it also draws on some foundational experiences of meeting wild animals. Hughes took inspiration from his boyhood encounter with a fox coming up the bank of the River Don. Both of them had been out hunting for rabbits. A few weeks before he wrote the poem, he had seen a television programme that contained a closeup of a fox in a snowy Swedish wood; this had triggered memories of his earlier amazement at the fox who gazed back at him, amazed.82 It was the moment when the fox looked him in the eye that made him aware of this creature's ability to perceive him, and their

80 Such interest in animal perception has fuelled enquiries in animal studies that range from the scholarly to the downright eccentric. The former include Cary Wolfe's Animal Rites (2003, see Chapter 2) and Donna Haraway's When Species Meet (2008); an example of the latter is Thomas Thwaites' 2014 project to design prosthetics that would let him experience what it is like to be a goat.

81 BL Add MS 88918/7/2 pages from small ruled notebook 1 recto.

82 BL Add MS 88918/7/2 handwritten notes 13. 
common goal as hunters. The poem can be seen as an attempt to allow a breath of the 'inner nature' that exists within all of us into the dreary urban landscape of London, and as a celebration of the creature that made Hughes aware of his poetic vocation. Even the first line, 'I imagine this midnight moment's forest' ( $\mathrm{CPH} 21)$ merges the urban room with a habitat beyond human dwellings. The poem is created as the speaker is inspired - or possessed - by the fox: 'Till, with a sudden sharp hot stink of fox | It enters the dark hole of the head'. Hughes's remark that this creature is both fox and spirit (PM 20) is a telling example of the way his mythical imagination is intricately bound up with his perception of animals. Hughes made undated notes about Chinese and Japanese legends of people possessed by foxes that enter their bodies under fingernails or through the chest.83 Hughes goes beyond the animal encounters and Lawrentian thought-foxes of the first glimmerings of his environmental consciousness, to create a greater sense of co-operation between man and spirit-animal. Just as it had set 'neat prints' into the snow earlier in the poem, the fox's prints fuse with the words on the page, and 'The page is printed' ( $\mathrm{CPH} 21)$. The 'outer nature' of snowy wood, canal bank and pungent fur, imprint themselves on Hughes's 'inner nature'. Poetic possession and symbiosis lead to collaboration. The equality between helping spirit and poet foreshadows Hughes's later evocation of 'fellowship' between humans and animals.

Yet even if the poem itself gives a pungent sense of nature inspiring culture, the process of its creation highlights both its literary allusiveness and the surprising influence of modern media. At readings, Hughes stressed the link between 'The Thought-Fox' and his earlier dream of the burnt fox (Bate 2015 75, 94). There is no doubt that the dream of the burnt fox was a keystone of Hughes's personal mythology. But when he emphasises the influence of the dream on this particular poem, he downplays the influence of real foxes, of twentiethcentury literature, and film. Among earlier critics, only Sagar has noticed the influence of a television broadcast on the poem's central image of a fox in a snowy wood - and his surmise that the Swedish film of the fox was by Bergman (2009 75) is incorrect. In his autobiographical notes, Hughes privileged the influence of the memory of the fox by the Don and the fox in the film, and did not mention the burnt fox at all: the 'Swedish fox pushed my xx earlier memory aside, \& he finished my poem. The two memories wrestled for possession of my poem'.84 When Hughes writes that he wishes he had captured 'the twitch and craning of its ears, the slight tremor of its hanging tongue and its breath making little clouds, its teeth bared in the cold, the snow-crumbs dropping from its pads' ( $P M$ 20), he is not remembering the fox at Old Denaby, which fled as soon as it saw him: he is drawing on the Swedish film,

83 BL Add MS 88918/9/13, pages inserted into folktale notebook 5-7.

84 Hughes relates that 'It so happened, that a week or two before I had watched seen-a Swish film of winter night-life in the snowy winter woods in Sweden. One sequence in this film showed a fox coming through the snow towards the camera - closer \& closer, right into close up. The similarity to my memory of my own fox was evidently close enough for my poem to jump the rails. This pretty well Swedish fox pushed my xx earlier memory aside, \& he finished my poem. So the two memories wrestled for possession of my poem.' (BL Add MS 88918/7/2 TS autobiographical notes, 13-14.) This film was clearly a wildlife film. A possible source of Hughes's fox in the snowy wood might be Arne Sucksdorff's En Sommarsaga (1941), broadcast in Britain in 1955, the year of the poem's composition, with the English title Adventures of a Baby Fox. The film's rhyming narration would have suggested the poetic possibilities of its subject matter. 
which did give such a detailed close-up. Lurking in the background of the poem is also the fictional fox of Lawrence's novella, and the kindling vixens of his own student poetry. A persistent sense of the poem's engagement with memories of flesh-and-blood foxes, and with its cinematic and literary predecessors, comes into tension with Hughes's narrative of this poem as a shamanic revelation from the burnt fox. The thought-fox is neither charred nor bloodied; it is able to 'live for ever, it will never suffer from hunger or hounds' (PM 21). The multiple influences on this poem - hunting fox, fox in deadfall, Lawrence's fox, burnt fox, fox in film - do not detract from its evocation of the cooperation between poet and animal. But when Hughes emphasised the link between the dream and this particular poem, he was enhancing his mythical image of himself as a premodern shaman. The origins of Hughes's 'green' thinking were at once primitivist and modern; the influence of a wildlife film on 'The Thought-Fox' testifies to this. Moreover, the encounter between human and animal is necessarily mediated in the cultural space of the poem. Its multiple layers of animal and cultural influence do not suggest an engagement with nature in the raw, but instead foreshadow Clark’s ‘bafflingly complex’ web of nature and culture.

Even if Hughes could not yet be called an environmentalist, there are glimmerings of ecological thought everywhere in this collection. 'Macaw and Little Miss' (20-21) describes the bird's rage at being kept in a tiny cage. The hero of 'Famous Poet' is described as a Stegosaurus, whose predicament resembles that of the jaguar and the macaw: he is condemned 'To blink behind bars at the zoo'. Hughes would examine the distress of captive beasts again in Lupercal, and yet again in Wolfwatching. The woman in 'Secretary' is a stereotyped caricature of frustrated lust, and yet she resembles a starling that pecks 'under the bellies of bulls' (25). Denying one's instincts is dangerous: 'Egg-Head' is a critique of the Cartesian dualism that attempts to separate humankind from the environment (34). The most successful animal-poems in his strong debut collection are 'The Jaguar' and 'The ThoughtFox', which examine animals as potent totems, natural energies, symbols at the origins of representational art, and cultural archetypes. Yet these poems drew on memories of fleshand-blood creatures, and they recognise that these animals have an inner life of their own.

\section{America: Suburbia, 'Archaic Natural Beauty’ and Pollution}

In June 1957, Plath and Hughes had embarked for America. At first, Hughes found his time in the States to be intellectually and creatively stifling. He was frustrated by the dullness of domesticity and suburban life, and longed for the Yorkshire landscapes of his boyhood. Nevertheless, it was America that made him aware of the dangers of artificial additives in foods, water pollution, pesticides, and nuclear waste. He read Carson and Thoreau, and came face to face with wildlife and landscapes that made a lasting impression on him: chipmunks, bears, the Grand Canyon, Winthrop Bay. When he could escape the towns, Hughes encountered the 'estuaries and rocky woods' and the 'Red Indians \& smoking encampments' ( $L T H ~ 103$ ) that he and Gerald had dreamed about when they were boys. Hughes's guide in these landscapes was Plath, and her presence was the main reason why these places would become so important much later, when he published Birthday Letters. By now, Hughes was being influenced by her compassionate attitude towards animals. In July 1959, Hughes rescued a fallen bat, although he later realised that its bite might carry rabies (147, see also ' 9 Willow Street'). Before he met her, a diseased bat might have met the same fate as the sick grouse: '[m]y instinct was that if it were a sick grouse or wounded grouse, you killed it' (Pero 55). The two of them also cared for a fallen baby bird, although Hughes reluctantly put it out of its misery in the end (SPJ 400-403). Plath's sympathy for animals, Hughes's interest in 
American animals and landscapes, his frustration with the sanitised American way of life, and his concern about issues such as nuclear technology, paved the way for his explicitly environmentalist activities of the 1970s. Daniel Huws thinks that 'when Ted came back from America he had become an environmentalist'. 85 It was too early for Hughes to know the term 'environmentalist', and if his interest in the environment began in earnest in the States, it was galvanised by the 'environmental revolution' of the 1960s.

Hughes's letters from his time in America suggest that initially, he felt separated from his wild, vital life, and that his creativity was not flourishing as it had before. Everything was '[s]terilised under cellophane' (LTH 105). He longed to 'get some fishing tackle and keep myself buried as deep in what these 85ft long Cadillacs cannot touch, as I can’ (104) - as if his knowledge of how to connect with the American landscape were deeper than that of Americans themselves. Shortly after Hughes arrived at Sylvia’s family home, he told his brother that he wanted to 'spit, pea [sic] on shrubbery' and had developed 'a strong desire to sleep on the floor - just to keep in contact with a world that isn't quite so glazed as this one'. Domesticity and American sanitisation made him 'instinctively recoil' (LTH 103). He was concerned about how food was produced, '10,000 miles from where it was plucked or made'. The bread was 'bleached, double-bleached, rebrowned, unsanforised, guaranteed no blasphemin', purged of 'the last molecule of their original wheat' (106). On Cape Cod, he mocked the wealthy urban fishermen 'struggling to disentangle their reels, along the beach,' (107), the inept American hunters who 'drive about loaded with armour' but ended up killing seven deer and seven deer shooters (109). A month after he arrived, he felt that his thoughts were 'as stones in a wall'. He struggled to 'fasten some associations into this place' 86 and felt that Lupercal consequently lacked 'the natural flow of spirit and feelings'.87 He drew on natural energies, invoking 'Floods. Black rivers' to open the floodgates of inspiration (110). These circumstances helped to produce Lupercal's preoccupation with powerful energies and predatory violence. But Hughes was also becoming increasingly aware of the causes and extent of the violence that human beings inflict on the environment.

Lupercal focuses closely on hunger and devouring - and American life provides a clue about why the collection might do this. Unpublished drafts from Birthday Letters reveal that in the States, Hughes was able to eat his fill after an 'ever-hungry childhood' and postwar rationing. He describes the 'bred in the bone machinery | Of devouring hunger' and writes that he 'ate | For occupied Europe, for the vacuum mouth-gapes | Of the camps.' 88 Issues of wartime starvation and late Fifties consumerism are hiding behind Lupercal's wolf-masks. The way that Hughes presents animals is most important to this ecocritical reading of him - but the ever-hungry creatures of Lupercal are clearly linked to Hughes's critique of human-caused problems such as capitalist overconsumption. Hughes wrote to Baskin that he was developing

85 Letter from Daniel Huws to Terry Gifford, 15. 07. 14, ctd in Gifford 20144.

86 Emory MARBL 865, Box 1, folder 3, TH to Lucas Myers, Autumn 1957.

87 Emory MARBL 865, folder 7, TH to Lucas Myers, Winter/Spring 1961.

88 BL ADD Ms 88918/1/6, Birthday Letters MS drafts, red notebook labelled 'Hildrid History', marked 3.S by Hughes, 4 recto, 5 recto. 
an idea of 'Man as an elaborately perfected intestine, or upright weasel' (LTH 147). Hughes may have meant that the biological drive to feed is so powerful that it can make us behave like the predatory 'weasel' (see also WP 259), but the letter suggests further dimensions. Human beings who are close to nature are usually portrayed very positively by Hughes, but lurking in the background of his letter is the more disturbing idea that human beings' 'baser nature' drives them to relentless consumption.

\section{Environments, Violence and Animal Survivors: Lupercal}

In Lupercal, associations with British places are remarkably vivid (Roberts 2006 44). It is as if Hughes's sense of connection to British environments was actually deepened by his time in America. By early 1959, he was pleased to be writing more productively, and told his parents that his poem about the Pennines had appeared in print ( $L T H 139$ ). He was clearly homesick, and a few months before Lupercal was due to be published, he reflected that 'exile' had drawn him to 'nostalgic themes' (152-53). 'Mayday on Holderness', 'Crow Hill', 'Strawberry Hill' and 'Pennines in April' have titles that map their British locations; 'An Otter', 'The Retired Colonel', 'View of a Pig', 'November' and 'Sunstroke' are redolent of British landscapes. 'The Bull Moses' lived on Oats’ farm at Old Denaby (LTH 125), while 'Esther's Tomcat' references a South Yorkshire legend about a killer cat (CPH 1244). The short stories 'Sunday' (1957), ‘The Rain Horse’ (1958) and ‘The Harvesting' (1959) are written in a similar vein: they were begun as a series 'of autobiographical stories about [Hughes's] boyhood in Yorkshire' (DB vii). Hughes's writing in America foreshadows his later writing about British places and British agriculture in Moortown Diary and Remains of Elmet. Yet Lupercal does not ignore American landscapes completely. 'Bullfrog' describes a distinctively North American animal, and was researched for a collaboration with the American artist Leonard Baskin (LTH 136), while 'Fourth of July' laments the polluted lifelessness of 'sewage estuary', 'trout-stocked tarn' and 'traffic crossing' ( $\mathrm{CPH} 65)$.

Even if Hughes rarely wrote poems about American animals and landscapes at this time, American writers were making him aware of their connection to the environment, and of specific environmental problems. During the spring of 1958, Hughes taught classes on Thoreau's Walden (Golden 48), now hailed as a masterpiece of early environmental literature. 89 That July, with Plath, he read two of Rachel Carson's 'books about life in the sea which are wonderful' (LTH 127). Hughes read Carson's Under the Sea Wind (Plath 1982 345-6) and also acquired a 1959 edition of Carson’s 1955 book The Edge of the Sea,90 which describes a 'widespread change of climate' and a 'general warming-up' (23). He read The Sea Around Us, as Plath did,91 and absorbed further information on very early predictions relating to climate change. In his speech on farming, Hughes remembers reading Rachel

89 Lawrence Buell champions Thoreau's book in The Environmental Imagination: Thoreau, Nature Writing and the Formation of American Culture (Cambridge MA: Harvard University Press 1996).

90 Emory MARBL QH91 .C3 1959 HUGHES.

91 Lilly Library, Plath Manuscripts II, Box 6, letter from Sylvia Plath to Aurelia Plath, 19 $9^{\text {th }}$ July 1958, requesting The Sea Around Us for Hughes's birthday. The present author is grateful to Dr. Heather Clark for this information. 
Carson's influential book on pollution by chemical pesticides, Silent Spring. He told Tracy Brain that Plath had also read it (Brain 2001 86). Hughes remembers that he read it in 1959; it is possible that he and Plath read the letter that Carson wrote to the Washington Post that year, which contained the arguments that would be key to Silent Spring. The book was first made public when it was serialised in The New Yorker in the summer of 1962 (Carson 1962). It is more likely that Hughes and Plath read the serialised book when they returned to Britain, but Carson's influence had begun while they were in America.

In Lupercal, Hughes began an in-depth exploration of predation and our predatory behaviour towards the natural world. On a metaphorical level, his predators also function to articulate a bleak vision of God the devourer, with mother-love as the only escape from evil (LTH 148). The words that he uses of his collection-in-progress suggest the development of a new writing style: tough, unsentimental, controlled. 'All the poems for my second book are a little out of favour. They are hard-headed. I have tried so hard to take nothing for granted in matters of cadence \& rhythm, that sentiment \& warmth has seemed like a proscribed outlaw. In an effort to express myself trenchantly \& controlledly, I have kept out softness'. Poems written in this vein include 'Relic', 'Of Cats' and 'Crow Hill' (122). Within a few months, he would attempt to vary this trenchant style with an altogether different voice. Hughes told his sister that he was 'trying to make my style more closely woven \& subtler in pitch', more 'quietly written', about 'smaller' subjects - poems such as 'View of a Pig', 'Wilfred Owen's Photographs' and 'The Bull Moses' (129). 'To Paint a Water-Lily' exposes the miniature violence of pond ecologies. 'The Bull Moses' is a poem of colossal yet docile power, of animal violence (just) restrained.

While these poems display a distinct focus on predatory violence, they also celebrate survival and animal agency and will. In the late 1950s, Hughes was making notes on The World as Will and Idea by the eighteenth-century German philosopher (and fellow Beethoven enthusiast) Arthur Schopenhauer. Schopenhauer's work 'impressed' Hughes because it represented 'something on its way back to the surface' - something that he described in strikingly animalistic terms as the 'rough beast' in Yeats (Faas 1980 205). Hughes wrote out a quotation from Schopenhauer that articulates a bleak view of nature: 'The thought of nature producing her beings - unconscious, inexhaustible, without love or rejection. Untroubled even as they are destroyed'. Nevertheless, Schopenhauer wrote that animals and human beings go through their lives with 'confidence', as they possess 'the peace of the species, which death does not affect' and which is an 'indestructible principle'.92 Sexual desire is so vehement because it furthers the survival of the species. Thus, Hughes's vision of nature at this stage sees the individual animal as subordinated to the will of the species - and yet, the survival of the species actually brings peace to individuals. Even at this stage, Hughes does not view nature as unrelentingly violent. While Lupercal contains images of violent, rapacious predation, it is also a collection about survival. In 1998, when Hughes discussed the 'violence' of his thrush and shark, he was clearly remembering Schopenhauer's idea of

92 BL Add MS 88918/129/2 16 recto and verso. These undated notes are placed between diary entries from 1958 and 1960. They are likely to be contemporaneous with the composition of Lupercal. 
the peace of the species when he wrote that these animals were 'At peace with essential being' (WP 260).

The poem that most clearly articulates Hughes's preoccupation with survival is 'An Otter'. It is influenced as much by Schopenhauer as by Tarka the Otter. In an interview with Alvarez from August 1960, Hughes recalls that

While I was writing ['An Otter'] I was reading a great deal of old English history, in other words pre-Conquest history; and this notion of the life in England, and particularly the life of the animals in England, carrying on from generation to generation, and through all the historical eruptions that were going over them, this life continues as a single life, as a single thread of life. So that, in fact, in the first part I speak about not generations of otters but one otter, as if the one otter were thousands of years old, and were a pre-historic animal surviving [...] And in the second part I make this more definite. Coming down from the succession of generations of otters, I come down to this particular otter - and this particular otter in a crisis when he's being hunted for his life. (Qtd in Scigaj 1986 62)

This is a quintessentially English poem, with its resonances of Henry Williamson's work. Hughes celebrates the otter; even if otter hunting enables one to observe the animal at close quarters, the poem hints at the tragedy of killing it. Whereas Tarka and the hound Deadlock kill each other at the end of Williamson's novel, Hughes's poem is more ambiguous. The second section begins, 'The hunt's lost him': he appears likely to escape. Hughes celebrates the otter's ability to exist in spite of human violence: the hunters' 'hounds and vermin-poles' $(\mathrm{CPH} 79)$. Here is Schopenhauer's idea of the will of the species: the archetypal, ancient otter represents the species with its powerful drive to survive, while the instinct to perpetuate the species compels it to mate in an open field, regardless of livestock and humans. However, the ending of the poem acknowledges that otters frequently fell victim to the hunt: the dead otter's pelt is 'nothing at all' (80). The first section of Hughes's poem celebrates the species' will to survive, and the second section examines the impact of human violence on the individual animal. Hughes does not condemn otter hunting outright, but implicitly criticises those who annihilate the otter for its pelt. The poem evokes an uneasy, ambivalent view of the hunt; Hughes would continue to express contradictory opinions about hunting until the end of his life, and would end up supporting hunting-to-hounds (see Chapter X). He would write letters urging for otters to be protected from pollution - a more insidious threat than hunting - in the 1980s.

But of course, predators such as otters survive by eating other animals. Lupercal is preoccupied with killing and devouring prey. Sometimes, this is done by humans, as in 'View of a Pig'; and there is a hint that human beings behave in a frighteningly animalistic way in times of war in the 'cenotaph' that ends 'Relic'. The fangs, jaws, bellies and guts of animals keep the collection's focus clamped well onto the food chain. Sagar links the image of the gut in 'Mayday on Holderness' to Hughes's letter about 'Man' as a 'perfected intestine' (2009 82). Another letter, this time addressed to his sister, describes his vision of Lupercal:

It's strange how since the title occurred to me an entire vision of life seems to have grown up for me around the notion of God as the devourer - as the mouth \& gut, which is brainless \& the whole of evil, \& from which we can only get certain concessions. But no sermons. The whole idea makes a metaphor of the Holy Family, and logically poses love - all derivatives of mother-love (of Mary, you see) - as the only protection against evil. [...] (The lower orders of life do not have any love - no 
mother-love: the adults devour their own offspring as they find them - their world is entirely evil.) (148)

Hughes was interested in the idea of the 'lower orders of life' as predators - and in human beings' 'baser nature' as embodied by God the devourer. Mother-love is present in this collection in the figure of Penelope in 'Everyman's Odyssey', but it is complicated and disrupted in later poems. Consequently, the protection from evil that Hughes's letter evokes is absent until the promised fecundity of 'Lupercalia'. 'Mayday on Holderness' hears a soldier shot through the head during the Gallipoli campaign cry 'Mother! Mother!' Yet the residue of cordite that he leaves is 'Curded to beastings' (CPH 61). Beestings is the first milk produced by female livestock after they have given birth, but when Hughes curdles and corrupts the spelling, it symbolises a relentless predatory appetite and human beings' animalistic behaviour in times of war. A particularly vivid encapsulation of Hughes's bleak reimagining of a holy family of devouring beasts is 'Relic'; the relic of the title is at once the remains of his gluttonous god, a 'cenotaph' remembering the First World War, and a relic of animals' battle for survival. He imagines life in the deeps below: 'Nothing touches but, clutching, devours'. The image of jaws gnawing each other recurs throughout: jaws and jawbones are mentioned four times in as many lines. 'Relic' focuses excessively on the biological drive to kill and eat. Richard Kerridge offers the important caveat that Hughes's poetry does risk inviting the interpretation that 'technological warfare and ruthless industrial exploitation are primarily determined by evolved natural instinct, and therefore not susceptible to conscience' (2014 182). Yet for Hughes, who thought that 'higher' animals were redeemed by mother-love, such instincts must clearly be kept in check by conscience or by activities such as farming, fishing and hunting. Hughes's poetry about animals becomes more balanced when it considers the drive to breed (in the salmon-poems) or the bonds between mother animals and their offspring (in the farming-poems). He would argue later in life that the predators in Lupercal are 'innocent, obedient, and their energy reaffirms the divine law that created them as they are' (WP 259). Yet in these poems, they are only 'innocent' in the Schopenhaurean sense that their predatory violence is instinctual; if human beings behave in this way, their actions are judged to be 'evil'.

Hughes delves deeper into his exploration of predatory violence, and the importance of powerful predators to the human mind, in 'Pike', one of his 'prize catches' (PM 21). The poem is a 'celebration of a totem' ( $L T H$ 133). It conceals multiple levels of meaning, relating to English history and to the depths of the unconscious - but it is also a consideration of the predatory instinct, in humans as well as animals. Hughes did not wish to reveal the precise location of the pond described in 'Pike'; Ely writes that it might be Crookhill or the lake at Roche Abbey, ten miles from Mexborough (2013 29). What is far more significant than exactly where those pike the size of railway sleepers lived ( $P M$ 21), however, is that the water they dwell in is 'as deep as England.' Here, Hughes transforms R. S. Thomas's salmon of Llyn Llifon (RB 29), a symbol of Welsh antiquity, into an embodiment of an England of the mind that dates from before the Reformation (represented by the monastery) and before recorded history (the legendary depths of the pond). The creature's brindled, 'tigering' scales and its hideout 'jungled' in weed exoticise it, but its Englishness remains significant. At multiple points in his career, from his pre-conquest otter to the lions and salmon in the Laureate-poems, and the Ancient British grouse of 'Grouse-Butts' (1985), Hughes celebrates the most ancient Briton of English beasts. Such creatures embody vestiges of his boyhood 'fanatic patriotism' ( $C P H$ 1216), although national identity and a sense of belonging are far from straightforward for Hughes. The later Hughes of 'On the Reservations' is painfully aware of class divisions and the north/south divide; it was Alaska, not North Devon, which he came to describe as ‘the most fantastic land I’ve ever been in' (LTH 434). Yet such British 
animals as the pike, the otter and the salmon suggest that his environmental campaigns sprang, in part, from a sense of national and regional pride. The unsettling creature of this poem, however, suggests that Hughes also draws up murky histories: the dissolved monastery evokes a history of religious conflict, one that Hughes would explore more fully when he put forward his theory of Shakespeare's possible Catholic sympathies in Shakespeare and the Goddess of Complete Being. The iron and vice of the pike's eye suggest war-machines manufactured in South Yorkshire's steelworks. As Solnick has pointed out, the pike's 'submarine delicacy and horror' evokes a link to contemporary military technologies (68).

The pike comes from a symbolic realm far vaster than the national, however: the poem casts into the depths of the unconscious on a freezing night. When Hughes describes a phrase as 'the visible moving fin of a great fish in a dark pool', with a meaning that is difficult for most people to catch, and then evokes Jung's gift for reeling it in (PM 121), he invites the reader to contemplate not only the disjunction between words and experience, but the way that natural symbols can examine the complex relationships between modern, technologically advanced society and its own 'inner nature'. Some of the animal instincts that Hughes's poem snags are distinctly uncomfortable. When they were boys, Hughes and John Wholey had kept three baby pike in a fish tank at school. The boys forgot about them during a school holiday; they returned to find that, with no-one to feed them, one pike had eaten two of the others (Feinstein 13). Hughes's remark that his jaguar is 'a symbol of man's baser nature shoved down into the id and growing cannibal murderous with deprivation' is actually a more appropriate description of his pike. The devouring instincts of the repressed id, more Freudian than Jungian here, surface in the behaviour of these cannibal fish: 'One jammed past its gills down the other's gullet'. Indeed, the 'vice' in the pike's eye is a symbol of its gunsight gaze with undertones of manual toil - but it also calls up associations with vice as opposite of virtue. O'Connor has pointed out that the pike's 'eye' is also an 'I' (loc. 814): the mirror of its eye-film produces troubling reflections of what human beings do to members of our own species during wars and moments of extreme violence. In later life, Hughes would posit fishing as an antidote to such aberrant, violent impulses (see Chapter $\mathrm{X}$ ). The darkness beneath night's darkness frees a dream that rises slowly towards the speaker, watching (86), their gazes locked. This is 'one of the monsters I never even hooked' (PM 21), and in the poem the pike progresses from having a 'hooked' jaw to being 'freed'. It is unclear whether it watches the fisherman as a wary prey animal or as a predator looking to engulf him. Even if Hughes later tried to make the case that his pike was an angel, a 'fish of 'light' (WP 262), this uncanny poem leaves a lingering sense that the pike's eye reflects an aspect of humankind's baser nature: certainly the human predatory instinct, and the more frightening impulses for which fishing can be substituted.

However, Jung noted that fishermen dream of fish (1974 96) and that all archetypes can have 'a positive, favourable meaning or a negative, evil meaning' (1968 81). The phrase 'green tigering the gold' ( $\mathrm{CPH} 84)$ is inspired by some significant dreams that Hughes related to Thomas Pero very late in his life: 'When I was feeling good I'd have dreams full of giant pike that were perhaps also leopards' (50; see also LTH 711-12). The interview with Pero suggests further dimensions to the ending of this poem. Hughes comments that pike had become fixed at a deep, active level in his imaginative life. His recurrent dream of catching pike reflected how he was feeling about life at the time:

My obsession with pike maybe was my obsession with those energies. So it wasn't all fishing. It was something else. It was a psychological thing. This went on for years. A very bad time might produce a nightmare dream of the lake lined with concrete and empty. I remember the day before I got married the first time. I hooked a pike in my 
dream. I hooked it at tremendous depth. As it came up, its head filled the lake. I brought it out and its girth filled the entire lake, that same lake. (Pero 50)

Although it is described in sinister terms in the poem, Hughes's dream suggests that catching a monster pike was an extremely lucky event. The barren, empty lake has important implications for his perception of his own creativity, which is linked to wild aquatic life in this dream. Far later, Hughes would describe Plath as 'slim and lithe and smooth as a fish' with a 'Pisces chin' ('18 Rugby Street'). Hughes's joy at marrying her produces a dream about catching an enormous fish, although the pike's vastness suggests that the combined creative energies of these two strong characters might be uncontrollable. Pike symbolise powerful, creaturely energies, and once again, Hughes uses a thought-animal to suggest the link between powerful natural energies and our own inner nature, and to examine the ways in which our species changes the physical environment around us. Pike are harmed by the ultimate expression of 'negative violence': human damage to the environment. Hughes revisited one of his Yorkshire pike-fishing ponds in 1997, when he wrote to Terry Gifford: 'There were big pike in that tiny pond at Crookhill. Another bit of soul-damage there, the last time I saw that.' 93 Hughes noted in a letter of the early 1970s that the pond was 'now a rubbish dump, pretty well, with an oily puddle at the bottom’ (Summerfield 269).

One of the most challenging animal-poems that Hughes ever wrote is 'Hawk Roosting'. In his notes to the collection, Hughes writes that 'I imagine the hawk speaking to himself. He is like a dictator, who thinks he is God and invincible'. Hughes said in a radio broadcast that the poem was about 'totalitarian' truth and 'peace' - but did not explain this (qtd in Bate 2015 165). Unless his comment about peace is deliberately misleading, the only peace it can possibly describe is Schopenhauer's peace of the species. In an interview a decade after Lupercal was published, Hughes is more cautious:

That bird is accused of being a fascist ... the symbol of some horrible totalitarian genocidal dictator. Actually what I had in mind was that in this hawk Nature is thinking. Simply Nature. It's not so simple because Nature is no longer simple. I intended some Creator like the Jehovah in Job but more feminine.

The complications with 'nature' arise, he explains, because when Christianity banished the devil, what it actually banished was nature - and nature became the devil. Here, he explains his critique of Christian religion's view of humankind as separate from a demonised nature. This is why the hawk does not sound 'like Isis, mother of the gods, which he is.' Rather, he 'sounds like Hitler's familiar spirit' (Faas 199). Hughes was understandably wary of discussing the ways in which his hawk sounds like a dictator in 1970. In 1963, Plath had called the husband-figure in her poem 'Daddy' a man in black with a Meinkampf look. Hughes would not have wished to risk drawing any parallels between his writing and this character.

Hughes clearly researched the troubling dimensions of arguments that attempt to apply such raptorial thinking to human politics. This was prompted by Plath's angry - but unfounded accusation that her father admired Hitler (SPJ 431), and by the replacement of Stalin's totalitarianism with alternative forms of oppression under Khrushchev. He was reading texts that vigorously oppose totalitarian thought. Hughes was making notes on the work of Hannah

93 BL Add MS 88988/2: 1992-1997. TH to Gifford, 6 ${ }^{\text {th }}$ October 1997. 
Arendt, the German-born Jewish political theorist, in the late 1950s, and he owned several books by her. The citations that he copied out from Arendt illuminate the political dimensions of 'the rules of the animal kingdom'. Arendt writes of pan-movements such as Nazism: 'A 'divine' people lives in a world in which it is the born persecutor of all other weaker species, or the born victim of all other stronger species. Only the rules of the animal kingdom can possibly apply to its political destinies.' 94 When human beings use them, arguments that envisage animal behaviour as exclusively predatory and dominant, ignoring animal symbiosis and co-existence, dissolve into totalitarianism. In later years, Hughes would challenge the view that human beings are a 'divine' species; he would become a defender of species weakened by human greed and neglect.

But neither the explanation that 'Hawk Roosting' is a satire on totalitarianism, nor Hughes's assertion that his hawk is like a nature-goddess, is completely convincing. There are further key dimensions that come from Hughes's 'sacred canon': this hawk is related to Lawrence's 'Eagle in New Mexico'. Hughes and Heaney selected an excerpt from this poem for The Rattle Bag. Lawrence's eagle is 'Erect, with the god-thrust entering him from below' and is 'Foot-fierce' ( $R B$ 138); Hughes's godlike hawk holds 'Creation in my foot' ( $C P H$ 69). If Lawrence's eagle has an 'old, old allegiance' with the sun, but never looks at it directly, Hughes's hawk has the sun behind him. The eagle sacrifices the hearts of rabbits and birds, a priest 'Whom the Indians aspire to'. It is indeed an 'American eagle', but a Native, primordial one, in a continent 'cold from the ice-age still' (RB 138-9). Here is a source of Hughes's hawk's atavistic assertion that 'Nothing has changed since I began' ( $C P H$ 69). Hughes's hawk is very likely to refer to the American eagle, as Bate suggests (2015 165): Lawrence's eagle is indeed American, but his obvious sympathy with Native Americans, and the influence of his eagle on Hughes's hawk, add significant complications to a reading of the hawk as a symbol of European totalitarianism. By 1989, Hughes had gone back to describing his hawk as just a hawk, blind to its own death: 'the hawk represents a natural world in that the natural, the living world, the animal kingdom [...] is unaware of death' (Skea, Asia Festival Interview). Hughes's contradictory assertions about his hawk at different times lay false trails to outfox us. But blindness to death is part of the survival instinct; this is the commentary that remains after Hughes has stopped referring to his hawk as either mythical or dictatorial.

\section{Co-Operation, Fellowship and Symbiosis between Human and Nonhuman}

The first chapter has shown that Hughes's part-industrial animals smash together organic and mechanical parts, beginning to draw out the links between 'nature' and 'culture'. Yet Hughes's idea of the interactions between animals and human beings was subtly changing. A significant development between 'The Hawk in the Rain' and Lupercal is that Hughes describes closer-knit relationships between humans and other creatures. Such ideas are forerunners of his later evocation of kinship and 'fellowship' between humans and animals. Hughes's horses in The Hawk in the Rain were standalone megaliths; the horses of 'A Dream of Horses' are so close to their grooms that the grooms are even willing to be torn limb from limb by them ( $\mathrm{CPH} 66)$. The Nile flows in Cleopatra's body (87). The grooms live in co-

94 BL Add MS 88918/129/2 unpublished prose notes 2 verso 
operation with the horses; Cleopatra seems to live in symbiosis95 with the country she rules. Of course, the tutelary spirit of this collection is the wolf, and Hughes explores the relationships - sometimes co-operative but often fraught - between wolves and several characters. It is mainly the Roman feast of Lupercalia that Hughes references in this collection, although other Western myths come up as well. As he explained to Olwyn:

The Feast of Lupercal was a Roman festival held on $15^{\text {th }}$ February, in honour of Zeus as a Wolf. Nobody knows how it originated, but it came from Mt Lycaon in Greece, \& combined sacrifices of goats \& of a dog (- originally a wolf, I suppose)[.] It was mainly a fertility rite. Various bachelors stripped naked \& ran a certain course through Rome [...] They were splashed with the blood of the dog \& the goats, \& carried thongs cut from the skins of the goats. Women who wanted a child stood in the way of the runners \& held out their arms which the runners lashed with the thongs as they went past - this was supposed to make the women fertile. ( $L T H ~ 148$ )

Scigaj's reading of this poem focuses on the mythical dimensions of 'February': 'Hughes apparently believes that primitive people were more honest in recognizing potential complicity with the destructive powers of nature and less inhibited about attempting to control that energy through ritual' (1986 66). 'Primitive' rituals are indeed behind this poem, but Hughes makes them distinctly ecological and modern by engaging with species extinction and the persecution of predators. The 'hairless, knuckled feet' of the last wolf killed in Britain are poignantly lifeless. The description of the Spanish wolf as 'scraggy' suggests both its leanness and a slang term for strangling that echoes the gibbeted wolf of the previous line, while 'doggily begging' ( $\mathrm{CPH}$ 61) evokes the absurdity and pity of its confinement. Wolves are caged, stuffed with pebbles, gibbeted and exterminated in Britain in this poem. It is a record not of wolfish violence, but of human violence against wolves. Hughes also articulates his concern about British wildlife hunted to extinction in 'The Retired Colonel', which preserves relics of 'the last English |Wolf' and 'the last sturgeon of Thames' (77). Elegies for extinct or vanishing animals foreshadow Hughes's later concern with endangered species in poems such as 'Wolfwatching' and 'The Black Rhino'. Yet the last two lines of 'February' restore wildness, dignity and agency to this persecuted animal. The character who makes wolf-masks connects to a vivid experience of animality by wearing the wolf's jaws that clamp onto the world; he is attuned to his own instincts. At the very end of December 1958, Hughes made a wolf-mask out of an old sealskin (SPJ 454). The poem suggests a ritual that might be able to restore a lost connection to animals. It is an eloquent lament for a British animal annihilated by hunting, and a poetic ritual that seeks to call it up along with all that it symbolises. The poem is, however, complicated by the idea that its speaker might be complicit in the very processes of hunting and flaying that it criticises. The 'mask' of a hunted animal is its muzzle mounted as a trophy, a meaning that lingers in the background of the poem. The sealskin that Hughes recycled for his wolf-mask comes with a lingering whiff of animal blood. Hughes's second collection contains a totemic, primitivist argument for humankind's connection to animals; yet his examination of premodern blood-sacrifice in

\footnotetext{
95 Symbiosis is defined as 'Association of two different organisms (usually two plants, or an animal and a plant) which live attached to each other, or one as a tenant of the other, and contribute to each other's support. Also more widely, any intimate association of two or more different organisms, whether mutually beneficial or not' $(O E D)$. Hughes's early poetry is more likely to consider predation, parasitism and hunting than symbiosis - but he becomes increasingly interested in domestication, co-operation between humans and other animals, and symbiosis as his environmental thinking develops.
} 
'Lupercalia' is locked in an uneasy tension with the reminders of recent overhunting and extinction in 'February'.

\section{Explicitly Environmental Poetry}

Lupercal's 'greenest' poem begins as a war-poem. 'Mayday on Holderness' announces its examination of the First World War in the distress-call of its title and the 'pierced helmet' of its ending, but it is also a prolonged examination of the war against nature. The poem shows Hughes writing about water pollution long before his river-poetry reached its apotheoses in River (1983) and 'Rain-Charm for the Duchy' (1984). The Holderness setting is retrospective, as Sagar states that 'Hughes recorded that he began the poem at Willow Street, Boston, which he left at the end of June 1959' (2009 82). Indeed, Sagar notes that '[s]ome of the poems in Lupercal, most obviously 'Mayday on Holderness', were salvaged from an abandoned sequence about England, in which the unifying image was to have been a river insofar as it was a specific river, the Humber' (2000 26). Late 1959 was also the time when Hughes read the magazine article that caused his 'first big shock, as an Environmentalist'. In 1996, he recalled in an article destined for Country Life magazine that 'I read in a US magazine how the US Government had been disposing of its nuclear waste since 1945 dumping it with domestic refuse in a few fathoms offshore of Boston, seven days a week. The same article described where our Government was dumping ours - in the Irish Sea just off Cumbria and just off Anglesey'96 (see also Gifford 2009 14). There might be some discrepancy between Hughes's memory of the date of the article and writing the poem, but he was clearly concerned about marine pollution in Britain at this time. The river feeding the sea is a 'vein' that drains the water of the North of England: 'Sheffield's ores' and also 'Bog pools, dregs of toadstools, tributary | Graves, dunghills, kitchens, hospitals'. Hughes lists all the contaminants that might flow into the Humber, and which (ironically) become its 'tributaries'. In this list, five out of seven are human-made pollutants. The next few lines are in the first person, as if the river itself could speak of receiving these remains. Later in the poem, the Humber becomes a growing 'length of gut' (60). The poem ends with relics of the violence of war, including a 'bomb', broaching the speaker's 'palate' (61) - reflecting Hughes's concern that he might have eaten fish almost as radioactive as an atomic bomb, whether they came from the Irish Sea or Cape Cod Bay. It is not the best poem in Lupercal it hardly equals 'February' in quality - but it is one of the most incipiently ecological. 'Mayday on Holderness' brings together a host of environmental problems: water pollution, nuclear waste, nuclear warfare, the threat of global annihilation. This poem is the clearest instance of the distinction between The Hawk in the Rain and Lupercal: by the time he wrote it, Hughes had become aware of some of the environmental issues that would provide the focus of his famously determined lobbying for water quality and his staunch opposition to destructive nuclear technology.

\section{Nuclear Weapons}

One issue that Hughes's student typescript mentions is 'la bombe atomique' (Cam TS 14). The character mentioning it does so laconically, but in that early work, Hughes was touching on one of the major technological and environmental preoccupations of the late 1940s and the 1950s. Atomic weapons had annihilated Hiroshima and Nagasaki in 1945. In the same year, Donald Worster has written that 'the Age of Ecology opened on the New Mexican desert, near the town of Alamagordo [sic], on July 16, 1945, with a dazzling fireball of light and a

96 BL MS Add 88918/6/12 ‘ARTS FOR NATURE’ 2 (numbered 41 by archivist) 
swelling mushroom cloud of radioactive gases' (342). He suggests that understanding of invisible radioactive contamination in the environment, caused by nuclear tests such as this, paved the way for Carson to redirect public attention towards the equally insidious problem of pesticide contamination in Silent Spring (346-8). Atmospheric testing of nuclear bombs continued to be a pressing issue into the 1950s; it was 'the first truly global environmental issue' (McCormick 1995 60). Such explosions became a matter of wider public concern in 1954 when an American hydrogen bomb test on Bikini Atoll contaminated the inhabited Marshall Islands (62). Concerns about nuclear war would become particularly apparent in Hughes's writing in the late 1950s, and in Crow - but meeting Plath and moving to America heightened his awareness.

Nuclear weapons certainly worried Plath from her time at Smith College onwards. Horrific descriptions of victims of the Nagasaki bombing reminded her of the Cold War; a nuclear test in Nevada provoked the angry thought that the Americans would 'mash up the world' (SPJ 39). After a bomb-blast, 'the squirrels would still be there, and the birds. Long after, unless the smoke and radioactivity [...] got them' (26). Hughes and Plath would later become aware that nuclear power was also beginning to be used to generate electricity, but that this came at a terrible cost. The first major accident at a nuclear power plant occurred in Britain at Windscale in 1957; this was a few months after Plath and Hughes had moved to America. But it was Hughes's residence in the country that had first deployed atomic weapons, and which conducted more nuclear tests than any other nuclear power at the time, that would inspire him to write seriously about nuclear warfare.

In 'A Woman Unconscious' we see Hughes engaging with an environmental threat that threatens to destroy everything from human tissue to the very bedrock of the earth. He was living in an era when 'Russia and America circle each other'. 'A melting of the mould in the mother' evidences Hughes's awareness that radioactivity could damage unborn children, while 'The quick of earth burned out' suggests the annihilation of all forms of life ( $C P H$ 62). But the enormity of 'Earth gone in an instant flare' (63) is so great that 'flitting thought' shies away from it (62). Hughes would complain many times in later years that the human race needed to take more interest in environmental problems that might lead to its annihilation.

After he moved back to Britain, Hughes and Plath would join many others in protesting against the dangers of nuclear technology. The Campaign for Nuclear Disarmament was created in 1958, instigating the 'Aldermaston marches' from London to the atomic weapons research centre in Aldermaston, Berkshire. Initially, most of the protesters were involved for 'moral, political or religious reasons', although by the early 1970s the movement would become part of the broader environmental movement (McCormick 1995 75). But one protester whose motives were both moral and environmental from the outset, was Plath. After taking baby Frieda to the 1960 Aldermaston march, she wrote that 'I felt proud that the baby's first real adventure should be as a protest against the insanity of world-annihilation. Already a certain percentage of unborn children are doomed by fallout and no one knows the cumulative effects of what is already poisoning the air and sea' (Letters Home 378). 
It was concern about nuclear technology that inspired what was probably Hughes's first environmental protest poem. This poem about the dangers of nuclear radiation was written for the New Statesman ('If' 33), and Hughes had hoped to enter it into a competition. Hughes would publish part of his poem, with minor changes, far later ('If' 33). The powerful rhythms and satirical tone of this poem foreshadow Hughes's environmental 'semi-protest' poems of the 1980s. 97 In 1960, Hughes and Plath owned a map that showed the correlation between incidences of leukaemia in Britain and nuclear waste dumps. 'Nuclear business pre-occupied us a good deal', and so Plath and Hughes decided that they 'might as well be upwind of likely accidents'. This was one of the reasons why, when they returned to Britain, they moved to Devon in August 1961 (LTH 519). During the 1960s, Hughes was haunted by persistent dreams of surviving a nuclear explosion and finding that everything and everyone he touched was radioactive (Morrison 32). In one of the many children's books that he wrote in the aftermath of Plath's death to support and amuse his children, Nessie the Mannerless Monster (1964), Nessie participates in a Ban the Bomb march. The Aldermaston demonstrations opposed the annihilation technology of nuclear weapons, while Hughes's early protest-poem condemns the more insidious, localised environmental effects of nuclear waste.

Later Memories of American Environments and Environmental Thinking

America clearly paved the way for Hughes's explicitly environmentalist activities of the 1960s, but one has to look closely at his published and unpublished work in order to detect this change. American landscapes are the focus of some significant, unpublished ecopoems. The primary aim of Hughes's poems about America in Birthday Letters is to provide his account of his relationship with Plath. The volume stands as her poetic monument. Yet drafts of Birthday Letters occasionally mention the couple's growing environmental awareness. Several unpublished draft poems remember the happy times that Hughes and Plath spent together by lakes and the seashore, and mention water pollution. Hughes describes Plath's childhood at Winthrop Bay, when nothing was 'polluting' - he uses the term figuratively as well as literally to evoke the beautiful seascapes of her writing, such as the memoir 'Ocean 1212-W'. Later, when the couple visit, the bay is 'A fouled dish of landscape'.98 Another draft poem strikingly communicates Hughes’s concerns about aquatic environments. Canada is described as a paradisal, peaceful land, where Plath feeds deer by hand.99 However, while fishing Canada's Rock Lake in the Fifties, Hughes noted that the lake's famous lake-trout were 'vanishing', due to an increase in numbers of lampreys. The poem continues with some material that pinpoints the moment before Americans first underwent their 'greening':

Those were the days

Before the-Americans woke up

Earliest in the world, to the fact -

\footnotetext{
97 BL Add MS 88918/2/2 unbound, uncollected poems, TS, 'Blake comments on the statement used as a chant on the 1959 Aldermaston March.' Hughes submitted this poem under the nom de plume 'Nicholas Farrar'. Since this is a different spelling of the name of one of Hughes's ancestors (the protagonist of his poem 'Nicholas Ferrer') and the address given was his parents' at the time, it is clearly Hughes's work.
}

98 BL Add MS 88918/1/6 red notebook labelled 'Hildrid History’, marked ‘3.S.' by TH, 15 recto.

99 BL Add MS 88918/1/6 red notebook labelled 'Hildrid History’, marked ‘3.S.’ by TH, 17 verso. 
Hard to get used to - that the world

Is exactly what we make it. That the-great archaic natural beauty

Is actually in our hands, to do as we like with.100

These lines are highly significant: they remember a time before conservation and environmentalism were important political forces. At the time he wrote the draft, the lampreys had gone and the lake was full of salmon;101 Hughes longed to return, but knew that without Plath, he would find it 'Dead'.102 This draft illustrates Hughes's retrospective view of how the environmental movement developed first in the States. Plath was an important influence on Hughes's attitude towards shooting animals and his understanding of nuclear dangers, but it was also her fellow Americans who initiated his progression from a young man communing with animals and concerned about them, to a conservationist alert to multiple environmental issues. He was not yet ready for prolonged environmental campaigns, but his next major collection shows a deepening sense of humankind's complex relationship with the world in which we live.

\section{Wodwo: The Howling of Wolves, Shamanism and Ecological thinking}

In Wodwo (1967), Hughes creates a clearer sense of cooperation between humans and animals. But such cooperative relationships are far from stable; they are frequently fractured and disrupted. Indeed, he wrote to János Csokits that his book was ordered to suggest 'an undisturbed relationship with the outside natural world' being disrupted by a call 'from a subjective world' (LTH 273-4). Yet the 'outside natural world' sometimes intrudes upon human subjectivity in the collection; this creates moments of sympathy and even 'fellowship' with other animals. Here, then, Hughes is testing and challenging the Cartesian view of nature as a separate Other. Wodwo is a hybrid volume that alternates prose and verse, negotiates the difficulties of our relationships with landscape, other creatures, and the memory of loved ones - but it ends with an early poem of ecological integration. The composition of the book was also somewhat fragmentary, and much of the material was written by the end of 1962; that is why it largely belongs to Hughes's incipiently environmental poetry from before the 'environmental revolution'. The collection has a titular protagonist who is neither human nor animal, a 'half-man half-animal spirit of the forests' from Sir Gawain and the Green Knight (PM 62). The opening quotation from Sir Gawain... ( $C P H$ 146) fixes the image of Gawain battling dragons, wolves, wodwos, bulls, bears, boars and ogres in the reader's mind; although the volume often challenges such antagonistic relationships with animals. Here, Hughes's ecopoetry becomes more formally daring and sonically engaged with the more-than-human world. Here, too, he hints at his grief for Plath but it takes the form of Yorkshire place-poetry ('Heptonstall', 'Ballad from a Fairy Tale') or animal-poems ('The Howling of Wolves', 'Skylarks'). In 'Wodwo', he succeeds in creating one of his most accomplished poems about a hybrid creature. His interest in the environment has progressed to the point where he confounds 'Reformed Christianity's' distinction between human and animal in more profound ways than ever before.

100 BL Add MS 88918/1/6 red notebook labelled 'Hildrid History’, marked '3.S.' by TH, 18 verso.

101 Red notebook labelled 'Hildrid History’, marked '3.S.' by TH, 19 recto.

102 Red notebook labelled 'Hildrid History’, marked ‘3.S.' by TH, 19 verso. 
Plath wrote to her mother in June 1960 that Hughes wanted to study for a degree in zoology. He clearly wished to deepen his understanding of living organisms through science at once stage - but he continued turning his sharply-focussed observations of them into poetry. 'Second Glance at a Jaguar' revises Hughes's earlier jaguar-poem, and the resulting piece is a better ecopoem. Michael Malay wonders if Hughes was 'never entirely satisfied with the visionary quality of 'The Jaguar' (97). He finds the animal in the earlier poem 'symbolic', and the later jaguar to be described in an increasingly 'naturalistic' way (93). What Malay fails to mention is that the later poem is drawn from life. Hughes wrote it while sitting in front of the jaguar cage at Regents Park Zoo103 - the very zoo where a jaguar from his earlier poem had lived. It draws its rich layers of symbolism from Hughes's reading of anthropological texts. This creature is 'Like a thick Aztec disemboweller | Club-swinging' (CPH 151) with a 'club-tail' (152). Hughes wrote that South American warriors wore animal disguises and wielded clubs in pre-Columbian times, in undated notes on folklore.104 Predator and warrior fuse, which would explain why the jaguar must 'wear his skin out' (151), just as the warrior might wear out his jaguar skin mask. Hughes's poem draws on the close relationships between animals and premodern peoples that his anthropology textbooks had proposed. It is the formal qualities of this poem, and Hughes's use of verbs, that make it 'greener' than its predecessor. This jaguar is captured in allusive but realistic poetry, without the regular verse-form that kept 'The Jaguar' a little too hemmed in behind the bars of formal style. Unusually for Hughes at this stage, the poem is a single, long column of text, conveying the cat's pent-up restlessness; he will employ such a form more frequently in later collections such as Moortown Diary and Birthday Letters. Gone are the four-line stanzas and half-rhymes that prevented the earlier poem from fully striding into the wilderness of freedom. Descriptions of the jaguar's movement are abundant and vivid: it bowls along, hurries, glances, runs, waddles, swings its tail, swivels its foot, strides and shoves forward its body with head dragging and hind legs lagging. In constant movement, this jaguar embodies creaturely agency and strength, but also confined agitation. The poem's Wordsworthian authenticity and carefully observed details make it one of Hughes's best mature animalpoems.

Yet the big cat hurries through the 'underworld' in the last line for a reason that is potentially deeply personal. Its 'Cain-brands' are the marks of an all-too-human guilt. Jaguars were cardinal totems in Hughes's mythic life. 'Second Glance...' relates to a poem that Hughes nearly published much later: 'The Jaguar Skin'. This is a Birthday Letter that he typed up for publication, 105 but which he did not include in the published collection. In a manuscript draft, Hughes envisages entering the underworld in the jaguar pelt he owned. There, he will join Plath and his friends who have died: 'Death holds no terrors for me, if I can take | The skin of

103 BL Add MS 88918/7/2 pages from small ruled notebook 3.

104 BL Add MS 88918/9/12 lined pocket notebook 6 recto.

105 BL Add MS 88918/1/12. Final typescript and corrected proofs of Birthday Letters, 'THE JAGUAR SKIN' TS. 
a jaguar, so she will join me'.106 There is already a hint of this idea in 'Second Glance at a Jaguar', which also overlaps in significant ways with a sculpture of a panther (a black leopard or jaguar) that Hughes made in 1967, the year 'Second Glance...' was first published. At the time, he was living with Assia Wevill. Dalya Alberge notes that 'he branded the jaguar's forehead with the letter 'A', either for Assia or for "adulterer”, as recalled in Nathaniel Hawthorne's The Scarlet Letter (2012 14).’ The sculpture symbolises of Hughes's passionate but troubled relationship, is a scapegoat for adulterous guilt, and symbolises hidden energies. Both poem and sculpture evoke a sense of entrapment, or turbulent, pent-up power. The jaguar of the poem is realistically described; the jaguar of the sculpture is given deeper symbolic resonances. Rather than detracting from its animality, Hughes shows how the jaguar shapes his 'inner nature' in these complex, interconnected artworks.

If 'Second Glance at a Jaguar' contains visionary dimensions, these become much more apparent in the collection's next animal-poem. 'The Bear' does not contain many details that suggest Hughes's experiences of being in Yellowstone National Park while a killer bear was at large ( $L T H$ 150-51), and 'The $59^{\text {th }}$ Bear' from Birthday Letters would provide a very different depiction of this animal. Violence and dismemberment lead to a form of mythical symbiosis between human and animal. The poem is clearly marked by Hughes's interest in shamanism. He had investigated shamanism at university, and developed his interest in Arctic shamans by reading books such as Knud Rasmussen's Across Arctic America: Narrative of the Fifth Thule Expedition (1927) (LTH 637). His review of Mircea Eliade's seminal 1964 book on the subject107 shows that his interest in this set of beliefs continued well into his mature poetic career. Hughes summarises the shaman's initiatory dream thus:

The central episode in this full-scale dream [...] is a magical death, then dismemberment, by a demon or equivalent powers, with all possible variants of boiling, devouring, burning, stripping to the bones. From this nadir, the shaman is resurrected, with new insides, a new body created for him by the spirits. When he recovers from this - the dream may hold him in a dead trance for several days - he begins to study under some shaman, learning the great corpus of mythological, medical, and technical lore of the particular cultural line of shamanism he is in. (WP 57)

It is important that Hughes mentions that the helping spirit is 'usually some animal' among North American peoples (56) and that the shaman's calling is so all-consuming that once you have been chosen, 'you must shamanize or die' (58).

The intricate relationship that exists between shamans and animals is especially meaningful in Hughes's work. Gifford and Roberts note that the shaman has a 'special affinity with the animal world' (20). They cite Eliade to argue that the shaman 're-establishes the situation that

106 BL Add MS 88918/1/6. Beige school notebook labelled ‘1. S 18 Rugby St’ by TH, 8r.

107 For a critique of Eliade's tendency to downplay the diversity of shamanic practice, and an analysis of early critics’ responses to Hughes’s shamanism, see Taylor 103. 
existed in illo tempore, in mythical times, when the divorce between man and the animal world had not yet occurred' (Eliade 94; qtd in Gifford and Roberts 20). This is crucial to Hughes's particular brand of ecological thinking: Eliade thinks that shamans shamanise to call up that mythical time when human beings and animals were closer. Ted and Gerald's 'wild life', roaming among animals, resembles the illud tempus before humankind became separated from nature. A quotation that Hughes copied out some time in the early 1960s, drawn from his reading of Knud Rasmussen, suggests that he thought modern, Western society could learn from shamans. Hughes wrote, "“The only true wisdom lives far from mankind, out in the great loneliness, \& it can be reached only through suffering. Privation and suffering alone can open the mind of a man to all that is hidden in others.” Igjugarjuk (Eskimo shaman)'.108 Suffering in wild places, far from human habitation, is the only way that one can reach 'true wisdom' - a wisdom that technologically advanced societies might have lost. Part of the impetus behind Hughes's adult interest in animals, animal-poetry, farming and fishing - and his environmental campaigns - was to help him to evoke that lost, mythical wisdom by reconnecting with the environment. Of course, such a nostalgic project could rarely be realised in practice.

The bear of the poem's title presides over an initiatory ritual. The initiation of an Ammasalik shaman, or angakok, involves his being ritually devoured by a bear in Eliade (58-59). The poem anticipates the songs that Crow learns from his Eskimo shaman guide. The bear glues beginning to end 'With glue from people's bones' and digs through the Universe's wall 'With a man's femur' (160). What is most striking about this poem, is that a human being becomes prey, even if this occurs in a mythical realm. If Solnick argues that Hughes uses violence to restore a 'lost sense of corporeality' (76), this is never more marked than when human beings fall prey to other species. The last line, 'His price is everything' (161), shows the finality of the shaman's vocation: shamanise or die. Hughes is writing in mythic mode - but the result is a relationship between animal and human that is so close as to be potentially devastating. Hughes hints at an 'event' - some sort of quasi-shamanic crisis - occurring between 1961 and 1962 (LTH 273-4). This event saw him moving from that 'undisturbed relationship with the natural world' into the demands of the 'subjective world'. Hughes deferred his acceptance of this call, and 'paid for it quite heavily' (274). He describes the Western ego as being dismembered and re-formed; the resulting self gains a better understanding of his place among human and nonhuman creatures.

However, this complex interconnection of human and animal becomes increasingly disturbing and uncanny as Wodwo progresses. Hughes places his much earlier stories 'The Rain Horse', 'Sunday' 'Snow' and 'The Harvesting' after 'The Bear'. 'The Bear' and these stories describe 'the event', that refusal of the call in 1961. The subsequent poems describe the aftermath of the refusal (274). He uses these earlier stories to create a sense of how humans' relationship to the natural world is developed or disrupted. The titular animal of 'The Rain Horse' is distinctly unsettling in its seemingly aggressive following of the protagonist: 'Was it clairvoyant? Maybe a mad animal can be clairvoyant' (Wodwo 50). In

108 BL Add MS 88918/129/2 unpublished prose notes 51 verso. 
keeping with its origins in 1958, three years after Hughes composed the moment of symbiosis we see in 'The Thought-Fox', the rain horse is a real horse that also becomes a thought-horse: 'Its whinnying snort and the spattering whack of its hooves seemed to be actually inside his head as he fell backwards down the bank, and leapt again like a madman' (51). Action and sensibility are transferred from animal to man: if the horse is a 'brute', the protagonist's energy is 'savage' (etymologically 'wild', 53). Lawrence was a profound influence on Hughes, as we have seen, and The Rainbow is the most obvious precursor text to 'The Rain Horse'. But while Lawrence's Ursula is aware of the physicality of the horses - 'their movement travelled through her' (1989 452) - Hughes's character has a more acute sense of what is happening within the rain horse's mind. Hughes creates a 'greener', deeper examination of his character's 'inner nature' by allowing the inner life of an animal to intrude upon human subjectivity. Indeed, he wrote that the story documented the refusal of the call, and 'the event' was 'mental collapse into the condition of an animal' (LTH 274).

A similar exchange of sensibility occurs in 'Sunday': Michael sees perspiration on the rat's fur and becomes 'aware of the heat again'; a 'dull pain in his head' is not eased by the touch of his hand, which 'didn't seem to connect' with the pain (Wodwo 69). There are important parallels between the short story 'Sunday' and the later poem 'Song of a Rat': the rat's scream in the story is 'metallic' (Wodwo 67) and 'like torn tin' in the poem (CPH 169); the rat in the story dies with 'A little drip of blood' under its nose (Wodwo 69), and the rat in the poem has 'a little beseeching of blood on its nose-end' (CPH 169). In the story, Billy Red's killing of the rat actually creates a moment of sympathy between the animal and Michael.

Yet the most extraordinary and unsettling incident of transference is 'The Harvesting', with its epigraph from The White Goddess's shapeshifting witch Isabel Gowdie: 'And I shall go into a hare' (Wodwo 82; see also Graves 393). Grooby feels that 'None of his limbs belonged to him any more', and his yell becomes an 'unearthly thin scream' as he is worried by hunting dogs (Wodwo 91-92). As Hughes put it, 'The Harvesting' relates to 'the theme' of 'The Rain Horse': 'the man turns into the hare at the moment he shoots it' (LTH 274). It is likely that the story was influenced by Hughes's friend Charles Causeley's 'I Saw a Jolly Hunter', which describes a hunter who aims his jolly gun at a jolly hare and ends up jolly dead when the firearm backfires. This would link it to the largely negative ideas about bloodsports that Hughes was expressing in the 1960s; more on this later. The short stories in Wodwo from the late 1950s set up a network of connections that remind human beings of their corporeal connection to animals. More specifically, they articulate 'the human capacity for becoming animal' (Skinner 2011). Yet Skinner's brief analysis of animals and animality in ecopoetry needs to be expanded to accommodate how prose can work within a collection of ecopoetry, communicating the uncanny telepathy between horse and man, and the magical realist shapeshifting that transforms man into hare. The stories focus particularly on the expressive voices of animals; this is an ecopoetic theme that Hughes will further explore later in his collection. The screams of rat and hare in the early prose stories are echoed later in verse, by the cry of the 'poulterer's hare hanging' in the poem 'Karma' ( $\mathrm{CPH} 168)$, the 'long cat-gut cries' of the wind in 'Gnat-Psalm' (181), and of course by the screeching of the caged rat in 'Song of a Rat'. 
Two very significant poems about animal cries were written in the period immediately following Plath's death: first, 'The Howling of Wolves' in February 1963, and 'Song of a Rat' the following month (PC 33). Hughes was not ready to publish verse that dealt directly with the trauma of her suicide. Animals articulate the 'howls and whispers', as he would put it later, of her suffering and his grief. It is significant that he chooses to articulate his mourning through the cries of creatures. Skinner argues that the sound of ecopoetry expresses the delicacy of life on our planet and captures the 'sonic environments' in which organisms live - but to date, his critical prose has left unexplored important issues of how species communicate with each other through sound. Even more crucially for poetry, his analysis also leaves out the affective dimensions that writers of verse so often give to animal sounds. Poets have long written about why the caged bird sings and why the skylark voices its shrill delight. Yet if Hughes's predecessors used animal vocalisations to write about the very human affairs of racial oppression, sorrow, joy and the act of creation, they also remind us that the poet participates in nature's making by expressing powerful emotions in sound.

'The Howling of Wolves' and 'Song of a Rat' represent a significant stylistic and formal change for Hughes, and their aural quality places them among the most striking ecopoetry he wrote for the ear. They are also visually experimental. Along with 'Skylarks', these poems from Wodwo begin to take on the innovative formal features that Tarlo, Gander, Kinsella, Lidström and Garrard see as embodying an ecological ethics. The long lines and irregular form of 'Song of a Rat' would seem to be partly inspired by Plath's mature work - although it is also a bleaker and darker revisiting of 'Sunday'. The first section, 'The Rat's Dance', is a grim depiction of a caged animal's suffering:

The rat is in the trap, it is in the trap,

And attacking heaven and earth with a mouthful of screeches like torn tin,

\section{An effective gag.}

When it stops screeching, it pants (CPH 169).

This use of repetition suggests some of Plath's images of animal confinement. Hughes's opening line recalls the imagery in her bee poems, for example, the double repetition that describes bees confined in a dark box: 'There is only a little grid, no exit. | I put my eye to the grid. | It is dark, dark' (CPP 213). After this twofold repetition, Hughes weaves a distinctive triple iteration that is even more characteristic of Plath into the later parts of the poem. This threefold repetition is most memorable in 'The Applicant' ('It can talk, talk, talk') and 'Daddy' ('wars, wars, wars' (222)). Hughes reiterates the word 'screech', 'screeches', 'screeching' or 'screechings' five times in 'The Rat's Dance' section alone, rhyming it with 'beseeching'. The second line quoted above is noticeably longer than those surrounding it: the length of the animal's scream prolongs the line. The effect is of an overwhelmingly loud and persistent animal cry of distress, which externalises the suffering felt by Plath and then 
by Hughes. Although the second and third parts of the poem are 'ritual magic',109 the ritual is only partially successful at banishing the rat's pained cries and transfiguring it into 'godhead' ( $C P H$ 170). The trapped rat's cries are, of course, an expression of the rawness of Hughes's grief, but his decision to give his mourning an animal voice enmeshes his poem within a wider soundscape of natural communication. But it is important that the rat does not know human language, cannot explain why it suffers. The rat voices pain that Hughes does not yet dare to make public.

The earliest of Hughes's animal-elegies for Plath is 'The Howling of Wolves'. It was one of the few poems that Hughes wrote while he was staying at Fitzroy Road, in the aftermath of Plath's death. He wrote it one evening in 1963 while he was in bed,110 in a flat that is within earshot of London Zoo. Bate calls it a 'skewed elegy' for Plath (2015 226). As an elegy, it is indeed convoluted; but as an ecopoem, it is important. This poem is released from the constraints of regular metre by an irregular form and long lines that might have been suggested by, for example, the form of Plath's poem 'Lesbos'. Again, Hughes's characteristic command of powerful language is supplemented by a distinctive double repetition that honours her poetic style: 'That they must live like this || That they must live'. The tenth line is isolated from the previous line by a blank gap, and stands alone, with no punctuation mark to suggest that it needs to be linked syntactically to the next line. 'What are they dragging up and out on their long leashes of sound' ( $C P H 180)$ is preceded by a similarly abrupt pause. Short, isolated lines convey brief vocalisations, and longer lines represent long, drawn-out, modulating howls. In the white spaces on the page, the poem pauses, as if listening for an answer that never comes. Hughes allows the time signature of the wolves' howls to shape the length of the phrases in his poem: here is ecopoetry in the making. Of course, the mourning that this poem hints at remains implicit until the howls in 'Life after Death', published much later. February 1963 did not bring the feast of Lupercalia, but instead, sorrow that found its expression in the howling of wolves.

While the rat's cry expresses fear, it is unclear whether the howling in this poem voices 'agony or joy' (180). The volume and modulation of wolves' howls can vary according to what they are communicating. When a member of a wolf-pack leaves, the intensity of the remaining wolves' vocalisations increases in proportion to the closeness of their relationship to the missing wolf (Mazzini et al 1677). It is as if this poem uses some of Plath's own poetic devices as a form of summoning-call, one that will never be answered. But these wolves were responding to a human voice: the 'crying of a baby' brought them 'slavering' ( $C P H$ 180). They were responding to the cries of the young Frieda Hughes, if we are to trust Boyanowsky's memory of Hughes's introduction to the poem (48). At the beginning of the poem, the wolves are profoundly menacing; yet they become more pitiful as the poem continues: 'The wind sweeps through and the hunched wolf shivers' ( $C P H 180)$. The howls in 'Life after Death' are far more comforting: 'Wolves consoled us' (1161). 'Song of a Rat' and 'The Howling of Wolves' enter into a sensitive dialogue with Plath's work, and remind

109 BL Add MS 88988/2: 1992-1997, letter from TH to Gifford, 6 $6^{\text {th }}$ October 19973.

110 BL Add MS 88918/7/2 notes on composition of TH’s poems 3 recto. 
us that animals share our ability to vocalise pain. Skinner has commented on the significance of environmental sound (qtd in Sweeney 2012). Yet poems such as this show that ecopoetics scholars need to pay closer attention to animal vocalisations, the emotional associations they have for human beings, and the ways that animals use them for communication and expression.

'Skylarks', too, finds an animal symbol for grief, and its deep undertow of sorrow is well known. Elizabeth Stansell has mentioned this poem's connection to shamanic flight (81-82). The skylark undoubtedly symbolises Plath (Michael Parker 45) on one level, and Hirschberg finds it an 'all too human bird' (59). Yet even if the lark is anthropomorphised at times, the poem clearly contains a human observer whose questioning attitude prevents crude personification. The poem is as much about the skylark as it is about Plath, and the movements and calls of the lark even shape its visual form. Part of Hughes's project is to revise the pastoral associations that have been attached to the lark: he rejects the blitheness of Shelley's vision and the aspirant image of Wordsworth's bird. Here is a realistic evocation of the quintessential singer of Romantic poetry, pastoral verse and music. The bird has been shot through the head with the command, 'Not die', and yet, three lines later, it is 'Obedient as to death a dead thing' ( $C P H$ 173). Here is a more mournful, pensive revision of Lupercal's vision of dogged animal survival. Hughes's depiction of it is biologically realistic, with just a dash of the inorganic: 'Its feathers thrash, its heart must be drumming like a motor' ( $\mathrm{CPH}$ 174). If the poem begins with the lark as part-inorganic, 'leaden' and 'Like a bullet' (173), it moves quickly to addressing the lark directly, vividly imagining its life: 'not stopping singing || Resting only for a second'. The evocation of its 'Lamenting' (174) shows how Hughes's animal-poetry has developed from those early poems of clamping fangs: there is now intense pathos for the creature, and for Plath, who haunts this poem. Gifford and Roberts have commented on the 'bewildering' return to anthropomorphism in the last line of the seventh section (79), when the lark is described as 'Conscience perfect' ( $C P H$ 176). The poem springs from Hughes's grief for Plath, but he needs to deploy his observations of larks in order to write it: they ascend and descend rapidly in their courtship flight, as the column of the poem plummets down the page. The lark’s song, 'Joy! Help! Joy! Help!' (CPH 174) articulates the two poles of Plath's poetry by evoking the heights and depths of the bird's frenzied song. This poem draws on Hughes's careful observations of a moorland bird, in a poem whose stripped-down vertical column of text is an image of ecstatic ascents and plummeting falls. Tarlo, Gander and Kinsella stress the importance of such experimental form for expressing an ecological ethics, but like Skinner's work on ecopoetry and the acoustic, their theories do not adequately explore the way that ecopoetry can articulate the most visceral kinds of pain, terror and grief by showing that certain animals share these emotions with us. 'Song of a Rat', 'The Howling of Wolves' and 'Skylarks' work simultaneously on two levels. They are raw expressions of terrible human grief. Yet they are also ecopoems whose sound echoes back the cries of animal suffering. Not yet ready to unveil his distress about Plath's death to his readers, Hughes channels his mourning through the cries of a rat and the frenzied song of a lark. He makes another wolf-mask. 
Poems such as these have inspired a generation of ecopoets to express and mediate grief through their connection to the natural world, from David Morley's elegies for Hughes's son Nicholas in Enchantment (2010) to Pascale Petit's mourning for her father in Fauverie (2013). Max Porter's superb Grief is the Thing with Feathers (2015), in which Crow consoles a widowed Ted Hughes scholar and his sons, is an even more Hughesian example.

Traditional elegies often return the beloved to a landscape that brings comfort to the elegist; an example from The School Bag is Milton's Lycidas, who becomes 'genius of the shore'. In his monograph on Hughes's elegy, Edward Hadley writes that in pastoral elegy, 'The reverberations of death and grief are acutely felt by nature, but nature absorbs grief, reacting to it in an ordered, indeed, orchestrated fashion' (2). In contrast to this consolatory tradition,111 modern elegy, for Ramazani, tends towards 'mourning that is unresolved, violent and ambivalent', refusing 'such orthodox consolations as the rebirth of the dead in nature' (4). Yet when an ecopoet turns to elegy, the sense of human beings' participation in organic systems of death and regeneration becomes more marked. As will be argued in Chapter X, Hughes's laments for vanishing and extinct species in Wolfwatching further explore the elegiac and environmental possibilities of animal-poems. The best ecopoetry of mourning neither trivialises human grief, nor anthropomorphises other creatures. It is strengthened and deepened by its interweaving of human and nonhuman suffering.

At the end of Wodwo, Hughes creates a character that succeeds in bridging the divide between human-centred and animal-centred perspectives. His Wodwo is a hybrid. Hughes describes it thus:

I imagine this creature just discovering that it is alive in the world. It does not know what it is and is full of questions. It is quite bewildered to know what is going on. It has a whole string of thoughts, but at the centre of all of them as you will see, is this creature and its bewilderment. The poem is called Wodwo. A Wodwo is a sort of halfman, half-animal spirit of the forests. (PM 62)

Its first utterance is 'What am I?' (CPH 183). The form of this poem is unusual for Hughes, as it is not divided into stanzas and is made up of long, barely punctuated sentences. This echoes the fluidity and permeability of the creature's hybrid identity. When the Wodwo enters water, it adumbrates the dissolution of the self that will happen later, in River's 'Go Fishing'. Its interactions with the rest of its environment are striking: it inspects the interior of a frog and makes it its own, and yet this sense of ownership is completely confounded when the Wodwo wonders whether the weeds have seen him before and name him to each other, and whether he fits into their world. The creature even asks 'what shape am I'. The idea of a self that ends with the skin, where the body ends, is a Western view; some other cultures see the self as deeply linked to its surroundings. Scigaj describes this poem's common ground with the Zen concept of 'satori fusion with the landscape'. Yet while Hughes certainly was

111 Ramazani nuances his claim that 'modern' (twentieth century) elegy is invariably less resolved than 'traditional elegy' (such as Milton's Lycidas and Shelley’s Adonais) by identifying moments of 'masochism, irresolution, irredemption, aggression, and self-criticism' even in premodern examples; yet his argument is that these traits are more widespread in recent and contemporary elegy (10). 
influenced by Oriental mythology, the Wodwo does not see itself as the 'exact centre' (1986 114) of creation. The last lines of the poem destabilise and decentre the creature:

$$
\begin{aligned}
& \text { but there's all this what is it roots } \\
& \text { roots roots roots and here's the water } \\
& \text { again very queer but I'll go on looking ( } C P H \text { 183). }
\end{aligned}
$$

Sagar identifies this poem as the stage at which Hughes's vision of nature has progressed significantly beyond the violent thought-animals in earlier poems. However, 'Wodwo' recalls the dissolution and mending of the self, also articulated in poems such as 'The Bear'. A halfman, half-animal creature enables Hughes to negotiate the difficult problem of how to give a voice to nonhuman creatures, by evoking an entity that is neither fully human nor wholly animal. When Hughes draws inspiration from Sir Gawain and the Green Knight, he creates poetry that is 'green' in ways that its medieval author could never have foreseen. This poem is an important moment when Hughes anticipates posthumanism's project to decentre the human. 'Wodwo' was actually written in early 1961 (Bate 2015 249) and published later that year; but since it gives its title to the collection, it can be seen as ushering in the close entanglements of human and animal in poems such as 'Skylarks'. The form of this poem, which runs whole sentences together and destabilises the human-centred lyric 'I', would not be out of place in a modern journal such as ecopoetics.

In the aftermath of Plath's death, Hughes also created an eerie collection of lunar children's poems, The Earth-Owl and Other Moon People (1963). Most of these poems alternate between the fantastical and the unsettling, in rhymes whose sound adds a dose of reassuring lightness. But there is one poem that stands out as a meditation on the violence that human beings inflict upon animals. Hughes’s 'A Moon Man-Hunt' describes 'foxes in red jackets, they are their own horses and hounds' (1976 67). Sagar has analysed this poem briefly as a critique of the hunt (2006 147), but his account misses the extent to which humans and animals change places, and are even imagined to hybridise. Published a year after he had produced his spirited 1962 article about the 'class war', Hughes's poem attacks 'that noble rural vermin, the gentry' (1978 67). Yet the purpose of the poem is not just to mock the upper class, but also to attack hunt followers for their hypocrisy. '[T]hey pretend it is all a good game and nothing to do with death and its introductory tears' (67), but of course when the foxes bring down the unfortunate 'squire', 'Five catch his heels, and one on his nose, and ten on each arm, he goes down with a yell' (68). Hughes deploys a realistic description of the hunted man, who actually seems to take on the characteristics of a creature traditionally seen as evil and verminous: 'His bowels twist like a strong snake' (67). Hughes takes the theme he had begun in 'The Harvesting', and pushes it further: hunt follower becomes prey and the former quarry takes violent revenge. This is hardly 'fellowship' between human and animal: it is an animal revolt as violent as that depicted in Orwell's Animal Farm.112 Perhaps those

112 Hughes's library suggests that he knew Orwell's work well, and Animal Farm interested him: he owned a study guide to it. Emory MARBL archive, Iona McGregor and Tony Buzan, A Guide to Animal Farm. London: Hodder \& Stoughton, 1998. PR6029 .R94 A65 1998 HUGHES. 
red foxes in their red jackets carry undertones of proletarian revolution; but of course, the environmental revolution was a few years away, and the foxes also represent the enraged energies of a damaged nature that Hughes later unleashes in The Iron Woman. The tensions in this poem are drawn from Hughes and Plath's early residency in Devon. While Plath found the hunt followers' finery impressive, 'in spite of our sympathy for foxes' (Plath, Letters Home 436), Hughes's sympathy for the quarry was influenced by both his long interest in foxes and by his suspicion of elite equestrian culture. 'A Moon Man-Hunt' is a humorous children's poem, but its critique of hunt followers' hypocrisy is valid; Hughes's later letters in support of hunting still register his disgust at the attitudes of hunt followers (see Chapter $\mathrm{X})$.

From the early evocations of animal gazes in The Hawk in the Rain, Hughes was creating poems of animal agency, and evoking moments of close communion between creatures and humans. Yet it is clear that his time in America created important turning points in Hughes's environmental awareness. By the time Lupercal was published, he had had the first 'big shock' that would usher in his environmentalism: reading about secret nuclear waste dumps in the sea. He was beginning to write some of his first poems about nuclear technology and pollution. His talent for writing environmental prose became apparent first in his short stories, and later in the BBC broadcasts between 1961 and 1964 that became Poetry in the Making (Bate 2015 37; see also Chapter II). He and Plath demonstrated against nuclear weapons in 1960, paving the way for Hughes's activism of 1970s and 1980s. In 1962, he and Plath read Silent Spring: another significant environmental shock. A deeper and more terrible shock had shaken him when Plath took her own life in February 1963, and he would turn to animal symbols to give voice to his desolation. 'Song of a Rat' and 'The Howling of Wolves' evoke terrible human trauma, but in these poems, and in 'Skylarks' and 'Wodwo', Hughes was writing his most formally and sonically experimental ecopoems yet. Poems about human-animal co-operation had been a feature of his work from 'The Thought-Fox' and 'February', but with Hughes's continued reading about shamanism, his animal-poems gain a deeper and fuller sense of mythic connections between man and beast. One of his best early ecopoems, 'Wodwo' embodies a hybrid self dispersed in the landscape. He was beginning to criticise foxhunting, a practice that would later inspire several contradictory poems and prose statements. From the mid 60s to the early 70s, Hughes would deepen his awareness of environmental problems, write about the environmental movement, and create one of his 'darkest' ecological works. Yet few scholars have realised that he did far more than this. Perhaps for the first time in his career, he would propose a new environmental scheme. 


\section{CHAPTER VI: THE ENVIRONMENTAL REVOLUTION}

The 1960s were the decade when weather and climate data revealed that human beings could alter these vast systems (Hamblin 127) - and when NATO began to take an interest in the military possibilities of 'environmental warfare' (158). Silent Spring became a bestseller, and a new awareness of species extinction, the dangers of artificial chemicals, and the human and ecological cost of international warfare, culminated in the first Earth Day in 1970. For Hughes, the decade produced 'the whole idea of our ecological responsibility, fully developed - maybe the crucial awakening' (PC 80). By the end of 1960s, Britain would have its own environmental magazine, which was co-founded by Hughes. His understanding of environmental ideas in this important period becomes visible in two major written outputs: the poetry collection Crow (1970) and his editing of Your Environment magazine (1969-73), to which he contributed an important prose essay. This essay, and Hughes's vast archive of prose notes accompanying Crow, which are analysed here for the first time, show that Hughes was building up his corpus of environmental prose as well as ecopoetry. Thanks, too, to developments in ecological thinking of the 1960s and early 70s, he would launch a reforestation scheme. Ignored by previous scholars, this important scheme was an even more practical and direct engagement with environmental issues than his previous anti-nuclear protesting. Critics who have labelled Hughes as ahistorical and apolitical have missed just how committed he was to this major development in his time.

In the early 1960s, escalations in Cold War tensions catalysed developments in nuclear issues. The Berlin Crisis of 1961, and particularly the Cuban Missile Crisis of 1962, brought the threat of nuclear war closer. Nevertheless, there was some progress with restricting nuclear weapons testing: atmospheric and underwater detonations were banned in 1963 under the Partial Test Ban Treaty. McCormick argues that it is possible that this was the first global environmental agreement (1995 64), although it was of course intended to slow the arms race. A new awareness of the environment as a global whole began to develop thanks to this agreement (65). Hughes would write in greater detail about nuclear technology during the 1960s; it inspired some of the images that he would deploy in his poems of global conflagration, and the images of fallout in Crow.

But it was the publication of Silent Spring in a single volume in 1963 that brought much of the western world to a greater awareness of environmental issues. McCormick credits the book with 'marking the beginning of the environmental revolution' (65). Hughes remembers Carson's bestseller as an important catalyst for his environmental awareness, 113 and its exposure of the damage done by pesticides and chemicals to human bodies, animal bodies and the wider environment came as a shock to most of the Anglophone world. The book created a widespread change in attitudes and caused Kennedy to commission a report on pesticides (Rome 532). Two years later, President Lyndon B. Johnson gave a speech to Congress on the 'conservation and restoration of natural beauty'. Conservation, then, was entering mainstream political discourse in the USA. It was political developments such as

113 BL Add MS 88918/1/55, notebook containing drafts of Season Songs 2. 
these, and his reading of Rachel Carson, which Hughes evokes in his unpublished draft from Birthday Letters.114

The wreck of the oil tanker Torrey Canyon in 1967 was a major environmental incident with international ramifications, polluting the Cornish coastline with Kuwaiti crude oil. At the end of the decade Hughes would also become aware of a problem polluting the coast even nearer to his Devon home: sewage pollution.115 Local issues continued to preoccupy Hughes, but the 1960s also witnessed further developments in global environmental thinking. Between 1965 and 1968, politicians and writers developed the image of the earth as a spaceship116 'with finite resources for survival' (Heise 25). These images were linked to photographs taken during orbital flights in the early 1960s, the Apollo 8 crew's 1968 'Earthrise' image and the famous 'blue marble' photograph obtained by the Apollo 17 mission in 1972. Human beings were able to see their planet as a whole. These images were appropriated by environmentalists at the first Earth Day in 1970 (22).

The environmental movement had an international reach by the end of the decade. It had spread to 'North America, Western Europe and Japan’ (McCormick 1995 55), and Hughes would comment on its far-reaching effects in his prose. Joined with protest against both nuclear technology and the Vietnam war, it became a focus of countercultural expression (Rome 543, 46). As McCormick notes, 'If in 1962 there was growing unease about the state of the environment, by 1970 there was a new insistence on change in a global society seemingly bent on self-destruction' (1995 55-6). The 1960s saw the emergence of the view that environmental degradation was a 'war against nature' (Rome 542). Here are the origins of Hughes's call for politicians to deal with environmental issues 'as a war' (WP 131), the association of war with environmental cataclysm in Crow, and of his continued appeals to the government in the 1980s to treat the environmental crisis on a war footing (see Chapter VIII). The main difference between the conservationism of the 1950s and the environmentalism of the 1960s was that the new movement addressed the entire environment, including humans, rather than isolated issues such as wildlife, habitat, or natural resources. More 'overtly activist and political', it called for 'radical changes’ in society (McCormick 1995 56). Moreover, the 'new environmentalism' was able to define itself. Around 1966, the terms 'environmentalist' and 'environmentalism' came into use.117 By the 1960s, Hughes would have been able to identify himself as an 'environmentalist'.

114 BL Add MS 88918/1/6 red notebook labelled ‘Hildrid History’, marked ‘3.S.’ by TH, 18 verso.

115 For Hughes’s campaigns for cleaner water in the Torridge Estuary, see Chapter IX.

116 This holistic image of the earth appeared around 1965, when Adlai Stevenson used the image of the earth as a spaceship in a speech to the United Nations. The speech was drafted by the environmentalist and economist Barbara Ward (McCormick 80), who published Spaceship Earth the following year; Buckminster Fuller would further popularise the idea in his 1968 book.

117 The Oxford English Dictionary cites examples of the words 'environmentalism' and 'environmentalist' dating from 1966; 'environmentalism' is placed in quotation marks, suggesting that it was seen as a new term at the time. 
If Hughes's environmentalist opposition to pollution and nuclear technology chimed with the zeitgeist, one aspect of his environmentalism was distinctly primitivist. In this respect, he anticipated the 1960s' interest in the more mythical, spiritual aspects of our connection to the environment by nearly two decades. By the early 1960s, he was making much of his income from book reviewing, and he often chose books that resonated with his interest in mythology and pre-Christian religion. Susanna Lidström links Crow to 1960s countercultural thinking about the problems with Christianity, as exemplified by Lynn White's 1967 article 'The Historical Roots of our Ecologic Crisis' (2013 13). She also cites the alternative religious thinking of the time, which turned away from Western thought and became receptive to preChristian European and Asian belief-systems (14). Hughes certainly did think that the 1960s developed a sense of 'ecological responsibility' through 'ecological interconnectedness' (PC 80). However, Lidström misses the fact that Hughes's intellectual interests long predated the 1960s' countercultural interest in non-Western systems of thought. He said that he appreciated the Sixties because the political Left 'had the liberty to express itself' in Britain during the decade, but he was not interested in the mainstream cultural expression of the period: 'pop music'. He had, however, been interested in mystic cults since 1948 (Skea, 'Asia Festival Interview'), and in pre-Christian and Asian religions since adolescence and university. Perhaps his first encounter with stories of a corvine trickster occurred while he was at Cambridge, for he recorded a Native American myth in which Raven disguises himself as a baby in order to steal one eye from everyone in a village (FTNB 94). He later developed his interest in the trickster118 via his reading of Jung's essay on tricksters in The Archetypes and the Collective Unconscious, and his 1956 edition of Paul Radin's study of the Native American trickster.119 However, the Sixties also saw the republication of the 'essential literatures' (PC 80) of many non-Western societies, which would have reinvigorated Hughes's interest. By 1962 he had acquired 'a small library' of 'folk-tales of a particular sort (like the Ananzi stories, many African stories, the Ainu stories, the Trickster cycles' and The Táin (LTH 195). Hughes was both a primitivist sage among Yorkshiremen and an environmental revolutionary of the Sixties - and what united both of these strands of thought was his critique of consumerist modernity as spiritually alienating and environmentally damaging. In 1962 he had reviewed C.M. Bowra’s Primitive Song (1962), and in 1965, he reviewed John Greenway's Literature Among the Primitives (1964) and The Primitive Reader (1965). Hughes's longstanding interest in such texts permeates both his essay on 'The Environmental Revolution' and his darkly ecopoetic masterpiece Crow.

Hughes uses the term 'primitive' to describe both peoples and their cultures. He would not have seen it as pejorative: to him, it means 'primordial', suggesting the healthy, 'natural' sanity of civilisations that lack our dependence on potentially destructive technology. He articulates a spirited defence of it in a review of 1965. 'Primitive' literature has been recorded by the very Westerners who destroy 'the unique conditions of its flourishing' (WP 73).

\footnotetext{
118 Hughes's borrowings from trickster-tales are well known in Hughes scholarship, and are examined by writers such as Stuart Hirschberg (69-100) and Neil Roberts (2007 34-5, 2015 73-5).

119 Emory MARBL E99 .W7 R21 HUGHES
} 
Missionaries, lawmakers, compilers of children's stories and anthropologists subjected it to 'emasculations and and [sic] prettifications and denaturings' (74). His use of the last term is telling. Hughes characterises all 'primitive' peoples as 'think[ing] unremittingly about animals, herbage, weather, dependants and providers’ (33). Hughes’s ecopoetry in a primitivist vein seeks to undo our modern 'denaturings' and to bring literature closer to its 'primitive' origins in the natural world; of course, it necessarily does this via the contemporary techniques of free verse and via the Western publishing industry. Postcolonial scholarship would argue that Hughes might risk removing the oral literatures of preliterate peoples from their cultural context, and appropriating them - but an interest in indigenous culture was a common feature of 1960s counterculture, and it would be anachronistic to blame Hughes for this.

\section{Conservation and Extinction}

Hughes's visits to National Parks in the USA would have increased his awareness of megafauna conservation, but developments in conservationist thinking in the 1960s were more important influences. Conservation and the fear of extinction were also beginning to influence poetry. Hughes would have been able to read D.J. Enright's elegy 'The Quagga' anthologised with a selection of his own verse in Alvarez's 1962 volume The New Poetry. Hughes's acquaintance W. S. Merwin elegised grey whale, sea cow and gorilla in 'For a Coming Extinction', written in 1963 and published in his 1967 collection The Lice (Merwin 163). World Wildlife Fund was founded in 1961, but more significantly, 1966 was the year when US Congress passed the Endangered Species Preservation Act. The Act permitted the listing of native US wildlife species as endangered, gave them limited protection, and preserved their habitats; it would later be amended and expanded. This was also the year of Hughes's first explicit extinction elegy. Uncollected by Hughes but published in The Animal Anthology (1966), 'The Last Migration' is a more overt extinction elegy even than 'February'. Man replaces God and uncreates the Irish elk, the aurochs, the passenger pigeon and the buffalo. This poem sees Hughes create intense pathos for species that are dying out: they disappear into the 'vortex and rifling' of human overhunting with firearms (116). This is a portrait of animal suffering: the aurochs 'struggled to rise, it wanted to charge' (115) and the buffalo, those 'Great Lakes on the hoof', jostle 'at that bottleneck of bellowing and pain' (116). The passenger pigeon is an extinct North American bird; the buffalo neared extinction there in Hughes's time. Significantly, the aurochs and Irish elk lived in Eurasia and North Africa; the elegy begins to show the international reach of Hughes's environmental awareness, and suggests the need for European conservation movements to catch up with their American counterparts. It is a piece written to commission, and it is not Hughes's finest ecological elegy. But it is an important articulation of his concern about overhunting and extinction. At the end of the poem, 'the waters trembled | And began to move...' (116). The ominous suspension point shows that environmental destruction is ongoing, and the work of mourning extinct and endangered species must continue. Hughes will return to this elegiac strain in Wolfwatching (1986).

\section{'The Book of Crow is in the Egg'}

In Crow, it is unsurprising that Hughes's work becomes distinctly 'dark'. In the last year of his life, he reflected that Crow was an attempt to write about Plath's death 'obliquely' (PC 269). By the time it was published, he had suffered further terrible personal traumas. In March 1969, his partner Assia Wevill had killed herself, taking their daughter with her. Only 
two months later, his mother died; his friend and former lover Susan Alliston also passed away. Crow was published in 1970 and dedicated to Assia and Shura. Hughes could not bring himself to finish it in the wake of their deaths. Crow, like the Wodwo, is a part-human, partanimal hero; as with the rat, wolves and skylarks, Hughes would use the corvine character to channel human concerns and personal grief. Yet this complicated collection focuses more closely on environmental issues, and survival against the odds, than Hughes's earlier work.

The archives and Hughes's correspondence testify to the complicated genesis of Crow. As the collection and poems related to it evolve, we see Hughes's awareness of environmental issues developing and transforming. Early plans for Crow were optimistic about the possibility of solving environmental problems; but because of Hughes's increasing awareness of environmental risk and uncertainty, and because of traumas in his personal life, the published collection reaches no easy resolution. Prompted by an idea by the artist Leonard Baskin just weeks after Plath's death (Bate 2015 289), Hughes began creating Crow-poems in early 1963; he wrote to Baskin in 1964 that 'The Book of Crow is in the egg'.120 Hughes wrote many plans for Crow, at different stages in his career. He was reworking a prose narrative to accompany the poems as late as the 1990s. But one particular document in the British Library might date from as early as 1963, and it shows that Hughes had intended to end the book with 'world repair':

\section{Creation \& Invocations of Crow:}

Crow’s birth \& appearing: events \& circumstances.

Legends of the birth of Crow:

Childhood: among animals \& mothers.

Worldly travels \& education of Crow: ordeal, disasters, lovers, initiations.

Crow’s bride: her momentary appearance

Evaporation of Universe: Crow's elemental enemies, non-crow: his defeats.

Crow's journey to Otherworld.

Crow's trial in otherworld: conditions laid down.

\section{$\underline{\text { Crow's Defence of }}$}

Poetry.

Crow’s return: feats, reparations, marriage labours: world repair. 121

\footnotetext{
120 BL Add MS 83684, postcard from TH to Baskin, 14. 08. 1964.

121 BL Add MS 88918/11/1, notes written in a 1963 screenplay by Jon Manchip White.
} 
Even after the evaporation of the Universe - an event that suggests a nuclear holocaust Hughes considered letting Crow's reunification with his bride repair the damaged environment.

The Crow-project engaged with environmental issues from the outset, then. It consisted of both poetry and prose commentaries; Hughes left most of the latter unpublished. There are significant ways in which Crow responds to contemporary developments in ecopoetic theory, but it suggests ways in which ecopoetics need to be expanded to take into account poetry that grapples with depicting a world laid waste. The ecopoetry of Crow dramatises processes, interconnections and relationships (both between organisms and between masculine and feminine). This is tropological ecopoetry. But any poetry that contemplates the end of life on earth, actually contemplates a moment when tropological interconnections break down. Here, Hughes's work becomes most prescient of Anthropocene theories of terminal environmental change. Moreover, Hughes stated that Crow holds dialogues with everything he meets 'rocks and trees and rivers' 122 - because '[e]verything sings its own song about itself' (Sagar 2006 175). This resonates with Knickerbocker's view of the interlocutory function of personification and apostrophe in ecopoetry (2012 6). However, both Crow and these other creatures are envisaged as communicators and makers of meaning: here, Hughes stays true to his folktale sources, but he also anticipates posthuman thinking about other species' possession of culture (Feder 228). Crow writes songs and plays, and even defends poetry in the early draft quoted above; the collection does not aim at ecomimesis, but draws ironic attention to its own acts of literary creation. Compared with Hughes's more experimental poems such as 'Milesian Encounter on the Sligachan', Crow rarely represents the formal experimentation that Tarlo, Gander, Kinsella and Timothy Clark view as important to ecopoetry; although offshoots of the Crow-project that are written in hybrid forms, such as Eat Crow, would qualify. Crow straddles the archetypal world of Jung and Radin's tricksters, and Hughes's own, veiled 'mythic life' (LTH 706), hopping across the species boundary between human and bird: it interrogates our capacity for 'becoming animal' and our 'ethically challenged' interactions with other species (Skinner 2011). Hughes takes the subjectivity of an individual character, and pushes, tests and refashions it. In this respect, Crow resonates with Gander and Kinsella's call for the lyric I to be put under pressure.

There are some contemporary ecopoetic and ecocritical theories that are eminently applicable to Crow, but we need something more in order to account fully for the developments that Hughes's Crow-project creates. The collection might resonate with Gary Snyder's view of the poet as a detritivore recycling 'symbol-detritus' (71), although Snyder does not elaborate this concept as fully as he might. Skinner does mention that some critics view ecopoetry as confronting 'disasters and environmental injustices' (2011), although his work needs to be expanded to account for the precise ways in which poetry accomplishes this. Gifford's idea of the anti-pastoral as 'Unidealised - harsh, unattractive,' grappling with the concept of ecoapocalypse (2012 1961-62), is also useful. Hughes’s farming-poetry certainly complicates the pastoral, but in Crow, he is reacting to other poetic modes as well: hymns, epiphanic naturepoems, the sublimity of the Romantics' nightingales and skylarks, and even some of his own earlier work. Buell's idea of 'toxic discourse' is relevant: this mode of writing becomes more prevalent after Silent Spring (1998 645) and analyses the uncanny idea of 'communities, population groups, and finally the whole earth contaminated by occult toxic networks' (648). However alarming Buell's theory of occult toxicity may be, it is not broad enough to

122 There is also an allusion to Wordsworth’s ‘A Slumber did my Spirit Seal’ in this turn of phrase. 
encompass Hughes's terrifying vision of an entire planet laid waste. Dana Phillips has created 'excremental ecocriticism' in response to global sanitation challenges (2014); this might be adequate for interpreting the collection's filth and excreta, but Phillips's theory is too narrow for the wide-ranging scope of Crow. Ursula Heise's theory of environmental risk (119-59) is one of the best ecocritical responses to environmental hazards, but it does not examine how environmental writing engages with such hazards at a linguistic level. Crow's focus on mutation and hybridity is echoed by Timothy Morton's examination of the uncanny and unsettling aspects of ecological interconnectedness, environmental destruction and the 'personhood' of other species, permitting us to see the environment as uncanny, 'monstrous and mutating, strangely strange' (2010 61). The Trickster, too, is important to Morton: 'When we approach the idea that all sentient beings are equal and free, we discover the Trickster' (82). Bristow's idea that the Anthropocene lyric privileges 'disconnection' and 'breakdown' is a significant one, but Hughes examines the (often literal) fallout of such disconnections. Solnick's examination of Mahon's poetry of 'waste’s materiality (including junk/rubbish, pollution and excess emissions)' (120) provides an important starting point, as do the humanmade phenomena among Morton's 'hyperobjects' that exist on a vast temporal scale, from Styrofoam to nuclear waste (2013 1). But it is clear that to interpret Crow, we need a theory that is capable of encompassing the full sweep of ideas that inform its poetry of devastation. Ecopoetic theories that stress the need for the mind's reunification with nature, or the delicacy of our damaged planet's sound, would fail to account for Hughes's thoroughly indelicate Crow-poems: crass, dissonant, contaminated, their crops full of carrion.

The field of waste studies offers significant new insights for re-interpreting Crow. Susan Signe Morrison's The Literature of Waste: Material Ecopoetics and Ethical Matter argues for the importance of waste as an antidote to nostalgia for pristine environments and a way to appreciate the nonhuman (9). Although occasionally occluded by its bricolage-like leaps between Beowulf and A. R. Ammons, Morrison's work offers important insights into the pervasiveness of waste, and how it differentiates us from other species. Citing Kate Soper, she argues that 'Waste understood as the unused or inutilizable remands of human productive activity and consumption [...] must today count as one of the major markers of the distinction between humanity and the rest of nature. All animals excrete, but only humans create waste' (7). She offers a novel view of intertextuality that is eminently applicable to texts such as Crow and Eliot's The Waste Land: 'Recycled literary waste, as in intertextuality, forms the litter-ature of waste texts' (12). She characterises this literary mode as rich in humour (9), poetic metaphor, 'digressions, leftovers, puns, parody, and intertextuality (12)'. Here, then, is a way to account for Hughes's allusive references to the Eastern European poets and to trickster-tales - but as will be argued shortly, this theory does not fully account for the artful simplicity that Hughes creates in Crow. Her work also offers a fruitful interpretation for Hughes's poetry of survival in Crow. She argues that 'Only by cobbling together the pieces of a life and shards of memory can the bricoleur-poet hope to survive' - an insight inspired by Czeslaw Milosz's remark that poetry consists of 'remnants found in ruins' (196).' Here is a link to Hughes's Eastern European influences. While her celebratory reading of waste in literature has its strengths, it does not account for the far more disturbing aspects of waste that Hughes's collection raises: postbellum waste lands, species extinction, nuclear destruction. Also from the field of critical waste studies, Christopher Schmidt links poetry about waste to commodity capitalism's emphases on 'efficiency and disposability'. In the poetry of Stein, Ashbery, Schuyler and Goldsmith, 'a cultural logic of wasting and waste management is expressed formally as a tension between textual sprawl and stylistic precision, between excess and ascesis' (2). This theory resonates with Hughes's critique of wasteful capitalism in Crow. Unlike Morrison, Schmidt pays close attention to the formal features of 
such 'wasteful' poetry. In his view, poetry that engages with waste is inherently 'excessive' (3), and 'ungainly hybrid forms' such as 'the prose poem, the waste book, the encyclopedic chronicle' (2) proliferate. Hughes's Crow-project certainly contains some of these features, but the following discussion shows that, contra both Morrison and Schmidt, rough-hewn simplicity predominates over excess in this collection. This reading of Crow also complicates Morrison's positive poetics of waste and Schmidt's analysis of consumer capitalism to account for Hughes's deeply unsettling account of nuclear warfare and environmental apocalypse.

There are several dominant ecopoetic modes in Crow: the more prevalent, 'super-simple' and 'super-ugly language' (Faas 208) and a less frequent, but important, 'ethnopoetic' register influenced by Hughes's reading of 'primitive' literature. Occasionally, Crow sings parodic songs and skewed hymns, such as 'Song for a Phallus' and 'Apple Tragedy'; this is the collection's third poetic register. It is the first mode, the slangy language of pollution, mutation and filth, that requires a critical vocabulary adequate to its engagement with waste. Crow describes a new kind of waste land. Not Eliot's Waste Land with its stony rubbish through which branches grow, but a land full of filth, carrion, dropped ice-creams, abandoned utilities, bulletholes and nuclear fallout. A land that had survived not only two World Wars, but which had to endure the ongoing Vietnam War, the threat of the Cold War, and the 'war' against nature. A world where the only fire sermons relate to the global conflagration of nuclear warfare. This is poetry for a world in the process of being laid waste, with personal devastation at its heart. It requires a language that is in pieces, made up of the ugly and dissonant leftovers of more aestheticised poetic modes. Yet if the poems begin in a devastated environment, there is hope: Hughes's Faber collection will begin to advance towards a more balanced picture of nature's regeneration, although this is only partly achieved.

\section{Poetry from the 'centre of cataclysm'}

A key influence on Hughes's poetry of waste came from a source farther east than Britain's postbellum waste lands. When Hughes and Daniel Weissbort founded Modern Poetry in Translation in 1965, the first issue focused largely on Eastern European poets. These writers wrote from the 'centre of cataclysm', as the editors put it (Hughes and Weissbort 1). Their writing in the aftermath of war enabled Hughes to write about disasers such as personal loss, ongoing international warfare, and environmental destruction. These poets' grim vision of survival and their use of natural imagery influenced his poetry in significant and surprising ways. Hughes saw a 'primitive pre-creation atmosphere' in Serbian poet Vasko Popa's work (223), and he might have drawn inspiration from Popa's ‘surrealism of folklore’ (226).

Popa's 'The Quartz Pebble', which acquires eyes and at one stage seems to have turned into a bird (Hughes and Weissbort 9), is echoed in the genesis of Crow from a stone in 'Three Legends': 'Suddenly the stone opened its eyes. | Crow blinked at the world' (CPH 191). Hughes's ecopoetry of postwar waste is prefigured by Czech poet Miroslav Holub's 'The Fly', which appears in The Rattle Bag. When only 'a few arms and legs | Twitched jerkily under the trees', the fly lays her eggs on a dead man's eye, and is then eaten by a swift (Hughes and Weissbort 5). Such poetry would have influenced Crow's detritus-eating, biological optimism, and is echoed in the 'brains in hands' and 'legs in a treetop' of 'Crow's Account of the Battle' ( $\mathrm{CPH} 222$ ). If these poems by Popa and Holub prefigure Hughes's 'super-simple' poetics of waste, an effusive long poem by another Eastern European influence on Hughes informs a more 'excessive' mode, to borrow Schmidt's term (3). Hungarian poet Ferenc Juhász's 'The Boy Changed Into a Stag Cries Out at the Gate of Secrets' supplies some of Hughes's poetic images of environmental devastation in Crow. In 
1964 (LTH 232), Hughes had written an English version of the poem. Among his Eastern European influences, Juhász's poem is particularly significant for Hughes's ecopoetry both in terms of its imagery of struggles between human and animal, and its evocation of hunting and metamorphosis. 'Crow and Mama' might have been influenced by the stag's threat that 'I would burn you like tinder grass, | scorch you to charred clay (Hughes 2006 30): Crow's mother's ear is 'Scorched' by him ( $C P H 219)$. The stag's antlers become 'high-tension cable[s]' and his heartbeat a 'monster-infested sea'; Hughes might remember this when he describes the sea-dwelling Proteus transforming into a powerline ( $C P H$ 252). Juhász's images of industry and pollution take on an especially 'green' tinge when Hughes creates his version of them: 'Each vertebra is a seething capital, and a barge belching black smoke is my spleen' (2006 36). Hughes's image of the stag assailed by 'a hundred bullets' (2006 36) recalls his war-poetry - but it also paves the way for some of his later (contradictory) poems about hunting.

\section{Crow: Poetry in a Land of Waste}

Hughes's Crow-poems and poems with a Crow-ish tenor begin to examine environmental problems with increasing frequency in the early to mid 1960s. One of the first signs that Crow was hatching was a radio play dating from 1964 (1971 21). Hughes published it in partial form in 1965, as a dialogue called $X$. The play appeared in print in 1971, in the limited edition Eat Crow; the extract was later reprinted with the title 'Crow Wakes', which suggests that Hughes thought retrospectively that the sequence began with this piece. The character Morgan is 'Heartless, gutless, with a few rags and string-ends of memory, like a castaway's bundle [...] the heart, the lights, the memory' (9), foreshadowing Hughes's poetics of waste and carrion in the Crow-poems. Indeed, Morgan's gralloched remains recall the 'crow': in Hughes's draft notes to his collection, he defined this as 'the entrails, lungs, heart etc. everything extracted from a beast when it is gutted' (ctd in Solnick 79), the waste, offal and remains. Hughes evokes destruction on a global scale: 'the whole world's exploded in your face and vanished in shrapnel' (15), yet this relates as much to his preoccupation with the First World War (during which his father and uncle survived shrapnel hits) as to his concerns about nuclear warfare. The Goddess-figure who will be so important in the Crow-poems appears as a chorus of weeping women (11) - are they Plath-like plaintiffs? - and a mother called She (an allusion to Rider Haggard's goddess-queen?) Morgan endures a shamanic dismemberment that is related in verse, but while disintegration should bring the remaking of a new self, instead it brings destruction. The play ends with an ominous crow watching his stricken body in a desert. The statement that 'The crow is composed of terrible black voice' reads like an ars poetica for the entire Crow-project; it is this 'terrible black voice' that Hughes will use to evoke environmental destruction, warfare and grief. Hughes has moved beyond his poetry of shamanic dismemberment and rebirth, towards a mode of writing that has no time for neat resolutions; Morgan's trials speak of the raw aftermath of Plath's death. Hughes is also mixing prose, poetry, songs and dialogue in an audacious formal experiment. The allusiveness of this piece resonates with Susan Signe Morrison's arguments for wastepoetry as an act of bricolage (12), while its hybrid form displays a characteristic that Schmidt sees as important to excessive poetry of waste (2). Yet it will be Hughes's Crow-poems that most clearly echo his environmental preoccupations. 
Hughes made progress with the verse in the Crow sequence in 1965 before he went to Ireland, worked at it at Doonreagan in 1966 (Bate 2015 246), made further headway after he completed the 'Skylarks' lyrics published in 1966 (289), and added more poems during a holiday in Germany in 1968 (270). By 1965, his Crow-poetry was beginning to engage explicitly with environmental affairs. In 'Carol' (1965), which anticipates 'Snake Hymn', an atom tells Mary that God is weary of mankind, who has 'bulldozed all Creation'. Creation reacts by threatening to unleash nuclear weapons: 'So we stand arrayed to end him' (109). This is a Crow-ish parable of nuclear destruction, published in the aftermath of the Cuban Missile Crisis. Here are the beginnings of Hughes's Crow-poetry of destruction, devastation and waste. Its rhythm borrowed from 'Once in Royal David's City' resonates with Morrison's emphasis on parody and humour in the poetry of waste (12), but its irony is darker than the scatological humour that her account analyses (153). We see further intimations of this theme his 1966 poem 'Birdsong', an ancestor of 'The Lovepet'. Love starts out as a wren in an orchard. It becomes the 'fine falcon' (of Falcon Yard), turns into a leopard (is this the beast of Plath's 'The Panther?) and it ends up as a crow dancing 'Upon a desolation' (CPH 113). At this stage, the desolation is Hughes's grief for Plath, and he is writing a parable of his own 'mythic life' (LTH 706). But as the Crow-project progresses, Hughes will begin to link his grief for a wronged woman with Crow's attempts to placate the goddess of an earth laid waste.

From the folkloric surrealism of the Crow-poems 'Three Legends' (1967), Hughes moves towards a global evocation of environmental issues in his related poem 'T. V. On', published later that year. This is an important early ecopoem, and it draws images from televised images of the Vietnam War. It is surprising that earlier scholars of Hughes have paid so little attention to the way this major international conflict shapes his poetry. The poem also foreshadows Hughes's Crow-poems about nuclear conflagration, although he did not include it in Crow. The poem recalls the increased use of modern media to report global disasters, and is linked to Hughes's critique of both communication technologies and the weapons of destruction whose effects they show:

I see the Arctic circle collapse

With its peculiar people, quivering embers,

In a conflagration and after-glow

Of commentary

The amazon capitulates into the vortex

Of a chimney gullet.

Africa stripped of all its bests and peoples

Trembles in the incinerating mouth. (192-3).

But the poem's speaker himself feels complicit in this wholesale technological slaughter, feeding the blaze 'without moving' (192). For a moment, he wishes his dreams to 'unearth 
Eden! | And repopulate it!', but this is impossible as 'their faces are burned off' (194). This poem confronts the reader with genocide and ecocide on a global scale. Gone are the fantasies of 'world-repair' and a return to a pristine Eden in illo tempore. Here is Hughes as ecopoetic prophet of doom, foreseeing a world laid waste, with only 'charry shadows, fumes and evanescence' left (193). This is hardly a subtle poem, but its dark subject matter is timely. The year before the poem appeared in print, the USA had seen the first demonstrations against the use of napalm in Vietnam. Hughes pictures countries writhing in flame as if ‘douched with petroleum' (193), an ingredient of napalm. Yet the poem’s global scope also suggests the threat of nuclear weapons. It was published in the year of the 1967 Outer Space Treaty, signed by London, Moscow and Washington, which banned the placing of weapons of mass destruction in orbit or in outer space. Hughes's focus on an earth reduced to 'an ashen simulacrum, a fossil of char' (194) suggests that he did not find such measures very reassuring. The ashes and cinders here suggest a reappraisal of Morrison and Schmidt's models; Hughes's poetry of waste is significantly more unsettling here.

1967 saw Hughes publishing a series of Crow-poems that are distinctive for their focus on modern, technologised warfare: 'Crow's Account of the Battle' and 'A Disaster'. The year these poems were published saw Operation Junction City in northern Vietnam, the largest US air offensive since the Second World War. 'A Disaster' equates technology with warfare and environmental destruction. The blunt, ironic reportage of this poem could not contrast more markedly with the keenly felt, high-flown apostrophe of 'Skylarks':

There came news of a word.

Crow saw it killing men. He ate well.

He saw it bulldozing

Whole cities to rubble. Again he ate well.

He saw its excreta poisoning seas (226).

Short sentences, stripped-down syntax, repetition, a vocabulary of destruction and ordure, hints of Holub: by 1967, we clearly hear Hughes's super-simple, super-ugly Crow-voice. It is a voice preoccupied with the leftovers: rubble, human waste and bones; yet tersely ironic 'ascesis' predominates over excess, complicating Schmidt's model. The destructive word is both the Word of Christianity, which Hughes will mock in Crow's interactions with God, and the word that designs the blueprints for destructive technology. Around 1970, Hughes would become aware of excreta in sewage, poisoning the Torridge Estuary; but this image is also likely to draw on his knowledge of the harm done by nuclear waste.

In 1969, after the deaths of Assia and Shura, Hughes published a poem that lets Crow perch in a land strewn with rubbish. In 'Crow Alights', Hughes evokes an anti-pastoral scene where the 'Dark-spined' sea that holds 'the whole earth in its coils' and stars are 'the virus of God'. Even Crow 'shivered with the horror of Creation': he is aware of its uncanniness, a moment of unsettling interconnection that suggests the more challenging aspects of Morton's theory of ecological linkages. But more horrific is what humankind has done to the environment: 
In the hallucination of the horror

He saw this shoe, with no sole, rain-sodden,

Lying on a moor.

And there was this garbage can, bottom rusted away,

A playing place for the wind, in a waste of puddles (220).

One need not hallucinate to see a moor covered in discarded shoes and rusty garbage cans: the scene Crow sees could be any heath in Britain. Sublime nature-poetry is impossible in a rubbish-strewn 'waste of puddles': gone are Hughes's soaring skylarks and invincible hawks. Instead, this catalogue of discarded objects suggests a critique of consumer capitalism akin to that which Schmidt finds in Stein, Ashbery, Schuyler and Goldsmith. Hughes has also further refined his Crow-voice: the colloquial, casual style of 'this shoe', 'this garbage can' could be described as anti-poetic ecopoetry, an ugly, offhand style borrowed from the Eastern European poets to create a 'super-simple' poetry of waste.

By 1970, Hughes was publishing his Crow-project in series and sequences. The first of these sequences, 'Four Crow Poems', sets the scene in a wrecked environment where the human race has been annihilated. 'That Moment' begins this series of poems with the last human's suicide and ends with Crow searching for something to eat. We are in an 'abandoned world', among 'abandoned utilities' ( $C P H$ 209). Here, then, is an image that resonates with Morrison's idea of waste-literature as characterised by leftovers and bricolage (196). This poem suggests that even though human beings have been annihilated, nonhuman creatures will survive - along with human rubbish. By 'King of Carrion', the detritus of the world has become the remains of formerly living things. Crow becomes king of 'skulls', of the 'last splinters' of the body, the 'black of the last blood', reigning over 'The empty world' (209). This is a poem of the bones and offal that remain, the bleak life of the last scavenger to survive.

Hughes continues his project to demolish sublime nature-poetry as the 'Four Crow Poems' sequence progresses. 'Crow and the Birds' even evokes Hughes's own move from naturepoetry to ecopoetry. The first few lines have a highly-wrought, artificial tone:

When the eagle soared clear through a dawn distilling of emerald

When the curlew trawled in seadusk through a chime of wineglasses

When the swallow swooped through a woman's song in a cavern

These three lines encapsulate much that ecopoetry wishes to define itself against: they are heavily aestheticised, pastoral, 123 and describe animals in terms of human artefacts. In fact, they are somewhat reminiscent of the language of Hughes's own accomplished, but not fully

123 For more information on the difference between pastoral and environmental poetry, and their function in Hughes’s work, see Gifford 1994 129-41. 
mature, poetry from the Cambridge typescript (see Chapter III). This parodic, effusive tone is chimes with Susan Signe Morrison's view of the parodic allusiveness of waste poetry, and with Schmid's evocation of its excesses. The mid-sections of the poem become more unsettling. The heron labours against a 'Bessemer upglare', struggling against heat produced by the creation of steel, used for industry or war-machines. A bluetit escapes lace panties, a woodpecker evades a rotovator, a peewit flees a Laundromat: these birds struggle to evade omnipresent artificial obstacles. At the end of the poem, Crow takes up his usual role as scavenger: we see him 'spraddled head-down in the beach-garbage, guzzling a dropped icecream' (CPH 210). We are back in an environment laid waste, with Crow as opportunistic scavenger.

We have seen Hughes create a 'waste of puddles', a postbellum hinterland and a nuclear wilderness. Yet it is 'Crow's Last Stand' that most persuasively argues for Crow to be read as the inhabitant of mid-twentieth century waste land. Hughes opens the poem with the ending of Eliot's 'The Fire Sermon', in a disjointed form:

Burning

burning

burning

The furnace in which Crow is burning is the sun, but the last line, 'Crow's eye-pupil, in the tower of its scorched fort' (210) suggests that Crow is also the victim of incendiary warfare. Hughes's poem is applicable to nuclear warfare, but it is more suggestive of the ongoing conflict in Vietnam. This is a version of waste-poetry that is both 'super-simple' and deeply unsettling.

By the time of 'A Few Crows', published in October 1970, Hughes clustered together several poems that deal explicitly with the localised threat of pollution and the global threat of nuclear weapons. They are distinctive for their poetic form, which is taken up in many of the super-simple, super-ugly poems of the published collection. A dense introductory passage of verse is followed by isolated lines that create a poetry of fragments and remains. The prolix beginning of 'A Grin', for example, echoes Schmidt's analysis of waste-chronicles (2), although the shrinking lines of the following sections are closer to his idea of a waste-poetry of 'ascesis'. While Morrison's work accounts for such poetry of allusive leftovers, the fragmented formal features of these poems show that it needs to be expanded to account for the way form echoes sense. When Crow is born in 'A Kill', he smashes 'into the rubbish of the ground'; 'all the rubbish of the earth' evaporates in 'Notes for a Little Play' (212). Two creatures survive nuclear event in the second poem: they are 'Mutations - at home in the nuclear glare. | Horrors - hairy and slobbery, glossy and raw’ (CPH 212). Hughes confirms the link to nuclear technology in the interview with Faas (1980 207). In Crow's play, the mutants 'fasten together': this is their 'marriage' ( $C P H 212)$. Crow 'produces plays and stories', according to Sagar, but they always describe the same two characters, a man and a woman (2000 177); here is what the man and woman become. Hughes's poem was timely. The Nuclear Non-Proliferation Treaty had been opened for signature in 1968, and came into 
force the year this poem was published - yet at the present date, it has not achieved its aim of disarmament. But if the poem contains grotesque images of a nuclear waste land, it also dramatises survival under the most extreme circumstances.

Dark humour, tricksterish pranks, a moribund God and a proteiform female presence unite the Crow-project. But Hughes's most radical departure from both his own earlier poetry and the poetry of his British influences remains the ragged form and super-ugly language of his poetry of waste. The remains of life on earth, whether they are ashes, carrion, pollution or a nuclear wilderness, haunt the rest of the sequence: Crow roasts the earth 'to a clinker' (224), loses his faith when he sees 'strung-up mummifying crows' (227), and watches God's creation become 'a slime and ochre pond' in 'a town dump' (271). When Crow hatches and sits 'Trembling featherless elbows in the nest's filth' (218), we are reminded of the way our species has fouled its own nest. Parts of Hughes's collection certainly conform to Susan Signe Morrison's ideas of waste-literature as allusive bricolage, and Schmidt's waste-poetry that alternates between ascesis and excess; yet Hughes's Crow expands their paradigms via its disturbing evocation of an entire planet laid waste, and with its tendency to privilege blunt simplicity over excess. Important writers after Hughes have articulated their concerns about pollution by creating ecopoetry of waste. In the USA, one of the best-known examples is A. R. Ammons' collection Garbage (1993). In Britain, the poetic generation following Hughes's has created important engagements with filth, pollution and charred remains: they include Andy Brown, who has moved from ecopoetry to 'faecopoetry' between Exurbia (2014) and Watersong (2015);124 David Harsent's vatic Fire Songs (2014); and David Morley, whose 'Proserpina: View of a Landfill' echoes the colloquial voice of Crow and demolishes clichés about conservation. Yet poems about destruction, rubbish and waste are only predominant in Hughes's earlier Crow-sequences, and in the first part of the Faber collection. In later poems, growth, life and the character of the earth-goddess become increasingly important. From a poetics of waste, devastation and detritus, Hughes's Crow-project gradually begins to develop a closer focus not only on Crow's survival, but the potential survival of the wider environment.

\section{Crow and Mama: Nature and Creation}

Hughes's Crow: From the Life and Songs of the Crow, published by Faber and Faber in December 1970, moves broadly from Crow's genesis to his fall from an Edenic state, and his attempts to return to that state. As the collection progresses, the increasing number of poems about nature's survival, and clusters of 'primitive' songs, balance the earlier focus on destruction and detritus with a developing sense of nature's value and agency. Crow begins by damaging Mother Nature, experiences her elusiveness, suffers her revenge, and finally reaches a sense of communion with her, albeit tentative, partial and fleeting. 'Crow and Mama' is the most ecologically engaged poem of Crow's early life. Mama is especially significant for Hughes's environmental thinking: Sagar's summary of the plot states that Crow undertakes a quest for his Creator, whom he expects to be male. When he encounters

124 Andy Brown joked that he had become a 'faecopoet' at a reading with Kelvin Corcoran at The Bluecoat, Liverpool, $26^{\text {th }}$ June 2015. 
his creator, '[i]t's female, but not beautiful or obviously female'; he misidentifies her and even tries to destroy her (2000 176). The poem begins with Hughes's poetics of devastation: Crow's first cries scorch Mama's ear 'to a stump', his laughter makes her brow, breasts and palms bleed in a Christlike passion, his steps scar her face forever. Crow thinks he can see 'Creation' from his rocket ( $C P H$ 219), but he ends up crash landing on the moon and crawling out 'Under his mother's buttocks'. The poem is influenced by the first moon landings in 1969, but Hughes’s notion of Mama as an inescapable, all-encompassing naturegoddess also creates a developing sense of her omnipresence and sacredness.

Soon after Crow was published, the idea of the earth as a goddess-like life-form would gain currency among environmentalists of the day. Between 1969 and 1979, James Lovelock was publishing papers and books that formulated his Gaia hypothesis125 - but the idea of the earth as a single, self-regulating organism was not new, and it was an idea that Hughes already knew well from his interest in mythology. By about a third of the way through the collection, Crow is beginning to acquire a more reverent attitude towards the earth-goddess, although he still struggles to put his ideas into words. 'Crow Tries the Media' sees Crow attempt to hymn her, but the results resemble a 'poisoned estuary' and London 'Raising a filthy haze' (232). He cannot even sing to her without damaging the environment, and the poem ends with his revelation of her dimming. By the middle of the collection, however, the tone of Hughes's Crow-croaks has changed. 'Crow's Undersong' uses chantlike, reverential repetition and aestheticised images of natural beauty to create a successful song. This beautiful poem, which owes a debt to both 'primitive' song and anticipates the Tamil-style devotional chants in Gaudete, is a summoning-charm that attempts to call her - and it almost succeeds. Against his poetry of filth, waste and carrion, Hughes creates a poetry of natural abundance: 'She brings petals in their nectar fruits in their plush | She brings a cloak of feathers an animal rainbow'. The final line, in parentheses, gives the poem pause and reflects on humankind's connection to nature: were it not for the Goddess, '(There would have been no city)' (CPH 237). It is thanks to her that life exists at all. This hymn is not without its problems. Imagining the earth as feminine risks stereotyping women as mute, earthbound and fecund, while at the same time anthropomorphising our planet. And yet, the result is one of the most hopeful poems in Crow. The awareness that our environment allows us to exist in the first place confounds anthropocentric thought and shows Hughes's ecopoetry developing towards a holistic, Lovelockian vision of the ecosystem.

Yet two short poems see nature turning the tables on its technocratic destroyer. 'Revenge Fable' describes a person trying to get rid of his mother 'As if he were her topmost twig' ( $C P H$ 244). He attacks her with environmentally damaging 'disgusts, bulldozers and detergents'; when she dies, his head falls off 'like a leaf' (245). But by 'Glimpse', the naturedeity succeeds in shutting Crow up when he attempts to hymn the leaves, and the leaves are

125 The first of these was his paper 'A physical basis for life detection experiments'. Nature 207.7 (1965): 568570, followed by articles in 1972 and 1974. His popular book about the subject, Gaia: A new look at life on Earth, appeared in 1979. 
replaced by 'the god's head instantly substituted' (256). Although usually feminine, nature is occasionally androgynous, and Crow progresses from exploiting it to adoring it in silent reverence. There certainly are violent struggles between masculine and feminine in Crow, but while Hughes has been criticised by Jacqueline Rose for envisaging such struggles, this particular poem goes beyond his tendency to imagine nature as a goddess by creating a Frazerian vegetation-god. Hughes draws the Faber collection to a close with a nuanced view of nature's agency. Yet the Crow-poems that he published later, prevent the Crow-project from ending with any kind of glib resolution.

\section{Crow, The Animals and 'Primitive' Song}

As Crow progresses towards the hero's meeting with his bride, the tenor of the collection becomes more inflected by the reverential hymns and totemic chants of preliterate societies. Faas has analysed Hughes's work in relation to two of Bowra's 'primitive' songs (1980 102104), and his analysis of 'Littleblood' in relation to a Gaelic poem (103) is perceptive - but Crow contains even more elements drawn from preliterate culture than Faas realises. Everything sings its own song about itself, and Hughes gives voice to the robin in 'Robin Song'. The poem begins in primitive mode with the robin as hunted king of frost, but ends by holding a mirror up to humankind's arrogance:

I am the maker

Of the world

That rolls to crush

And silence my knowledge (235).

Hughes takes the 'primitive' influences that he read and reread closely in the early 1960s, and adapts them to create a fable that acknowledges that one species can never hope to remain dominant. Hughes's poetry in this vein draws very closely on his reading: 'Crow's Elephant Totem Song' echoes the Gabon elephant totem-songs collected by Bowra (51-52; 123-27). It is the voice of 'primitive' song, in the form of Crow's Inuit shaman guide, that ends the 1970 Faber and Faber edition of Crow, with the invocatory poem 'Littleblood'. The poem charms a disembodied bird-spirit to 'Sit on my finger, sing in my ear, O littleblood' (258). The speaker calls up this creature to sing songs that will inspire poetry; it is significant that the use of the lyric I resembles Hughes's own verse of poetic invocation, such as 'The Thought-Fox'. This version of the collection ends on a note of survival, creaturely creation, and the poet's communion with nature.

Hughes would reprise his Crow-project in Crow Wakes (1971), a limited edition pamphlet. Again, we hear the voice of Crow's Inuit shaman guide in 'Amulet', 'Song against the White Owl', and 'Snow Song' - but with the significant difference that the shaman's voice sounds significantly more 'green' here. 'Amulet' is a poem of ecological integration, and one of Hughes's most haunting uses of the chants of oral literature. It is also a primordial revision of 
Yehuda Amichai's126 'Poem Without an End', in which a brand-new museum, an old synagogue, the poet and his heart are found concealed within each other. A wolf-fang amulet evokes an interconnected boreal ecosystem: the poem calls up wolf, mountain, forest, horizon, deer, wind, North star and finally returns to the wolf. A repeating pattern, 'Inside the wolf's fang, the mountain of heather. I Inside the mountain of heather, the wolf's fur' ( $\mathrm{CPH}$ 260), creates a hypnotic rhythm that echoes through the poem. Yet the title suggests that the amulet is not only a talisman for its wearer. It is a protective charm for an entire bioregion.

But it is 'Snow Song' where Hughes's primitivist poetry is at its most ecologically aware. The poem voices similar conservationist concerns to 'The Last Migration', but it is executed with greater skill. There are suggestive parallels with hunting-songs anthologised in Primitive Song, where an Inuit singer boasts that he has harpooned a seal, shot a caribou, caught a fish and towed a bearded seal ashore without even having harpooned it (Bowra 123-24). Hughes's poem is a critique of overhunting. Firstman is permitted to kill an elk, a bear and a salmon: the Mother of All Things washes his 'ghost' and brings him a new knife. But Red Fox kills game wantonly and refuses to let the mother-goddess give birth to animals from the 'bloodsea' ( $C P H$ 266) and sate man's hunger for game. Hughes draws on the myth of the Inuit goddess of sea animals, Sedna, which he mentions in 'The Snake in the Oak' (WP 429). The Fox takes the place of Crow as trickster, and the poem ends with his well-fed grin ( $\mathrm{CPH}$ 267). It is possible that Hughes wanted a creature that is more hunter than scavenger to lead the rapacious killing - but could the Fox also represent Hughes's conflicting feelings about his boyhood indiscriminate hunting? His later attempts to defend hunting would see him using (problematic) conservationist arguments, but they would never entirely escape the guilt and concern that we hear in this poem.

Three main movements can be seen in the 'green' ideas behind Hughes's Crow-project. The first is a critique of technologized warfare and widespread pollution, which gives rise to Hughes's distinctive, super-ugly poetry of waste. The second is Crow's gradual, but fragmentary, move towards a more reverential attitude to the nature-deity, who is usually represented as a goddess. The third is a primitive strand drawn from his earlier reading, but given a more ecocentric tenor in songs of nature-worship and criticisms of overhunting. If Hughes had published more of his Crow-poems and the accompanying prose, the various stages of Crow's development might have been clearer; the 'green' themes in the poems are disjointed compared with the thematic unity of River. Crow was left unfinished because of traumatic events in Hughes's life. Yet the lack of a conclusive ending is also highly appropriate to the Anthropocene, when the hope of 'world repair' is thrown into doubt by the massive extent to which human beings have altered planetary processes.

\section{Crow in Prose}

If Wodwo saw Hughes writing prose that foreshadows his later preoccupation with environmental issues, he also attempted to create many prose narratives that would accompany Crow. Eat Crow appears to have been the only one that he published. Crow does

126 Amichai's work had been showcased in Modern Poetry in Translation. 
not have his adventures in a neatly ordered sequence in the published collection and the poem-sequences that appeared before and after. Yet Hughes often contextualised his Crowpoems within a narrative during readings and interviews. Sagar has 'amalgamated segments' of these interviews and readings, along with broadcasts and letters, to reconstruct the first part of the tale (2006 172-80), but earlier scholarship has rarely acknowledged just how much time Hughes devoted to the story of Crow, which he saw as reflecting his own 'mythic life' (LTH 706). A notable Crow-poem, 'Bride and Groom Lie Hidden for Three Days', appeared in Cave Birds, but many Crow-poems remained unpublished (Sagar 2006 172). As late as 1996, when he sold part of his Crow archive,127 Hughes was writing and redrafting a prose narrative to accompany the poems, which he might have been reworking until the very end of his career (LTH 706). The archives give us new perspectives on Hughes’s longstanding preoccupation with anthropocentric religion, his continuing horror at environmental destruction, his writing about waste lands, his interest in beast-fables, mutants and metamorphosis, and his attempts to reunite Crow with a wronged woman who represents the powerful nature-goddess and, in no small part, Plath. Many of these notes are undated, and the process of writing them was attenuated; parts of them are of course informed by later developments in Hughes's writing, but they have their origins in the Crow-project of the 1960s and early 1970s. The following summary contextualises some of the poems within the prose narrative, although this account is far from complete or exhaustive:

After having created the world, God encounters a nightmarish creature that mocks his creation, particularly God's masterpiece, Man. Their argument is interrupted by a message that Man is at heaven's gate, asking God to take life back (Sagar, 'amalgamated' account, 2006 172-73). (This is likely to correspond to the half-dead figure at heaven's gate in 'Crow's Song about God'.) God challenges the nightmare to create something better, and it creates Crow. Crow grows up in Eden among 'animals' and 'mothers',128 where God tests him with Genesis stories, and he meddles in creation. One of the outcomes of this is 'A Childish Prank'. God forgives him and gives him a second chance, and the result is 'Crow's First Lesson'.129 The facts that Crow learns about creation are detailed in such poems as 'Crow Alights' and 'The Black Beast'.130 Everything sings its own song about itself, and these songs include 'Tiger-Psalm' and 'Robin Song'.131 Crow is tempted by various female figures, commits murder, is put on trial and flung out of Eden.132 He journeys through a desert with

127 British Library, Integrated Archives and Manuscripts System catalogue 'Add MS 88918: Edward James Hughes Papers 18 Dec 1890-20 Mar [2005]' 60.

128 BL Add MS 88918/11/1, notes written in a 1963 screenplay by Jon Manchip White, 93 verso.

129 BL Add MS 88918/1/34, red spiral-bound notebook, 5 recto. All page numbering of Crow papers is mine unless otherwise specified.

130 Red spiral-bound notebook, 5 recto.

131 Red spiral-bound notebook, 11 recto.

132 BL Add MS 88918/1/30, cardboard mind map beginning 'HEAVEN' 
seven valleys and witnesses the repeated burning and resurrection of a gibbeted man, 133 while his companion, the Fool, sings Hughes's early poem 'Bawdry Embraced', along with versions of poems that resemble 'Apple Tragedy', 'Song for a Phallus' and 'Snake Hymn'.134 Crow and the Fool arrive at a valley full of rusting metal and poisoned rivers, where he watches the Great Mother give birth to monstrous machines containing dead infants.135 When Crow gets stuck in a rocky crevice, he is saved by a she-wolf, 136 and encounters the ghost of the Eskimo shaman who guides him and gives him powerful songs such as 'Littleblood' and 'How Water Began to Play' (Sagar, 'amalgamated' account, 2006 178). In a hellish city full of dogheaded people, Crow finds the dismembered but living body parts of a woman, 137 whom he restores to life - at the price of having his own flesh torn off. The woman reassembles his bones, and then vanishes.138 He comes to a river that he must cross, but an ogress insists that he carries her over on his shoulders. Seven times, her weight increases until he is about to submerge, and she asks him a question relating to love. The first few questions demand a pessimistic answer, such as 'Lovesong' and 'The Lovepet', but the answers become progressively more optimistic until his response is 'Bride and Groom Lie Hidden for Three Days.' 139 (Hughes echoes this motif when he wrote that he 'waded the river's freeze' in Birthday Letters ( $\mathrm{CPH} 1159$ ).) When they eventually reach the opposite bank, the ogress turns into a lovely young woman who runs off through the oakwoods, with Crow in pursuit. In one version of the tale, she transforms into a succession of chimeras, and Crow has to tell her tales such as 'A Bedtime Story' to restore her to humanity. When he runs out of tales, she disappears into the forest in the form of a giant grey rat with a woman's head. Crow searches for her and finds a crumbling statue of a giant woman, which contains a rat's nest. In the nest is a tiny girl, who grows until she fills the universe, then vanishes - only to reappear in the nest. The next time she grows, Crow seizes her when she seems to be about the right size. At this point, he becomes fully human, with a just few black feathers left in his hair.140 Hughes intended the narrative to end with an account of Crow's marriage and wedding-songs in the Mountains of Vision.141 Hughes's early plan for the sequence mentions the 'world-repair' 142 that accompanies Crow's marriage: at this early stage, the sequence was to end with

133 The motif of the burned man seems to have something in common with Hughes's notes on a Hercules-like figure who was 'Horribly executed at midsummer' on a 'T-cross' (FTNB 23).

134 BL Add MS 88918/1/23, blue loose sheet 1 and pink sheets 1-6.

135 BL Add MS 88918/1/23, white sheet labelled 'Act III 9 Valleys of sorrow. 1 The childbed.'

136 BL Add MS 88918/1/30, pages numbered 48-50 by archivist.

137 BL Add MS 88918/1/30, cardboard mind map beginning 'HEAVEN'

138 BL Add MS 88918/1/23, sheaf of loose sheets of white paper, just smaller than A4, 1-4.

139 Red spiral-bound notebook, 19 recto.

140 BL Add MS 88918/1/23, sheaf of loose sheets of white paper, just smaller than A4, 1-10.

141 BL Add MS 88918/1/23, sheet of torn card continuing mind map, beginning '(6) The City.'

1421963 screenplay, 93 verso. 
environmental (and emotional) reparation. Many of the feminine characters in the notes about Crow look alike.143 They are avatars of the nature-goddess who is so important in Hughes's work, and one also wonders if her face would resemble Plath's. Crow is a way for Hughes to articulate the guilt he felt in the wake of Plath's death, and its more optimistic moments of communion with the nature-goddess are also veiled addresses to her. Issues of gender, the environment and modern technology are cardinal preoccupations throughout the different stages of the project.

Hughes left off the poetry sequence because of the deaths of Assia and Shura, 'when Crow was just beginning the upward movement of the final third' (Sagar 2006 171). He published few of the Crow-poems that he wrote after their deaths. Hughes's early idea for a narrative ending in 'world repair' suggests a mythologised shallow environmentalism, where the earth can recover even from the most terrible of disasters if the anthropomorphic hero behaves correctly towards his nature-goddess bride. Yet the progression from the earth-mother as a damaged victim, to an elusive goddess, and finally to a character capable of exacting revenge, suggests that Hughes had developed a more nuanced view of nature's agency and its capacity to heal itself. Hughes evidently found that Crow was misunderstood by early readers, for he published a reply to his critics that stated that it should not be read as black comedy, but rather as a series of 'Trickster Tales of early and primitive literatures' (WP 239). He argues for the 'biological optimism' of trickster stories, which are committed to 'salvaging life against the odds' (239-40). Even if Crow lived in a world of 'biological optimism', his creator's views about the environment were considerably more intricate, occasionally pessimistic, and sometimes contradictory. Essays such as this, combined with the vast corpus of modern folk-tales that Hughes created as a back story to Crow, prove that he was developing his environmentally engaged prose. Even if his stories about Crow never fully hatched out, he would soon prove himself to be an able writer and editor of environmental nonfiction.

\section{Your Environment}

As we have seen, Hughes's poetry of the mid-1960s demonstrates his engagement with the environmental cost of war, technology, rubbish, carrion, mutants, and the complexities of our treatment of other animals. The poetry of waste in Crow resonated with the environmentalist preoccupations of its age, although its grotesque language and images of destruction were at odds with the peaceful activism of the year of its publication. 1970 was the culmination of the 'environmental revolution', for McCormick (1995 79): the first Earth Day was then the largest environmental demonstration in history (55). Activists spent the first day of spring campaigning for environmental reform. That year was also the first World Conservation Year.

Hughes was also becoming increasingly concerned about environmental issues close to his North Tawton home. He had long enjoyed taking guests and his children to the Torridge estuary at Bideford, Devon. Nicholas especially enjoyed developing his childhood interest in

143 See for example BL Add MS 88918/1/29, loose sheet of white paper 11 recto. 
wildlife at the shoreline - until about 1970, when Aurelia Plath, Hughes's mother in law, pointed out that the estuary was polluted, and no place for children.144 Water pollution would become a major concern for Hughes in the 1980s and 90s (see Chapter VIII), and his activism during the latter half of the 1980s focused on cleaning up the River Torridge. Hughes also informed himself extensively about contemporary developments in environmental science and philosophy. To gain an idea of how Hughes did this, it is necessary to turn to his coediting of Your Environment magazine, in which he published his review of Max Nicholson's The Environmental Revolution: A Guide for the New Masters of the World (1970).

In the winter of 1969, the first issue of Your Environment magazine was published by Hughes and his friends Daniel Weissbort and David Ross - the founders of the famous St Botolph's Review. The publication boasted that it was 'Britain's first environmental magazine'.145 Walter Patterson would later join them on the editorial board. Hughes is listed as an 'advisory' or 'contributing' editor after Issue I, and while his review of Max Nicholson's book The Environmental Revolution was his most substantial contribution to the magazine, his reading of Your Environment broadened and deepened his already extensive knowledge of environmental issues. The development of the environmental movement in Europe meant that the time for an environmental magazine was ripe: Your Environment reported that 1970 was European Conservation Year, with World Conservation Year following in 1972 (Boote 5). Contributors to Your Environment brought formidable scientific expertise; they included the industrial chemist Dr. David Jones, Sir Julian Huxley of the International Union for the Conservation of Nature and Natural Resources, and Dr. F. J. Simmonds of the Commonwealth Institute of Biological Control. Reading their articles helped Hughes to strengthen his naturalist's understanding of the living world with cutting-edge conservation science; he would continue informing himself about environmental science for the rest of his life.

Among the articles about oil spills and the environmental impact of cars, are pieces that resonate strikingly with Hughes's own environmental concerns; they helped to shape his later environmental engagement and might suggest his editorial preferences. 'The River Cleaners' lists contaminants from detergents to abattoir effluent that entered the hard-worked Calder (Whale 22-24). After reading Silent Spring, Hughes would have been concerned by recent findings about pesticides, including J. J. Hickey's research on chemicals that thinned birds' eggshells (Cramp 26-27). A harrowing article about a child who died from exposure to sewage pollution on Devon's beaches resonates with Hughes's campaigns of the 1980s to protect the Torridge estuary (Wakefield 29). Reading about deforestation and the cutting down of hedgerows in the Summer 1970 edition (Fairhall 74-76) would have provided added impetus for Hughes's afforestation campaign of 1972. David Jones's article on the hazards of enzyme detergents to both trout and human beings (1970 55-59) added to Hughes's knowledge of why fish populations in West Country rivers were declining, and contributed evidence to his later struggles to protect polluted watercourses.

144 BL Add MS 88918/121/1, ‘INTRODUCTION’ 1

145 Your Environment 4.2 (Summer 1973): front matter. 
Hughes had long been concerned about nuclear issues, and Your Environment disseminated further information about them. Patterson reported on the dangers of nuclear waste in the Summer 1970 issue, mentioning the Lowestoft Reports on radioactivity in the sea, and nuclear waste dumps in the North East Atlantic (99-104). Unfortunately, it was not possible to publish the information that Hughes had found out in The Nation, on nuclear waste dumps in the Irish Sea and off Cape Cod, because of the Official Secrets Act ('If' 34). The Spring 1972 edition contained a review of a publication proposing that climate change was anthropogenic (Patterson 42-3); climate change would become a major concern for Hughes in the 1980s and 1990s. An article about an issue very close to Hughes's heart, the decline in Atlantic salmon populations, was published in the last issue. The article cited the aptly-named Anthony Netboy's recent research on the decline in Atlantic salmon populations (Wallis 10506), although hatcheries gave reason for some hope (108). This article resonates with the hatchery-poems of River, and with Hughes's major campaign against salmon netting in the 1990s.

Yet Hughes lags incongruously behind current environmental thinking in one critical respect: the trade in endangered species. 1972 saw an import ban on tiger, snow leopard and clouded leopard skins (King 130), while Friends of the Earth were lobbying for stricter controls and a British Endangered Species Act (132). The first eight animals on the Red Data Book of endangered species were tigers (120). Hughes might have realised the full environmental implications of receiving a tiger's claw and a leopardskin hat and gloves from his brother in 1968 (Gerald Hughes 169); but by 1975, he certainly understood that asking for a tiger's skin and skull might contribute to its extinction.146 He joked to Gerald that tiger skulls were ‘desirable objects, in my tribe’ (LTH 361): his shamanic acquisition of animal body parts longs anachronistically for a time when these creatures were plentiful enough to be hunted without restrictions. When Hughes tries to play the twentieth-century shaman, he sometimes writes as though he has never been (entirely) modern.

Hughes encountered The Environmental Revolution early in 1970. That April, Hughes thanked Nicholson for his book and articles, and wrote that his review of the book would attempt to connect with the 'political force' of the environmental movement.147 Hughes also told Nicholson that he and his friends were setting up Your Environment.148 Hughes's activities show that he kept abreast of current environmental thought, and yet we cannot assume that he agreed with everything he read. The Environmental Revolution has its flaws: the subtitle's discourse of mastery is troubling, the strident revolutionary rhetoric of the introduction is equally unsettling, and its proposed reconnection with the 'wilderness values' that 'men and boys' have long espoused (Nicholson 330) would seem repugnantly sexist to modern readers. Hughes’s review of the book does not promote such troubling ideologies.

\footnotetext{
146 Hughes’s tiger skull was from an animal shot by Lord Curzon in 1905, and so his acquisition of it did not encourage the demand for new tiger products. The leopardskin items are more problematic.

147 Emory MARBL coll. 644 box 53 folder 2, TH to Max Nicholson, 23. 04.19701

148 TH to Max Nicholson, 23. 04. 19702
} 
Instead, he points out that The Environmental Revolution is a shocking book for many members of the public, because '[w]e have a biologically inbuilt amnesia against the fears of extinction', and because conservationists have not done enough to publicise their fears. His review contains the following striking statement: 'The subtly apotheosized misogyny of Reformed Christianity is proportionate to the fanatic rejection of Nature, and the result has been to exile man from Mother Nature - from both inner and outer nature. The story of the mind exiled from Nature is the story of Western Man' (WP 129). The story of man's exile from nature is at the heart of so much of Hughes's poetry. Here, Hughes echoes Nicholson's idea that one might find a sense of the spiritual in the environment, in a secular age (Nicholson 17). Here, too, we glimpse Hughes's critique of secular modernity. Hughes further discusses how humankind relates to nature by explaining that one of our primary myths is a 'quest' to return to 'lost life' - this explains our (misguided) desire for technological progress. He continues, '[w]hen something abandons Nature, or is abandoned by Nature, it has lost touch with its creator, and is called an evolutionary dead-end. According to this, our Civilization is an evolutionary error' (WP 129). These sentences encapsulate many views expressed in Hughes's poetry, and apply particularly to the collection that Hughes was about to publish when he wrote them. The review illuminates Crow's quest to regain contact with his creator - who turns out to be a 'creatress'.

Picking up on his image of 'Mother Nature' as feminine, Hughes makes clear his views on goddesses, which resonate with his later reading on Gaia theory:

The idea of nature as a single organism is not new. It was man's first great thought, the basic intuition of most primitive theologies. Since Christianity hardened into Protestantism, we can follow the underground heretical life, leagued with everything occult, spiritualistic, devilish, over-emotional, bestial, mystical, feminine, crazy, revolutionary, and poetic. ... Science, it has often been said, which began by deposing every primitive idea, will end by reinstating them as the essential conditions for life. (WP 132)

Not only does Hughes complicate Nicholson's masculinist rhetoric, but he reveals significant insights about his own work. Long before he wrote Shakespeare and the Goddess..., Hughes was connecting poetry with heretical ideas about the Goddess - and linking them all to the roots of environmentalism. He describes a very Crow-ish mythic lineage. Mother Nature is deposed by Christianity, which begets Science on her half-destroyed body, and she bears the Computer - which reinstates Nature (WP 132-33). Hughes says that in his time, people were seeing 'the re-emergence of Nature as the Great Goddess of mankind' (133). This does not correspond to Nicholson's view of mankind as benevolent 'masters' of the world, but it says a great deal about Hughes's own (spiritually informed) environmentalism. Hughes's idea of an abstract 'feminine principle' has troubled feminists, as we have seen; and yet Hughes's quest to make peace with the earth-goddess sounds more progressive than Nicholson's rhetoric of masculine, revolutionary mastery.

While much of Hughes's review sounds spiritual, it also reveals his factual understanding of environmental issues, and their social and political ramifications. Environmental awareness is 
a growing part of the contemporary 'geist' (135). He views politicians as the main opponents of conservation, and persuasively argues for the economic value of environmental legislation (131). Developers and big industry are formidable opponents who want to 'cash in the world' (130). Hughes did not oppose capitalism, but he was a fierce critic of those who encourage economic growth at the expense of the environment. His concern about water pollution was developing, and he mentions 'the industrial poisoning of the water-systems in and around England'. He writes of the need to educate farmers who treat the public as a species to be 'killed off quickly and profitably' (131) with poisonous pesticides and fertilisers. This anticipates his later writing about the problems of modern agriculture (see Chapter VI). Nicholson's fear that the artificially created 'technosphere' manufactures 'deadly poisons and irritants' (325) resonates with much of the toxic imagery that Hughes had created in Crow. However, Hughes mentions that Nicholson has kept his faith in the power of technology as an agent for environmental change (WP 134). Hughes was not opposed to technological progress: he deployed his extensive reading of environmental science in his later campaigns (see Chapter VIII). Nicholson also criticises the Forestry Commission, and Hughes himself is troubled by the 'sour parallelograms' of its tree plantations and the sound of the 'power saw' (132). This concern with deforestation would inform one of Hughes's next environmental activities: launching a campaign for tree planting.

In late 1971, Hughes heard a local council official's passionate defence of Devon's hardwood trees. He read an article about an American scheme where schoolchildren planted and cared for trees, 149 and decided to devise a tree-planting scheme for Britain. He was advised to take the idea to the County Planning Authority.150 Hughes then promoted the scheme to a national readership. In November 1972, the Times Educational Supplement published his letter 'Children plant trees for tomorrow'. Hughes persuasively argues that 'a personal concern' for the natural life surrounding us has now become 'vital'. He recalls the success of tree-planting schemes in the United States, and states that children are 'passionate about trees as few adults can be' and cannot see 'why the world should not be a natural paradise'. The UK was falling short of its target for tree coverage of fifteen per cent. The tree-felling license would be extended to include trees in hedgerows, and felled hardwoods would be replaced by trees grown by children. Farmers would resist initially, but could be won over due to their 'sensibility towards their land' (Children Plant Trees for Tomorrow'). Hughes was not only extremely well informed about developments in environmental thinking: he was committed to teaching children about environmental affairs. Here is a realistic and viable scheme to start replanting Britain's deforested areas. Although similar schemes already existed, 151 Hughes received a wealth of responses from tree banks, teachers, gardeners and charitable trusts.152

\footnotetext{
149 BL Add MS 88918/121/16, TH to Leslie Bailey, 21.01.1972

150 BL Add MS 88918/121/16, Leslie Bailey to TH, 07.02.72

151 BL Add MS 88918/121/16, letter from Trees for People director Simon Klinger to the Times Educational Supplement, 24. 11. 72.
}

152 These are archived at BL Add MS 88918/121/16. 
His 'green' ideas were already beginning to spread - and this was just the beginning of his high-profile activism.

\section{Developing global awareness}

Images of the earth as a whole, and international issues such as the Vietnam war, were beginning to foster global environmental awareness in the late 1960s and early 1970s. Hughes's knowledge of international issues had been strengthened by his reading of literature from abroad: the Eastern European poets, Yoruba poetry, the Bardo Thödöl. By the time of his review of 'The Environmental Revolution', Hughes clearly saw environmentalism as a global phenomenon. The United Nations conference on the Human Environment in 1972 helped to usher in 'the more rational, political and global' perspective of the 1970s that replaced the countercultural New Environmentalism of the 1960s (McCormick 1995 107), by taking the needs of developing countries into account (128). A more global perspective was becoming evident in Hughes's writing. A curious children's fable about an iconic big cat and some noble 'savages' resonates with the early 1970s' growing concern about environmental problems in developing nations.

Hughes’s 1974 play 'The Tiger’s Bones’ presents a trenchant critique of enforced westernisation, colonial science, industrial-scale agriculture and imperialist environmental 'improvements'. Idiotic Western scientists with Blakean names such as The Master, Dully and Jitterwit, mistakenly predict the Earth's destruction by a meteor (18). 'Savages' with 'brown hair' and 'stumpy tails' inhabit the precise spot where the meteor will fall (20). Hughes's depiction of such animalistic indigenes might trouble modern readers - but indigenous people are shown to be wiser than the westerners who exploit them. When the Master clears the Savages' forest for crops, 'destroys all the wild creatures' and 'poisons' insects and weeds (22), they end up 'starving' (26). A man wiser than the Master - a goatbearded, mountain-dwelling Sage decked in eagles' claws (33) - shows that Western hyperrationality is foolish when he transforms into a tiger and eats everyone but Dully (40). This is an environmentalist fable, but it is also a critique of the worst form of globalisation, which seeks to 'cash in the world'. The resurrection of the tiger at the end of the play also echoes the early 1970s' preoccupation with endangered species. Yet as the 1970s progressed, Hughes would become increasingly engaged in working with, and defending, endangered environments much closer to home. 


\section{CHAPTER VII. HUGHES'S FARMING}

One of the most controversial environmental issues in Britain in the 1970s and 1980s was the countryside (McCormick 1995 161). Britain had been intensifying its farming since the outbreak of the Second World War, but the Common Agricultural Policy (CAP) created further intensification after 1970 by allowing farmers to sell whatever they produced, irrespective of levels of production and demand. They were 'encouraged to produce more than consumers needed' (McCormick 1991 70) - hence the infamous surpluses of produce: 'mountains' of butter and 'lakes' of milk. But these surpluses came at a price. Britain, which imported a large amount of food and had a small agricultural sector, found the CAP a 'burdensome' cost in the 1970s (Miller 9). Subsidies encouraged farmers to use all the land they had, cutting down hedgerows and forests, augmenting production by burning straw, and increasing their use of pesticides and fertilisers (McCormick 71). Hughes was clearly engaging with the CAP policy of subsidising certain forms of land use. Even in Elmet's postindustrial landscape, the sheep have to 'get by | On the hill subsidy' provided by the CAP ( $\mathrm{CPH}$ 487). But there were also wider, cultural problems: farming was losing its grandeur. Hughes's Devon farming-collections celebrate environmentally-conscious agricultural labour while lamenting the decline of such farming practices.

In response to ideas such as Small is Beautiful, E. F. Schumacher's 1973 critique of unfettered economic growth, 153 and to the oil crisis of 1973-4, environmentalists were looking for new ways to mitigate the environmental cost of consumerism. Some of them did this by going back to the land. Hughes owned John Seymour's book The Guide to SelfSufficiency (1976), in which he could read about everything from slaughtering an ox to harnessing natural energy.154 In his speech about farming, Hughes appears to draw inspiration from Seymour. The self-sufficient farmer should 'leave some areas of wilderness on his [sic] land', 'keep in mind the needs of his soil' and avoid interfering with the 'chain of life', which includes him (Seymour 9). These are views that coincide closely with Hughes’s.

Organisations such as the Soil Association warned of the dangers of pesticides and additives to food, with the result that 'the health food movement began to expand towards the end of the 1970s' (Bramwell 218). Hughes was no recent convert to living off the land: he had shot his own meat in Yorkshire and grown vegetables for his family when he lived with Plath. His farm was a small-scale commercial enterprise, rather than an attempt to become entirely selfsufficient, but the idea of self-sufficiency appealed to him: he said in an interview that 'at the last crunch, you can eat a sheep, or you can kill a bullock' (Skea, 'Interview and Poetry Reading', 1976). The ethos of Moortown Farm had something in common with his contemporaries' reaction against both environmentally damaging agribusiness and rapacious consumerism. By the mid 1970s, the vogue for self-sufficiency had become the stuff of comedy. The 1975 television sitcom The Good Life followed two disillusioned suburbanites

153 Hughes knew Schumacher's later work. His copy of Schumacher's philosophical book A Guide for the Perplexed (1977) is kept at BJ1581.2 .S394 1978 HUGHES.

154 Emory MARBL S501.2.S45 1976 HUGHES 
in their project to run a self-sufficient farm in their Surbiton garden. Hughes, too, was satirising the alternative lifestyles of the 1970s. His cinematic hybrid collection Gaudete (1977) describes a rural village sex-cult, complete with herbal hallucinogens (95), animal costumes (145) and human sacrifice (147). The book is full of allusions to a countercultural sense of ecstatic unity with the earth, from a woman 'anointing' her face with the loam of a bluebell wood (32) to women buried up to the neck in a field (102-3). Hughes sends up the countercultural nature-rituals of the day, but he does not explicitly target the environmental movement. Yet Gaudete's fictional community is preoccupied with livestock, poaching and hunting: issues that would prove central to Hughes's more realistic rural poetry-collections. It is to these collections that we must turn, to gain a full picture of how Hughes examines farmers' closeness to land and livestock, but also the environmental and ethical dilemmas that they face.

Previous research on Hughes's politics has (understandably) paid particular attention to his complex engagement with the Miners' Strike (Bentley 2014 Chapter 4), and to his later, sometimes inconsistent, admiration of Thatcher (Bate 2015 482). Bentley has pointed out the allusions to the miners' strikes of 1972 and 1974 in Hughes's poem 'Foxhunt' (86), but when he describes the 'grim focus on the manual labour of farming' (85), he touches on ideological issues in Hughes's farming-poetry that need to be explored further. Tom Paulin reads Hughes as 'Laureate of the free market' and characterises Hughes's description of the birth of a calf as a celebration of 'commodity production' (272). Yet Hughes’s farming-poetry grapples with a far broader spectrum of ideological preoccupations than earlier critics have mentioned. Paulin misses Hughes's evident admiration of environmentally responsible agricultural work, and his 'green' opposition to water pollution, air pollution and European intensive farming policies. Season Songs and Moortown Diary are capable of suggesting the discourse of the political Right or Left: we encounter both a ploughed field as a private 'kingdom' (CPH 335) and a tractor that shows 'solidarity | With the concrete' (512). This is unsurprising, since 1970s Britain started out under Wilson's Labour Party, swung between Conservative and Labour governments, and elected Thatcher at the end of the decade. Hughes quite clearly objects to agribusiness as a capitalist enterprise that cashes in the world: 'This deeply satisfying, self-reliant if occasionally gruelling way of life had mutated - into a jittery, demoralized, industrial servitude, in effect farming not stock and land but grants and subsidies, at the mercy of foreign politicians, big business conglomerates, bank managers' ( $C P H$ 1204). In later life, Hughes would become acquainted with wealthy rural land-owners, and a fishing-diary records a conflicted response (see Chapter X).155 Hunting-to-hounds, with its ethical and class-related dilemmas, continued to provoke the mixed reactions recorded in 'The Stag' and 'Foxhunt'. If Hughes saw the First World War as entrenching the divide between working class and officer class ( $L T H$ 590), he saw farmers as fighting another war on the home front: a 'Third World War conducted by other means - the EEC Agricultural Policy war' (CPH 1204). The enemy this time was the European Economic Commission, rather than Germany, and large-scale agribusiness, rather than the officer class. Jack Orchard and his family may not have considered themselves to be working class farmers, but Hughes

155 BL Ms ADD 88918/122/1 handwritten sheets from spiral bound notebook, page numbered 26 by archivist. 
employs the language of hard labour to present Orchard as a tireless worker, and uses the vocabulary of trench warfare to show him battling to uphold traditional, environmentally responsible farming practices. This chapter examines the ideological strands in Hughes's writing about farming, and the poetic devices that he employs to communicate them.

After hinting at personal trauma and exploring ecocide in Crow, and after some years of instability in his personal life, Hughes felt the need for an existence that was more rooted. Devon's landscape and people - he later called the county his 'land of totems' (CPH 1121) would provide this. Hughes's mother's family had been farmers and she had a saying, "back to the land in three generations" ( $C P H$ 1203), and so he was able to identify with farming folk. He knew a little of farming, having helped with the harvesting in Yorkshire. Hughes married Carol Orchard, the daughter of a Devon farmer, in 1970. In 1972, he and Carol bought Moortown Farm. Alice Oswald sees Carol as key to Hughes's understanding of Devon, and credits her influence with inspiring the collections about farming, which are 'sitespecific' (2005 21). The Hugheses ran the farm with the help of Jack Orchard, Carol's father, a retired farmer (Roberts 2006 121). The poet Peter Redgrove characterised Orchard, a very able farm manager, as an 'earth father' (Feinstein 186). Part of the appeal of farming was that it fostered balance, even 'sanity': ‘these beautiful animals occupy your whole thoughts,' and they gave Hughes an alternative focus to the pressures of the literary world (Skea, Australia Festival Interview, 1976). When Orchard died in 1976, Hughes wrote to Janos Csokits that his father-in-law's 'unique archaic personality' had been key to inspiring his farming venture.156 Hughes's farming allowed him to reconnect with traditional English ways of life, and it was also an attempt to lure his brother Gerald back to England (Roberts 2006 212). Hughes loved Devon, had long enjoyed looking after animals, and had cherished the dream of farming with Gerald for years (LTH 26-27). His letters show that farming helped him to feel more integrated into the environment, and more at ease: 'It's reconnected me to the only world I belong to in any way' (LTH 365). He goes back to the land, keeping extensive naturediaries in prose (most of which remain unpublished), and recording his experiences in the verse-diaries that would become Season Songs and Moortown Diary. His farming reconnected him, in a Jungian way, to a (literally) more grounded existence.

Yet his farming had another aim, more practical, ethical and ecological. Hughes was quite aware of the horrors of large-scale, mechanised animal slaughter (WP 257). He later described the environmental impact of modern farming (CPH 1202-5). This work is well known to researchers. Yet earlier scholars have not realised the full extent of Hughes's engagement with the environmental and ethical problems of farming in his time. Robinson states that 'There are no battery chickens, insecticides, A.I. men, or factory-reared calves [on Moortown Farm]' (1983 263), but he does not mention that Hughes and his friends had been publishing articles about some of these very issues before Hughes began his agricultural endeavours. In 1970, Your Environment had reported on the controversial issue of intensive livestock farming, which at the time was practised by a minority of farmers. Ruth Harrison, author of the 1964 polemic Animal Machines, detailed the dangers of antibiotics and

156 Emory Mss 894, Box 1, ff. 1, TH to Csokits, May 1976. 
hormones in meat (137) and the unpopular practice of importing feed for intensively farmed animals (139). Waste from factory-farmed animals was a major environmental problem: 'Because of the addition of insecticides, antibiotics, hormones and so on this effluent has become a hazard and now represents waste - on a colossal scale - of natural fertiliser that once used to be returned to the land in the natural and self-perpetuating life sequence' (139). But Harrison's greatest objection to intensive farming was ethical. Depriving an animal of light, the room to move around, and interaction with other animals was 'robbing the animal of the only significant life that it knows' (140). The following year, the Ministry for Agriculture, Farming and Fisheries issued a report on soil quality: intensive grazing was damaging to poorly drained soil (Jones 1971 5). During the 1970s, Hughes also became aware of the 'dying of the fish' and 'cancer' 157 being linked to environmental pollution. Half of his fields drained into the Taw, and the other half into the Torridge:158 Tarka's Two Rivers. This was a landscape that he had dreamed about since boyhood, and he had good reason to be concerned. Farming was changing rapidly in the 1970s. Hughes evokes the Devon farmers' past way of life on their 'undateable cob-walled farms' (CPH 1203): Hughes saw their traditional farming methods as environmentally sustainable until the major changes of the 1970s. The Hugheses were soon caught up in 'the financial nightmares, the technological revolutions and international market madness that have devastated farmers, farms and farming ever since'. Hughes describes Orchard's resistance to trying some of the 'foreign breeds of cattle' and the enthusiasm with which Hughes and Carol read of 'new chemicals, new machinery, more chemicals' in Farmer's Weekly. The price of this was that livestock became an 'unwanted surplus' and a 'danger to public health', the soil became 'a kind of poison' and 'the rivers sewers' (1204). In the end, the Hugheses opted for a traditional way of farming: a herd of beef cattle and a flock of sheep. The livestock were free range and the land was free from damaging chemicals. Hughes's farming represents an important chapter in his environmentalism, which sees him taking a substantial, practical step to implement his environmental ideas. He put them into practice in a more muted way than he would do in the 1980s and 1990s, when his environmental campaigns took up a greater amount of his time.

But he was also spreading the word about environmental issues, albeit in a quieter way than in his later campaigns. Your Environment magazine ran until 1973, and Hughes soon began writing letters, often anonymously, to major newspapers. Olwyn Hughes remembers that in 1978, he was writing about 'fish stocks and on injecting cattle with steroids' (Gifford 2011 147). Indeed, a certain 'E. James’ from Court Green, clearly Edward James Hughes, wrote to The Times in 1976 about depleted fish stocks in the North Sea.159 He did not feel ready to lend his name to every environmental cause he supported; this would change in the 1980s, due in no small part to the added gravitas that the Laureateship provided. Other environmental concerns came to Hughes's attention at this time. In 1976 Robert Ardrey,

157 BL Add MS 88918/1/55, notebook containing drafts of Season Songs 2.

158 BL Add MS 88918/7/2, TS autobiographical notes 8. My numbering.

159 Emory MARBL archive, Collection 644, Box 53, Folder 2, 'Letters Editor The Times'. 
author of Thunder Rock in which Hughes acted as an adolescent, put forward his Hunting Hypothesis. Hughes's library suggests that he read Ardrey's theory that hunting was an important development in human evolution; the book also contained early warnings about climate change (170-73).160 Climate change would worry Hughes for many years to come.

The poetry inspired by Moortown Farm does not always have the poetic distinctiveness of Lupercal, nor the thematic unity of Birthday Letters, Crow or River. Yet neither Hughes's farming nor his farming-poetry should be dismissed. Was it really the case that, '[u]nhappy about his failure to make a major poetic breakthrough, he distracted himself by becoming a farmer' (Bate 2015 318)? Season Songs and Moortown Diary follow in the long tradition of Spenser's The Shepheardes Calendar.161 Moortown Diary also serves to elegise Jack Orchard, and Hughes compiled it for Carol ( $\mathrm{CPH}$ 1025). Hughes honours Devon farmers for performing rural work in a traditional and environmentally sustainable way. It is the concept of work - and ecologically sustainable work - that is key to Hughes's rural poetic project.

\section{Hughes’s Georgics}

Gifford summarises Moortown Diary as a reaction to the pastoral genre (2002 77): it is harsh, unattractive and unidealised, emphasises realism, shows tensions, disorder and inequalities, challenges literary constructs as false distortions, and demythologises Arcadia and Eden (2012 19). Yet Hughes's Moortown-poems do not necessarily seek to repudiate an earlier poetic mode; instead, they follow in a long tradition of poetic engagements with rural work. In this respect, Hughes's farming-poetry is more georgic than anti-pastoral. The georgic was made famous by a great poet who was the son of a farmer: Virgil. Seamus Heaney has mentioned that 'a book like Moortown could be read as a local variation of the theme of Virgil’s Georgics (2013 225).162 Virgil frankly discusses pests and vermin (11-12), the damage done by storms (19) and how disease afflicts flocks (66). The fourth book of his Georgics mingles instructions about beekeeping with an elegiac retelling of the myth of Orpheus and Euridice. Hughes's elegies for Jack Orchard create georgic laments in the Virgilian tradition. Virgil's tone may be didactic - but so is Hughes's in his speech about farming, which shows him at his most georgic. For Andrews, writing about the georgic poetry of eighteenth-century working-class poets, what differentiates the georgic from the pastoral is the 'centrality of labor'. This is foregrounded by Virgil from the start (116). For Raymond Williams, Virgil’s Georgics are ‘working descriptions of country life’ (20). Theresa Adams argues that 'In georgic, the laborer's life consists of difficult work occasionally interrupted by periods of brief rest' (372). Yet Hughes's georgic engagement with agricultural toil is permeated by his environmental awareness, and Williams' and

160 Robert Ardrey. The hunting hypothesis: a personal conclusion concerning the evolutionary nature of man.

London: Fontana, 1977. Emory MARBL GN280.7.A72 1977 HUGHES.

161 Hughes's library shows that he owned de Selincourt's edition of Spenser's Poetical Works. Emory MARBL Rose Library, PR2351.S5 1948 HUGHES.

162 Jack Thacker's forthcoming work will provide further information on the georgic qualities of work by Hughes and other recent poets. 
Adams' definitions need to be expanded to include this dimension. When his poems focus on human beings' agricultural labour, they are georgic. But when Hughes's farming-poetry is at its most environmentally aware, we could call it eco-georgic.

Hughes had known about the centrality of labour to agricultural life since his adolescent work on a South Yorkshire farm, and his shooting expeditions to Manor Farm. Someone who laboured for much of his life, and who was one of Hughes's most important influences, was a poet of his 'sacred canon': John Clare. Clare's language that is ever green is revised by Hughes to consider not only green issues in the late twentieth century, but environmental and agricultural economics. Clare was writing during a period of profound rural change in the form of the enclosure of common land; Williams identifies this as 'the destroyer of a traditional and settled rural community' (96). Expropriation and more efficient forms of agriculture compelled the working class to move to industrial towns (98), which Hughes would evoke in his Elmet-project. If Clare was a proto-ecological poet for the time of enclosure, then Hughes was an ecopoet for the Common Agricultural Policy. Clare also showed Hughes the idea that animals, people and agricultural tools participate in rural work, and that animals can enjoy play. Clare writes of a plough that resembles 'toil a resting' and hares 'at play' that are frightened by milkmaids going to work ( $R B$ 184). Hughes's 'Work and Play' contrasts a swallow who 'toils all summer' (322) with a traffic jam of holidaymakers 'Inhaling petroleum' (323). Here we see Hughes's view of animal activities as rural 'work', and his critique of modernity as environmentally damaging. But what is most striking about the way Hughes describes rural work is the way he often shows how humans and animals struggle and labour together, their roles in production and consumption. A river can be alternately rich and poor, swallows and corn-gods toil, a calf faces butchers and markets. Season Songs and Moortown Diary are aware of environmental and agricultural economics: an organic stock farm is a worthy 'green' enterprise but it is not particularly profitable, as everything needs to be kept going 'on baler twine' (1204). The collections ponder the ethical implications of animal husbandry, meat and wool consumption, hunting-to-hounds and shooting vermin.

The vividness of his farming collections is due to Hughes's mode of composition. He called his poems 'improvised verses' that had to be 'set down soon after the event', without even a night passing between event and writing. Otherwise, 'the processes of 'memory', the poetic process, had already started' ( $C P H 1205)$. It is likely that he turned to this mode of composition to jolt his writing out of the mythical depths of Prometheus on His Crag (1973), which he considered to be a 'numb poem about numbness' (LTH 340). There could not be a greater contrast between the abstract vulture of Prometheus..., which might be a 'lump of his mother' or his ‘dying and his death' ( $C P H$ 295), and the realistic animals of Hughes's farming-poetry. Hughes's drafts in the British Library suggest that he sometimes used a similar mode of composition for Season Songs as well. The swiftness with which many of these pieces were composed attempted to capture the lived experience of farm work. Of course, 'ecomimesis' can never hope to capture its animal subjects faithfully. Yet what Hughes creates here is not the narcissistic idolatry of the text that Rigby warns against, but a vivid mode of eco-georgic celebration, tinged with elegy. Resonating with Rigby's call for 
poetry that turns our attention back towards the environment (117), Hughes's poetic realism encourages his urban and suburban readers to consider rural and environmental problems that they might not otherwise encounter.

Both collections celebrate traditional farming practices, yet Moortown Diary more clearly expresses regret at the decline of old ways of farming. A key difference between the two collections is that the British edition of Season Songs is marketed for children (Roberts 2006 126); it was written 'within the hearing of children' (Feinstein 195). Many of the poems in the collection would be very enjoyable for young readers, but there are some that would be beyond their grasp. The poems in this collection have mainly upbeat endings, more to raise Hughes's own spirits than to make them suitable for children (Roberts 2006 126). Season Songs and Moortown Diary were published three years apart, yet they can be considered together, since Roberts has pointed out that the writing process for both books largely overlapped (2006 126). Season Songs demonstrates Hughes’s commitment to educating young people about farming, the countryside and environmental issues; he would continue this project in his later involvement with the Sacred Earth Drama Trust and the Countryside Movement. Hughes might have dismissed Season Songs (Bate 2015 327), but the poems that are written with children in mind evidence his continuing commitment to ecopoedagogy. Along with the tree-planting scheme, the ecopedagogy articles in Your Environment, and the later children's book What is the Truth?, Season Songs should be seen as another example of his long engagement in environmental education.

\section{$\underline{\text { Season Songs }}$}

The collection begins with 'A March Calf', which progresses from anthropomorphising the animal to considering its role in food production, and finally contemplating its place in the wider environment. The description of the calf as 'Little Fauntleroy' would appeal to children, yet the three lines that anthropomorphise the creature quickly give way to the realistic 'dunged straw' and 'cobwebby beams' of his immediate surroundings. The tone of the poem changes when Hughes states that 'Hungry people are getting hungrier, | Butchers developing expertise and markets' ( $\mathrm{CPH} 307)$. Hughes hints at the world's growing population, at rapacious Western consumerism and at the demands of agribusiness, in a way that children would understand. The calf's world-view is also about to expand, but when he goes outside for the first time, he will discover the wonders of the world around him. He will 'scatter his seething joy' and 'find himself himself' (308). The uneasy relationship between beautiful calves and beef production is explored in this poem, which reacts against idealised, bucolic views of cattle reared for meat. Yet the calf clearly enjoys his existence: he is not subjected to the constraints of a veal crate. After Hughes had written 'Crow Tyrannosaurus', and before he would write 'Poetry and Violence', this poem is somewhat surprising: it is the 'ear's | deafness' (CPH 215) and humankind's wilful ignorance about meat production (WP 257) that mean that the calf goes to the abattoir in the first place. From the outset, there is an undercurrent of unease about slaughter that undermines even the collection's georgic celebration of agricultural work. Practices such as hunting with dogs will add further complexities and contradictions to the way Hughes's farming-poetry presents our 'ethically challenged' relationship with animals (Skinner 2011). 
Underpinning the collections is also an awareness of what CAP-style agribusiness does to the environment. This current of thought adds a note of unease to its otherwise eco-georgic engagement with organic farming. In the six years before Season Songs was published, Hughes had witnessed a shocking decline in fish populations on the Taw especially. In 1969, he was troubled to catch a Taw trout afflicted by the epidemic of ulcerative dermal necrosis, a fish disease that had arrived from Ireland. By 1973, he reported that the river was polluted with 'white threads' of waste from a local cheese factory. A year later, the trout were nearly gone.163 'The River in March' anticipates River, while introducing young readers to the idea of water pollution and environmental economics. The feminised river 'squats between draggled banks, fingering her rags and rubbish' (308). This line is echoed in River's 'Four March Watercolours', when the river tries to revive 'A bedraggle of dirty bones' (645). Yet Hughes's evocation of the rags and rubbish that the floods bring shows a child the problems that litter can cause to an aquatic ecosystem. In the summer, the river 'has lost all her fish' (308). This line foreshadows Hughes's later concerns about climate change and the effect of droughts on rivers (see Chapters VIII and IX). Yet by the last stanza, the fish have returned and the river is healthy. 'A salmon, a sow of solid silver' (309) likens a fish that Hughes enjoyed pursuing to a farm animal. Land and water are united and made whole in that single line. The poem's idea of a river being alternately rich and poor might suggest the financial risk that came with farming in the 1970s: when the poem was first published in 1974, Britain had entered a recession, and one of the issues that prompted a referendum on its European Economic Community membership was the heavy cost of the CAP. The sow of solid silver that ends the poem demonstrates a hope that farming will continue to be rewarding for both humans and animals, although the poem's 'upbeat' tone might not have reflected Hughes's real views.

Hughes attempts to pursue the idea of healing and integration in 'March Morning Unlike Others', which begins with some of Hughes's most objective ecological poetry. The first twelve lines contain no lyric 'I'. Although there is an anonymous 'we' in the last few lines, the first section of this poem supports Tarlo's theories about the lyric by demonstrating that an impersonal tone can help to illustrate human beings' dependence on their environment.

Blue haze. Bees hanging in air at the hive-mouth.

Crawling in prone stupor of sun

On the hive-lip. Snowdrops. Two buzzards (309).

This poem does not begin in a georgic vein, but as it progresses, Hughes mentions knee-deep mud that stiffens around a trough and lambs that have the freedom to be 'foolish', narrowing down the focus to a farmed landscape. The earth is then personified as a woman who has undergone a 'frightful operation.' In a draft of his notes to this poem, Hughes explained that a mild March after a severe winter coincided with his mother's convalescence from an

163 Ted Hughes. 'Trout on the Upper Taw.' Taw Fisheries Association News Letter. (Summer 1990): 6. Print. 
operation; in the poem, land and mother become unified.164 The imagery of healing might also suggest a sensitive revision of Plath's poems about convalescent women, such as 'Tulips'.165 Yet the ending of the published poem is very reassuring: the earth is exhausted but 'smiling' and 'we sit, and smile, and wait, and know | She is not going to die' (CPH 309). Robinson states that '[o]ur being cast as relatives visiting a convalescent implies a human responsibility towards the rest of creation which it is the main task of all these works to advocate' (1989 201). There is a deeper green tinge to the poem than Robinson admits: the poem in its published form devotes more space to the landscape than to the mother-figure. She is shown to be a small, human part of earth's far vaster systems. By positing a close relationship between land and mother, and by placing so much emphasis on the land, Hughes challenges anthropocentric thinking. After all, it was his own mother who predicted that her family would go 'back to the land in three generations'.

Hughes continues to illustrate human beings' dependence on land and environment via carefully crafted anthropomorphism. 'The Golden Boy' is a wise riddle for children. It is grounded in the very ancient tradition of Old English riddles from the Exeter Book, while its short lines and occasional rhymes suggest Hughes's longstanding interest in ballads. The poem begins with the boy's 'burial' in March, and his resurrection:

He toiled in the fields

And his murderers cared for him

He grew a gold beard

And his murderers laughed. (324)

Hughes uses the riddle-tradition to make every aspect of his poem about wheat, and simultaneously about the corn-spirit. The final stanza changes in form, becoming a (barely Christianised) prayer to the god of grain; it is redolent of Frazer's catalogue of traditions in which a human incarnation of the corn-spirit is sacrificed to ensure a plentiful future harvest (Frazer 510-537). Hughes's anthropomorphic corn-spirit harks back to his reading of premodern mythology. The poem also has the ecopedagogical objective of showing children how closely they depend on soil, grain, wheat and farmers. The corn-god toils in the fields: here is Hughes spreading an eco-georgic awareness of traditional labour, showing the role that grain plays in the agricultural economy.

When composing Moortown, Hughes aimed to capture the immediacy of lived experience. Some beautifully written, unpublished nature-diary entries by Hughes from June 1976 show him actually in the process of recording his experiences of the Devon summer around him,

164 BL Add MS 88918/1/45 typescript drafts of notes to Moortown Diary 3.

165 A notebook filed with drafts of Season Songs contains an unpublished poem called 'Tulips', dated 'Oct 24', which mentions a 'Caesarian' and an 'operation'; it is followed by a poem about a flood. BL Add MS 88918/1/55 blue ruled exercise book 3 recto. 
with insects crawling across the page; 166 there are many such pieces archived with drafts of his farming-poems. His ‘Autumn Nature Notes' clearly draw on such nature-diaries. A particularly striking passage from this collection relates an encounter with a fox: 'I thought I'd brushed with a neighbour - | Fox-reek, a warm web, rich as creosote' (329). This very tactile and olfactory passage recalls Hughes's statement in Poetry in the Making about the senses calling up a creature alive, while the idea of the fox as a 'neighbour' recalls his affinity with this animal of totemic significance. This fox is dead, and the speaker comes up with a powerfully primordial way of remembering him: 'Then I shall steal his fangs, and wear them, and honour them' (330). This poem goes beyond Hughes's eco-georgic focus on agricultural labour, and places the fox as the farmer's 'neighbour'. Here is a more searching piece of antianthropocentric writing than many of Hughes's rural poems. The totemic fox as a 'neighbour' would be echoed many years later by Hughes's idea of animals as 'fellow citizens', although it could be argued that the stealing of his fangs is an act of appropriation.

Hughes continues to explore our interactions with animals, but there are several further pieces that examine our 'ethically challenged' (Skinner 2011) treatment of them. The plight of hunted deer clearly captured his poetic imagination (see Chapters IX and X). His poem 'The Stag' describes deer hunting on Exmoor, a long tradition. Human beings observe a stag pursued by dogs from his 'favourite valley', which gives way to a 'strange country', a 'strange earth' and lashing brambles. The lines become progressively longer as the animal sprints with his last strength. Hughes’s description of the stag's terror and incomprehension as his body seems to betray him to the hounds is harrowing: 'And his heart became just a club beating his ribs and his own hooves shouted with hounds' voices' ( $C P H 334)$. Here is a poem that implies 'an ecological ethics' (Gander and Kinsella 2) via its headlong structure, its lack of line breaks to pause for breath. It is indeed ethics that the poem examines: the sympathies of most of its human characters are with the stag. The crowd (which includes spectating farmers) ends up 'Wet-through and disappointed' (335) to see him killed. This poem complicates Solnick's view that Hughes uses violence to reassert a lost sense of corporeality (76): the destruction of the stag's body, the replacement of heart with artificial club and hooves with tame hounds' voices, creates a rupture between rural folk and animal. Hunting would continue to divide opinion for the rest of Hughes's life. He indicates a tension between the 'military parade' of 'blue horsemen' and the crowd of disappointed farmers - a tension that is linked to the rural class system. If one of georgic poetry's aims is give an unflinching account of rural work, this poem probes an aspect of rural leisure that is divisive for ethical and social reasons. Juhász’s stag assailed by bullets and Ovid's Actaeon might have informed the poem's focus on animal distress and human reactions to it. The poem might also count Clare's 'The Badger' among its predecessors (RB 57-8). Also in this collection, Hughes lists a hanging pheasant and a hunted fox among the 'seven sorrows' of autumn ( $C P H 331)$. Hughes would write of what he saw as the importance of stag hunting to deer conservation towards the end of his life (see Chapter X), but the vivid evocation of the stag's suffering, and the farmers' disappointment at seeing him killed, make his later assertions in favour of the hunt seem contradictory.

166 BL Add MS 88918/1/55 beige exercise book dated 'June $15^{\text {th }} 76$ ’ 1 recto. 
Another significant dilemma - this time to do with the tension between industrial labour and environmentalism - haunts one of the collection's closing poems. 'December River', written about the Taw (Wormald 2013 115), is mainly concerned with the life-cycle of the salmon. This poem might be difficult for children to understand, but it would introduce them to the idea that death and decay are as necessary in the natural world as birth and growth: it is an 'entropological' poem. Nevertheless, it shows how such 'natural' systems are altered by human actions. It also raises environmental dilemmas that relate to social issues. The speaker finds a dead salmon, which one might expect to have been killed by sources of water pollution that preoccupied Hughes: ulcerative dermal necrosis or waste from the cheese factory. Yet Hughes evokes another significant source of pollution in this poem. He alludes to air pollution: the 'slag-smoke west' suggests the processing of iron and its potentially damaging effects, but also its connection to heavy industry. The river is 'molten' and made of 'unfolding metals,' the width of a 'tin bath' (339-40) - a reference to tin and copper mining in Devon and Cornwall. Lurking in the background of this poem are memories of Hughes's childhood in the industrial North: water that 'mills,' the 'engineered' salmon and 'steel' ice (340-1) are from the lexicon of West Yorkshire textile mills, steelworking and engineering. The speaker hopes in vain for a touch of the salmon's 'wealth' (340) - this suggests not only the glint of new-minted scales, but contemporary concerns about economic recession and inadequate wages. A different form of mining, coal mining, was affecting all British businesses just before this poem was published in 1974. A longstanding dispute with Edward Heath's government over pay (Sandbrook 576) led miners to vote to take industrial action in October 1973, if their demands were not met. As a result of the anticipated coal shortage, and compounded by the high price of imported oil (578), the working week was reduced to three days at the end of December 1973 (585). Miners would begin industrial action the following February (608). 'December River’ hovers uneasily between images of industrial power, and an acknowledgement that industrialisation causes water pollution. Hughes had known since he read Your Environment what mining did to rivers such as the Calder, and a river of unfolding metals is a tainted one. If Hughes's georgic poetry engages with rural toil, then the industrial toil that this poem hints at provokes unease.

\section{Moortown Diary}

Both Moortown Diary and Season Songs contain 'Sheep', the first section of which describes the death of a lamb 'born | With everything but the will' to live. The second section evokes the distinctive, haunting sound of shorn sheep bleating for the lambs from which they have been separated. Hughes's descriptions are especially rich in sounds: 'Shaking their voices in desperation. | Bald brutal-voiced mothers braying out, | Flat-tongued lambs chopping off hopelessness' (532). The line about the mothers reads like an alliterative medieval line, while the capturing of animal sounds exemplifies the echoing of animal sound that Skinner sees as so important to ecopoetry. The version of 'Sheep' in Season Songs included three sections. There was a middle section written partly from the point of view of a sheep being shorn: 'What is that buzzer what is it coming | Buzzing like a big fierce insect on a long tangling of snake' (319-20). Hughes's evocation of mechanised shearing is both a georgic description of the labour of shearing, and a consideration of the ethical questions it raises. Of course sheep 
need to be shorn, but the process is unpleasant: the ewe hears 'murder voices', feels the cutters as 'painful', is 'helpless' (319). The section written from the ewe's point of view uses some ingenious devices to suggest a sheep's perception of the world: as Skinner puts it, the poem suggests the human capacity for 'becoming animal' (2011). Hughes applies descriptions of animals familiar to a sheep (insect, snake) to describe unfamiliar, artificial objects (cutter, flex). He was drawing on the work of an earlier environmental writer: Williamson uses 'the images of an otter's mind,' such as water with claws, paws and a tail, to describe its environment (1928 ix). Yet Hughes's descriptive mode is more striking than Williamson's, as it negotiates the difficult task of representing human artefacts from an animal's perspective. It might be absurd, and highly problematic, to put poetic words into the mouth of a sheep. Yet Hughes's evocation of shearing remains vividly successful by speaking for a sheep, translating its thoughts and echoing some of its vocalisations, rather than speaking as one (Bate 2000 72).

Shearing is usually uncomfortable, but it should not damage animals; but Hughes continues to explore our 'ethically challenged' (Skinner 2011) interactions with them by describing acute suffering. In 'Dehorning', the georgic celebration of co-operation between man and animal breaks down: this procedure inflicts pain on livestock and leaves their owner shaken. In his notes to 'Dehorning,' Hughes mentions 'what a shattering effect the operation had on me, though I am not squeamish. As if the horns had been repeatedly sawn off me' ( $C P H$ 1205). What is most shocking about it is that it describes animals that are fully conscious, although anaesthetised; 'View of a Pig' and 'February $17^{\text {th' }}$ are less disturbing because the animals they describe are dead. As in the story 'Sunday', the speaker experiences a visceral, physical response to animal suffering:

The needle between the horn and the eye, so deep

Your gut squirms for the eyeball twisting

In its pink-white fastenings of tissue.

This poem also develops the theme of human beings' reactions to animal eyes and the animal gaze: 'the eye | Like a live eye caught in a pan, like the eye of a fish | Imprisoned in air'. It is the sight of the eye in particular that makes the speaker's gut squirm. The human eye seeing and being seen by the animal eye creates a sense of reciprocity that recalls Derrida's view that the animal's eye is our mirror. There are further descriptions of pain. One cannot read 'a water-pistol jet of blood' without remembering Plath's 'The blood-jet is poetry' in 'Kindness' (CPP 270). The possible echo of a line by Plath contrasts a figurative blood-jet with a very real blood-jet, one which is bathetically likened to a water-pistol and which must be stopped by 'Twiddl[ing]' an artery into a knot. The 'white-rasped and bloody skull-crater' ( $C P H$ 504) intensifies the impact of this gory description. This is not the poetry of violence that Hughes had once been accused of writing. It is poetry that criticises violence: a violent procedure that might be unknown to beef-eating, milk-drinking, urban readers of Hughes's work. Hughes imbues the georgic mode with tensions by describing how farming should not be done: he notes that the painful removal of fully formed horns has been superseded by the more 
humane method of debudding calves ( $C P H$ 1205). The poem raises uncomfortable ethical questions about how much suffering is acceptable, if any. Hughes's writing has largely turned away from his earlier focus on predation, and begun to create more complicated and nuanced views of animal suffering.

Hughes's examination of controversial rural practices, and our relationship to animals, continues in 'Foxhunt'. This is not necessarily a georgic poem, as hunting is a country practice rather than an agricultural one; but it does raise uncomfortable, class-related questions about who works on the land, who owns it, and who has mastery over animals. Even at this stage, Hughes's views on hunting the tutelary animal of his poetic life were contradictory. Hughes captures his thoughts on fox hunting in an unpublished typescript note to this poem, stating that since he has tried to keep foxes as pets in the past, his sympathies are with the loser. On the other hand, he writes that he supports the hunt, 'on which so much of country life depends'.167 But in a children's poem of 1984, Hughes would describe the fox as a fellow 'farmer', implying affection for it; more on this later. Yet in his published notes to an edition of Moortown Diary that came out in 1989, Hughes reflects that hunting on horseback with dogs was a means of keeping a thriving fox population in Devon; it allowed foxes to survive in a county where they had previously been annihilated ( $C P H 1206)$. Hughes begins the poem with one of his distinctive descriptions of animals that seem to be partorganic and part-industrial: the hounds' voices are 'like rusty, reluctant | Rolling stock being shunted'. This evocation of antiquated, poorly functioning machinery questions the contemporary relevance of the hunt. In a collection that examines rural production and consumption, a practice that creates such useless products as 'Dog-shit and dead foxes' is shown to be problematic. Hughes wonders what will become of the fox:

Will he run

Till his muscles suddenly turn to iron,

Till blood froths his mouth as his lungs tatter,

Till his feet are raw blood-sticks

Hughes's description of the hunted animal has a startling immediacy: this sentence runs over five lines, only pausing to catch its breath at two commas. There is a clear echo of 'The Stag' in the anatomisation of the quarry fleeing at full tilt, and again we see an 'ecological ethics' (Gander and Kinsella 2) embedded in its headlong form. But this creature might still escape. At the end of the poem, Hughes encourages us to picture him in his writing hut: 'As I write this down | He runs still fresh, with all his chances before him' (507). Of course, Hughes knew the outcome of this hunt. Viewed alongside 'The Stag', this poem and the notes accompanying it are rife with contradictions. Only certain aspects of country life depended upon the hunt, which was an elite sport; Hughes himself was torn between his sympathy for the individual animal and his desire for its species to be preserved - for hunting.

167 BL Add MS 88918/1/45 ‘MOORTOWN: Notes to the Poems’ TS 1-2. 
Ethical dilemmas persist: in the business of livestock husbandry, sometimes it is impossible to save a sick or damaged animal. 'Orf' ends with the shooting of a severely ill lamb. The idea of its life 'Asking for permission to be extinct' contrasts with Hughes's other poems of cooperation between human and animal: it might be seen as anthropocentric. The poem does, however, acknowledge that the lamb's request for 'permission' to die happens 'Inside my head' (523). A clearer picture of humans and animals toiling together comes from 'February $17^{\text {th }}$, although the outcome is not particularly happy for the sheep. As Hughes noted, his poems concern 'the nursing if not the emergency hospital side of animal husbandry' (1209). The description of the speaker cutting off the dead lamb's head is graphic, but it is followed by a striking global contextualisation:

Sliced the lamb’s throat-strings, levered with a knife

Between the vertebrae and brought the head off

To stare at its mother, its pipes sitting in the mud

With all earth for a body.

This is an arresting image of ecological integration. In its focus on environmental systems, this poem exemplifies the collection's tropological features. The body of the lamb must be pushed back into its mother's womb to stimulate her to push: 'She pushed crying and I pushed gasping' (519). Here is a moment of understanding and collaboration between a (presumably male) speaker and a female animal. If the business of livestock husbandry is traditionally presented as hierarchical, here labouring farmer and ewe in labour struggle together in a poem that recognises the agency and efforts of both. This acknowledgement of the efforts of human and animal constitutes eco-georgic poetry.

Livestock and their life-cycles are especially important in poems such as 'February $17^{\text {th' }}$, and Hughes further examines the cycles of death and decay - and human beings' attempts to arrest them. 'Coming down through Somerset' evokes a sense of peculiar kinship between a human speaker and a non-human creature, this time a dead badger. It is not necessarily a georgic poem, but it is certainly an ecopoem because it explores Hughes's idea of 'fellowship' with animals: the badger is 'Passenger' in the car, like a human, while the speaker has 'Brought him close | Into my life'. Too late to skin the badger, the speaker does not want to boil it for the skull; what he does want is for the badger 'To stop time'. This animal's most coveted attribute is 'His rankness, his bristling wildness' ( $\mathrm{CPH} 525)$. The fascination with 'wildness' is particularly significant for ecocriticism. Robinson reads the badger as a representation of vitality, which can be possessed because it has been killed (1983 276), and yet this poem could equally be read as an acknowledgement of the perpetuation of lives in a trophic web - and an (admittedly complicated) 'wildness'. The badger attracts flies that 'Bejewel his transit' ( $C P H 524)$ into the underworld. Roberts has commented on the paradox of harbingers of decay being compared to durable jewels (2006 125), and this metaphor ennobles the flies and celebrates their vitality. Dead animals do not usually stay just as they are, for their remains feed other animals. The badger carries on existing in the space of the poem, which preserves him more permanently than any kind of taxidermy could ever 
do. This poem is an entropological meditation on how animals - and implicitly human beings - participate in the cycles of growth and decay. Yet it also contemplates our human resistance to the passage of time, and our attempts to disrupt such cycles.

Hughes's collection shows us the labour of shearers, stock buyers and hay cutters; the 'toil' of ewes and draught-horses. But of course, Moortown Diary’s eco-georgic poetry primarily celebrates the life and work of Jack Orchard. Hughes honours his strength, his dexterity and his closeness to the land, building 'A monument':

$$
\begin{aligned}
& \text { Your burrowing, gasping struggle } \\
& \text { In the knee-deep mud of the copse ditch } \\
& \text { Where you cleared, with bill-hook and slasher, } \\
& \text { A path for the wire }
\end{aligned}
$$

Working to lay a fence in 'knee-deep mud' becomes a 'battle' among 'posts': Hughes evokes the barbed wire, mud and stakes of the Great War here. The title sets up a faint echo of the war-monument in 'Griefs for Dead Soldiers'. If Hughes had seen the First World War as a class war, then he viewed 1970s farming as an economic and environmental war: the 'EEC Agricultural Policy War’ was a 'Third World War' (1204). Paulin’s reading of Hughes’s farming-poetry as a celebration of capitalist commodity production is complicated by Hughes's likening of Orchard's labour to that of an infantryman, and then a miner: 'You were like a collier, a face-worker | In a dark hole of obstacles' (535). Hughes published his poems as Moortown Elegies in a limited edition in 1978 - a year of bitter strikes for British coalminers. Here is a quiet moment of solidarity with them. But the Common Agricultural Policy was also a war against nature, a war against traditional, environmentally-conscious forms of farm work. Hughes moves from georgic to eco-georgic when he evokes Orchard's profound understanding of, and connection to, land and animals. Orchard's 'burrowing' struggle to lay the wire is not only a miner's toil, but an animal's digging. 'The day he died' goes beyond the elegiac tradition's usual focus on nature as a comforting backdrop, and instead stresses Orchard's closeness to the land and the combination of force and gentleness that is needed to handle livestock. When Hughes evokes his 'suddenly savage, suddenly gentle | Masterings of the animal' (535), it is quite clear which species is at the apex of the hierarchy. Yet what is most striking is when Hughes's ideas shift to show symbiosis and cooperation between land and farmer. Orchard's death leaves the land 'With roots cut' (533). He is described as 'A tree with two knot-eyes, immovable', 'Powerful as a horse' (535), with hands that are 'Lumpish roots of earth cunning' (536). Hughes celebrates the rootiness and rootedness of the Devon farming community, the work of farmers and workhorses. Orchard takes on characteristics of some non-native species: his hands are 'monkey delicate' and resemble 'crocodile leather' (537), one of many descriptions evoking Africa that reference tales of the Orchards' imagined Moorish ancestry (1211). Whether his hands are compared to roots or to crocodile skin, Orchard is shown to have a deep kinship with the more-thanhuman world. Hughes's cultural narratives that examine cultivation are some of his most complex destabilisations of the boundary between 'nature' and 'culture'. The land is as 
'dazed' (533) at his death as those he leaves behind. Edward Hadley has commented that Hughes engages with some pastoral tropes, such as flowers, and cattle as a procession of mourners; '[b]ut although Hughes uses certain pastoral conventions, his lamentations are for a man who dealt with a rural world, one as adverse and challenging as it is beautiful and rewarding' (76). Hadley's observation that these poems are rural, rather than pastoral, is significant: it indicates this poem's georgic focus. Orchard's earthiness and rootiness move the poem beyond a georgic focus on rural labour, to an eco-georgic consideration of land and trees as fellow sufferers in the cycles of death and decay. When Hughes shows this level of kinship with the nonhuman, his farming-poetry takes on its deepest shade of green.

Hughes realistically evokes a close relationship between human beings and livestock, and destabilises and unsettles any poetry that would sanitise or aestheticise animal husbandry. But Hughes's eco-georgic mode is distinctive for its focus on environmental concerns, the suffering and agency of animals, and environmental economics. By the early 1970s, Hughes had an extensive knowledge of the ethical, environmental and political issues surrounding intensive livestock farming, the use of pesticides and chemicals, and the felling of trees and hedgerows. He was expressing an ambivalent attitude towards hunting. He certainly celebrates hard labour, although moments of tension arise when he hints at controversial issues of the time, such as his sympathy with heavy industry on the one hand, and environmental causes on the other. If Season Songs contains elements of ecopedagogy, and both of Hughes's farming-collections are largely georgic, the knowledge that underpins them is distinctly eco-georgic. When Hughes ends Moortown Diary in elegiac mode, he mourns not only the passing of an extraordinary farmer, but the end of his farming: the end of that deep connection between family, land and livestock. The Hugheses no longer kept animals after Orchard's death, although they retained the farm. '[T]he pastoral dream of farmer Ted had come to an abrupt end', Bate writes (2015 329); but that dream had always been too alert to environmental issues to be pastoral. Hughes would now have to find other ways of reimmersing himself in the landscape and living according to his environmentalist principles.

Nevertheless, the environmental aspects of Hughes's farming project were not without contradictions. Hughes would now have been able to vote Green: the movement that would become the Green Party was founded in 1973, changing its name to The Ecology Party in 1975. Much later in life, Hughes would admit that his farming endeavour provoked some conflicting thoughts. A letter of 1990 to the Department of the Environment states that he has 'been actively involved in the fight against the pollution of Water, Air and Earth since 1970'. Yet he candidly admitted that he had 'seen both sides of the Pollution debate' because he was a 'polluter' during his time as a farmer.168 (His farming would have been less polluting after he stopped using artificial chemicals, although the local rivers would still have been at risk from animal waste.) Moreover, even if Hughes was in tune with Seventies' vogue for selfsufficient, environmentally conscious farming, he was reluctant to engage overtly with two of the decade's other important preoccupations: the anti-hunting movement and the animal ethics movement. Led by the Devon journalist John Prestige, who had been outraged at the

168 Emory MARBL archive Collection 644, box 54, folder 1, 'Dept of The Environment'. 
hunting of a pregnant hind by the Devon and Somerset staghounds, there was a rise in the sabotaging of otter-, deer- and foxhunts near Hughes's Devon home in the 1960s (Ryder 167). Blood sports continued to cause controversy as Hughes began his farming. The hunt was still associated with the aristocracy, but its traditional link with farmers began to decline: 'With fewer free-range hens, farmers by the 1970s had begun to realize that the fox, far from being a pest, was probably doing them a service by keeping down rats, rabbits and slugs' (Ryder 170). A ban against hare coursing was passed by the House of Commons in 1975 (but rejected by the Lords), and otter hunting was banned in 1978. It is possible that developments such as these provided the background to Hughes's ambivalent hunting-poems. His 'A Moon Man-Hunt' had sounded harshly critical of hunting, but he began to express surprisingly favourable opinions of the hunt in the late 1980s; by doing so, he was not necessarily expressing an opinion shared by most farmers, but he was siding with the elite.

Related to the anti-hunting lobby, but initially separate from the environmental movement, animal ethics and animal rights also became serious intellectual preoccupations in the 1970s. In 1975, the Australian bioethicist Peter Singer published his seminal book Animal Liberation. Singer's book meant that the "“animal welfare” attitudes of older generation were subjected to fierce analysis and criticism’ (Ryder 201). Hughes the countryman would have had little time for the animal liberation movement, founded by a group of Oxford University intellectuals and occasionally appropriated by fringe groups of animal rights extremists. In spite of his obvious interest in conservation and his caring husbandry of livestock, Hughes's attitudes towards the ownership of animals and the use of their meat and body parts remained those of 'the older generation'. Some animal liberationists criticised the environmental movement for preserving habitats and systems but ignoring the rights of the individual animal (Regan 362), although other philosophers suggest that the concept of a 'metahuman moral community' could provide a unified 'animal-environmental ethical theory' (Baird Callicott 254). Hughes's argument in favour of foxhunting prioritises the survival of the species above the protection of individuals - although later poems such as 'The Black Rhino' will stress the need to preserve individual animals because they are members of an endangered species. The complexities and tensions in Hughes's attitudes towards animals will continue to vex his writing in the later years of his life (see Chapter X). It is also somewhat surprising that Hughes's farming-poems grapple with the issues surrounding painful dehorning and disappointing livestock casualties, but do not venture into the abattoir or the butcher's shop. In the fictionalised rural village of Gaudete, a section that reads like a first draft of 'Dehorning' (Hughes 1976 127) is surpassed in goriness only by a description of the sacrifice and evisceration of bulls:

Heavy cattle are surging through gangways

Driven through banging steel gates

By bellowing men

Who jab them with electrified clubs (18). 
Graphic descriptions of spilling intestines and the sound of the 'despair of beasts' (19) raise uncomfortable ethical questions about animal suffering. It goes without saying that sheep and beef cattle exist to provide meat, yet this method of transporting, goading and killing them is not necessarily the most humane way. Seymour argued that the farmer should slaughter an animal on the farm, shooting it in the head and giving it 'no inkling that anything nasty is about to happen to it' (112). Hughes's farming-poetry does not comment on large-scale slaughterhouses or mechanised meat production; this is unusual in the light of his unflinching engagement with such issues in Gaudete and 'Poetry and Violence'.

Farming continued to be important to Hughes's environmentalism and to his writing as his career progressed. Carol Hughes proved to be as able a manager of the land as her late father had been, and Hughes proudly writes of her abilities in his letters (LTH 498). Hughes's 1984 children's book What is the Truth? continued the Moortown-poems' georgic preoccupation with farm labour, and extended Season Songs' focus on ecopedagogy. The children's poems contain some unlikely examples of collaboration between man and beast: 'The Fox is a jolly farmer and we farm the same land, | He's a hardworking farmer, with a farmer's hard hand' (Hughes and Lloyd 34). The idea of foxes 'farming' poultry as well as farm rodents creates a humorous sense of partnership between farmer and fox, and it contrasts with Hughes's defence of foxhunting in his 1989 notes to Moortown Diary. Hughes celebrates the shepherd's hard graft (39) and the 'noble, tireless' work of the hen (76), and gives more space to country lore and the speech-rhythms of country workers than he does in his collections for an older readership: 'Kill a badger kill your granny' (60). Folk wisdom gives a striking sense of kinship between human and animal. But perhaps the most outspokenly 'green' element of the book is Hughes's outright critique of agribusiness and the CAP:

The milk-herd is a factory,
Milk, meat, butter, cheese.
You think these come in rivers? O
The slurry comes in seas

seas

The slurry comes in seas.

Here is one of his most overt versified criticisms of modern factory farming and the European Economic Commission's policy of overproduction; it also humorously evokes the damage that slurry runoff can do to water: 'Your shining river dies' (22). This poem suggests that Hughes did not yet feel comfortable about voicing such a strong opinion to an adult readership. It would not be until after he became Poet Laureate that he would publish protestverse in national newspapers.

In the unpublished speech collected with drafts of Season Songs, but written after 1984,169 Hughes continues to express his concern about the effect that agriculture has on the 
environment. He begins with the chronology cited in the introduction to this book: the dying of the fish at Old Denaby due to silage pollution in the 1940s, his reading of Silent Spring in 1959 (it was more likely to be 1962), concerns about DDT in the 1960s, his awareness of the dying of the fish and of cancers in the 1970s, the public's turning against farmers in the 1980s and the problems with silage, slurry and nitrates. Yet Hughes does offer a hopeful vision of the future. He outlines his vision for better farming, humorously proposing that the farmer with the most environmentally sound methods will win a 'Hughes cup'. His manifesto for good farming includes planting trees, containing dairy effluent, sowing wild herbs to supplement animal feed, keeping chemicals out of the meat, remembering that the farmer only borrows the soil for a short time, and realising that what he throws in the ditch ends up in his cup.170 Hughes not only wrote about environmentally sound farming and ran a farm according to his principles: he encouraged others to do so too.

The Hugheses' high-level involvement in rural affairs continued for many years. In 1992, long after Hughes published the Moortown poems, Carol set up a 'Devon Schools Environment Award'. This scheme raised children's awareness of the value of farms as havens for wildlife, and improved wildlife habitats by letting pupils help with fencing and tree-planting.171 Yet they were also involved in more controversial debates relating to rural life. Hughes and Carol helped to redraft the Countryside Movement's charter. The Countryside Movement was established in 1995, and became part of the Countryside Alliance in 1997. These organisations defended hunting and represented the views of certain rural groups. In 1995, the aristocratic Devon landowner George Lopes suggested that Hughes might write a poem to accompany the Movement's launch.172 The Hugheses read the treaty and responded with some queries about its wording. The first draft of the Treaty stated that a divide between the urban and rural communities prompted animal rights activists to 'take issue with the movement of live animals, with hunting, with egg production, with shooting, with national hunt racing and even with fishing. Indeed, they question all aspects of our management of the animal world.' 173 The Charter's lumping together of chicken farmers with hunt followers, livestock handlers with fishermen, elided the class differences in rural society and glossed over the fact that issues such as hunting polarised opinion among country people. Hughes was uneasy about this implicit 'call to arms' against activists;174 such activists would be involved in the controversy over hunting that continued into the 1990s (see Chapter X). Hughes was concerned that the media might misinterpret the Charter, and was sceptical about the use of the term 'urban' to describe the majority of British people.175 Instead, he suggested

170 BL Add MS 88918/1/55 blue ruled notebook 4.

171 Emory MARBL collection 644 box 160 folder 1 'DEVON SCHOOLS ENVIRONMENT AWARD’.

172 BL Add MS 88918/121/2 Alan Kilkenny to Hughes, 28 ${ }^{\text {th }}$ September 1995.

173 BL Add MS 88918/121/2 ‘The Countryside Movement: Our Charter’ 4. All further page numbers are given in parentheses in the text.

174 BL Add MS 88918/121/2, TH to George Lopes, 30"th October 19951.

175 TH to George Lopes, 30 $0^{\text {th }}$ October 19951 
that rural and urban populations should work together.176 His idea that town and country people should cooperate can be seen as a way to help end city-dwellers' supposed exile from nature. His comments were taken into account, and used as the basis for emendations to the final Charter, 177 creating a more measured tone. Yet if fields and farmlands were clearly important preoccupations for Hughes, the next major current of thought in his environmental awareness would see him defending environments, creatures and pursuits with which he was 'obsessed' (Pero 50).

176 TH to George Lopes, 30 ${ }^{\text {th }}$ October 19952.

177 BL Add MS 88918/121/2 Alan Kilkenny to Hughes, undated. 


\section{CHAPTER VIII. 'JOIN WATER': HUGHES'S RIVER-POETRY}

Hughes saw rivers as primal conduits to the core of our inner nature. On a mythic level, they are the arteries of his nature-goddess. But on an ecological level, they sustain all life. Protecting rivers was a key motive for Hughes's environmental activism - primarily thanks to his love of fishing. Without fishing, Hughes might never have become an environmentalist. After all, it was the dying of the fish at Old Denaby that first awakened him to an awareness of environmental pollution. By the 1980s, he was developing a deeper awareness of water pollution in the British Isles, and was continuing to create ecopoetry in the local, topological strain that had created his Moortown-poems. Yet some important fishing trips abroad helped to refine his awareness of global environmental problems; as a result, his ecopoetry ventures farther afield. Hughes takes his focus on 'spots of time' and applies it to Alaska's Gulkana River, Scotland's Dee and Ireland's River Barrow, as well as many familiar localities in the West Country: a widening reach that would continue to broaden in the late 1980s. A significant reason why this vision of ecological wholeness develops in Hughes's poetry in the early 80s, is that he and his son Nicholas were reading one of the seminal environmental books of the age: James Lovelock’s Gaia: A New Look at Life on Earth.178

River is the summit of Hughes's ecopoetic achievement. The book has a wholeness that equals the thematic unity of Lupercal and Birthday Letters - but with the critical difference that River's cyclical structure is mimetic of natural processes, and the disruptions to them that human beings can cause. It brings together disparate locations in the great loop of the water cycle; the entire book is an entropological ecopoem. Although Hughes was reading Lovelock's Gaia theory, which envisaged the earth as a self-regulating system that creates optimal conditions for life, River is not naïve to human beings' interventions in climate systems, hydrological processes and fish life-cycles. It creates a deep sense of humankind's attachment to places at home and abroad: touches of topophilia. River celebrates environmentally conscious practices, and criticises river pollution, without lapsing into the awkwardness of Hughes's 'semi-protest' verse. The collection's only shortcomings are is its frequent feminisation of the landscape, a vein of tired Christian symbolism that sits oddly alongside Hughes's heathenish rain-charms and goddess-hymns, and its uncritical attitude towards fishing. Feminists might object to the appearances of Hughes's goddess, while ecocritics would wonder why Hughes was employing Christian symbolism when he had written earlier that 'Christianity deposes Mother Nature' (WP 132). But the publication of the volume itself fulfilled an explicitly environmental agenda, contributing to Hughes's environmental activism in a more effective way than his early protest-verse about nuclear waste and extinction. This is an important corrective to Paulin's view that the coffee-table edition of River was a project centrally concerned with 'saleability' (275). Some of Hughes's lesser-known prose writing about fishing, published in the same year as River, also reflects his interest in environmentally responsible book production. Using publications and poems themselves to aid his cause is a significant development in his environmental activities. After he received the Laureateship, Hughes would continue to deploy poetry and publications as a surprisingly effective means of raising awareness and funds for environmental causes.

178 Hughes owned two copies of this important book, which was first published in 1979. Nicholas Hughes received one as a gift in 1980, which Hughes later acquired (Emory MARBL QH313 .L68 1982 HUGHES); his other copy dates from 1982 (QH313 .L68 1982 HUGHES). 
An inspired idea by a fishing companion, a chance encounter with a man on a train, and a discussion in a pub in Newton Abbot, helped Hughes to publish the collection that consolidated his reputation as one of Britain's finest environmental poets. Many reviewers consider River (1983) to be one of Hughes's greatest works. West thinks that 'River is perhaps Hughes' finest collection' (115) and Scigaj praises its 'visionary depth' (1985 380). Sagar calls it 'the acme of Hughes' achievement' and rhapsodises that it 'takes rivers to be the bloodstream of the goddess, Nature, and contributes more than any other collection to the respiritualization of a fallen world' (2009 xiv). In the article that introduces Drue Heinz's interview of Hughes for the Paris Review, River is mentioned as the collection that preceded Hughes's appointment as Poet Laureate (81). Such eulogistic judgements about the book's spiritual qualities need to be balanced with a more sustained examination of its realism, its site-specificity and its engagement with environmental causes.

Of course, Hughes had written poems about rivers, fish and fishing from his boyhood onwards. This is hardly surprising: in his interview with Pero, Hughes used the word 'obsessed' of his fishing during adolescence and after Plath's death (50). He declared that if fishing were banned in the UK, he would have to leave the country (55). Undated notes by Hughes that are likely to relate to River even begin, 'Me as the river'.179 Far earlier, Hughes had intended to write a sequence about the British Isles, united by the trope of a river (Sagar 2000 26). He had written about pike in Lupercal, mentioned water pollution in Remains of Elmet and captured the experience of fishing and the kill in a problematic poem in EarthNumb.180 Poems later included in River had appeared in earlier publications. 'Ophelia' was included in Orts (1978), while the Morrigu Press, which Hughes ran with his son and his sister, had published limited editions of 'Night Arrival of Sea-Trout' in 1979 and 'Three River Poems' in 1981. The critical difference between this earlier work and River, though, is that the collection contributes to the work of Hughes's environmental activism.

In 1976, Hughes met the photographer Peter Keen, who shared his love of fly fishing. Keen wrote to Hughes suggesting that they should collaborate on 'a book of poetry and photographs with a theme of rivers and the wildlife associated with them'.181 Hughes bumped into the publisher and literary agent James MacGibbon on a train, and the idea for the book was discussed in a 'Newton Abbot pub'.182 Since The Observer and Faber and Faber did not initially seem willing to pursue the project, MacGibbon and Olwyn Hughes, who acted as her brother's agent, approached British Gas and Shell for funding to cover the book's escalating production costs. Hughes and Keen would be able to publish their ecologically-inspired book of river-poems and photographs, and enable a major energy company to promote its 'green' image. Shell demanded the uninspiring title The Shell Book of the River,183 and so British Gas seemed a preferable alternative sponsor. The river-book would help British Gas to demonstrate 'their care of the landscape,' 184 since they prided themselves on laying pipelines

179 BL Add MS 88918/9/9, page torn from an A5 ruled notebook, 'Me as the river'.

180 For a discussion of this poem, see Gifford 1999 150-51.

181 BL Add MS 88615, fol. 3035C. Note by Peter Keen to papers relating to River, dated 2004.

182 BL Add MS 88615, MacGibbon to Keen, 17. 09. 82.

183 BL Add MS 88615, fol. 3035C, James MacGibbon to Olwyn Hughes, undated 1 recto.

184 James MacGibbon to Olwyn Hughes, undated 1 recto. 
under rivers without disturbing the ecosystem. The poetry took Hughes nearly three years to write, and since MacGibbon took a large cut of the sponsorship money, Keen and Hughes ended up making far less than they had anticipated; Hughes even wondered if he should have put a stop to the entire project.185 Fortunately for his readers, he persevered. The book was published by Faber and Faber in the end, with funding from British Gas186 and the Countryside Commission. Tom Paulin dismissively calls River 'a commercial for British Gas’s environmental friendliness' (274-75). In 1970, Your Environment had reported on an 'encouraging' environmental film by Shell (Ross et al 40-41); British Gas's backing of River would have been seen as progressive at the time. The Countryside Commission's involvement, and Hughes's own committed activism, prevent the project from smacking of corporate greenwashing.

The subtler River-poems that deal with conservation, links between different elements of the biosphere, and specific places and times, are among Hughes's most accomplished ecological poetry. River anticipates a broad array of recent thinking about ecopoetics. To use Skinner's classification of the 'species' of ecopoetry, much of the collection is 'topological' (placebased) and 'tropological' (evoking ecosystemic interconnections) (Skinner 128). Some of the poems in River are certainly 'ethnological': concerned with the problems that indigenous peoples face when the environments where they live are destroyed (Skinner 129). The collection's cyclical structure mirrors the turning of the seasons, seeking to participate in natural cycles of growth and decay: it strives towards the 'entropological' (Skinner 128). Yet metaphors of aquatic processes as either industrial or literary prevent River from creating narcissistic 'ecomimesis'; pollution, droughts and disruption to fish migrations foreshadow Bristow's focus on 'discord' in the Anthropocene lyric (6). Hughes uses innovative poetic forms to evoke the shape of landscapes and the movement of creatures, which thinkers as diverse as Gander and Kinsella (2) and Tarlo (2011 9) see as a significant feature of progressive ecopoetry. Scott Bryson views a love of place (2005 11) and human humility as characteristic of ecopoetry (2); Hughes's collection speaks of his love of favourite fishing spots and his reverence for the endlessly-renewed landscape. Even if Hughes's feminisation of landscapes becomes excessive, there are moments when his personification of landforms is subtle enough to remind us of our connection to the environment. Robinson finds Hughes's later work to contain 'anthropomorphic imagery and the personification of the natural', which encourages 'a gentle, practical co-operation between man and natural environment'. Female personification of landscapes in River forms part of 'the realignment of our religious sensibilities towards the feminine which is attempted in Cave Birds and Gaudete' (1989 201). While Rose would probably see this idea as problematically Gravesian, Hughes would have seen it as part of his mythologised, environmentalist vision of the earth-goddess. He follows Lovelock in this respect, but goes one step further: for Lovelock, Gaia was alive and feminine, but not sentient (x); in Hughes's river-poetry, she is alert, queenly, at times dangerous. As will be discussed shortly, his rivers sometimes escape essentialist depictions of gender by becoming androgynous or masculine, and when masculine characters attempt to revere the goddess via worship and even sacrifice. While many of the poems are considerations of the individual's place within interconnected systems of weather and water, some poems explore more societal, practical, 'environmental' issues: they exemplify the two currents of thought that Lidström and Garrard find in ecopoetry (37). However, individual epiphanies and societal issues frequently coexist in the same poem, showing that the

185 BL Add MS 88614, fol. 3035C, TH to Keen, dated only 'Wednesday’, 1-4.

186 BL Add MS 88615, fol. 3035C, Frank Pike to Keen, 19. 10. 82. 
dichotomy they propose is not so clear-cut. 'The Morning Before Christmas' examines individual fishermen's observations of a salmon hatchery, but engages with the wider picture of salmon conservation. 'Salmon Eggs' suggests an individual's reverent encounter with a regenerating stream, but it raises societal issues by critiquing anthropocentric Christian religion.

The collection's engagement with river conservation is visible from its outset. 'The Morning Before Christmas' sees the cold earth poised to welcome the coming spring - and the setting is a salmon hatchery. Hughes did actually witness salmon being 'milted', or having their eggs and milt collected to perpetuate their numbers: a draft of the poem in the Emory archive is entitled 'Dec $24^{\text {th }} 1979$ To Lifton, to Tamar, to see the Salmon stripped'. The river is the Tamar in Devon, Peter Keen is there to take photographs, and Hughes’s son Nicholas accompanies them.187 The precise location on the Tamar is evoked in careful detail: this is a prime example of Skinner's place-based, 'topological' ecopoetry. The fourth line of the poem describes a barren landscape, whose trees are 'fractured domes of spun ghost'. And yet, the 'brand new stillness' of the second line already suggests renewal. The first five salmon mentioned are dead, but the sixth is a ten-pound female, a 'hen-fish', and she is 'lurching alive'.

Nameless men perform the milting, which is described with all the realism of uncomfortable farming procedures in Moortown Diary: the hen-fish has her eggs removed with a 'Rough grip and her head in an armpit' ( $C P H$ 639), the milting of a cock-fish is described as a 'violation' and a hen-fish comes out of the 'prison' of the fish-cage (640). Yet this rough, basic method of removing eggs by hand and fertilising them in a kitchen bowl is necessary for the survival of West Country salmon whose spawning gravels are polluted. In future years, Hughes would campaign to restore those gravels and the fish they supported. The fish is 'noble' because she ensures the continuation of her species; Hughes will explore the 'nobility' of fish at greater length in 'October Salmon'. Paulin sanctimoniously writes that the poem 'celebrates fish-farming, a process now regarded as ecologically damaging' (275). Yet the young salmon that hatch from the fertilised eggs will replenish the falling salmon population of the Tamar, rather than being farmed in pens for food. At one stage, Hughes put forward the idea of a smolt farm on the river Torridge, to preserve the natural strain of salmon likely to return to its waters to spawn.188 From the collection's outset, Hughes presents the connection between fishermen and rivers as mediated by artificial processes; the poem does not reunite its speaker with an untouched, pristine 'nature', but envisages a complex web of interactions between species in which salmon conservation plays a part.

From the Tamar, Hughes's river-epic continues through the West Country, via the weirdly mythic diversion of 'Japanese River Tales'. 'Flesh of Light' concerns a 'new-born' river that crawls into existence among 'heather-topped stones' ( $C P H$ 642). Hughes displays his very specific knowledge of fish lifecycles and the environmental need for hatcheries in this poem. 'Eyed ova' are fish eggs in which the embryos' eyes have developed;189 he adapts this to

187 Emory MARBL coll. 644 box 74 folder 32 'Dec $24^{\text {th }} 1979$ To Lifton, to Tamar, to see the Salmon stripped'.

188 Emory MARBL coll. 644 box 169 folder 5 undated TS 'PROPOSAL FOR A SMOLT FARM ON THE RIVER TORRIDGE'.

189 See Chapter VIII for an account of Hughes’s views about a National Rivers Authority scheme to replenish fish stocks, which involved buying 'eyed ova'. 
'Eyes of ova' ( $C P H$ 642). The eggs in the hatchery are quickening, growing, beginning to see. By 'New Year', Hughes's river-woman lies deep in snow, anaesthetized by numbing cold. The speaker of the poem fears that the salmon have died, but their eggs have not survived: we see 'The lank, dying fish. But not the ticking egg' ( $C P H$ 643). Human and nonhuman are brought into close association in this poem, which superimposes the hospital ward onto the riverside hatchery.

This sterile tone does not persist, and Hughes's nature-goddess gradually revives in spring. Human and nonhuman begin to co-operate, with the result that they seem to fuse; a confounding of categories that anticipates the notion of 'nature-culture' that thinkers such as Latour, Morton and Clark call for. The fisherman-persona of the first section of 'Four March Watercolours' becomes one with the riverscape via the shadow he casts on a bank: 'My shadow, soft-edged | On drying, pale sand, among baby nettles, | Where floodwater whorled and sowed it' (CPH 644). As in 'Wodwo', the speaker of the poem is presented as dissolving into the environment; but in contrast to the Wodwo's tentative quest for an identity, this speaker is confident in his connection to the more-than-human world. Hughes's transferral of the act of germination from wild nettles to human shadow is a masterful merging of nature and the human, a testimony of Hughes's view of the power of fishing to restore humankind's damaged relationship with 'the source'.

The fisherman is looking out at 'The pool by the concrete buttress' (644), which suggests that this is a very specific fishing-spot that Hughes knows well. Resonances with 'The River in March', Hughes's mention of this particular pool, and echoes of the sounds of cows and ewes in the poem hint that it is near the rural Devon landscapes described in Season Songs and Moortown Diary. Indeed, manuscript drafts of 'Four March Watercolours' refer to the Taw and Torridge in March 1978 and 1979. 190191192 Hughes published a Rainbow Press edition of Moortown Elegies in October 1978, and Moortown exactly a year later; he was preparing to publish his rural diary-poems in the springs of 1978 and 1979, when he wrote these realistic, but not diaristic, river-poems. The 'pool-tail' (646) even suggests a creature's-eye view, and Hughes was perhaps remembering his boyhood reading of Tarka the Otter, in which water is described as having claws, paws and a tail (Williamson ix). The 'pool-tail' also references the language of fishing magazines that Hughes read, in which pools have 'throats, necks and tails' (Wormald 2014 125-26). The carefully observed topological details of this poem combine with creaturely vocabulary to create a beautifully ecocentric hymn to place. Hughes's collection often displays a holistic view of Gaia - but his love of individual spots such as this, and his knowledge of specific fishing-spots from Alaska to Lake Victoria, helped him to develop an environmentalist awareness of the importance of protecting the entire system on regional, national and international levels.

The second movement of the poem sees Spring beginning her 'real convalescence', as if the river-woman described in 'New Year' has begun to heal. With her recovery, the persona of this section of the poem changes, and we glimpse the perspective of 'We trees, | We tall ones, somewhat mutilated, | Inured by one more winter' ( $C P H$ 645). The collection is already striving towards ecological wholeness and healing: the recovering river-woman becomes numb, pale Spring; she has been 'mutilated' by winter but her bankside trees are inured and

190 Emory MARBL archive coll. 664 box 74 folder 18 'March 3d 79 '.

191 Emory MARBL archive coll. 664 box 74 folder 18 'March 2nd Torridge'.

192 Emory MARBL archive coll. 664 box 74 folder 18 'March 9 (?) 78 at the hidden long bend on Taw Dimits'. 
toughened by it. The force of green fuse and flower is everywhere in this landscape, including within the fisherman. A man's shadow sown by floodwater, speaking trees, an anaesthetized river-woman who recovers to become Spring: Hughes's collection creates a sense of human beings' place in an intricate mesh of ecological connections. Here, too, he shows nature working through human beings: an important revision of his earlier presentation of them as separated from nature in 'The Environmental Revolution'.

Hughes continues to hear language in the environment in this sequence of 'watercolours'.

The river-epic

Rehearses itself. Embellishes afresh and afresh

Each detail. Baroque superabundance.

Earth-mouth brimming. ( $\mathrm{CPH} 646)$

Words relating to culture and poetry - epic, rehearse, embellish, detail - cast the river as a maker of art, language and meaning. The fluent liquid consonants $r$ and $l$ capture the sound of flowing water. As with the grouse's cry in Remains of Elmet's 'Grouse Butts', Hughes's evocation of the river as a maker of meaning goes a step further than Skinner's idea that we should 'listen, to listen' to our planet's delicacy. When Hughes hears the river-epic and translates it into words, he is not merely hearing ecological fragility. He is doing as the people of the Golden Age do in his translation of Ovid (see Chapter IX): listening deeply, keeping faith with the source, acknowledging nature as the wellspring of culture. Yet such writing also draws attention to the poem's textuality, pushing it beyond the deceptive 'ecomimesis' that Morton mocks, and towards a sense of the complex web of interrelations that meshes nature and culture. Hughes welds the natural and artificial together when he writes of the river's 'intricate engine,' a blue-tit that 'de-rusts its ratchet' and water whose 'wheels churn' (645). The pervading ideology of this collection is profoundly green: one cannot tell the voices of fisherman, trees and river apart in these March 'watercolours'. Hughes’s watercolours complicate, deconstruct and reject anthropocentrism.

River is set in a 'world preoccupied with water' ( $C P H$ 647), and rivers locked up in ice are a real concern for the collection's fisherman-ecologist. In 'Dee', an unseasonable cold snap means that 'the salmon have turned back into the sea'. This not only spoils the fishing, but has serious consequences for other creatures that depend on the salmon. '[T]his is the majesty of the April Dee' (647), notes Hughes, but as long as the fish are few, it is a sterile majesty. Yet the landscape has its beauty:

Nevertheless, the lit queenliness of snow hills,

The high, frozen bosom, wears this river

Like a particularly fine jewel. (648)

Roberts finds Hughes's simile 'frigid and inert' (2006 143), but there is a good reason for its boreal stateliness. Hughes's courtly, queenly poem has an association with the Royal Family: it was inspired by a landscape near Balmoral.

Hughes's notes for a reading of 'Dee' show that he fished the bank of the Dee opposite Balmoral in April 1979, after a winter that had touched over thirty degrees of frost. A lack of 
snowmelt to raise the water level meant that there were few fish.193 Hughes did not catch much, but he certainly appreciated the beauty of the nature reserve where he was fishing. Hughes's fishing diaries offer further information: Hughes, Nicholas and Keen fished the Dee on the $1^{\text {st }}$ of April that year.194 That afternoon, they headed to Bridge of Dee and fished 'the royal pools' at the Farqueson Estate opposite Balmoral; neither trip yielded catches.195 On Thursday the $5^{\text {th }}$, Hughes noted that snow was still lying on the Cairngorms, but their 'crowns' were 'rounded' and 'upholstered' with snow, and bright in the sun.196 This image in the fishing diary inspired Hughes's description of the regal hills' bosom with its bright jewellery in 'Dee'. An early draft had the word 'chastity' instead of 'majesty', reinforcing a sense of the landscape's purity, and described the snow as 'ermine', a fur worn by monarchs.197 It would be inappropriate for Hughes to imbue this regal landscape with the languid sensuality of, say, 'Low Water'. Frazer's myths link land to monarch; the personification of the snow hills in this poem revisits Hughes's early reading of Frazer to illustrate the closeness of land and monarch. This courtly river-poem is significant because it foreshadows an important aspect of the next phase in Hughes's environmentalism: once he became Poet Laureate, his status as shaman of the tribe gave his environmental campaigns significantly more impact. That 1979 fishing trip to Scotland was also the occasion that inspired 'The Merry Mink'. In his fishing diary for Thursday the $3^{\text {rd }}$ of April, Hughes records seeing a mink that had drowned in a trap.198 Although Hughes admires the mink, he would be concerned about the damage that this non-endemic predator and rival fisher could do to British aquatic ecosystems.

One of River's greatest strengths is its sense of wholeness, both ecological and poetic. It is testimony to Hughes's powers of description that his water-cycle can transport us from the River Dee back to the West Country in the space of three poems. 'Under the Hill of Centurions' describes a river during late spring, weaves together human and natural history, and hints at the past sacredness of ancient landscapes. The ecological undertones of this poem lie in its naturalist's observations of fish life and its topophilic delving into the natural - and human - history of place. It is 'Easter' and the river's 'resurrection fever' brings back cock minnows. The poem hints at earlier, pagan myths behind the Christian festival of Easter. Of course, the fish is an early Christian symbol for Christ, 199 but Hughes intimates that the 'resurrection' of the first line has a non-Christian, ecological dimension, for the minnows have abandoned Christian 'contemplation and prayer'. Hughes's metaphors transform them into Roman settlers in Britain: they have 'Roman | Bottle-glass green bodies' and wear a 'panoply' (649), a Classical term for full armour. The fish in their panoply are soldiers 'Toiling together' in 'Steely jostlings': it is as if they are the 'Ghostly' (650) centurions of a Devon tale of the supernatural that Hughes liked to tell (Boyanowsky 105), with scales for

193 BL Add MS 88918/1/54, TS notes to reading from River 4 recto. My numbering.

194 BL Add MS 88918/122/2, grey ruled notebook labelled 'March 31 ${ }^{\text {st }} 1979$ ', 107 recto. Numbered by archivist. All numbering of fishing diaries is the archivist's unless otherwise specified.

195 Grey ruled notebook, 108 recto.

196 Grey ruled notebook, 112 verso.

197 Emory MARBL archive, coll. 644 box 74 folder 11'Dee’.

198 Grey ruled notebook, 109 verso.

199 Greek IXTHYS: Iesous Christos, Theou Yios, Soter - Jesus Christ, God’s son, savior. The initial letters IXTHYS spell the word for 'fish'. 
steel corselets and breeding colours for military insignia. (The Eurasian minnow begins to breed in late May, with the males' bellies turning red when they are ready to spawn.) These military minnows are likely to have been inspired by the fort that the Romans called 'Nemetostatio' (Nantstallon), near Hughes's home in North Tawton, on the banks of the River Taw. Its name means 'the road-station by the sacred groves', built on the site of an ancient Druid sanctuary (Romanbritain.org, 'Nemetostatio'). This vein of etymology will be explained in depth in relation to the poem 'Nymet' in the next chapter. The idea of a sacred grove would have been extremely appealing to both Hughes's Gravesian mythic imagination, and his environmentalist concern for the health of woods and waters. The river's 'resurrection fever' is a clear sign for hope. Hughes had lamented the decline in the polluted Taw's fish populations during the 1970s ('Trout on the Upper Taw' 6); the 'resurrection' of lost fish species is a heartening sign.

Hughes continues his topophilic map of spots of time in the West Country, giving pride of place to a beloved fishing pool as spring returns to the river. One of his loveliest and most successful place-based, ecosystemic poems is 'Stump Pool in April'. When he read this poem aloud, Hughes stated that Stump Pool was a famous deep pool on the Torridge, and that the poem describes one of those moments in April when the river resembles an insect that swims up from the bottom, bursts its skin, and flies up.200 This is the same 'stump pool' that Hughes recommended to Keen in a letter about fishing (Armitage, 'Dear Peter'). The poem is full of carefully observed, place-based details that deepen its sense of topophilia. The river has 'new limbs' and seems to emerge like an insect out of its old skin, with 'gluey splittings | All down its living length'. The river trying to 'rise out of the river' becomes like a freshly-emerged insect, readying its wings for flight:

Its limp wings

Crease in their folds, hump and convulse

To lift out over the daffodils. (651)

This poem was informed by Hughes's knowledge of the life cycle of insects such as dragonflies, damselflies and mayflies, which emerge from their nymphal skin and leave the water as winged adults. Mayflies are especially important insects for trout fishermen. The poem ends with the river itself metamorphosing, to:

$$
\begin{aligned}
& \text { fasten - in wedlock - } \\
& \text { With the hill-wood waiting high there, flushed } \\
& \text { In her bridal veil of haze-violet. (652) }
\end{aligned}
$$

Hughes replaces Eliot's lilacs growing from the dead land with insects taking wing and a violet bridal veil, suggesting germination, flourishing and renewal. Insect life is critical for supporting fish populations, as Hughes would note when he supported fellow fisherman Ian Cook's court case against South West Water in 1992. This poem celebrates the Torridge's thriving aquatic ecology in an evocation of rich and intricate ecosystemic interconnection.

200 TS notes to reading from River 5. 
Of course, Hughes's river-poems draw on a lifetime of angling, and River's contemplative fishing-poems are among Hughes's best. Leonard Scigaj finds the next poem in the riverepic, 'Go Fishing', to articulate 'the core of Hughes's deeply biocentric vision'. Scigaj explains, ' 'Go Fishing' is one of the most exquisite capturings of the psychological process through which one can become very deeply absorbed in Nature's ecological cycles. It suggests that by at least temporarily divesting oneself of the mean ego and opening the self to the river's cleansing action, one can let the mud and river-water dissolve and then heal the self' (1994 175). But 'Go Fishing' is even more biocentric than Scigaj suggests: the process of absorption in ecological cycles becomes physical as well as psychological, environmental as well as ego-dissolving. The poem continues the imagery of shamanic dismemberment that Hughes had used in poems such as 'The Bear', Eat Crow and some of the Gaudete epiloguepoems - but with the difference that healing is explicitly mentioned in the last line, whereas in Eat Crow especially, it is impossible. The poem also pursues the theme of an ego that dissolves into the wider environment, which Hughes began to explore in 'Wodwo'. In his notes for a reading, Hughes said simply that the poem was an attempt to define exactly what happens to those who succumb to the 'strange drug' of fishing for beautiful fish in beautiful rivers. 201

The first line, 'Join water, wade in underbeing', suggests that fishing immerses one in the physical landscape and in a primordial stratum of one's own being. When the brain is allowed to 'mist into moist earth', the excessively rational intellect can cease, and calm, mindful awareness can begin.202 With the imperative, 'Lose words', the struggle to express oneself ceases and one returns to a prelinguistic state. Shamanic dismemberment is followed by healing: 'As if creation were a wound | As if this flow were all plasm healing'. One is invited to be 'supplanted by mud and leaves and pebbles' and by 'rainbow monster-structures', which suggest rainbow trout. Since the human is to be supplanted by the surrounding landscape, this poem is far more ecocentric than Scigaj implies: here is an idea that anticipates posthumanism. Shamanic dimensions return when the fisherman is 'Dissolved in earth-wave' and 'Dismembered in sun-melt'. Like a Wodwo, or a newly-emerged mayfly waiting for its exoskeleton to harden, he must 'Crawl out over roots, new and nameless | Search for face, harden into limbs'. Hughes evokes a process that seems to be physical as well as psychological: the touch of earth-wave and sun-melt remind us that our physical bodies are our primary means of being in the living world. The resulting person seems to be a hybrid, a newly-created being whose sense of ecological interconnection is so great that he sees himself as part-fish, part-insect. Hybrids, so important for Bruno Latour and Timothy Morton, are among the most powerful reminders of the complex interconnections between human beings and other species. The process of letting the human 'world' return is slow; human activity is a disconcerting 'white hospital | Busy with urgency words'. The fisherman cannot even speak at first, and needs to 'Heal into time and other people' ( $\mathrm{CPH} 652)$. (Hughes told Pero that after he had come back from fishing alone, he would at first struggle

201 TS notes to reading from River 5.

202 See Chapter III for an analysis of Hughes's reading of Jung and his views on the Jungian dimensions of fishing. 
to speak properly, as 'It takes time to readjust, as if I'd been into some part of myself that pre-dates language’ (56).) The poem ends without a final punctuation mark, which suggests an ongoing process of moving between the meditative mentality of fishing and returning to the business of day-to-day life. Hughes's post-Jungian view of psychology creates a poem that supplants the human and encourages a profoundly ecocentric mindset.

If Hughes's River is usually channelled in organic, relaxed free verse, the book's second fishing adventure in Scotland changes the form significantly. 'Milesian Encounter on the Sligachan' is innovative, open-form ecopoetry, some of Hughes's most experimental. This is an exciting development in his verse that allows the lie of the land to shape the layout of his lines. In his typescript notes for a reading of this poem, Hughes remarked that it was about fishing the Sligachan river on Skye, and explained humorously that Gruagachs, Boggarts and Glaistigs are different sorts of goblins that speak Gaelic.203 Hughes had written out several Irish and Scottish tales about Gruagachs during his adolescent reading of folklore; they are spirit-maidens with an unusual connection to the natural world. As the young Hughes wrote, Gruagachs often have their souls in external things, such as a bird on a hill, or - most significantly for a keen fisherman - three trout in a stream (FTNB 2). Here is an ancient myth that evokes the fusion of an anthropomorphic figure with the landscape.

Experimental and prose-like, the fourth to the twentieth lines describes a journey across marshy territory 'after the two miles of tumblequag, of Ice-Age hairiness, | crusty, quaking cadaver and me lurching over it in elation | like a daddy-long-legs'. This dense chunk of text acts like a map in verse, charting every precise detail. For Gander and Kinsella, the form of a poem on the page can 'express an ecological ethics' by suggesting the 'interdependency' of living things (2); for Skinner, 'poetic experimentation' creates a 'more reciprocal relation to alterity' (2011). Both of these theories hold true when they are applied to this poem, but it is Tarlo's evocation of 'a relationship between the spatial arrangement of the poem and the landscape' (20119) that most elegantly captures the crux of what Hughes is doing with form. As the poem travels hurriedly across dense bog, long dashes and a large blank space make the reader of the poem pause for breath as the speaker leaps over clatterbrooks, stops to look at snipe, and falls 'up to my hip in a suck-hole'. This poem even captures the sensations of journeying across the bog on foot: an intimate relationship with this environment of daddylong-legs, bog-cotton, snipe and eagles. The verse-form changes and is pulled up short by a full stop when the speaker experiences 'The shock' ( $\mathrm{CPH}$ 653) of seeing the silent river and its current. He glimpses his common ancestry with the fish, 'my fellow aliens from prehistory'. Their eyes are 'So like mine, but fixed at zero' (654). If Derrida argued that the animal gaze enabled human beings to see their own animality reflected (51), then the fish's eye enables the speaker to contemplate the aquatic origin of all vertebrates. Hughes creates a profoundly biocentric glimpse of the ancestry we share with fish: here, he formulates his idea of our 'kinship' with them. It is very significant that the creature in the pool 'grabbed the tip of my heart-nerve': the speaker is hooked through the chest as the animal takes the bait. With Milesian exaggeration, the creature becomes a mythical 'Gruagach,' a 'Boggart' ( $C P H$ 654) and a 'Glaistig' (655): these are, respectively, a fairy-maiden or hobgoblin, a malevolent genius loci and a half-human Green Lady. Yet Hughes undercuts the mythical tone of this part of the poem when he identifies the water-creature as a little salmon and gives its scientific name, Salmo salar. The fish returns to the Palaeolithic at the end of the poem, back

203 TS notes to reading from River 1 . 
to that mythical illo tempore (Eliade 94) before technology and environmental destruction. The poem charts the external landscape and gazes deep into landscapes of the mind: it is an accomplishedly ecocentric poem of place-making.

Hughes's project to evoke aquatic biodiversity will see him using other experimental poetic forms. Hughes continues to allow 'wild' form and movement to sculpt his lines; later in his collection, Hughes lets the flight of a particular bird shape his verse. Gander and Kinsella explore how the line breaks, syntax and mise en page of a poem can reflect an ecological ethics; Hughes goes a step further here, by actually allowing the sudden bursts of a kingfisher's flight to break up the end of his poem. In the section of this poem quoted in Chapter II, our eye moves across the page as the fisherman turns to observe the kingfisher darting away. The poem is not an example of uncomplicated 'ecomimesis': the metaphors of bird as artificial 'electric wire' and 'blue flare' remind its reader of both the technicity of its technique, and of human beings' place in the intricate mesh of nature and culture. It also signals its debt to culture, as the myths behind it run deep. If we reverse the compound noun 'kingfisher', we get 'Fisher King': Hughes read about this figure in Jessie Weston's From Ritual to Romance and in The Waste Land. Wounded in the groin and fishing vainly in his sterile moat, the Fisher King waits for the healing of his wound to restore fertility to the land in which he lives. Infertility caused by pollution would become a significant preoccupation for Hughes from the mid-1980s. But a kingfisher is a heartening sign of a river's fecundity: a talisman against fishing fruitlessly in sterile, polluted streams.

Hughes cannot always allow regeneration and fertility to be stronger than death, and there are some poems in the collection that do not end with an easy progression to new life. Hughes has shown in Moortown Diary how human beings are part of nature's cycles of death and new life; sometimes, even the thought of a loved one's reintegration with the living land brings little consolation. 'Ophelia' is a sensitive, but veiled, elegy. Much scholarship has downplayed the importance of Plath's memory in Hughes's writing. Heather Clark writes that 'River is relatively free of Plath's influence'. However, 'his frequent use of marriage and death metaphors (or "Copulation and death" as he puts it in "Low Water" (CPH 670)), which he applies mainly to spawning salmon, suggest the memories of Plath and Assia Wevill are not far from his mind' (220). 'Ophelia' is clearly a delicate homage to Plath. Many years before he wrote this poem, Hughes had cast himself as a Hamlet-like writer of poems and letters when he wrote 'Oh I am ill at these numbers' to Plath in 1956 ( $L T H$ 81). Sylvia was his Ophelia in that tender letter of his youth. 'Ophelia' revises that early characterisation in the light of Hughes's grief after Plath's death: he styles himself as Hamlet in mourning after Ophelia's apparent suicide. This poem was first published in Orts, which suggests that it is one of the elegies for Plath that Hughes had long been writing, many of which would be published in Birthday Letters. As with 'The Howling of Wolves' and 'Song of a Rat', an animal symbol hints at a human tragedy.

The speaker of this poem sees Ophelia slip away on the current into the afterworld. Hughes's manuscript and typescript drafts of the poem show that it was originally written in the first person, from Ophelia's perspective. So many of Plath's poems about feminine subjectivity, as well as nature-poems such as 'Elm', use the lyric I. Hughes attempts to speak for the aquatic ecosystem here, in an ecocentic move that recalls Bate's view of the need to speak for the earth. Strikingly, he is also attempting to echo a woman poet whose voice could no longer be heard. But he did not publish the version of the poem that gave a voice to the 'Darkfish': his attempt to speak for the voiceless breaks down. In the early drafts, Ophelia challenges an unnamed interlocutor to 'Catch me', either teasing or begging for help from the anglers who 
also appear in the draft.204 Hughes had dreamed of catching an enormous fish the night before he married Plath. His compound noun 'Darkfish' echoes some of the descriptions in Plath's 1957 poem 'Words for a Nursery', where the woman is a 'flatfish' (CPP 74) surrounded by 'limber hooks' (73). The drafts also echo Plath's 'Burning the Letters', in which the speaker is a 'Dumb fish' that is 'strung just under the surface' (204); she refuses to continue being strung along dumbly. 'Ophelia', especially in its early drafts, imagines that this character continues to speak. Plath's poems suggest that Hughes's letter-writing - and his fishing offer cruel lures. The loops of Hughes's letters were like hooks dragging her fish-persona from the depths. Yet it was only by writing, by fashioning such hooks, that Hughes could capture her voice after her death - and, perhaps, symbolically placate her in this elegy. The fish must stay in 'this peculiar engine' that 'keeps it going' and 'works it to death' $(C P H$ 655). The poem at once mourns Plath and contemplates the crueller aspects of the cycle of life and death: even the drive to survive works the trout to death. While most of the poems in River find hope and consolation in the thought that the landscape will regenerate every spring, the repeated movement of Ophelia through the churning water suggests a continuing act of mourning. While most of the poems in River are profoundly ecocentric, this poem functions instead as an expression of deep human grief.

If Hughes originally considered giving speech and agency to the 'Darkfish' in 'Ophelia', he gives agency to the river itself in 'After Moonless Midnight'. This poem describes the uncanny experience of an observer who feels that the river also watches him. Once again, Hughes's own notes to a reading of this poem prove particularly illuminating. He remarks that sea-trout come up from the sea to spawn in rivers, and are so wary that they usually can only be caught at night, by casting a fly: an especially 'eerie' process. 205 He enjoyed the 'drama' of fishing by night, according to Michael Martin, a fishing companion and fellow Devon campaigner ('Ted Hughes: Eco Warrior'). The poem becomes increasingly ecocentric as it moves towards an attempt to imagine the river's perspective. The fish 'Listened to me' and 'watched my each move | Through their magical skins' while 'Their eyes waited' ( $\mathrm{CPH}$ 659). Hughes's knowledge of animal perception is beautifully conveyed in the first part of this poem. A fish can sense danger approaching via the sensors on its lateral line, which detect movement in the water. The following lines are especially significant:

The whole river

Listened to me, and, blind,

Invisibly watched me. And held me deeper

With its blind, invisible hands.

'We’ve got him,' it whispered, 'We’ve got him'.' (660)

When the fisherman on the Sligachan hooked a little salmon, the water grabbed his heartnerve. On this dark river, the angler is caught bodily in the river's hands. The fisherman is so captivated by the river that he sees himself as prey. Here is a welcome reversal of Hughes's

204 Emory MARBL, coll. 644 box 68 folder 28, 'Ophelia’ TS

205 TS notes to reading from River 1. 
frequent feminisation of fish. Human predator and animal prey have changed places. Here, too, he is revising Lovelock's inert Gaia: this river-person is envisaged as active, even predatory.

For a fisherman caught by the river, adverse weather conditions are a frequent worry. Hughes has shown us the effect that an unusually cold spring has on fish; the salmon also face troubling problems during a drought summer. River is a celebration of water-cycles and aquatic life-cycles, but when he describes disruptions to them, Hughes hints at disturbing anthropogenic changes to the world's climate. 'An August Salmon' follows a salmon that has come upriver to breed. Salmon have to wait in the river all summer, usually finding a deep hole, but occasionally moving up or downstream if there is plenty of water. A drought might see salmon trapped in pools; the poem describes just such an unfortunate cock fish, during an August drought.206 The fish is 'Waiting for time to run out on him', but the sombre atmosphere of the poem communicates more disturbing problems than his wasting body and his likely death after spawning. This is a 'closed' river with 'poor flow' where 'Summer wastes in the pools'; these are only 'Four feet' deep, with 'premature leaf-crisps' floating on them ( $C P H$ 660). The drought is unusually severe: even the leaves of bankside trees have shrivelled. When Hughes writes about the impact of abnormal weather on wildlife, he shows a localised effect of climate change. Environmentalists had long been worried about freak weather conditions, and Hughes knew of Carson's early work on the effect of warmer waters on animals in the sea. Following severe droughts in the 1970s, the USA National Academy of Sciences published a report on carbon emissions causing climate change in 1977 (Weart 102). By the time Hughes wrote this poem, human beings were known to have affected the world's weather in profound and alarming ways. Reports that Hughes read in the late 1980s explicitly consider climate change as a cause of droughts and poor fishing in the West Country (see next chapter). But of course, Hughes's affecting descriptions of the fish give the poem's ecological ideas their appeal to the heart: we see the 'tail-frond' and 'dragonised head', admire the 'torpedo launch of his poise' but pity him for the 'muddy net of bruise' that covers his silvery flank (660-61). Hughes's evocation of the stagnant drought and the fish's wasting body are more successful ecopoetry than the idea that he is awaiting 'execution and death | In the skirts of his bride' (661); the last line would have been more poignant if he had not anthropomorphised the female salmon. Yet those last two lines encapsulate one of Hughes's overarching poetic preoccupations: the sacrifice of a masculine character to appease a feminine goddess, illustrating his respect for both Gaia and the feminine. But Frazer's priestkings were also sacrificed to end a drought. Will the male salmon be able to perpetuate his species? Will time also run out on fish of his kind? The collection's next poem hopes that the vintage of river is unending, but there will be other instances when Hughes's archetypal river does not manage to wash itself of death.

When a collection about rivers contains two poems about drought, it becomes clear that something very sinister is going on. 'Last Night' describes a river so severely diminished that it only reaches the fisherman's knees. Surrounded by 'high fields', this shrunken stream is in

206 TS notes to reading from River 1. 
the West Country; but there is a marked contrast between this river and the healthy Dart or the thriving Alaskan salmon-rivers. The river-god becomes old, sick, afflicted by a nameless evil:

\author{
Evil came up \\ Out of its stillest holes, and uncoiled \\ In the sick river, the drought river of slimes - \\ Like a sick man lying in the dark with his death.
}

Water pollution is felt most acutely in times of drought, when the river is unable to wash itself of contaminants; this point was raised during Ian Cooke's 1993 court case against South West Water.207 The water is 'Rusty peaty blood-dark, old-blood dark': images that evoke at once a sickened body, and metals and abattoir effluent polluting a watercourse. Here, Hughes shows a form of insidious, widespread environmental contamination of the sort that he first encountered in Carson's work; it seeps from tainted watercourses into human bloodstreams. If Hughes usually presents human beings' (re-)immersion in their environment as effecting a highly positive psychological healing process, he offers important complications to that view here. With 'Deep fish listening to me | In the dying river' (665), the angler stands accused of the crimes of his species. The poems about drought successfully articulate Hughes's concerns about the vast problem of climate change and the localised problem of water pollution, without losing their poetic sophistication and becoming protest verse. Sadly, Hughes's poetry after River presents many British watercourses that are close to death.

River begins by taking us through water-cycles and fish life-cycles in the British Isles. The collection's Alaskan poems manifest an exciting development in Hughes's environmentalism: a global awareness that begins to make itself felt in work such as Crow and 'The Tiger's Bones', and which becomes fully developed in Tales From Ovid. Both Hughes's West Country poems and his Alaskan poems describe locations he loved, but the key difference is that Hughes presents Alaska's environments as largely unspoilt: they act as contrasts to throw the threatened beauty of Britain's rivers into relief. 'That Morning' is one of Hughes’s ‘most ecstatic poems of ecological integration' (Gifford 2011 91-92): a tropological ecosystem-poem and a topological hymn to a valued place. Hughes and his son Nicholas visited Alaska between June and September 1980. Hughes described Alaska as 'Just the most fantastic land I've ever been in' to Karl Miller (LTH 434). Nicholas, too, was ‘smitten' (439), and father and son would later return for fishing trips in 1981 and 1986. Nicholas eventually moved to live there permanently, in 1990, and pursued a career in freshwater biology.

1979 had seen a record run of red salmon in Alaska's rivers. In 1980, the year when Hughes first visited, the run was 'reckoned just twice as big'. Hughes told his fishing companion Barrie Cooke how he and Nicholas fished the Kenai at its confluence with the Moose (437)

207 BL Add MS 88918/122/4, blue ruled notebook 197. 
and caught red salmon and lake trout on the Katmai peninsula with 'Bears everywhere' (438). 'That Morning' displays Hughes's striking awareness of the web of life that makes up an ecosystem, and its details correspond to careful notes that he made in his fishing diaries. At the Katmai peninsula, Hughes recorded lupins, kingcups and bright green marsh grasses. 208 He observed drifts of blue lupins, manes of devil's club, clover and dandelions at Turnagain inlet, 209 the day before he and Nicholas fished the Kenai-Moose confluence. In a later diary, he mentions lupins, a 'bear path' and seeing a black bear during his 1981 fishing trip to the Gulkana.210 These notes show Hughes to be a skilled naturalist; they inform the 'topological' evocation of spots of time and the 'tropological' sense of an interconnected ecosystem in his Alaska poems.

'That Morning' begins with a comparison of Alaska's massed salmon to Lancaster bombers flying over Britain: these thronging aircraft are all that 'England could add' by way of comparison. Hughes's description of South Yorkshire's 'sooty twilight' is telling; he is contrasting the polluted air of industrial Mexborough with the more pristine landscapes of Alaska (663). The 'massed' salmon of 'That Morning' are used to draw attention to the diminished salmon-run of West Country rivers. Hughes needs to look back to before the Industrial Revolution before he can use the term 'massed' of fish spawning in England. His 1992 notes to Rain-Charm for the Duchy state that an eighteenth-century diarist could not ford the Tamar when his horse was frightened by 'massed fish going up over the gravel, through the ford, backs out, tails churning like propellers' - there were 'huge numbers in those days' (1215). Hughes creates a melancholy contrast when he places the pollution-poem 'Last Night' between the Alaskan poems ‘That Morning' and 'The Gulkana'. In Britain, it was once possible to stand 'Waist-deep in wild salmon swaying massed | As from the hand of God', to experience their 'dazzle of blessing'.

Hughes's 'ecstatic' tone is created by the wonderful sight of a thriving environment:

As if the fallen

World and salmon were over. As if these

Were the imperishable fish

That had let the world pass away -

It is as if the polluted, industrialised Old World had passed away, as if this unspoilt river of the New World were a revelation. Hughes gives his poem a Biblical tenor, but the actual fish, not Christ the Fish, are imperishable. Hughes mentions 'a mauve light of drifted lupins': this poem captures ecological interconnection right down to the last botanical detail, and the

208 BL Add MS 88918/122/1 unbound, white and blue ruled notebook, 38 verso.

209 White and blue ruled notebook, 56 verso.

210 BL Add MS 88918/122/2, notebook labelled 'June $23^{\text {rd }} 81-2^{\text {nd }}$ July’ 119 recto and verso. 
fishing diaries suggest that the flowers are drawn from life. Two 'gold bears' arrive and eat pierced salmon from their talons beside the fishermen. Upliftingly beatific, this poem sees Hughes and his son 'alive in the river of light | Among the creatures of light' (664). He communicates the psychological effect of a purifying chrism of unpolluted river. He is so moved by the sight of massed salmon and plentiful bears, because the fish are dwindling in Britain's rivers and because Britain's bears have been hunted to extinction. He would comment in a later interview that he preferred fishing around grizzlies to the safer but tamer riverbanks of Britain - 'the wilder the experience is, the better it is' - and that what the fisherman seeks is 'something sacred and unspoiled'. His interviewer remarked that this was why anglers were flocking to Alaska (Pero 56-57). Here is why when Hughes feels 'hunted' in 'The Gulkana', part of his inner nature 'exulted | Recognising his home' (CPH 666-67). For Hughes, our inner being craves visceral reminders of its place in the interconnected web of life. An important part of the experience is not just pursuing prey, but feeling the fear of becoming prey.

Hughes and Nicholas fished the salmon-filled Gulkana from the $23^{\text {rd }}$ of June to the $2^{\text {nd }}$ of July 1981, and Hughes's fishing diary relates his meeting with the Native American headman, and the confluence of the Copper and Gulkana Rivers.211 This was Hughes's first experience of catching huge Pacific King salmon.212 'The Gulkana' is especially important from an ecopoetic perspective because of the information it gives about Hughes's perception of indigenous people's relationship to their environments. It is important that the river's name is a 'pre-Columbian glyph' (665): here is a word that has survived the invasion of Alaska by Russian and American colonists. 'Strange word, Gulkana', Hughes muses. If he had asked the headman what the river's name meant, he would have found out that the toponym has its origin in the language spoken by Alaska's most widespread First Nation group, the Athabaskans, for whom it means 'tearing river' (Bright 159). Here, Hughes does risk essentialising the Athabaskans as 'Indians', and their language and territory as incomprehensible in their alterity. But his description of an Athabaskan village is more sympathetic, more alert to the circumstances that have eroded their traditional ways of life:

A scrapyard of boxy shacks

And supermarket refuse, dogs, wrecked pick-ups,

The Indian village where we bought our pass

Was comatose - on the stagnation toxins

Of a cultural vasectomy. They were relapsing

To Cloud-like-a-boulder, Mica, Bear, Magpie. (666)

211 BL Add MS 88918/122/2 118-119.

212 TS notes to reading from River 1-2. 
It is significant that Hughes uses metaphors of pollution and sterility to communicate cultural decline. His descriptions of wrecked pickups and supermarket rubbish deplore the Native Alaskans' enforced conformity to white American economic practices and values. These values are polluting 'stagnation toxins': modernity brings environmental degradation. The Native Americans are relapsing to their old totemic symbols, and one hopes that this will help them to renew a sense of their cultural identity. This poem draws out the intricate debates surrounding what Skinner terms 'ethnopoetics': poetry that explores the connection between plundering territory and exploiting its autochthonous people.

Hughes's 'ethnopoetics' become more complicated as the poem progresses. He evokes warpaint and ritual dances when describing the movements of the salmon and the vibrant pigmentation of their breeding colours. The fish have 'mulberry-dark torsos' (667), and this detail is drawn from life: Hughes wrote of catching a 'dark' male fish with 'black head \& mouth' in his fishing diary.213 In his preface to River in the later Three Books, his descriptions of the pigmentation of fish are more figurative: the colours of cock fish 'can become almost violent, like warpaint' (1212). While the images of breeding colours as war paint are apt, the comparison of the salmon to 'Drugged, ritual victims' whose death is a 'sacrament' is at odds with the imagery of emancipatory rituals that Hughes also employs. Here, though, is an echo of Lawrence's 'The Woman who Rode Away', where a white woman becomes a sacrificial victim in a Native Mexican ritual. Hughes later compares the fish to 'Aboriginal Americans', and their redds to the 'circle' in which they 'dance their deaths' (668). This suggests the Ghost Dance, an emancipatory Native American religious movement that arose in the 1870s among the Paviotso (Du Bois 5) and the Lakota in 1890 (Andersson xi), spreading to over thirty tribes and prophesying a peaceful 'return of the old [pre-European] ways' (Andersson x). The dance in question was circular (Du Bois 12). Hughes would return to the Ghost Dance later in his career, in 'On the Reservations'. Hughes's weaving of Ghost Dance imagery into his description of salmon celebrates the autochthony of North American peoples and creatures, although it does risk conflating the Alaskan Athabaskans with the Great Plains Lakota and the Great Basin Paviotso. Hughes, however, is aware of his foreignness and his incomplete understanding of these people: the Headman smiles at the white fishermen's 'incomprehension': with his face like a 'whole bat' ( $\mathrm{CPH}$ 669), he understands local ecology better than they do. Nowadays, a white Englishman who compared salmon to Ghost Dancers and a Headman's face to a bat might be accused of stereotyping Native Americans as animal-like, of anachronistically labelling them as environmentalists, or of appropriating their cultural heritage. Hughes clearly admires Native Americans and wants to identify with them, but it is surprising that we meet so few them in his published work. Lawrence, a major influence, makes Native American culture and the power relations between races a far more important focus of his writing. In 'The Woman who Rode Away', we meet indigenous Mexicans, hear their voices in translation, witness their rituals. More critically, we see them sacrifice a white woman to win 'The mastery that man must hold, and that passes from race to race' (2002 71). Hughes's readers hear the voices of Sitting Bull, Smohalla and Owl in 'On the Reservations', but the Navajo dancers play a

213 BL Add MS 88918/122/2 121 recto. 
surprisingly small role in 'Grand Canyon'. The 'Indians' we meet in 'The Head' are fictionalised and unrealistic. In the less scrutinised space of his fishing-diaries, Hughes writes candidly about encountering uneven development, racial difference, and the surprise of his own foreignness when travelling in abroad.214 In North America, he saw a Canadian chief carving a sun mask and heard of Ehor Boyanowski's solidarity with 'Indians.' 215 It is possible that Hughes was disappointed to meet Native Americans in 'boxy shacks' rather than 'smoking encampments' (LTH 103), or that his boyhood image of himself as a Native American hunter broke down when he met real Alaskan Athabaskans. He shows his solidarity with them in oblique and rather problematic ways, by identifying them with endangered animals and miners on the picket line. His engagement with postcolonial and development issues focused mainly on championing lesser-known literatures and preserving rare species abroad.

When the speaker of 'The Gulkana' leaves Alaska, the river leaves a profound impression on him:

Word by word

The voice of the river moved in me.

It was like lovesickness. (669)

The river's voice communicates with the angler, creating language and meaning, continuing to shape Hughes's river-epic. Moreover, feeling 'lovesickness' for an environment, a detail drawn from Hughes's fishing diaries,216 speaks of his deep attachment to these rivers: the Tuanian 'topophilia' that Scott Bryson finds in ecopoetry (11). He feels strangely at home in this foreign land via his encounters with wild animals and with the northernmost state of Plath's homeland - but primarily because the rivers are largely unspoiled and their biodiversity is preserved. The sensation of being hunted actually makes him feel more at home, deepening his sense of belonging to place. This is profoundly 'tropological' ecopoetry. The fisherman takes his place in the ecosystem when he occasionally kills a salmon to eat; but the presence of grizzlies threatens to let local ecologies devour him as completely as the dismembered shaman in 'The Bear'. Skinner's definition of tropological ecopoetry, which suggests that poems function 'like ecosystems or complex systems' (128), does not fully explore how the poet and other human beings fit into those ecosystems. His model could be expanded to account for human beings' participation in the trophic web as predators and (rarely) as prey.

Participating in the nature's cycles of predation, death and renewal is vital to the human mind in Hughes's vision, and River articulates this especially clearly. Between his Alaska-poems,

\footnotetext{
214 BL Add MS 88918/122/6, terracotta notebook, labelled P. H. Sassoon, numbered 16. Page 1 verso 215 BL MS ADD 88918/122/1, notebook labelled '11' by archivist and 'Fairbanks: Sept $4^{\text {th }} 1986$ ' by Hughes, 18 recto, 19 recto.

216 BL Add MS 88918/122/2 128 recto.
} 
Hughes had placed 'The River', which integrates the resurrection-myths of Christ and Osiris with the ecologist's hope that the river can 'wash itself of all deaths' after 'swallowing death and the pit' (664). (The 'pit' evokes both the pit of hell and mine-tailings from coal-'pits' washing into the rivers of his Yorkshire childhood.) He underscores his idea that healing nature heals our inner nature in 'In the Dark violin of the Valley'. Lawrence Buell finds the violin metaphor to be problematic (see Chapter I). Yet Buell has missed the sense of an intricate mesh of nature and culture that this poem creates: music sews body to soul, soul to sky, sky to earth and river to sea. Envisaging the river as an 'aorta' (670), Hughes draws on Lovelock's Gaia-theory to imagine the earth as a single organism. Hughes commented at a reading that the poem was inspired by a night spent over the River Dart, below Dartmeet; the poem is topological. He stated that he imagined the river's music as a surgical operation deep inside the body, as if surgery could be performed on the spirit.217 The river-music heals the damaged human spirit, reimmersing the speaker in the 'primitive' human and returning his 'inner nature' to a state of wholeness. There is an environmental imperative behind this poem: damaging the bloodstream of the land means damaging the human body and spirit.

One of the unifying principles of the collection is its emphasis on rivers as the lifeblood of the ecosystem and of the human circulatory system. In view of its focus on fluidity and mutability, one wonders why so many of Hughes's rivers are feminised. Critics have found this to be one of the collection's flaws: Roberts notes that his 'persistent feminization of the natural world results in a vein of arch sexual symbolism’ (2006 140). Hughes’s introduction to his reading of 'Low Water' gives his explanation for this symbolism. He stated that rivers can be likened to women, whatever mood they are in. The obsessive nature of angling, he explained, has something to do with the feminine qualities of rivers.218 Hughes's assertion risks reproducing the essentialist gender binaries that second-wave feminism was seeking to dismantle at the time the collection was published. Yet the collection as a whole creates some balance between genders: the river is feminine in 'New Year' 'Dee', 'Low Water', 'September', 'Fairy Flood' 'Torridge' and 'Salmon Eggs' but masculine in 'Japanese River Tales', 'The River' and 'Last Night'. Among the collection's rivers are strong brown gods as well as fecund goddesses. 'Low Water' did not feature a gendered river in early drafts, and when the river's gender was not mentioned, the poem was (arguably) a more successful imagining of the 'voice' of water. Very significantly, Hughes considered writing this poem in the first person in early drafts.219 Hughes told his son to 'live like a mighty river' (LTH 515). That undated draft that begins, 'Me as the river', 220 further helps to relieve Hughes's writing of the occasional tendency towards biological gender essentialism that appears in River, by showing how Gaia's rivers also run through men. Imagining a river's perspective could be seen as a profoundly biocentric endeavour - akin to, say, Aldo Leopold's attempt to think like a mountain in A Sand County Almanac. There is also one moment in the collection when

217 TS notes to a reading from River 2.

218 TS notes to reading from River 2.

219 BL Add MS 88918/1/54 17 recto.

220 BL Add MS 88918/9/9, page torn from an A5 ruled notebook, 'Me as the river'. 
a fish is presented as changing sex. Hughes did not live to witness the interest in 'queer' nature that followed in the wake of work by biologists such as Joan Roughgarden (2004). Yet it was known at the time River was published that eels may be intersex or may change sex,221 and 'An Eel' begins by referring to the eel as male, and quickly changes its sex to female ( $\mathrm{CPH}$ 675). If Hughes's goddess is always feminine, his fish and rivers occasionally display a spectrum of sexualities that challenge the heteronormativity of much of his work.

Hughes's awareness of very specific problems with Britain's rivers is an undercurrent throughout the collection. 'Eighty, and Still Fishing for Salmon' shows an elderly fisherman's view of 'Estuary nets | Empty. The river fishless' (674). Hughes was aware of the effect of interceptory netting on Atlantic salmon thanks to his reading of Your Environment, and salmon netting would become a focus of one of his major late environmental campaigns. In 'Performance' the banded demoiselle, Agrion splendens (PC 96), has 'acetylene jewels' ( $\mathrm{CPH}$ 672). Acetylene is a word from Plath's lexicon: she underlined it in her dictionary (Brain 2001 117), and uses in 'Fever 103', whose speaker is a 'pure acetylene | Virgin' (CPP 232). The intense flame that acetylene produces is used for blowtorches, which is the image that immediately springs to mind when Hughes describes the damselfly's bright jewels. Yet acetylene is sometimes used as an insecticide, as Plath and Hughes learnt from their reading of Carson (Brain 2001 117). The damselfly progresses towards her 'doom' ( $C P H$ 673): while this evokes a necessary part of the insect life-cycle, the poem offers the possibility that it is hastened by deadly acetylene. The problems that plague Britain's waterways are ever-present in these poems, but the most poignant elegy for a damaged ecosystem is 'October Salmon'.

The pathos of this poem comes from its focus on one particular fish and from elements of veiled personal elegy. This poem is especially significant because it expresses the fragility and vulnerability of wild creatures - and humans - to sickness, ageing and pollution. Hughes's evocation of the salmon's declining strength testifies to the maturity and sensitivity of his environmental awareness: his work has developed a great deal since he wrote about the fearsome predators and charismatic megafauna that helped to establish his reputation. 'October Salmon' is poignant for another reason: some remarks that Hughes made about the poem suggest that it draws on memories of his father. He remembers that

I had gone to visit my father who was very ill at the time and I stopped by a nearby salmon river. This was in the autumn, in the early 1980s. And from a bridge I saw this one fish, a little cock salmon, lying motionless is [sic] the clear shallow water - the only fish in a long pool that in October 1961, [...] had held more than 100. (Pero 57)

Like William Hughes, the salmon is a 'veteran', a ‘death-patched hero' (CPH 677). In another interview, Hughes described encountering England's polluted rivers as like seeing 'a dying relative' ('Bookshelf'), underscoring the idea of his own kinship with Britain's watercourses and water-creatures - and also evoking the insidious effects of water pollution

221 Wiberg, U. H. 'Sex determination in the European eel (Anguilla anguilla, L.) A hypothesis based on cytogenetic results, correlated with the findings of skewed sex ratios in eel culture ponds', Cytogenetics and Cell Genetics, 4. 36, (1983): 589-98. Print. 
on humans and nonhumans alike. The human insignia of warfare are replaced by the universal and all-conquering livery of Death, who robes the salmon 'In her clownish regimentals, her badges and decorations | Mapping the completion of his service'. We glimpse the former dynamism of the salmon, when he was animated by an energy almost as colossal as that of the hawk and pike. He was 'king of infinite liberty', borne '[o]n the surgeride of energy' ( $\mathrm{CPH} 678$ ). The description of the sea-dwelling young salmon suggests an idealised vision of power and strength. However, this discourse of supremacy is quickly rejected: the fish's whole body is 'A fungoid anemone of canker' (678). This disease suggests skin conditions in fish that are aggravated by pollution. Hughes explained the behaviour of salmon in the months leading up to spawning in his detailed notes to River in Three Books. After several months in rivers, salmon develop 'patches of fungus - if not the full-blown Ulcerative Dermal Necrosis (that hit rivers in the British Isles at the end of the 1960s, and has all but wiped out some stocks)'. The disease ulcerative dermal necrosis (UDN) was a particular concern, as Hughes and his associates thought that it might be linked to river pollution. In 1969, Hughes first caught a trout with UDN on the Taw, and became aware that this unique river was in decline ('Trout on the Upper Taw' 6). In 1993, Hughes wrote to Gifford that when UDN arrived from Ireland, it might have been exacerbated by the increased 'chemical load' in British rivers, especially from 'detergents'. Hughes had learnt this back in the 1970s, from his work with David Jones. The 'farming revolution' created further pollution in the 1970s (Gifford 2011 148-49). By the early 1980s, when Hughes visited his ill father, the pool in which the October salmon lay had also been profoundly reshaped by human interference:

this uneasy channel of minnows

Under the mill-wall, with bicycle wheels, car-tyres, bottles

And sunk sheets of corrugated iron.

People walking their dogs trail their evening shadows across him.

If boys see him they will try to kill him. (CPH 679)

Disease is not the only threat that the salmon must negotiate: rubbish of all kinds has been dumped in the pool, affecting the quality of the water. Boys wanting to kill him are an added threat. From 1983 onwards, the year when River was published, Hughes was to become increasingly engaged in defending Devon's river environments from suffering such a sad fate.

Hughes ends his river-epic with a hopeful view of salmon populations recovering, as if the salmon born in the hatchery were ending their life-cycle and perpetuating their species. In 'The Morning before Christmas' there are enough fish for them to begin 'shivering together, touching at each other' in an entirely natural spawning. The fisherman returns to the redds near the headwaters of Devon's rivers. This is a topological poem that communicates a love of place: it is January, and the location is the Torridge (LTH 448). As in 'Go Fishing', the river 'supplants' (680) the speaker as he encounters forces more potent than human activity. If 'New Year' saw the river undergo a fruitless Caesarean birth (643), then this 'Caesarean' (680) brings new life. Hughes wrote to a friend that the poem was inspired by ancient Celtic statues of fertility goddesses. 'Salmon Eggs' was originally about 'Sheila-na-gig', a highly 
sexualised ancient British and Irish fertility goddess (LTH 448); a 1982 typescript has a dedication to her.222 The poem is full of the vocabulary of birth: a child is said to have 'crowned' when its head is visible, and 'travail' can mean labour. Hughes's focus on a welling 'cleft' and a 'swollen vent' overdoes the imagery of female fecundity, but it is understandable in a poem where 'Only birth matters' (CPH 681). The collection ends as the voice of water hushes the voice of the poet: the river 'Silences everything in a leafmouldering hush' (CPH 681).

In 1983, the year he published River, Hughes continued to celebrate the West Country’s rivers and examine their problems in another publication produced in an environmentally responsible way. This time, he did so in prose. He published an essay called 'Taw and Torridge' in an anthology edited by his fishing companion, Anne Voss Bark, who was to cofound the West Country Rivers Trust with him. Peter Keen also contributed photographs. This book was written to attract fishermen to the area, but it also had an explicitly environmentalist aim: it was printed on paper made by an environmentally conscious mill that also ran a fishery on the River Erme (West Country Fly Fishing viii). Hughes's article celebrates North Devon as a region of 'wilderness', which harboured peregrine falcons in the 1960s despite the 'DDT crisis' ('Taw and Torridge' 25) and rare 'porcupines',223 in spite of those who would prefer to see them 'stamped out' (26). He stresses the great worth of the rivers' fisheries (27), and details the dangers they have faced: metal deposits in the Okement created a 'sudden spill-out of pollution' that killed all of the trout after a drought summer (29). Yet a new fish pass was letting salmon through to spawn on the Okement, and the Torridge had seen an 'astonishing' spawning run a few years later, despite heavy netting in the ocean (29). '[S]ophisticated poaching' was a threat to spring fish (33), and in a dry summer, interceptory netting sometimes sometimes meant that the 'whole run is killed' (37). Hughes balanced his environmentalist critique of poaching, pollution and overfishing with more upbeat information because he wrote the essay for friends, 'to glorify the rivers while suppressing the knowledge that they are going down the drain’ (Gifford 2011 85). If River expresses Hughes's hopes for the world's waterways, his prose about rivers 'going down the drain' is a more candid glimpse of his perception of the complexities and difficulties of the environmental situation in Britain.

River is the acme of Hughes's ecopoetic career. He evokes the pathos and outrage of environmental destruction without using the protest-verse that diminishes the poetic quality of his more propagandist pieces. He fashions experimental poetic forms that contrast with much of his earlier work. These celebrate the experience of journeying to a river-pool or watching a kingfisher in flight. His topological project of place-making takes us back to the Calder Valley, and especially to the rivers of the West Country. Yet the key difference between these poems and his Elmet-poetry and Moortown-poetry, is that River is more thorough in its treatment of environmental problems and far broader in its geographical reach. Hughes contrasts unspoilt rivers in Alaska with some of their polluted British counterparts, but the collection is unified by the water-cycle and by the life-cycle of salmon. His poetry of

222 Keith Sagar's private archive, carbon TS of The River, 'Salmon Eggs For Sheila-na-gig'.

223 Hughes does not mention that porcupines are not native to the UK, and have been introduced. Mark Hows. 'British Isles exotic and nonnative mammals', 2010. Web. $7^{\text {th }}$ Nov 2016.

http://www.hows.org.uk/inter/birds/exotics/gbm.htm 
interconnection often reads like a mythologised version of Lovelock's Gaia-theory, although River is also painfully aware of the pervasive effects of human activities on aquatic systems. His poetics of habitat widens its scope to reflect the experience of living in an increasingly globalised world, and his poems about drought reflect the beginnings of his concerns regarding climate change. His poetry was articulating his theory of why humankind feels a psychological need to connect with the natural world. These ideas would be elaborated later, in his interview with Pero and his correspondence with Gifford about ecopsychology. He was beginning to consider the Royals' relationship to the land, an important aspect of the next phase of his activities. Although the collection opens at a hatchery on the Tamar and ends on the Torridge, the collection implies that the Tamar's salmon hatchery is a successful conservation measure. Yet more strikingly, the very publication process of River was explicitly environmentalist. Backing from the Countryside Commission, and from a hydrocarbons company keen to be seen as progressively 'green', testifies to a new strand in Hughes's environmentalism: using poems and books to gain the support of corporations, charities and prominent public figures. Not even Your Environment had been so successful in achieving this aim. Hughes's essay for West Country Fly Fishing was produced in a similarly environmentally responsible way. Yet Hughes's letter to Gifford reveals that he was more anxious about the state of Britain's rivers than he implied in either the essay or in River. His activities after he accepted the Laureateship corroborate this: he began to focus increasingly on political lobbying and high-profile environmental campaigns, while the subtle ecopoetry of River was often replaced with protest poems. 


\section{CHAPTER IX: GREEN LAUREATE}

The 1980s were the decade when environmental awareness became more visible in mainstream British politics and society. By the end of the decade, the Conservatives were trying to sound 'green', environmental concerns were shaping the choices of individual consumers, and both the Green Party and environmental pressure groups had seen a surge in support. This was also the decade when Britain would appoint a distinctly 'green' Poet Laureate. Thatcher had come to power in 1979 with little interest in the environment, describing it as a 'humdrum' concern (McCormick 1991 58). But by 1988, she highlighted problems such as population growth, global warming, threats to the ozone layer and acid pollution, speaking of the Tories as 'friends of the Earth' (60). The Iron Lady was beginning to sound more like Hughes's Iron Woman. The demand for environmentally friendly products also increased in the late 1980s; The Green Consumer Guide became a bestseller, and one of the 'green consumers' to purchase it was Hughes. 224 With the rise of green consumerism came an increase in support for green politics. The Green Party surprised many British people by winning fifteen per cent of the vote at the European Parliament Elections of 1989 - a far higher proportion than before (109). Greenpeace saw its membership soar by 3,100\% from 1980 to 1989 (153). There was a strain of 'radicalization occurring in the environmental movement', fostered by Thatcher's initial unwillingness to engage with environmental issues and the sense of urgency that accompanied the 1986 Chernobyl disaster (154). By 1990, Friends of the Earth and Greenpeace were also becoming less confrontational in their tactics (158), and brought about 'substantial changes in public policy' (165). As we shall see, Hughes was contributing to this radical strain in contemporary environmentalism, in his own quiet way.

Hughes's environmental activities were becoming more high-profile, more public, and more campaign-oriented. The years 1984 to 1992 saw some of his most sustained campaigning. With his appointment to the Laureateship in late 1984, Hughes found that his poetry had a far wider audience. He was able to harness the recognition that he gained from this wider readership to sell his protest-poems to major national newspapers, disseminating their green message in the media. Indeed, Terry Gifford has called him 'Laureate of nature' (2011 Chapter 6) - but the Laureateship represents a specific current of thought in Hughes's environmentalism and in his writing. It gave him the gravitas to criticise politicians who did not do enough for the environment, and form alliances with powerful people who could help his cause. His letters to newspapers about environmental issues now bore his name. He befriended Conservative politicians and lobbied those in power with letters. The environmental poetry that Hughes produced during this time is not always his best ecopoetry. His 'semi-protest pieces' do not equal River in poetic quality, but they offer a more factual, hard-hitting environmentalist message than his aestheticised water-song. But with the launch of Arts for Nature in 1988, and the Sacred Earth Drama Trust's children's writing competition in 1990, it was clear that Hughes was renewing his efforts to use the arts for environmental education and awareness. As Gifford's research has shown, he campaigned determinedly against the pollution of the Torridge Estuary from 1984, and supported his friend Ian Cook's high-profile 1992 court case against South West Water. With the publication of his children's environmental fable The Iron Woman in 1993, he broadcast his concern about water pollution and waste, and articulated his respect for women

224 John Elkington and Julia Hailes, The Green Consumer Guide. London: Gollancz, 1998. Emory MARBL, TX337 .G7 E43 1988 HUGHES. 
environmentalists. Although he was rubbing shoulders with Conservatives, he donated royalties from his poems to Friends of the Earth and Greenpeace.

Hughes's 'green laureate' activities are distinctive for their focus on affairs in the British Isles, targeting either specific localities or nationwide problems. Of course, they overlap chronologically with a more global current of thought in Hughes's environmentalism, which had long been developing and which becomes most clearly visible in the late 1980s and the 1990s (see next chapter). In 1984, Hughes became involved in a prolonged campaign to protect the Torridge at Bideford from sewage pollution. Hughes heard about the Torridge Action Group, six campaigners determined to protect the river's estuary from sewage pollution, and rang Torridge Action Group member Monica Pennington to offer his help ('Ted Hughes: Eco Warrior'). They campaigned against the installation of a fine screening plant at Bideford, which would remove 'solids' such as hair and cardboard from sewage, but would leave the sewage itself untreated.225 Levels of dangerous bacteria in the estuary were high (12-13) - hence the prevalence of ulcers, stomach, throat and chest ailments among Bideford's residents (13). An area of deoxygenated water, polluted by sewage, also prevented migrating salmon and seatrout from swimming up the Torridge and forced them either to swim up the Taw, or to stay in the sea and be decimated by netsmen (20-23). They were unable to spawn, which damaged the lucrative fishing industry (23). The lifting of a building embargo in the area would only worsen the situation by creating yet more sewage (27-8). By June 1985, Hughes had grown 'sick' of the battle over the River Torridge (PC 144). Yet he persevered with the cause, lobbying those who could raise money to pay the Action Group's legal fees ('Ted Hughes: Eco Warrior), and delivering a persuasive speech as the main witness at a public inquiry into Bideford's sewage problem in September of that year. Hughes begins his speech by stating that although he is a writer, he takes a 'Scientific interest' (TS draft of speech for Enquiry 4) in environmental matters. His speech is full of carefully researched statistics and persuasive readings of scientific documents. Unfortunately, the other side also deployed 'scientific research' to obscure the real dangers of the contaminated estuary ('If' 33), and the battle for the Torridge would continue in future years. Hughes's publications continued to reflect his concern. In a 1984 coffee-table book of photographs of British landscapes, Hughes complained that for forty years, water authorities had 'ravaged' Britain's rivers in the name of flood control, turning 'winding wildernesses' into 'sterile aqueducts in which no wildlife can survive'. While other contributors rhapsodised about Britain's scenic beauty, Hughes bludgeoned his reader with alarming information about otters killed by dieldrin and habitat loss, the inadequacy of the 1981 Wildlife and Country Act, and the political pressure that 'landowners' exerted to drain land for their 'private gain', thus 'depriving the public of a priceless landscape' ('A Devon River' 16). This environmental essay reads more like Hughes’s pessimistic letter to Gifford (Gifford 2011 85) than the quietly hopeful tone of River. At this point, riverine landscapes and water pollution proved a key theme of his first Laureate-poem.

\section{Environmentalism and Monarchism}

Hughes's royalism was influenced by his mother (Bentley 100), and he would come to regard Prince Charles and Prince Philip as allies in his environmentalist cause. The previous chapter explored the courtly dimensions of a river-poem, and it is clear that Hughes was considering how his poetry could honour the Royal Family - and examine Britain's environments several years before he accepted the Laureateship. In 1982, the Sunday Times asked him to

225 BL Add MS 88918/121/1 4. TS draft of speech given by TH at public Enquiry; archivist's numbering. The page numbers of further references to documents in this folder are given in parentheses in the body of the text. 
write a poem to mark the occasion of Prince William's birth (LTH 497); a national newspaper was positioning Hughes as a potential successor to Betjeman. Hughes was trying on the Laureate's mantle in the resulting astrological poem, 'The Zodiac in the Shape of a Crown'. Hughes's monarchism was an important facet of his patriotism (1216), but it was partly informed by his rejection of materialistic modernity and contemporary politics, his longing for a timeless alternative to the 'tabloid scrimmage of ideologies' (1217). His environmentalist ideology also provided an alternative to 'tabloid' ideologies (but it can hardly be seen as timeless since it was very much a product of its historical moment). His Laureate-poems are not always his best, but they imagine an antidote to warfare, societal division, pollution and species loss. The poems for the Queen Mother 'project an Eden - not just a childhood land of the animals, but a land of communal protective care' (LTH 507). Hughes wrote 'Little Salmon Hymn' for the Queen Mother because she enjoyed fishing and was patron of the Salmon and Trout Association ( $C P H$ 1216). He disliked the ceremony and suit-wearing that accompanied his acceptance of the Queen's Medal for Poetry ( $L T H 354-$ 56), although he found the Queen, Prince Charles and the Queen Mother 'easy to speak to quite intimately' (738). His environmentalist collaborations with Prince Philip and Prince Charles are explored later in this chapter.

\section{'Rain-Charm for the Duchy'}

Hughes was appointed Poet Laureate in December 1984. His first Laureate-poem, published in The Observer on the $23^{\text {rd }}$ of December, commemorates Prince Harry's christening a few days before Christmas 1984. Yet Hughes admitted in early 1985 that his poem had originally been intended to add 'a few pieces of different voice \& focus' to River (PC 142). It was conceived as a rain-charm for bringing back the salmon226 after a five-month drought.227 The poem describes the breaking of the drought in 1984, but also draws on memories of the severe drought of 1975 (CPH 1216). The tone of 'Rain-Charm' is regional, humorously shamanic, and distinctly environmental. The title marries Christian and pagan symbolism, prompting Heaney to call Hughes’s poem 'bardic' (1985 6), The Times to report the appointment of 'The Crow Man as Tribal Poet' (1984 9) and Robert Nye to call Hughes the 'royal witch-doctor' (48).

'Rain-Charm's' title suggests that this poem is a piece of slyly heathen, faux-primitive fertility-magic - and that the poet himself is a rain-maker. Rain-making is an important role in many pre-Christian societies, and is often the province of kings (Frazer 101-104). Hughes alludes to his careful reading of Frazer and Jessie Weston, and Eliot's (perhaps mockscholarly) deployment of their work in The Waste Land, especially in 'What the Thunder Said'. Ritualistic symbolism in the poem is handled with a light touch, but it is present: bracken does a 'rain-dance' and the moors are two 'stone-age hands' that hold water, 'Cupped and brimming, lifted, an offering' ( $C P H$ 805). The 'you' in the poem climbs into a car, 'Scattering oxygen like a drenched bush' (803). Middlebrook finds in the 'drenched bush' a reference to Eliot's reworking of Weston's fertility myths: 'Slyly suggestive, it points to an ancient belief in the relationship between the king's fertility and the nation's health' (4).

226 MARBL c. 644, subseries 2.2, b. 78, fol. 6, 'RAIN CHARM FOR BRINGING BACK THE SALMON' TS. 
This allusion to human fertility is apt considering that a new prince had just been born, but the fertility of the land and its rivers is more important to Hughes.

West Country rivers such as the Barle, Lyn, Mole, Little Silver and Crooked Oak are named and personified in an epic catalogue. The poem creates a realistic river-map of a large region, beginning at the rivers' moorland sources and ending at their estuaries. Hughes described these rivers in detail in his 1992 notes to the collection Rain-Charm for the Duchy (CPH 1214), and his river-map in verse is topological ecopoetry. The poem begins with the pools at Cranmere - near the sources of the Okement and Dart. These are now 'ulcer craters', but they 'had been river pools'. The focus shifts to an urban setting, where 'Thunder gripped and picked up the city' (803). Environmental issues predominate in the latter half of the poem. The 'smoke of life' that seeps into the Taw is more than figurative: it relieves a parched river. The Torridge is a 'washed cherub, clasping the breasts of light', the cleansed river becoming a christened child. An undated prose piece expresses Hughes's disgust at seeing litter in the Torridge after floods, 228 and the clean Torridge that 'Rain-Charm' describes must have been a welcome sight. The Okement begins moving the litter that clogs up its course, 'nudging her detergent bottles, tugging at her nylon stockings, starting to trundle her Pepsi-Cola cans' (804). The tectonic power-surge of the line 'And the Tavy, jarred from her quartz rock-heap, feeling the moor shift' is followed by a personification of the river in which 'she' is 'Rinsing her stale mouth, tasting tin, copper, ozone'. Alongside a powerful evocation of the forces of nature, Hughes includes a realistic list of the pollutants that human beings have poured into the Tavy. There is a distinctly regional flavour to the poem, which incorporates local dialect: the Tamar has 'shillets' (805). Hughes first encountered this word in Tarka the Otter, which taught him that it means 'Flat stones of the river bed deposited by flood waters' (Williamson 187); he later heard it used by the Devon farming community.229 Hughes ends the poem with very precise descriptions of estuaries: the Torridge and Taw meet the sea at Crow Point and Bideford Bar, the Dart debouches at One Gun Point, the Ness ends its journey at Teignmouth and the Tamar flows into the Hamoaze. The rain-charm ends with the salmon, which have been waiting to swim up the rivers to spawn, beginning their journey upriver:

The salmon, deep in the thunder, lit

And again lit, with glimpses of quenchings,

Twisting their glints in the suspense,

Biting at the stir, beginning to move. ( $\mathrm{CPH} 805)$

Hughes's 1992 note to the poem explains that salmon will wait for a rise in river levels before attempting to swim up to their spawning grounds, and demonstrates that salmon catches in West Country rivers have declined since the eighteenth century. Because salmon are 'such sensitive glands in the vast, dishevelled body of nature' (1215), they are attuned to changes in the weather - but also to changes in water quality, which Hughes does not discuss in his notes to the poem. Sewage in Bideford Estuary was a particularly significant problem for returning salmon. Hughes's protest poems tackle environmental issues, but his ecological Laureatepoems have a particularly significant societal role, as they are written for a monarch and are designed to be read by an entire nation. Originally published in a national newspaper, and the

228 BL Add MS 88918/6/12 undated MS notes 15-22. My numbering.

229 Letter from Carol Hughes to Yvonne Reddick, 28. 01. 2013. 
only Laureate-poem to make it into his New Selected Poems, 'Rain-Charm' was a highprofile way for Hughes to demonstrate his concern about Britain's river environments. The other Laureate-poems contain powerful plant and animal symbolism. Yet it is striking that Hughes's critics - and Hughes himself - regarded this Laureate-poem about salmon as his best.

There is an old tradition of deriding the Laureate (Roberts 2006 152-54), and in January 1985 Hughes wrote Sagar a humorous rhyme saying that he paid no more attention to his critics than to 'the horrible same old effluvia going down the River Don' (PC 141). Water pollution was clearly a significant concern for Hughes in the year that he presented evidence at the inquiry into Bideford's sewage problem. Although some of his Laureate-poetry might have been mocked, Hughes's 'Rain-Charm' did have a very practical effect. One of the 'perks' of being Laureate was that his lines about pollution in the Okement caused 'great agitation in Okehampton', and he hoped that they 'might even affect the Council's laissez faire'. Hughes had cut some lines describing the Torridge as a 'leper in her pit' because of the 'doctored and scabby farms from Welcombe to Hatherleigh to Torrington', since they seemed in 'poor taste' (PC 142), but his later protest-poems would expose such unpleasant details. Poetry seldom makes anything happen, but a poet of Hughes's status does not need to use raincharm magic to make people listen. What is even more extraordinary is that Hughes donated the payment he received for the poem to Greenpeace ('Ted Hughes: Eco Warrior'). He used his earnings from his first Laureate-poem to benefit a radical green pressure group: a daring act that contrasts with the conservative, conservationist tone of some of his writing about fishing.

Hughes revisits the 1984 drought in '1984 on 'The Tarka Trail', a poem that was first published in the Three Books version of River in 1993. Moreover, one section of it, 'Nymet', was first published in a different arrangement in 1980 ( $C P H$ 1299); Hughes considered including it in the 1983 edition of River,230 and finally collected it in Three Books in 1993. Terry Gifford calls the two sections of the poem 'hard-hitting' (2009 58). Hughes begins by using richly figurative language, describing the eutrophied stream as 'glutted' and its remains as a 'ditch-carcase'. Yet he also mentions a realistic catalogue of pollutants: 'Surfactants, ammonia, phosphates'. A dead mussel is not 'Queen of the River', a pearly incarnation of the White Goddess, but 'A yawn of putrid phlegm'. Most worryingly, this part of the river goes into the mains (842). It is impossible to escape pollution, because even Peter, 'our clean corn farmer' (843), a nature-lover, heaps 'poisons' into those who eat his corn, following advice from 'The Min. of Ag and Fish.' (842). 'Nymet' is the poem's second movement, and it evokes an ancient landscape spoiled by recent pollution. Hughes goes in search of the genius of the stream - 'What was her true name [?]' (843) - but this river is so polluted that its nymph has departed. The Georgian manor Nichols Nymet House was where Carol lived when she first met Hughes, and she says that the word Nymet, preserved in many local place names, means 'a sacred place'.231 Hughes also told Blake Morrison that a large Celtic circle in a field near where he lived was probably sacred to the goddess Nymet (Morrison 32). The name Nymet would have reminded Hughes of the sacred grove at Nemi, where the priest-

230 Keith Sagar's private archive. Carbon typescript of The River, 13 June 1982. 
kings of Diana were sacrificed (Frazer 3) - hence the image of the May bridegroom's head crushed into the river's flood. The river-goddess used to bear eels, peal and salmon, but she is now 'Drowned in the radioactive Irish Sea' - the site of the nuclear waste dumps that Hughes had read about so many years earlier. She is contaminated by effluent from the 'Express Dairy Cheese Factory' and mourns her 'doomed parr'. Yet most alarmingly, 'The death-rags that she washes and washes are ours' ( $C P H$ 844). This poem explores a previously venerated landscape; water pollution desecrates it and endangers its inhabitants. Here, Hughes's work responds to Rigby's call for an ecopoetry that 'bears prophetic witness, in anger and grief', to environmental damage (127). Scathing, shocking and impassioned, these protest-poems do not omit any unsettling details.

Flowers and Insects, Hughes's 1986 collaboration with Baskin, does not match River's unified structure or so poetically suggest an environmental ethics. Uncollected poems from between 1987-89 are more informative about Hughes's concerns about environmental issues. 'Devon Riviera', published in the Poetry Book Society's 1986-87 Anthology, exposes the turpitude of a coastline thronged with holidaymakers whose waste overwhelms the Torridge Estuary. Its speaker is fishing contaminated waters off the coast, his boat 'Hauling the rich robe of sewage' (729). There is some resemblance between this piece and an undated prose passage humorously entitled 'Fishing for Mackerel in the Shit Sea', whose comparison of the water thick with sewage to 'velvet' might have suggested the poem's image of a 'robe'.232 Hughes expanded upon 'Devon Riviera' and republished it in The Sunday Times in 1998 - a high-profile publication in which he could articulate his concerns about water pollution to a wide audience.

1985 was a year when Hughes became aware of several significant, new environmental issues. He read information in New Scientist about a Japanese method of extracting oxides of nitrogen and sulphur from power station smoke, and about a form of carcinogenic pig feed that might be introduced into Britain.233 On the other side of his notes about New Scientist, he drafted a letter to scientists at the Pitlochry Laboratory about the vulnerability of local salmon smolts.234 He wrote to The Times about the economic value of the UK's salmon ('Putting a value on UK's salmon riches'). His concern for the salmon would be reflected in his Laureate-poem 'Little Salmon Hymn' for the Queen Mother. Also in New Scientist, he read about the film Half Life, which deals with the effects of nuclear testing. $235 \mathrm{New}$ Scientist was an important source of Hughes's environmental information: in August 1986, it published an article about how wild otters were 'supersaturated with poisonous industrial and agricultural chemicals,' resulting in severe tumors and lesions ('If' 3 ). Two months later, Hughes read an article in The Times about the release of artificially bred otters into the wild ('Return of the otter') - and responded by writing to the editor, quoting New Scientist's account of the damage that agricultural chemicals might do to them, and the dangers that humans might also face from such chemicals. 236 He was frustrated by an editor's reluctance to publish details of

232 BL Add MS 88918612 'Fishing for Mackerel in the Shit Sea’ 23-28.

233 BL Add MS 88918/11/1 'New Scientist 10 ${ }^{\text {th }}$ Jan 1985' 10 recto

234 BL Add MS 88918/11/1 'New Scientist 10 ${ }^{\text {th }}$ Jan 1985’ 10 verso

235 BL Add MS 88918/11/1 ‘New Scientist 10 July 1985’ 14 recto

236 BL Add MS 88918/131, undated cutting from unspecified newspaper, 'Otters in the wild'. 
the otters' gruesome symptoms ( $L T H$ 534); it would be some years before many East Anglian farm workers would be hospitalised, 'poisoned by agricultural chemicals' ('If' 3). That spring, he had reminded the nation of his wish for cleaner rivers in 'A Birthday Masque' for Queen Elizabeth II. Among the unusual gifts that he proposes is an Angel to heal 'the kingdom's hurt rivers' and wash 'the refuse of gutters' (807).

Hughes was also increasingly active in promoting the arts as a means to help environmental causes. After a 1986 conference at which religious leaders discussed environmental issues, Prince Philip invited prominent artists and writers to contribute ideas for artistic involvement in conservation. Hughes and the Duchess of Abercorn devised the Sacred Earth Drama Trust. The Trust ran an international competition in 1990 to create 'ultra-imaginative dramas, on environmental themes' for children to perform (Hughes 'If' 5); Faber and Faber published the resulting plays in 1993 ( $L T H$ 578). The Duchess also proposed The Arts For Nature, an initiative to raise funds for WWF. Hughes played an important role:237 his poetry readings opened and closed The Arts for Nature's launch event at Syon House in October 1988.238 In a statement about The Arts for Nature, Prince Philip wrote that it was easy enough to quote alarming statistics about environmental destruction. He stated that the arts have the advantage of helping people to 'see the really tragic aspect' of environmental decline, and of appealing 'directly to the heart'.239 Hughes took up this idea in his foreword to the Sacred Earth Dramas anthology, explaining the need for 'language that comes from the heart and soul' (vii), and highlighting the pathos of environmental writing by young people who would pay the price for their elders' destruction of 'poisoned and starving landscapes' (viii).

If Hughes had long been concerned about future generations, in the mid 1980s, he became increasingly worried that pollution affected human reproductive health. The Poisoned Womb, John Elkington's 1985 polemic on reproductive toxicology, was Hughes's third 'big shock' as an environmentalist - so important to Hughes that he mentioned it some of his most highprofile poetry. According to Elkington, 'Today we all live on the toxic frontier and [...] our reproductive systems have been showing the strain' (9). Elkington's information on fish cancers caused by pollution (23), the nuclear waste processing plant at Sellafield causing leukaemia (25), high mercury levels in fish (31; 209-10), water pollution by detergents (34) declining sperm counts in industrialised countries (48-64), and a drug given to poultry and cattle that caused birth defects (110-11) resonated with Hughes's own preoccupations. Elkington's book also informed Hughes of the political implications of our increased dependency on artificial chemicals. A 1984 study found that in Britain, one-third of fresh fruit and vegetables tested were contaminated by chemical residues. Despite pressure for tighter controls from both the pesticide industry and environmentalists, Thatcher's Cabinet, 'with its strong links with the farming community, initially dragged its heels' (231). This initial resistance partly inspired Hughes's political poem 'First Things First'. Hughes would also mention The Poisoned Womb in his 1992 protest-poem 'Lobby from Under the Carpet'. Elkington's book certainly engages with international environmental issues, and in this respect, it does inform Hughes's global environmental awareness (Gifford 2014). But Hughes hoped that the book would have a national impact: he sent a copy to Margaret Thatcher. 240

\footnotetext{
237 'ARTS FOR NATURE’ $1-2$.

238 Emory collection 664 box 155 folder 7: 'The Arts for Nature’ programme.

239 Emory MARBL archive collection 644, box 155, folder 7, statement about Arts for Nature by Prince Philip.

240 This is corroborated by a draft letter of 1985. Emory MARBL Collection 644, box 55, folder 61, 'Dear P. M.'
} 
The uncollected poem 'First Things First' is an 'Election Duet' performed by foetal twins in the womb, marking the 1987 re-election of Margaret Thatcher to a third term of office. This piece of trenchant political criticism points out the environmental cost of the butter and grain 'mountains' created by the Common Agricultural Policy: 'poisoned water', 'poisoned bread' and 'Leukaemia'. Increasing the gross national product costs trees their leaves, waters their fish and adults their health. An increase in chemical production has led to 'a 40\% drop in the sperm count of all human males' over two decades. The Second Twin's words echo a statement that Hughes had made in his speech about farming (see Introduction): 'everything pitched in the ditch | Comes back into the cup'. Water pollution does not just destroy aquatic life: it also affects human beings. We witness Hughes's global preoccupations in this poem: he is concerned about the 'World Chemical Industry' and waste being 'released on the $3^{\text {rd }}$ World' ( $C P H$ 730). The twins end with a statement about the paradox that the human 'Monkey Mutant', despite its intelligence, does not seem to have 'a brain with brains' (731). This line recalls Hughes's Jungian ideas about the evolution of human rationality, but it also hints at the damage that chemicals could do to human and animal brains. Hughes wrote later that acid rain caused the leaching of aluminium sulphate into water, 'killing all underwater life' and afflicting livestock and humans with 'fatal neurological diseases' ('If' 32). Hughes had congratulated the organic farmer Mark Purdey on his investigations into possible chemical causes of the neurological disease bovine spongiform encephalopathy (BSE) - and Purdey in turn congratulated Hughes on writing 'First Things First'.241 The poem was published in The Times in 1987: it had a very visible presence in the national media.

The political views expressed in Hughes's writing are seldom clear-cut, but the overt political critique in 'First Things First' reflects his activities as a lobbyist. In a letter that mentions 'First Things First', Hughes complained that Thatcher was 'no ordinary woman'. If she were, she would have 'some conscience about cleaning up'; but instead, she listened to consultants who would 'say what she wants to hear'. (He would later articulate his admiration for her (Bate 482).) He was also aware that Thatcher's husband Dennis was 'involved in the waste disposal business' (LTH 365), a theme that would recur in The Iron Woman. Of course, Hughes lobbied Thatcher - along with many members of her cabinet, including the Minister for Agriculture, John Selwyn Gummer, and Michael Heseltine, with whom Hughes sometimes fished. In 1986, Hughes wrote to his son that Gummer could not 'move mountains like he ought to be able to do' (LTH 525). Hughes's lobbying of Gummer would continue into the 1990s, when he warned him of the damaging effects of driftnetting and farming nonnative salmon on wild salmon fisheries.242 In later life, he began using fishing as a means to show influential political figures the importance of conservation. He wrote to his brother in 1986 that salmon fishing in Devon was popular with former 'high ranking servicemen', whom Hughes portrays as conservationists: 'without them, I fancy there'd be no Salmon rivers left at all'. Hughes views those who shoot with greater ambivalence: '[t]he shooting -

241 BL Add MS 88918/121/5 Mark Purdey to TH, 25/11/87

242 Emory MARBL archive, Collection 644, Box 53, Folder 11, 'The Rt Hon John Gummer Esq MP', $10^{\text {th }}$ September 1991. 
in which I seem to have lost all interest - belongs to the Bankers, Landed Rich, \& Company directors - plus a few rich farmers' ( $L T H$ 526). Hughes fished with Conservative politicians, such as the Bideford-born Secretary of State, John Nott, in the mid 1980s and 1990s, 243 and with Heseltine, the Secretary of State for the Environment. He wrote to Thatcher that he was 'stunned with incredulity' about the effects of oestrogens from the Pill, which changed the sex of fish. He argued for things to be put on a 'war footing' to prevent acid rain, and wished the Government to 'clean up the act of rubbish disposal' ('Ted Hughes: Eco Warrior'). Given his strong views on environmental policy, one might wonder why Hughes was not more politically active. Yet a letter of 1987, which Hughes wrote to the Yorkshire politician Jack Brown, gives the reason for his reluctance. In the aftermath of the failure of the first Miners' Strike, Brown had expressed bewilderment at Hughes's acceptance of the Laureateship, but Hughes thought that his nomination was 'a feint of sympathy for the North'. The whole operation of the Laureateship, however, 'has to be kept somewhere beneath Party Politics' because 'this country is split like a schizo with nine minds.' The Monarchy was a unifying symbol - which Hughes envisaged in naturalistic terms, as a 'biological necessity' (LTH 530). Political lobbying was a way for Hughes to engage with high-level environmental issues, without openly committing to a political agenda; moreover, Hughes's lobbying was partly triggered by Thatcher's initial resistance to engaging with environmental issues. In the 1990s he continued to associate with Conservative politicians and his conversation often, but not always consistently, suggested the politics of the right (Bate 2015 482). Yet these were not the only ideological strains in his life and work. If his public support of WWF's conservation of endangered species was a perfectly respectable form of environmental engagement for the Poet Laureate, his donation of fees from protest poems to Friends of the Earth ('Ted Hughes: Eco Warrior) hints at a desire to link social and environmental justice. His donation of royalties from 'Rain-Charm for the Duchy' to Greenpeace was a covert way for him to use his status as Laureate to support a more subversive environmental pressure group.

Closer to home, the rivers were open but no returning salmon had arrived. Yet Hughes was pleased that the UK government had 'admitted national culpability' in causing acid rain that affected trees, lakes and rivers in other parts of Europe (Boyanowsky 69). Later that year, he voiced his concern about acid pollution in Scottish rivers. He railed against silage and sheep and cow products being fed to livestock in Devon, and the resulting runoff polluting Torridge and Taw. He expounded his worries about sea lice from fish farms and gillnetters in the North Sea decimating the returning salmon. He was tired of the British government's inaction. It is no wonder that Hughes ended his tirade about environmental problems with the words that 'if it were up to me alone, I would give all my money to Greenpeace' (73).

Many of Hughes's uncollected environmental poems from this time reflect this preoccupation with aquatic environments. 'If' was first published in the Sunday Correpsondent in 1989 and later included in Three Books (1993); Hughes gave the earliest published version the fable-

243 BL Add MS 88918/122/1, notebook labelled 'Fairbanks: Sept 4th 1986’ 22; Add MS 88918/122/4, blue ruled notebook 256. 
like title 'What the Serpent Said to Adam', but its later title more effectively conveys the insidiousness of environmental contamination. It is a protest poem where the river drinks the 'infected' sky and the 'fatal' disease of the earth, with human beings described as an overnumerous 'virus' ( $C P H$ 740). Images of corrupted flesh and sores that run like rivers take Lovelock's holistic image of Gaia and subvert it, showing earth's systems to be pervasively affected by human activities. Its ending is prophetic:

Already - the drop has returned to the cup

Already you are your ditch, and there you drink (741).

Hughes's poetry is preoccupied with the image of polluted water returning to the person who contaminated it, and its reiteration here underscores the inescapability of water pollution. It is when Hughes expresses the pervasiveness of human alterations to the earth's systems, that his poetry becomes especially prescient of ideas about the Anthropocene. Michael Morpurgo remembers that Hughes would repeat this adage at dinner parties and pub gatherings; he was not afraid to speak his mind among politicians, even if this sometimes made him unpopular ('Ted Hughes: Eco Warrior'). At this time, Hughes was also taking direct action to protect Britain's rivers. He was present at the first meeting of the National Rivers Authority's Regional Rivers Advisory Committee in October 1989, where he raised questions about droughts since 1974.244 He was concerned that global warming might cause an increase in droughts, freak floods and sea levels.245 1989 saw another severe drought, which increased the levels of acidity and metals dangerous to fish - and Hughes underlined an item in a report about an increase in sewage pollution.246 With this in mind, the Torridge Action Group continued its determined efforts to protect the Torridge estuary, with Hughes and other Action Group members regularly writing to the MP Emma Nicholson for much of 1989.247 The inadequate sewage treatment plant was eventually adapted to discharge Bideford's sewage into the sea rather than the estuary (Gifford 2011 93).

The 1990s saw Hughes continuing to inform himself about environmental issues, with the result that he campaigned ever more determinedly. At the Globe 90 conference on environment and business in 1990, his friend Ehor Boyanowsky delivered a lecture on 'civil disobedience in the face of threats to the environment and lack of action from the government'. Inspired by this, Hughes lectured a local branch of Friends of the Earth. Boyanowsky states that incidents of ecoterrorism began to occur (125); not the result that Hughes would have wanted. Between 1991 and 1993, Hughes was involved with setting up the Farming and Wildlife Advisory Group’s programme for schools, which enabled children

244 BL Add MS 88981/121/10. Minutes from NRA meeting on 11. 10. 19892.

245 BL Add MS 88981/121/10 Minutes from NRA meeting on 11. 10. 19893

246 BL Add MS 8891812112 'National Rivers Authority South West Region: Study of the 1989 Drought' 3536.

247 BL Add MS 88918/121/14, Torridge Action Group. Emma Nicholson to Ted Hughes, $8^{\text {th }}$ May 1989; see also Hughes's undated reply to Nicholson's letter to Pennington of the $19^{\text {th }}$ of December 1989. 
to learn about farms and ecology.248 In 1990, ahead of the 1992 elections, Hughes wrote in an open letter to the 'Premier':

Treat the Environmental cataclysm as a War, on all its fronts. In other words, as an Emergency, displacing every other concern that stands in its way. Ask the people to pay for it directly [...] Nothing would lift the morale of this country so steeply, or so unanimously. The Government's inertia on these issues has demoralised everybody. ('Dear Premier' 96).

There is nothing conservative - or Conservative - about this urgent call for profound change. These activities show Hughes wavering between the 'maverick' environmental campaigns of pressure groups and political lobbying, and tamer ecopoedagogy activities that would be acceptable to the Establishment.

By this time, it was clear that farm slurry was clogging the upstream gravels necessary for salmon to spawn. Hughes called on the Taw Fisheries Association to 'get a JCB into those gravels', to restore the once-plentiful salmon ('Trout on the Upper Taw' 6). Fundraising ideas included a Torridge Rescue Fund 249 and a Torridge River Poetry Competition.250 When the TAG met in October 1991, the National Rivers Association had helped to subsidise gravel cleaning in the Lew - and a month later, salmon were seen spawning.251

These examples of low-profile, local activism contrast with some far more high-profile causes that Hughes also supported. Hughes's friend Ian Cook took legal action to defend his stretch of the River Creedy, where Hughes had fished (Brown 4). Hughes made detailed notes on the court case in a fishing diary. Up until 1979, the River Creedy at Cowley had contained abundant flies to support the trout population, but by 1985, there were almost none. In 1989, the trout population plummeted.252 Cook had noticed that at times of low flow, the river stank and the water was covered in foam. Pollutants were more concentrated during times of low flow,253 and the judge found that South West Water had breached the consent levels for pollution.254 When Cook won the case, Hughes wrote a speech for the occasion in his notebook. He stated that Cook had rediscovered and proven the ancient force of common law, restoring ordinary citizens' power to defend rivers. He pointed out that one of the ingredients

248 Emory MARBL coll. 644 Series 5, subject files, c. 1966-95, box 60, folder 1: 'Farming and Wildlife Advisory Group School Competition'.

249 BL MS Add 88918/121/12, ‘Minutes of C’ttee Meeting: 1⁄2 Moon: Wed 17 April 1991’ 2. Hughes contributed to the 'Torridge Rescue Fund'.

250 Emory MARBL 644 Series 5, subject files, c. 1966-1995, box 169, folder 4: 'Torridge River Poetry Competition'.

251 BL Add MS 88981/121/10 ‘Torridge catchment Action Meeting - minutes from 10 Oct 1991’ 1.

252 BL MS Add 88918/122/4 blue ruled notebook 195.

253 Blue ruled notebook 190, 196-7.

254 Blue ruled notebook 223. 
in detergents was responsible for severe pollution of the Exe, and mentioned that the South West Water Authority was sponsoring research to solve this problem.255

Cook won his case on the $15^{\text {th }}$ of April 1992, exactly a week after Hughes had published his poem 'Lobby from Under the Carpet' in The Times. At this time, Hughes was conducting extensive research into water pollution to support his vigorous engagement in environmental affairs. The poem describes how sperm counts in Britain are 'down forty | Per cent in real terms'. Those to blame are the 'Waste-Disposal man', the 'World Chemical Industry' and 'Shareholders' who gag voices of protest, including that of Hughes's muse ( $\mathrm{CPH} 837$ ). Hughes recounts in the seventh stanza that he had sent Margaret Thatcher a copy of The Poisoned Womb, and in the eighth, he states that research by 'Professor Skakkebaek' had revealed a fifty, not forty, per cent drop in sperm counts (838). Hughes had clearly been researching this topic carefully. His unpublished notes state that the Danish fertility expert Nils Skakkebaek had launched an international scare about male fertility in 1992, and he corresponded with Nick Gammage about Skakkebaek’s work (LTH 620). However, Skakkebaek's findings would be called into question in later research.256

Hughes had mixed feelings about such protest poetry. He admitted in a 1992 radio interview with Nigel Forde that 'I've tried to write sort of semi-protest pieces of verse about this sort thing, but I don't think it works.' He did not feel that protest-poems were 'the real thing' (Gifford 2011 149). Although these 'semi-protest pieces' were certainly powerful, the ecopoetry of River was more like 'the real thing'. Perhaps he would have been able to create more poetically successful protest-poetry if he had reinvigorated the slangy, hybrid voice of Crow. Hughes's protest poems were most effective when they were sold to raise funds for conservation charities and when they changed local attitudes, as was the case with the lines about the Okement. Yet his public speaking and his lobbying were yet more effective in helping Hughes to achieve his goals.

\section{The Iron Woman}

Hughes had long been publishing poetry and letters in high-profile national newspapers, and attracting media attention for his environmental campaigns. Yet in 1993, he published one of his most public literary statements against water pollution. The Iron Woman is a children's fable about the dangers of industrial waste and contaminated water. Hughes had begun the book in the mid-1980s (Morrison 32), finishing it after he had completed Shakespeare and the Goddess... (PC 234). Hughes explained that he needed a story about a girl to follow The Iron Man, 'for balance' and stated that the book imagined nature's 'enraged' response to its destroyer (Morrison 32). The book begins with a girl, Lucy, seeing a sick eel writhing and bobbing its mouth at the surface of the water (1993 2) - just as Hughes had seen fish gasping at the surface of the polluted oxbow at Old Denaby. Hughes's awareness of environmental issues permeates even the smallest details of the text: the night before she meets the Iron Woman, Lucy dreams of a girl so 'slimed with black oil' that she resembles an oiled seal (11). Three years before Hughes’s book was published, the Exxon Valdez tanker had foundered off the Alaskan coast; the sobering image of oiled wildlife was topical. The canal

255 Blue ruled notebook 254-55. The Authority contributed a £5,000 grant to the Institute of Freshwater Ecology (Gifford ‘Hughes’s Social Ecology’ 91). 
where the Iron Woman wants to wash herself is full of 'rusty bicycle wheels, supermarket trolleys' and other litter (17), just as the October Salmon's pool is full of 'bicycle wheels, cartyres' ( $C P H$ 679). Lucy has a vision of the river creatures in a 'fiery bubble' of toxicity, which culminates in the sight of a struggling human baby (1993 22). This image is a simple way for children to visualise Elkington's 'poisoned womb': the insidious contamination that affects even a child in utero. The Waste Factory processes industrial waste of all kinds and has grown rapidly (35); the 'Waste Disposal' man from 'Lobby from Under the Carpet' would no doubt approve. A company called 'Global Cleanup' gets rid of waste by burning it, or dumping it 'in far-off countries, where nobody protested', or 'in the sea', in 'rubbish dumps' and 'holes under fields wherever they could persuade a farmer to let them' (61). Many of these methods of waste disposal echo Hughes's earlier writings, especially his concern about radioactive waste being dumped in the sea. His Iron Woman was not an explicit response to the Iron Lady, although during Thatcher's time, Britain's importation of toxic waste increased 'by hundreds of times' and farmers were encouraged to infill their fields with rubbish (Morrison 32); Hughes was, of course, aware that Dennis Thatcher was involved in waste disposal. The screams of poisoned creatures become a contagion that everyone in the Waste Factory can hear when they touch each other: the inescapable poison of a polluted water supply. Chaos ensues when the men at the Waste Factory turn into water creatures that must be taken to the river (Hughes 1993 63), only to find it polluted (65). The Prime Minister himself becomes an enormous dragonfly nymph (68) - and Hughes did indeed wish that he could send a copy of his book to John Major (see Introduction). When the waste transforms into a magic fuel (82-83), the story is resolved with unrealistic neatness. However, converting waste into useful products was a real research priority at the time: the day Hughes sent the book to Faber, he heard that Japanese scientists had found a way to convert plastics into fuel (Morrison 32).

The Iron Woman received mixed reviews. The Times Education Supplement and Daily Mail praised the book. However, Brian Alderson called the ending 'idealist,' and wondered if the book was 'an attempt to placate feminist members of the Green Party' ('Myth with Metal Fatigue'). Dinah Hall criticised a 'clumsy balancing of the sexes' ('Metallic Moralising'). Hughes expresses binary, biological views of gender in the interview with Morrison, where he sounds distinctly pre-feminist. He states that man only becomes destructive 'once he's lost touch with the biological, reproductive powers of woman'; Morrison rightly finds this Lawrentian (32).

Morrison was not the only one to be troubled by Hughes's biological conception of gender. As we have seen, of Hughes's most incisive feminist critics, Jacqueline Rose, had objected to both Hughes and Graves for their depictions of violent power-struggles between men and muses. Commenting on the goddess in Hughes's essay on Shakespeare, Rose writes that the denied feminine principle becomes destructive, 'turns into an image of terror for the man and provokes his retaliatory violence' (151). Turning to the difficulties that Graves's idea of the muse presents for real women, she argues that 'this concept of the female principle leaves no place for women' (154). Incarnating the Muse places an 'impossible demand' on a woman. She becomes a muse for only a few years, ‘at risk of her own self-inflicted death' (154). Rose 
comments on how 'this conception of femininity was being consciously or unconsciously negotiated between [Hughes and Plath]' (155). Hughes had seen a draft of Rose's book (Rose xii) a few years before he published The Iron Woman.

Hughes was understandably wary of the feminist movement, but he thought that its genesis was contemporaneous with that of the environmentalist movement. He wrote in an unpublished autobiographical piece that the 1960s groundswell of support for new ideas gave rise to both currents of thought. 257 He was clearly interested in writing about women's connection to the environment. He praised Clarissa Pinkola Estés's Jungian feminist naturebook The Women who Run with the Wolves in his interview about The Iron Woman (Morrison 32), and had long been reading books that aligned women with nature-goddesses, by writers such as 'Starhawk', 258 Shirley Nicholson259 and Ann Baring.260 The Iron Woman contains ideas that recall contemporaneous developments in ecofeminism, although Hughes cannot be called an ecofeminist, and he did not research the movement extensively. The term 'écoféminisme' had been coined in 1974 by Françoise d'Eaubonne (Merchant 184). Although it gained currency the USA in the 1980s (Mies and Shiva 14), publications that consolidated the aims of the movement appeared in the 1990s. 1993, the year Hughes published The Iron Woman, saw a flourishing of ecofeminist publications by writers such as Greta Gaard, Lori Gruen, María Mies and Vandana Shiva. Mies sees 'a connection between violence against women and children and violence against nature' (Mies and Shiva xxii). Her collaborator Vandana Shiva characterises science as oppressively patriarchal and evokes the mystical 'rights of Mother Earth' and the 'laws of Gaia' (xix). Experts on queer theory would object to 1990s ecofeminism's upholding of a binary difference between men and women, and to the idea of gender as biologically determined rather than socially constructed. As Drangsholt has put it, even Hughes's nurturing goddesses 'can be experienced as oppressive to all those women readers who do not feel at home in the role of the Earth Mother' (86). But Hughes's book also goes beyond the ecofeminism of the time in important ways.

Hughes sometimes repeats a stereotyped view of 'the natural world's foremost representative - woman' (WP 267). Initially, Hughes's book replicates this view, and presents the men of the Waste Disposal Factory as caricatured incarnations of patriarchal science. However, his book quickly begins to call these simplistic views into question. When the Iron Woman emerges from the marsh, Hughes clearly identifies her as a living organism - her mouth moves like a 'crab's', her bulk is like a 'gigantic dinosaur' (4). But her hair is 'huge coils of wires' (15), her body is both 'ship' and 'sea beast' (17), she is made of 'millions of rivets' (18). She is not a robot, she is the 'real thing' (18). Hughes wishes children to see her as a

\footnotetext{
257 BL Add MS 88918/7/2, unpublished TS draft of a prose essay, 'and all of a piece right back to my first
} awareness, is what I brought'

258 The Spiral Dance: A Rebirth of the Ancient Religion of the Great Goddess. Emory MARBL BF1566.S77 1989 HUGHES.

259 The Goddess Awakening: The Feminine Principle Today. Ed. Shirley Nicholson, contains an ecofeminist essay. Emory MARBL BL325 .F4 G63 1989 HUGHES.

260 The Myth of the Goddess: Evolution of an Image. Emory MARBL BL473.5.B37 1991 HUGHES. 
cyborg: both industrial creation and magical living person. When men at the Waste Factory turn into aquatic animals (68), Hughes further unsettles the idea that women are necessarily 'closer to nature' than men. The book presents the triumph of magical 'green' technology over environmentally destructive capitalism - and it is highly significant that both Iron Woman and Iron Man deploy futuristic technologies. Hughes might have wished The Iron Woman to gain him favour among ecofeminists, but he perhaps unwittingly challenges some of the stereotypes that the ecofeminism of his time perpetuated. The Iron Woman begins with an 'enraged' nature and a battle of the sexes, but it later redresses these problematic gender dynamics. Hughes is rarely seen as challenging stereotypical gender roles. Yet his notes about Jung's concept of the anima (the feminine aspects of a man's unconscious) and the animus (the masculine aspects of a woman's unconscious)261 open his work to the possibility that one can find representations of gender that complicate the 'Lawrentian' views he expresses to Morrison. The Iron Woman is a cyborg, and while she does not confound traditional categories as radically as the creatures in Donna Haraway's famous 'Cyborg Manifesto', she does recall Haraway's call for socialists and feminists to turn away from their sense of the 'deepened dualisms of mind and body, animal and machine' associated with their critique of scientific culture (loc. 3150). Instead of returning to the imagined organic, natural body of early ecofeminism to 'integrate our resistance' (loc. 3150), Haraway urges feminists to turn instead to cyborgs as transgressive creatures, 'simultaneously animal and machine, who populate worlds ambiguously natural and crafted' (loc. 3058), beings from a 'postgender world' (3070). While Hughes’s pairing of Iron Man and Iron Woman, of schoolboy and schoolgirl, is far more conventionally heteronormative than Haraway's post-gender vision, his Iron Woman profoundly unsettles many of Hughes's own attempts to align nature with the feminine. Later ecofeminist writers have also challenged a simplistic equation of nature with the feminine, and broken down dualisms (Tarlo 2008 10), while ecocritics such as Catriona Sandilands have deployed queer theory to question heteronormative assumptions about the sorts of behaviour that are 'natural' for humans and nonhumans $(2010,2014)$.

After he had published his Iron Woman’s call for ‘big, deep change’ (1993 85), the green Laureate continued to fight for profound change to be put into practice. March 1993 saw Hughes encouraging his fishing associates and local landowners to found the South West Rivers Trust ('Ted Hughes: Eco Warrior'),262 which would later become the West Country Rivers Trust. The Trust's aims were to 'improve the management of the rivers streams water courses and water impoundments of the South West', and to 'promote scientific research' into the effective management of watercourses.263 That year, Hughes also contributed

\footnotetext{
261 Hughes copies out the following quotation from Jung: “ "Circumstances have forced her to master a part of masculinity, which alone could saver her from remaining embedded in an antiquated purely instinctive femininity, like a spiritual baby, alien \& forlorn in the world of men. Similarly, man will find himself forced to develope [sic] within himself some feminine characters, namely, to become observant both psychologically \& erotically. It is a task he cannot avoid'. BL Add MS 88918/129/2 20 verso.
}

262 BL MS ADD 88919/121/10 1993 'Deed of South West Rivers Trust’.

263 BL MS ADD 88919/121/11 1994 'Deed of South West Rivers Trust’ 4. 
information to a survey of the Taw and Torridge, ahead of a review of salmon netting.264 The issue of nuclear waste in the sea finally became more widely publicised, as in June 1993, Hughes read that the government had been dumping nuclear waste from 1964 onwards.265 He informed himself about surfactants that not only polluted water, but that might also cause infertility in animals; the government had known about this since 1987.266 Reading this would have exacerbated his concerns for human and animal fertility, and deepened his frustration with Britain's politicians. The South West Rivers Trust and the salmon survey are, like 'Rain-Charm', distinctly regional and 'topophilic'. His work as 'green Laureate', of course, tackles national issues as well. The other Laureate-poems collected in Rain-Charm for the Duchy and other Laureate poems (1992) are not as successful as 'Rain-Charm', but the preponderance of totem beasts and plants such as the lion, the salmon, the honey bee and the thistle hints at Hughes's desire for Britain's living things to thrive alongside its royals. Hughes would continue his 'green Laureate' activities as a campaigner for environmental causes and a patron of environmental charities for the rest of his life.

This chapter has shown how Elkington influenced both Hughes's global awareness and national environmental engagement, and how a speech by a Canadian environmentalist informed his local activism. But one of Hughes’s Laureate-poems seems to encapsulate a dual perspective on nation and globe, manifesting a distinctive, international strand in his environmental awareness. Hughes's environmental activities were becoming by turns local, national, and international, and it is this global thinking that inflects the poem 'For the Christening of Her Royal Highness Princess Beatrice of York'. The poem not is one of Hughes's most accomplished ecopoems, but its simplicity makes its message clear. This 1988 song offers, as blessings, a tear to 'cure the sick and poisoned seas', a word to 'cleanse the airs that choke the globe', and a groan to 'break the heart that spoils the earth' (CPH 820-21). Hughes's international environmental awareness and activities were beginning to encompass Lake Victoria's Nile perch problem, the decimation of the black rhino, and the fight to save the Amazon rainforest. The British shaman of the tribe was engaging with problems that had a global reach.

264 Emory collection 644 box 165 folder 4, letter from TH to ‘David’ [probably David Solomon], 05. 10. 93 1-2. 265 BL Add MS 88918/9/13 ‘Britain’s Little Errors’ - New Scientist - 1877: 12 June 1993’ 266 BL Add MS 88918/9/13 'S $\underline{\text { Surfactants' }}$ 


\section{CHAPTER X. GLOBAL ENVIRONMENTALISM}

If Hughes's 'green Laureate' activities were primarily focused on British issues, some of his research, campaigns and literary outputs began to develop an international scope in the 1980s. The global dimensions of his environmentalism would become clearest in his writings of the following decade. Environmentalists' understanding of international issues had been increasing in Britain and America since the late 1960s and the 1970s, but the 1980s and 1990s saw important developments. The World Conservation Strategy of 1980 promoted the integration of conservation and development programmes, and one of its primary objectives was to prevent species extinction (IUCN). The 1980s were the decade of WWF's 1980 'Operation Rhino' (Adams 135), when Greenpeace supporters' dream of saving the whale were realised, and when CITES intervened to restrict the trade in endangered macaws. All of these conservation issues would influence Hughes’s poetry.

Further alarming international environmental problems were becoming apparent. The fears of anti-nuclear protestors were realised in 1986, when an explosion and fire at the Chernobyl Nuclear Power Plant, Ukraine, sent radioactive particles into the atmosphere. Fallout from Chernobyl contaminated surrounding countries, and Hughes would later write about the human cost of the disaster. Other environmental problems with international causes and effects became apparent, such as the depleted ozone layer. Global warming remained a pressing concern. The Intergovernmental Panel on Climate Change was set up in 1988, and 1990 saw the publication of its first report, in which scientists stressed that climate change was human-caused; the 'business as usual' model of economic growth would have disastrous consequences (IPCC 1990 xiv, xxx). The 1992 'Earth Summit' in Rio de Janeiro was 'the largest meeting of its kind ever held' (McCormick 1995 viii), resulting in greater protection for biodiversity and forests (Adams 177), with the promise of further action on climate change. Yet even a few months afterwards, there was still 'a yawning chasm between the promises and the deeds of national governments’ (McCormick 1995 viii).

Hughes had clearly expressed a vision of the afflictions of the entire earth in the 1970s and 1980s; he had hinted at this awareness in some of the Crow-poems. In his 1970 review of Nicholson, he related that the environmental movement had developed 'in the US and in Britain'; there had followed 'largely successful attempts to make the movement international' (WP 128). If it matures in the 1980s and 1990s, the global aspects of Hughes's environmental knowledge had been developing for many decades. The poetry of Hughes's global environmentalism reflects first his increasing awareness of species extinction, and later moves towards a fuller consideration of international pollution and climate change. Three important works illustrate this progression: Wolfwatching (1986), the prose essay 'If' (1992), and finally Tales from Ovid (1995), Hughes's most thorough engagement with the alarming prospect of a world damaged by extremes of climate. Yet if climate change was a significant issue in his writing and activities of the early 1990s, he had long been developing an awareness of a pressing global problem: the exploitation of endangered wildlife.

\section{Endangered Species, Overhunting and Extinction}


Chapter III shows that Hughes's first attempts to elegise extinct species occur in 'February', 'The Retired Colonel' and 'The Last Migration'. Several prose works illustrate his engagement with the international issues of excessive hunting and the threat to wildlife from introduced species, in North America and Africa. In 1978, four years after he published The Tiger's Bones, Hughes began 'The Head', a 'grotesque' (LTH 449) ghost story set in a country of 'Indians' (DB 135) that criticises excessive hunting by white outsiders. The main characters are two former collectors of animal 'skins and heads' that are 'sold to tourists' (135): a glimpse of Hughes's critique of environmentally damaging global capitalism. The narrator describes the local tribe scathingly, as 'a filthy, secretive pack' of 'mongrelized' hunters (135). Yet he becomes more sympathetic to them when they correctly predict that hunting during a time of sacred taboo (136) will be disastrous: his bloodthirsty brother is reduced to a vicious, animate, flayed head (152). Hughes champions indigenous people's understanding of game conservation and their spiritual veneration of the land. Since Hughes's time, Krech has argued that such portraits of 'ecological Indians' anachronistically attribute environmentalist sympathies to them. Between 1963 and 1973, images of Native Americans were deployed in the environmental movement's battles over 'pesticides, oil spills, flammable rivers, industrial and human waste, and related environmental issues' (Krech 20). Yet we should not judge Hughes for echoing the values of his own time. Hughes criticises white intruders for disturbing the lives of both indigenous people and animals, creates a dire picture of 'animal wounds and animal pain and animal death' (146), and describes how the result is a land 'empty of animals' (151). The story is linked to Hughes's boyhood fantasies of fur trapping in British Columbia, and to his later unease about his indiscriminate hunting. Yet it also reflects an environmental issue nearer to the time of its composition: Greenpeace had begun its campaigns against the killing of seals for the fur trade in Canada in the 1970s, and the campaign was ongoing when the poem was published. It is curious that Hughes would speak out in favour of conservationist hunting in his later years: this short story shows a form of hunting that is anything but.

In 1983, Hughes would come face to face with a biodiversity issue that had international causes and consequences. This time, it was due not to overhunting, but to the introduction of a non-indigenous species. His fishing diaries and verse accounts of his journey to Kenya illustrate his growing awareness of how animal populations were damaged by human actions, but they also hint at the difficulties of western-led conservation in developing countries. Hughes hauled his fishing gear to Kenyan-owned Rusinga Island in Lake Victoria. His son Nicholas was conducting a scientific study of the invasive Nile perch, introduced by British colonial officials into Lake Victoria in the 1950s; the Nile perch had damaged local fisheries by preying on indigenous fish species. Kenya had gained independence less than two decades before the Hugheses visited. Nicholas and Ted went to Kenya shortly after a time when a German scientist 'had gone out to advise the Africans on fishing methods' and had 'all his advice ignored' - Kenyans had replaced such western advisors with their 'local fishery 
inspector' (LTH 465). Nairobi dust reminds him 'Of the tribe fallen | From the primate’s Eden.' ${ }_{267}$ This reflects his Jungian perception of consciousness, of Nairobi's 'fall' into colonial, then postcolonial, modernity, and the associated turn away from traditional farming and hunting to an economy modelled on that of the West. On Rusinga Island, he stayed with Chief Kefer and his wives. The edge of the lake was 'primaeval' ${ }_{268}$ - a term taken from Hughes’s reading of Jung and colonial-era anthropologists. His first impressions of the exaggerated 'wildness' of the place echo colonial thought: 'Africa incredibly wild looking, like the hide of a red wild dog.' ${ }_{269}$ As Caminero-Santangelo notes, 'Africa has been defined [by colonial and neo-colonial writers] by its embodiment of timeless and dangerous, if aweinspiring, wilderness' (16). Yet Hughes appreciated and respected Africa's wild creatures. His understanding of lake ecologies and his careful observations of animals, from hefty Nile perch ( $L T H 468$ ) to delicate insects, set him apart from the less environmentally aware safari tourists and trophy hunters who usually pursue Kenya's wildlife. The sight of mauve dragonflies carpeting the ground moved him to poetry; he marvelled at the electric colours of a sunbird at the mouth of a flame lily. ${ }_{270}$ He understood that the lake's environment had been damaged not only by the Nile perch, but by a new causeway connecting island to mainland, and was concerned for both people and fish affected by the disease-filled water (LTH 465). He admired local fishermen and remarked on their skill in bringing a canoe loaded with fish to shore in a storm ( $\mathrm{LTH} 468)$. He was not always sympathetic towards the islanders: his approval of Nick's authority over them ${ }_{271}$ would strike modern readers as problematic. But if some of Hughes's views were developed by his upbringing in imperial Britain, and by his reading of colonial anthropology, he certainly knew what misguided British intervention could do to the environment of a former colony. One evening, Nicholas kept his father 'laughing most of that time recounting the disasters of introductions of new fish into African lakes.' Colonial environmental mismanagement was the subject of a lighthearted joke 267 BL ADD Ms 88918/122/6 terracotta-coloured notebook, labelled 'P H Sassoon', numbered by archivist, 18 recto.

26865 recto

269 BL ADD Ms 88918/122/4 navy blue A5 notebook, numbered by archivist, 63 recto.

270 BL ADD Ms 88918/122/6 terracotta ruled exercise book labelled ‘P.H. Sassoon’, 26, 34.

27174 recto.

27282 verso. 
between them, and Lake Victoria's Nile perch problem provided enjoyable fishing - but such environmental 'disasters' were the subject of serious articles by Nicholas, most notably a coauthored article in Nature journal (Barel et al). The lake had been home to several hundred unique species of cichlid fishes; the damage to their populations was an 'ecological tragedy' (20). The Hugheses' attitude towards local wildlife displays admiration and conservationist concern, occasionally tinged with a degree of paternalistic authority. When a fishing eagle chick fell into the lake, Nicholas and Ted 'persuaded [Okomo, a local man] not to kill it for eating. [Inserted above: He said they're very good]. We were told today it dried \& flew off'. The Hugheses, with their knowledge of western environmental science, seem to have thought that they knew better than Okomo (LTH 466); but their actions were motivated by kindness. Hughes sees the Kenyans as close to nature, but needing advice about managing their environments. This was an attitude that prevailed in conservationist thinking at this time (Adams 113). His concern about pollution and biodiversity elsewhere in Africa is manifest during the 1980s. A year later, he fished the Nile, and learnt that its banks were 'compacted refuse spilling from the town'; the river contained fish despite its 'miasma', although Hughes noted the scarcity of bird life and lizards ( $L T H 495)$. This awareness of the importance of African biodiversity would culminate in his support of Rhino Rescue in 1987.

\section{Extinction and Elegy in Wolfwatching}

Wolfwatching contains some of Hughes's most accomplished poetry about extinction. These poems usually succeed in uniting environmental engagement with poetic accomplishment, although the clarity of vision in the animal-poems is occasionally obscured by excessive mythological and religious references. Bate calls the collection's evidence for poetic development 'thin' and works such as Hughes's elegy for the black rhino 'occasional' (2015 428), but these late animal-poems should not be dismissed. 'A Sparrow Hawk', 'Macaw' 'Wolfwatching', 'The Black Rhino', 'Manchester Skytrain' and 'Us He Devours' are not occasional: they form a sequence of mournful animal-poems that is carefully placed between clusters of family elegies that continue Remains of Elmet's project of memorialisation. Hughes's ecological elegies serve an environmentalist purpose, whereas his acts of mourning for relatives form part of an autobiographical project that is usually, but not invariably, separate. These two elegiac strains are linked by a '[c]oncern for familial and environmental loss’ (Gifford 2011 83), but it is important to distinguish these two types of loss; Hughes had created a more sustained meditation on the connection between landscape and lost loved ones in Moortown Diary and Remains of Elmet. There is clear evidence of poetic development, for Hughes is revising the relentless, predatory dynamism of some of his early animal-poems: the 
sparrowhawk, macaw and wolf are familiar from The Hawk in the Rain and Lupercal. Yet the mood of the animal-poems in Wolfwatching is less dynamic, more mournful, more attuned to death and extinction: more eco-elegiac. Hughes was dissatisfied with the book: it was 'Elegiac - obsequies over a state of mind that is to me now defunct' (PC 165). But Hughes's 'obsequies' for his past preoccupation with animal dynamism are eminently appropriate to the seriousness of the environmental problems that he had researched in the 1980s.

Edward Hadley has established Hughes as a major elegist, and he perceptively analyses the elegiac strains in Hughes's environmental writing. From the elegiac tradition, Hughes draws 'imagery such as water, vegetation, sources of light, and emblems of sexual power'. The natural world is depicted as 'either injured victim or site of renewal' (1). Writing about the environment reminds the elegist of his/her connection to the nonhuman world, with its systems of decay and regeneration: 'who better to consult on life and death than nature itself, whose very processes are a continuous cycle of decomposition and renewal' (100). Hughes's work as an elegist would reach its apogee in his deeply personal, long-concealed elegies for Plath. But Wolfwatching collects his most important environmental elegies.

Environmental elegy is a special kind of elegy. Morton finds that the elegiac work of mourning for a damaged environment can never fully be accomplished: 'We have lost the objective correlative for loss itself, and have slipped away from mourning, which finds an appropriate way of symbolising loss, back into melancholia, which has no way of redressing woe' (2010 253-54). Environmental elegy necessarily has a forward-looking dimension: it ponders problems that will remain ongoing in the future. Morton writes that 'Environmental language [...] speaks elegies for an incomplete process, elegies about events that have not yet (fully) happened' (2010 254). David Gilcrest agrees that environmental laments look to the future: the environmental jeremiad 'is necessarily prospective in that its lamentation is aimed at rectifying unsatisfactory conditions' (22). The resolution of traditional elegy is not appropriate for elegiac environmental writing, according to Morton, as it implies too stark a separation of the poetic speaker from nature; instead, environmental elegy necessarily remains unresolved (2010 256).

Wolfwatching contrasts shamanic dreams and animal-poems with poems about the Yorkshire landscapes that Hughes had long been evoking in verse. Images of the canal, the Don and chapels in 'On the Reservations' weave the cultural decline of Native American populations into a narrative of Yorkshire’s economic decline (Gifford 2011 83). 'Anthem for Doomed Youth' is a poignant elegy for Hughes's lost boyhood, and it is surprisingly critical of shooting. Although Gerald has been abroad, he retains an affinity with the Yorkshire landscape and the birds he used to poach. In Oxenhope, just north of Mytholmroyd, Gerald's soul is 'a warm egg' (762) and his glance 'Hawked', as if he were a predatory raptor. Perhaps there is a sense that Gerald and Ted's hunting is more sinister now than it might have seemed when they were boys, as the 'dream broke' (like an egg) and the 'dodo birds' now fall as 'dark-hearted poppies’ (763). Gerald is vulnerable as a hawk’s egg, while emblems of extinction and remembrance show the negative environmental implications of reliving their boyish 'dream'. Here is an act of personal memory that contains elements of environmental elegy. Yet while Hughes’s Yorkshire elegies largely look to the past, the animal-poems often 
imply the concern for the future that Morton and Gilcrest see as essential to environmental elegy. As will be demonstrated in the next chapter, Hughes opposed poaching in later life; this was one facet of his concern for the future of Britain's environments.

While many of the poems in Wolfwatching point to the ways that humans and animals suffer similar ordeals, some of them deal explicitly with the complex ethical problems of hunting rare creatures and keeping animals in captivity. 'Macaw', first collected in A Primer of Birds (1981), is a poignant evocation of an endangered animal's suffering. The speaker addresses the bird, stating that nothing will help it while it lives in this ' $[\mathrm{t}]$ rembling degradation and prison' with a ' $[\mathrm{t}]$ orture instrument of brittle plastic' gagging its throat. The poem ends with a bleak vision of its captivity: 'Nothing will help, you know' (CPH 752). Seven species of macaw were placed on CITES' list of species that would become endangered if trade was not regulated, in the year this poem was published. This second glance at a macaw focuses more closely on the bird than on its captors, and is more successful than the violatory 'Macaw and Little Miss' in articulating pathos for a captive animal. Here is ecopoetry that answers Skinner's call for work on our ethically challenged relation to other animals, and an ecological elegy that responds to Morton and Gilchrist's idea that ecopoetry should articulate a concern for the future. The poem testifies to the maturing of Hughes's environmental knowledge. In contrast to, say, Hughes's jaguars, this creature cannot find any way to transcend its anger at being caged. But underlying Hughes's concern for the individual animal is his worry on behalf of the species. It was the demand for pet macaws such as this one that had reduced their numbers in the wild.

The year after Hughes published his poem about the miserable macaw, environmentalists had reason to celebrate a victory on behalf of the world's biggest megafauna. After years of pressure from conservation groups, including Greenpeace's famous Save the Whale campaign (Adams 192), the International Whaling Commission agreed in 1982 that there was to be a pause in commercial whaling in the mid 1980s. The resulting ban on commercial whaling continues to this day. The Commission referred to whales as 'whale stocks', a distinctly utilitarian term that implies that whales are an exploitable resource (International Whaling Commission). Hughes would have welcomed the whaling ban, but his 1982 poem 'Little Whale Song' reacts against such baldly human-centred language. The poem, dedicated to his friend Charles Causeley, articulates a deep respect for whales, cataloguing their remarkable attributes and the reasons why their survival is important. The last line delivers a hard-hitting reminder of the threats they face. Hughes had long been aware of the impressive capabilities of cetacean intelligence ('Man and Superbeast'), and here, he praises their 'global brains'. Hughes's evocation of animal sound and the power of echolocation is expressed in his words about their 'X-ray all-dimension || Grasp of this world's structures' (775). The open, echoing vowels in some of the poem's lines seem to mimic echolocation in a poetic sounding back of the whales' depth-charge song: 'Their body-tons, echo-chambered' and 'Moon-lifted incantation' are full of resonant Os. Here is ecopoetry shaped by animal sound, an example that resonates with Skinner's focus on listening to the fragile sound of the damaged biosphere. Yet this evocation of whale sounds answer's Rigby's call for ecopoetry to turn the reader's gaze from the page towards real environmental problems: the last line 
prophesies '[t[he most terrible fall' (776). The myth of the fall from an Edenic illud tempus to an era of ecological destruction is one that preoccupies Hughes in so much of his work. Despite the new legislation to protect whales, Hughes hints that environmentalists cannot be complacent about their efforts to protect these creatures. The ominous ending of this poem evokes the interminable process of elegising species that remain endangered.

Hughes continued to deepen his awareness of conservation, environmental writing and the behaviour of threatened animals. He was also responding somewhat sceptically to contemporary initiatives to breed captive populations of endangered and exotic species. In 1978, Barry Lopez had published Of Wolves and Men, which Hughes acquired.274 Lopez immerses his reader in the sensory world of a wolf in the North American boreal forest:

He moves along now at the edge of a clearing. The wind coming down-valley surrounds him with a river of odors, as if he were a migrating salmon. He can smell ptarmigan and deer droppings. He can smell willow and spruce and the fading sweetness of fireweed. Above, he sees a hawk circling (11).

Lopez went wolfwatching from his cabin outside Fairbanks, Alaska (1), which Hughes found to be a fantastic land for wildlife. Hughes's response to Lopez could not create a starker contrast: the poet contemplates a miserable captive beast whose kind is extinct outside zoos in Britain. London is no place for an Arctic wolf who has to spend 'all his life | Behind wires' ( $C P H$ 754). It is specifically the wolf's exile from the environment where his species usually lives that Hughes laments. Hughes wonders,

Is he hearing deer? Is he listening

To gossip of non-existent forest? (755)

The poem could be called anti-tropological: it shows the distress that an animal suffers when the connections between it and the species it usually lives alongside, or preys upon, are severed. 'Wolfwatching' suggests an important revision to Skinner's idea of the tropological ecopoem: in our age of environmental damage, broken connections are as significant as healthy ones, and Bristow's idea of the disruptions and disconnections of the Anthropocene lyric becomes increasingly pertinent. All of Hughes’s poems about captive wolves are accomplished studies of human and animal distress, yet 'Wolfwatching' is by far the most biocentric. Rather than 'capturing' wolves, the poem shows how human and animal suffering are alike - and attempts to look at wolves from their own point of view. Although zoos and captive breeding programmes had been seen as important for conservation in the 1970s (Adams 140), Hughes nuances his earlier critiques of keeping bored, unhappy beasts behind bars by suggesting that both individual animals and wider ecologies suffer when animals are taken from their habitat.

One of Hughes's most significant interventions in international conservation was his fundraising poem 'The Black Rhino'. He was commissioned to write it in aid of the charity

274 Barry Lopez, Of Wolves and Men. New York: Scribner, 1978. Emory MARBL: QL737 .C22 L66 
Rhino Rescue, in March 1987. In August of that year, after he had worked on the poem while fishing in Canada (Boyanowsky 46), Hughes gave a moving talk in Vancouver about rhino's plight. Copies of 'The Black Rhino' were being auctioned to raise funds for the charity, which operated in Zambia. This speech, which he altered slightly and published in the notes to Wolfwatching, testifies to Hughes's careful research and his deep commitment to environmental affairs. He told his audience that the rhino's body was highly prized in Indian and Far Eastern medicinal traditions. In 1980, there had been 18,000 black rhinos left; by the end of 1986, there were only 4,000. There was great demand for rhino horn in North Yemen, 'where the outcome of the Civil War combined with the oil crisis to produce a freakish, mass market for the costly rhino-horn-handled djambia, the ceremonial curved Yemenite dagger' (CPH 1213). There were four parts to the poem that was offered for sale. Hughes stated that the first part was advice to the photographer, the second part was an account of the rhino charged in court, the third part described the fatal illness of the rhino and the slow motion impact of a bullet, and the fourth was a 'doggerel elegy'.275 The fourth section was not included in Wolfwatching, but it is included in an appendix to the Collected Poems (1296).

'The Black Rhino' deals with a form of poaching that contrasts markedly with Hughes's boyhood excursions with a rifle. Its first and last cantos contain some very fine ecopoetry, marked by its high poetic quality, the ethical dilemmas it raises, and its eco-elegiac concern for the future. The middle section is a protest poem. Hughes's views about hunting rare megafauna changed gradually during his lifetime. By the time he wrote 'The Black Rhino', he had moved far beyond his boyhood interest in Haig-Brown's panther hunting, and his later phase of acquiring eagles' feet and leopardskin fashion accessories. While Hughes had no qualms about hunting managed populations of grouse or foxes, 'The Black Rhino' conveys the horror of poaching an endangered species. Hughes conducted meticulous research for this poem. Over 200 pages of research materials on rhinos are kept at the Emory University MARBL archive. He drew on an interview with the artist and conservationist David Shepherd,276 and an article by the writer and filmmaker Martin Booth;277 both cite poaching as the primary threat to rhinos, although Shepherd does not oppose the hunting of more numerous, fast-breeding species. Such western-led projects would now be seen as running the risk of dismissing local knowledge of animals and environmental management (Adams 113). But between 1982 and 1992, two World Congresses on National Parks and Protected Areas would create a shift in conservationist thinking by beginning to encourage increasing community involvement in conservation, encouraging local people to become conservation 'partners' rather than 'poachers' (Adams 118-120).

The poem superbly encapsulates the sense of past, present and future that Morton and Gilcrest find in the environmental jeremiad. The first section, Hughes’s advice to a photographer, describes the rhino's past as 'Behemoth, sixty million years printing the strata',

275 BL Add MS 88918/122/1 notebook titled ‘DEAN RIVER Aug 29 1987 ’ 31.

276 Emory MARBL archive collection 644 box 77 folder 4 'Ambassador for Life', article by Nic Barlow in Landscape 39.

277 Emory MARBL archive collection 644 box 77 folder 4 'ARTICLE ON RHINOS IN ZAMBIA’. 
while his present is 'the brain-blink behind a recoiling gunsight' and his future is 'a cheap watch shaken in your ear' (763). Hughes evokes the rhino's ancientness, the instant in which we see it through the crosshairs of a gun, its parlous future as a saleable 'commodity'. This section ends as the rhino's life ends - with the 'gagging stench' of his decay (764). The next section sees the rhino tried in a Cave Birds-like court, by a sepulchral human judge. By the third section, the rhino's mythical associations have had disastrous consequences: 'Every cell of her body is ruptured with human delusion' (766). In contrast to the ideological subtlety of much of his work before his Laureate protest-poems, Hughes creates a barbed critique of global consumerism. The horns change hands for cash among 'African bigshots', in the Far East, in Yemen, and in Dubai. No doubt recalling the 'country poverty' of his youth (CPH 1138), Hughes has some sympathy for those driven to poaching by destitution: he gives precise data about the financial incentive to kill rhinos in countries where 'Twenty-five pounds sterling feeds a family for ten weeks'.

The poems ends amid the silence of water-holes, scrub and mountains - where the only sound that can be heard is human:

\section{The Black Rhino \\ Is vanishing}

\section{Into a soft}

Human laugh (767).

No final punctuation mark ends this line. It trails off into soft, Crow-ish laughter, and then into silence. When Hughes first published the poem in the Daily Telegraph Weekend magazine in 1987, the rhino was male in all sections. He later changed its sex to female in the last part. This accentuates the creature's vulnerability, as the female rhino is smaller than the male, with a less formidable horn. This environmental elegy gives us a glimpse of the rhino's future, in Rigby's angrily prophetic mode - and it is a horrifying prospect. But this poem is also significant for other reasons: the trade in rhino horn is fuelled by the need for financial gain, which encourages consumerism and perpetuates inequality. 'The Black Rhino' adds to Hughes's earlier critique of those who would 'cash in the world', and to his later condemnation of the sprawling, transnational web of Wealth in The Iron Woman (76-7). For Hughes, international environmental problems are often related to uneven development and the drive for economic gain.

As Hughes draws Wolfwatching to a close, he confronts us with a vision of real extinction. 'Us He Devours' presents an elegiac revision of Hughes's early poetry of devouring jaws: he shows us a museum specimen of 'Megalodon | Carcharadon' ( $\mathrm{CPH} 775$ ), an extinct species of huge shark. When Hughes places 'Little Whale Song' immediately after this poem in the collection, he encourages us to contemplate the future of our planet's marine life. Morton and Gilcrest view the environmental elegy as looking prospectively to an uncertain future; Hughes's elegies for captive macaw, caged wolf, endangered rhino and threatened whale 
wonder what sort of future these creatures will have in an increasingly crowded and polluted world. If this collection looks back to Hughes's Yorkshire ancestors, it also raises difficult ethical questions about the way human beings treat animals, and how future generations will tackle the problem of vanishing species. The poems raise important dilemmas that were current in the conservation policies of the 1980s: is it right to cage an Arctic wolf in order to preserve his species? Should rhino conservation be prioritised over the destitute poacher's need to feed his family? Is a ban on commercial whaling sufficient to protect whales when the oceans are overfished and polluted? Hughes’s ecological elegies offer no easy resolutions.

\section{From 'Earth Summit' to Earth Goddess}

Hughes continued inform himself about the latest research on biodiversity, extinction and conservation. He read about extinct and endangered animals from quagga278 to quetzal.279 He was discussing issues in Devon, in Europe, and terrifying scenarios of global import. Writing to Boyanowsky in early 1988, he described 'strange, fiendish weather, perhaps portending the collapse of the ecosystem with global warming, ozone depletion and the reversing of ocean currents' (Boyanowsky 69): anthropogenic changes to planetary systems on a vast scale. Later that year, he sent his poem 'The Bear', about fishing in British Columbia, to be auctioned to raise funds for the Canadian Steelhead Society (96). He acted as a judge for a 1989 poetry competition to raise funds for WWF. The competition's aims were to 'celebrate nature, explore relationships between people and the environment or in any other way examine the problems created by the way we live or organise ourselves', and would fund global projects such as a forestry reserve in China and rainforest conservation in Nigeria and Mexico ('Paeons to Nature' 17). He acquired environmental books on topics ranging from scientific changes in the biosphere,280 to the rockstar Sting's Jungle Stories: The Fight for the Amazon.281 Hughes wrote to Sting in 1990, congratulating him on his environmental activism and sending him the American poet W. S. Merwin's book about 'a catastrophic assault on Hawai's [sic] last bit of Rainforest'.282 But one of the most critical influences on his global environmental awareness was recent thinking about climate change. He acquired the 1990 publication Global Warming: the Greenpeace Report, a frustrated response to international governments' unwillingness to take the warnings of the Intergovernmental Panel on Climate Change seriously.283

278 David Day. Noah's choice: true stories of extinction and survival. London: Puffin, 1991. Emory MARBL QL88 .D42 1991 HUGHES.

279 Jonathan Evan Maslow. Bird of life, bird of death: a naturalist's journey through a land of political turmoil. New York : Simon and Schuster ; 1986. Emory MARBL QL696 .T7 M37 1986 HUGHES. 280 The Earth as transformed by human action: global and regional changes in the biosphere over the past 300 years. Emory MARBL GF75 .E15 1990 HUGHES

281 Emory MARBL F2520.1 .C45 S75 1989 FOLIO HUGHES.

282 Emory MARBL Collection 644, Box 53, Folder 9, 'Dear Sting'.

283 Jeremy Leggett, ed. Global Warming: The Greenpeace Report. Emory MARBL QC981.8.G56 G583 1990 HUGHES. 
In 1992, Hughes reviewed Your World, a collection of environmental photographs taken for a competition that marked the 'Earth Summit'. Hughes raises his concern that 'mankind has difficulty finding a language' in which to 'interpret the Earth's needs' and 'realign' itself to those needs. He is concerned that 'a deafness built into our governments, our industries, into all our institutions, into our brilliant culture and cleverness' ('If' 31) keeps us from realising just how much damage we are doing. He is frustrated with 'the Bush administration's oldstyle disregard for the environment' (31): a clear broadening of his awareness beyond British environmental politics. A 'keen, new listening' is necessary - and the idea of 'listening' to the earth will be stressed again in Tales from Ovid. Hughes articulates his frustration that environmental science often faces the challenge of the 'other kind of science' funded by national authorities and polluting industries - the sort of science that the opposition had deployed at the Torridge inquiry (33). The 'Babel of Sciences' and government cover-ups complicated his own efforts to expose marine nuclear waste dumps and journalists' attempts to draw attention to high levels of radiation around Sellafield. Hughes relates that he was shocked to read a speech in Your World by the Russian nuclear physicist Vladimir Chernushenko, which details the obfustication surrounding the full death toll from Chernobyl (4). The situation is 'not without hope' (35): Hughes hopes that photography will 'by-pass the language barrier' of conflicting jargons. His evocation of a 'Babel of Sciences' is significant: for Hughes, an accomplished literary translator with a scientific interest in the environment, the environmental movement needs a common language and a unified mission to take better care of the planet. The photographs create a 'portrait of the Earth and her life as a half-dark, many-breasted miracle who - almost like the great archaic Goddess who wore a tower on her head - wears on her head a Nuclear Reactor' (35). Hughes ends his article with an image of the nature-goddess: a holistic, Lovelockian evocation of Gaia. Yet in his next major environmental publication, he would translate an ancient text to give Gaia a voice of her own.

\section{Tales From Ovid}

It is Hughes's Tales From Ovid (1997) that contains his most sustained descriptions of the globe and its environments. Several of the poems that would be included in Tales from Ovid were published in 1994 in an anthology of 'new' Metamorphoses; the editors mention 'pollution' as one of the modern issues with which the poems engage (Hofmann and Lasdun xi). Bate has analysed the ecological dimensions of Hughes's version of Ovid, calling it 'his mythic paradigm for the crisis of Western Man's self-exile from Nature' (2000 28). Bate astutely points out the narrative of decline from Golden to Iron Age. 'The more telling respect in which the ancient narrative of the Four Ages is, so to speak, ecologized in its Hughesian retelling is revealed by that reference to the 'inward ear': the Hughes version consistently heightens the notion that harmonious dwelling with the earth is a matter of staying put and listening in, whereas the rapacious drive of 'progress' is towards travelling out and making claims - the claims of knowledge, conquest and possession' (29). Yet for Hughes, the worst of these is the desire for possession: he and Ovid attack the cruel ideas brought by 'gold' ( $\mathrm{CPH}$ 871), much as he had attacked unscrupulous corporations in 'The Environmental Revolution'. Sagar's interpretation of the Flood that follows the Four Ages is distinctly environmentalist: '[m]an has made such a mess of creation that God decides to 
delete him, with hurricane and tsunami' ('Ted Hughes and the Classics' 14). Gifford is right to privilege this collection in his paradigm of Hughes's 'greening' (2014 6), but the 'creation' section he quotes is not necessarily the most engaged in the environmental problems of Hughes's age.

But none of these critics realises the full extent to which Hughes 'ecologises' Ovid. Only Solnick has spotted the connection that Hughes creates to climate change (199). Two of Hughes's Ovidian tales evoke the apocalyptic effects that would occur in an advanced stage of climate change. In Rolfe Humphries' translation of Ovid, Jove creates a great flood by imprisoning the dry North and West winds and unleashing the stormy South Wind (11). In Hughes's version, Jove creates the flood by melting the icecap at the North Pole: 'In a moment he had withdrawn the blast | That fixes the Northern ice' (CPH 878). This is a clear reference to climate change. Ovid follows the myth of the flood with tales of Deucalion and Pyrrha, Apollo and Daphne, Jove and Io, and then the tale of Phaethon. Hughes goes straight from Jove's flood to Phaethon's fire, linking two myths to suggest the extreme weather events that were happening due to climate change. Hughes's 'Phaethon' calls up a horrific vision of a world consumed by a blazing sun - just the sort of environment that we might experience in future stages of global warming. When Hughes writes, 'Now Phaethon saw the whole world | Mapped with fire', he concurs with other translators of Ovid (Humphries 35), but one is also reminded of views of the earth from space that influenced Crow, which Ovid could never have seen. Hughes devotes nearly an entire page to a catalogue of affected rivers, from Meander and Euphrates to Ganges and Nile: the watercourses of the whole world, as it was known in Ovid's time. Lines such as 'Yellow Lycormas poured a reeking soup. | Looped Meander steamed like a scalded serpent' remind us of Hughes's unsettling descriptions of polluted rivers in times of drought. 'The Rhine, the Rhône, the Po and the Tiber | Which had been promised an Empire | Were bubbling pits of quag and scabby trenches' (CPH 891) recalls the 'scabby' farms whose effluent runs into the West Country's rivers in 'RainCharm' - but here, the drought is of global proportions.

But the most important development in Tales from Ovid, is that both Ovid and Hughes speak for the Earth. Hughes had rarely given his earth-goddess a voice in earlier work, although he had come close to doing so when he evoked the river's message that 'Only birth matters' in 'Salmon Eggs', and when the Iron Woman took up the cause of Britain's polluted waterways. Hughes's goddesses - Crow's Mama, Gaudete's dedicatee, the nymph of 'Nymet' - are usually silent. Here, Hughes lets the entire earth speak. The Earth-goddess protests at being afflicted by the scorching sun, since she has already had to endure having her 'flesh gouged and attacked and ground to a tilth' by the 'ploughshare', the 'pick and the mattock' (893). When he reinvigorates Ovid's vision of a whole Earth speaking, Hughes's global awareness is most clearly manifest.

Hughes 'ecologises' Ovid in other significant ways. He chooses tales that resonate in our age of habitat destruction and human-caused extinction. Hughes’s 'Erisychthon' echoes his long concern about Britain's declining hardwood forests: Erisychthon cuts down the 'sacred grove of Ceres'. Previously, this was '[a]n ancient wood that had never, before that day | Jumped to the axe's stroke'. On hacking at a 'prodigious oak' ( $\mathrm{CPH}$ 924), Erisychthon notices that its 
leaves and acorns blench; it bleeds when cut (925). The nymph living in the tree even has a voice to curse her murderer - a mythic fusion of nature and the human, with elements of ecological elegy. Erisychthon is punished with terrible hunger that leads him to eat his own limbs (930). Ovid might not have known that deforestation can lead to increased soil erosion, lower crop yields, and potential famines - but Hughes certainly did.

Hughes's entire project to adapt the Metamorphoses suggests that human and nonhuman life spring from the same root, and are linked by a complex network of interconnections. When Myrrha is transformed into a tree in punishment for her incestuous union with her father (953), and her son Adonis becomes an anemone (963), the myths destabilise the species boundary and adumbrate posthumanism. As Jacobsen puts it, Ovid presents a 'wholly animate and mutable Nature, enmeshed with humanity' (157). Shakespeare's Venus and Adonis had interested Hughes since his adolescence.284 Goddesses associated with aspects of nature - Ceres, Venus, the 'tower-crowned' Cybele (962) whom he mentioned in 'If', and that archetypal white goddess Artemis - remind one of Hughes's long interest in feminine nature-deities. But Hughes also used his ecologised tales to raise funds for an environmental cause. Hughes read 'Salmacis and Hermaphroditus' at an Arts for Nature gala in November 1996, and the Duchess of Abercorn praised the tale's 'resonances'.285 Hughes's Tales from Ovid looks both backwards and forwards. Backwards, with elegiac nostalgia, to a golden age when man listened deeply and kept faith with the source. Forwards, to a world that is already warming, where the sacred groves have been cut down, and where unsettling biotechnology replaces the gods' power to change bodies into other bodies. To use Gilcrest's term, Hughes's Tales from Ovid is prospective: he adapts an ancient text in the face of an uncertain future. Hughes tackles environmental issues as weighty as those discussed in Crow, but does not use its super-simple idiom, to create ecopoetry capable of expressing the anxieties of what would later be termed the Anthropocene.

The interactions between Hughes's local and global environmental thinking are complex, and their implications are especially interesting in the light of recent ecocritical theory. Relatively early in the development of British ecocriticism, Bate argued that 'Stay true to the pull of the spot as opposed to the nation and you have a longing for belonging that is the essence of ecopoesis' (2000 212). The pull of the spot may have been relevant to the Romantics whom Bate was analysing here, but it becomes increasingly complicated in contemporary ecopoetry: by the late twentieth and early twenty-first centuries, the idea of the 'spot' is brought into dialogue with poets’ awareness of our imbrication in vast weather systems and communications networks, and by the fact that human beings undertake more national and international travel now than at any other time in history. When Bate argued that poetry and ecology engage with the 'bioregion', a territory that rarely respects national boundaries (231), he began to articulate an important international dimension that later scholars have analysed in greater depth. The bioregion alone is no longer adequate for analysing contemporary 
literature: by the late twentieth century, we need to examine how spot, nation and bioregion interact with the global. One of the most thorough examinations of the local and the global has been conducted by Ursula Heise. The authors she analyses 'highlight the imbrication of local places, ecologies, and cultural practices in global networks'; the later Hughes certainly does this. Yet the culture products that Heise discusses are 'ambivalent' towards globalisation, suggesting that 'it might sometimes need to be resisted by some form of "reterritorialization," but that it might in other cases become the basis for cosmopolitan forms of awareness and community, both ecologically and culturally' (210). She writes that 'climate change poses a challenge for narrative and lyrical forms that have conventionally focused above all on individuals, families, or nations, since it requires the articulation of connections between events at vastly different scales' (205). Hughes certainly was drawn by the pull of the spot, and in the 1970s, his farming endeavour suggests that he was attempting to consolidate his attachment to a specific locality - evidencing a desire for Heise's 'reterritorialization'. But he published both Moortown Diary and Remains of Elmet in the same year: his rootedness in two regions simultaneously, and his homage to them in collections whose time of composition overlapped, speaks of his dual sense of being at once Northern and Devonian, of an identity that could not be easily reduced to regional or national particularities. If Hughes in 1970 longed to immerse himself in the North Tawton landscape, and in 1984 he wished his Laureate-poems to celebrate a unified nation, his 1988 celebratory poem for Princess Beatrice is inescapably global in its outlook. Local environmental activism took up more of Hughes's time than his engagement with international issues; but by the 1990s, it was no longer possible for environmentalists to focus on local issues and ignore vast global problems such as species extinction and climate change. Hughes's writing is aware that such international predicaments have implications for both salmon returning to his favourite Torridge fishing-spots and for the world's weather-systems. Since Hughes's time, writing about the Anthropocene has engaged with phenomena that are not only translocal, but which cover vast timeframes, such as Morton's hyperobjects (2013).

But another environmental preoccupation of Hughes's was emerging alongside his writing about international species conservation and global environmental problems. From the mid 1990s, Hughes was attempting to develop a conservationist defence of hunting and fishing. His engagement with hunting with dogs becomes visible in Tales from Ovid in his retelling of the myth of Actaeon. This hunter kills so many animals that 'The slopes were patched red with the butchering places' (937); this recalls the 'blood-soaked blackened grass' (DB 151) of the hunters' camp in 'The Head'. Actaeon's fate is echoed in the metamorphosis of the hunting-obsessed brother in 'The Head'. It takes an entire page for Actaeon's own hounds to finish tearing him to pieces ( $C P H$ 941). His human awareness of his animal body is harrowing: 'Human tears shone on his stag's face | From the grief of a mind that was still human' (939). Ovid's ancient work enables Hughes to create a very modern meditation on our human 'capacity for becoming animal' (Skinner 2011). Hughes supported stag hunting in the West Country for conservationist reasons (PC 256), but he was certainly aware of the horrendous 'tugging and ripping' ( $\mathrm{CPH} 941)$ that end Actaeon's life. One of Hughes's most longstanding conservationist preoccupations, and the source of many tensions and contradictions in his writing, was hunting. 


\section{CHAPTER XI. HUNTING, SHOOTING, FISHING - AND CONSERVATION?}

From that early poem about the 'frost-chilled snap' of the wildfowler's gun, to his unpublished Birthday Letters poem 'The Grouse', Hughes was writing about shooting and hunting. His poems engage with these practices at different points in his life; this book has examined some of the differences of opinion that hunting provokes, and the often contradictory statements that Hughes put forward at different times. Yet the promise of greater protection for wildlife in the Labour Party's manifesto of 1994 and the threat of a hunting ban in 1997 caused him to articulate his views about them in poetry, letters and a newspaper article. In the lead up to the general election of 1997, the environment had gained in salience as a political issue; a poll conducted by MORI and The Independent on Sunday indicated that it was the tenth most important issue for voters. Animal welfare was twelfth above Northern Ireland, devolution and trade unions (Dorey 245). Hughes was even considering writing a book about blood sports in the last year of his life, and the last interview he ever gave focused on fishing and hunting. Hughes's defence of hunting is more complex, and contains even more elements, than his 1994 defence of fishing (Gifford 1999). He was thinking back to his early shooting expeditions with Gerald, and because he felt ready to publish Birthday Letters, he was also considering how Plath's reaction to the killing of the grouse affected his views. He was continuing his 'green Laureate' activities by lending his support to different conservation charities and selling poems to raise further funds for environmental causes, and his global awareness was continuing to develop. Yet his environmental activities from 1994 until his death are distinctive because he articulated his defence of blood sports on conservationist grounds.

Several critics find Hughes's participation in blood sports to be at odds with his ecocentric endeavours. Indeed, he does show clear sympathy with the quarry in poems such as 'The Stag', 'Foxhunt' and Tales from Ovid's 'Actaeon'. Roberts comments that Hughes expresses 'no sign whatsoever of remorse' for his indiscriminate shooting of animals in Yorkshire during the interview with Pero (2014 2). Sagar summarises these contraditions pithily: ' $[w]$ henever he moves into imaginative mode, his identification with the hunted animal is boosted to the point where it overrides his rational justifications of hunting' (2006 147). The narratives that Hughes constructs about shooting imply that there were two moments in his life when he began to call his boyhood obsession with killing animals into question: the end of his shooting expeditions with Gerald, and the incident when Plath rebuked him for killing the sick grouse. There is a discrepancy between Gerald's account of shooting only agricultural pests, and Hughes's recollection that they also shot rarer prey such as owls and curlews (WP 11). Roberts, too, picks up on this distinction, wondering if Hughes was drawn into 'camaraderie with an interviewer who campaigned for hunting and fishing' (2014 2). Sagar notices that during his boyhood, Hughes 'had no compunction about shedding the blood of animals' and does not explore the 'negative implications' of shooting in 'Two' (2006 146). 
Rural hunters do not usually express remorse or compunction about killing animals. Hughes grew up surrounded by hunters, poachers and farmers, and the values of the Devon farming community influenced him at a later stage. In the last year of his life, he wondered if he was 'the last of a breed' of trappers, and thought that 'it was easier in the 30s and 40s to preserve the hunting \& trapping sensibility intact - especially if you'd grown up inside it' (LTH 705). One need only speak to the West Yorkshire Riding poet, Hughes scholar, Ted Hughes Award nominee and hunter Steve Ely to understand how country people's respect for animals can go hand in hand with the enjoyment of hunting them, why hunters and shooters need to conserve populations of their quarry, and how they develop empathy and respect for it. Ely explains:

Shooters/fishermen became intimate with their quarry via the stalking and observational processes that lead to the kill/capture. This intimacy is characterised by an embedded knowledge of the quarry and its habitat that is so attuned that the expression of it sometimes appears to be a form of intuition or even magic. Empathy, respect, a sense of affinity and a sense of wonder also develop, which can lead to compassion, restraint and a concern for conservation that goes beyond simply maintaining stocks. This is clearly evident in Hughes.

Anyone who takes delight in nature, as Hughes did, must ultimately seek to conserve it. Hughes initially experienced his 'delight' as a trapper, shooter, fisherman and farmer. In the first two instances he killed for sport; in the third for sport but also as a form of predator control (pike) and for food (salmon); in the final case he raised animals for commercial slaughter, but found joy in acts of husbandry. Hughes's deep knowledge of and delight in nature arose from his exploitation of it.286

Boyanowsky, too, takes a similar stance: 'I am delighted to discover the depth of Ted's concern for the environment [...] it is the human predator (the hunter, the fisher) who is most keenly aware of the state of the river' (69). Ely's description of hunting is remarkable because he argues that hunting can actually promote empathy and compassion. This would explain why Hughes created visceral evocations of the quarry's suffering, while still accepting that it must die. Yet Hughes does not seem to have considered the potential negative environmental consequences of managing game populations. Instead, his library contains a great number of writers who praise hunting. The archive at Emory contains thirtythree books on hunting, gamekeeping and poaching, from the hunting-stories of Jefferies and Williamson to accounts of colonial African big-game shooting and tales of trapping animals in the Malay jungles.287 Hughes’s reading of Michael Brander’s 1964 The Hunting Instinct advocated a sportsmanlike ethic (17) and for the opponents of hunting to join with hunters in opposing 'the uncontrolled policies of poisoning the earth' (165). In the work of these writers are the origins of Hughes's attempts to defend hunting on conservationist grounds. There are, however, environmental and animal welfare issues that his defence of hunting overlooks. But Hughes had said in Poetry in the Making that he lost interest in hunting because he accused

286 Email from Steve Ely to the present author, 26. 10. 2015.

287 Henry Astbury Leveson. Sport in many lands: Europe, Asia, Africa, and America, etc. London: Warne, 1890. Emory MARBL SK31.L65 1890 HUGHES. Charles Mayer. Trapping wild animals in Malay jungles. London: Unwin, 1922. Emory MARBL GV1827 .M3 1922 HUGHES. 
himself of disturbing animals' lives. He does seem to have felt twinges of shame about trapping and killing indiscriminately - and especially about poaching.

\section{Origins of Hughes's defence of hunting}

Hughes's late defence of hunting drew on strands of thinking that had been developing very early on his career. Even after he had accused himself of disturbing animals' lives, he occasionally shot vermin for 'recreational purposes', such as jackdaws on the roof of Court Green in 1962 (Ely 2015 102). Although his boyhood poetry celebrates fishing and shooting, by the 1960s, he had begun to articulate his uneasiness about killing foxes, in 'A Moon ManHunt' in particular. Hughes's Moortown-poems 'The Stag' and 'Foxhunt' articulate an empathy for creatures run down by dogs, and show that some farmers dislike the hunt. Yet Hughes's most ambivalent and intriguing poem about killing a fox - and about shooting - is 'A Solstice'.

This poem was first published in 1978 as a pamphlet, and Roberts describes it as 'hidden' in What is the Truth? (2014 3), where it appears without a title. Despite the unsettling events it describes, the poem appeared in All Around the Year (1979), a children's collection of farming diaries edited by Hughes's friend Michael Morpurgo. 'A Solstice' is related to the Moortown Diary project: Hughes and Gerald are on 'the small hills of the West', so they are in Devon. Gerald wants 'a taste of English sport' ( $\mathrm{CPH} 382)$ : for Gerald, this is shooting for pleasure, but there might also have been a practical motive, which will be examined shortly. Roberts dates the events described to Gerald's visit in the winter of 1965-6 (2014 4), and the poem is addressed to Gerald. Ted takes the role of a retriever as he did as a boy: 'I am your dog' (382). The fox is an 'Ancient Briton' (386), like the Ancient Briton of 'The Ancient Briton Lay Under His Rock': a symbol of Britain’s wild, autochthonous life. Roberts has linked this poem to Hughes's story 'The Deadfall', and commented on the personification of the gun and its 'sinister' role (2014 4). A peculiar alertness comes with shooting, in this poem and elsewhere: Hughes told Pero that he became 'intensely alert to the whole landscape and the life in the landscape'. He associated shooting with heightened awareness: 'It was as though all my senses had been restored to me - by the gun'. Roberts comments that 'the gun seems to facilitate the speaker's awareness' in the poem (2014 5), much as it had in the interview Pero. Yet the transferral of agency to the gun, rather than to Gerald, absolves him and Ted of any responsibility for killing the fox:

The gun

Is working its hunter's magic.

It is transforming us, there in the dull mist,

To two suits of cold armour - (CPH 384).

Hughes creates intense pathos for the fox who struggles 'As if he could catch the broken pain I In his teeth, and pull it out of his shoulder'. Yet the description that follows, of the wounded fox in 'overcoat' and 'shirt' (385), is bizarrely anthropomorphic. Here is one of those 'little manikins in an animal skin' that Hughes himself had criticised (1962 18). Roberts traces 
Hughes's description of the fox as an 'elegant gentleman' to a Beatrix Potter story, and comments on the aesthetic distance between fox and speaker at this point (2014 8). Gerald has shot a totemic symbol of Hughes's creative life, and it is if Hughes can only ease his discomfort at writing about it by describing the animal's living skin as a shirt and shed blood as a stain. Solnick has argued that Hughes deploys violence restores a lost sense of corporeality (76). But here, both the perpetrators of violence and its victim are deprived of their corporeality by the imagery of cold suits of armour and a bloodied shirt. The coup de grace that kills the fox with a 'sky-bursting bang' ( $\mathrm{CPH} 386$ ) was anticipated by Hughes's reaction to the initial gunshot, 'The blast wall hits me' (384). Roberts notices that the 'cracking blow on the head' (386) that Hughes feels when Gerald shoots the fox might be paralleled by Hughes's realisation that Gerald would not return to Britain, which 'knocked me out' (LTH 358, qtd in Roberts 2014 10). Hughes's speaker empathises with the wounded fox and seems to feel guilt, but this is complicated by evasively anthropomorphic descriptions of the fox and a transferral of agency to the gun. Sagar calls the killing 'a shameful and pointless destruction of a sacred life', and points out the similarity to Hughes's 1978 story 'The Head', in which the elder of two brothers is punished for rapacious hunting (2006 149). Hughes identified with foxes, and the fox's energy was 'necessary to is poetry and to his life'. The fox is, of course, a predator - and 'to suppress his own predatory instincts would be at least partly a refusal of the energy’ (Roberts 2014 11). But neither Sagar nor Roberts mention that there is a practical reason why the Hughes brothers shot this fox: one brother had been a gamekeeper in Devon, the other farmed, and both would have regarded foxes as pests. However, some statements about hunting artificially managed foxes that Hughes put forward in the 1990s, significantly complicate the idea that this was a form of pest control.

By the 1980s, Hughes was beginning to rethink his earlier killing of animals that were becoming scarcer. This is particularly evident when one considers his writing about hares. Hughes had no qualms about shooting hares in East Yorkshire in the mid 1950s: meat was rationed, and he posted the carcasses to his friends ( $L T H$ 705). Yet as we have seen, 'The Harvesting', written between 1958 and 1959, had shown a man attempting to shoot a hare, and ending up being hit by his own gun, changing places with the hare ( $D B$ 89). 'The Hare' (1984) creates a striking transferral of feeling from a hare killed by a car to the driver: it 'cries with human pain' and is a 'flying harp' that makes the driver's nerves 'flail and cry' like a 'burst harp' ( $C P H$ 688). One section mentions the hare's blood: 'astounding | How much blood there is in her body!' (689). This speaker clearly knows how to jug hare, a culinary practice that Hughes problematises in 'The Afterbirth'. (It is possible that Plath's sympathy for the dead hare also affected his views.) Yet in the last canto the hare escapes the huntsman's shotgun, kicks dirt into the eyes of the lurcher, and slips 'Into tomorrow' (690). Hughes gives the creature much more than just a sporting chance: he celebrates its escape and its survival. It is likely that he grew to find hare coursing unacceptable because hares soon became endangered: there was an eighty per cent decline in their numbers during the twentieth century, partly due to mechanised farming and pesticide use (Hare Preservation Trust, 'Status of the Brown Hare'). His ambivalence about killing hares was due to the heightened awareness of environmental issues that his activities of the 1980s gave him. 
Just a year after 'The Hare', Hughes published the uncollected poem 'Grouse-Butts' (1985), which describes hunting a managed population of game birds: a practice he found acceptable. The poem is nowhere near as successful as his 1978 Elmet-poem with the same title, but it conveys a significant development in Hughes's thinking. The poem is addressed to a nameless 'you', who thinks of the grouse-butt as 'The bird-murderer's house'. This might be an animal rights advocate, Plath, or even Hughes addressing his own past self, the writer of the earlier 'Grouse-Butts'. The poem has a similar jaunty rhyme scheme to 'The Best Worker in Europe', the fishing-poem preceding it in the Collected Poems; this marks it out as a 'semi-protest' piece, a conservationist manifesto. 'Grouse-Butts' sounds decidedly conservative: here are birds that 'inherit the moor' and 'Bequeath' their lives in an oldfashioned celebration of lineage, patrimony and Englishness. Hughes explains how hunters 'nurse and worship the breed || And protect its sanctuary lands' from poachers. The bird is an 'Aboriginal Brit': fox, grouse and Ancient Briton are tutelary figures from England's past, and this idea consolidates the link between Hughes's patriotism and his support of conservation. Without hunting, poachers would kill the last wild grouse, and would intensively rear 'millions crying in a shed'. It is especially significant that Hughes criticises poachers in this poem: grouse need to be protected from 'what I was, in the past', since he would have 'slaughtered the last' ( $\mathrm{CPH}$ 699). Hughes and Gerald's bags of poached game included Lord Savile’s grouse.

The conservationist argument for shooting that Hughes puts forward in 'Grouse Butts' breaks down in 'Rights', a poem published only two months later. 'Rights' does not give a flattering picture of the 'guns' who shoot grouse. It is telling that the moor has been 'cleaned out' of birds, 'by the public' (701): they have been eliminated by poaching. Hughes's 'Rights' appears to suggest that grouse moors are not actually effective for protecting game birds. Hughes felt a deep attachment to moorlands because they were his childhood huntinggrounds. Yet he does not explore the negative environmental consequences of moors, which far from being 'wild', are highly maintained. Hughes knew by 1985 that burning heather to encourage new shoots for grouse and sheep to eat, could contribute to atmospheric pollution and climate change. By 1990, he would certainly have been aware of the full implications of this practice for the climate. Recent authors stress that maintaining moorlands impoverishes Britain's biodiversity: the environmentalist George Monbiot states that upland woodlands harbour no fewer than thirteen times more important species than moors (2016). Worse still, gamekeepers have to contend with predators that eat grouse - and some of these predators are very threatened indeed. The short-eared owl, which gamekeepers sometimes target, is a species of European conservation concern (RSPB). The hen harrier, which inhabits British uplands such as moors, has been given red (globally threatened) status and is 'intensively persecuted' (RSPB). One need only turn to David Harsent's elegy 'Bowland Beth', written for a hen harrier illegally shot on a grouse moor, for a poetic account of how (unscrupulous) gamekeeping can inflict a lingering death on an endangered animal (Harsent loc 119). A grouse moor is only good for the grouse that survive shooting and poaching. It is bad news for biodiversity, it may endanger predators, and it contributes to climate change. 
If poaching was clearly unacceptable to Hughes by the 1980s, his attitude towards shooting was becoming intriguingly ambivalent, tinged with elements of guilt. He associated shooting with heightened awareness of landscape and the life in the landscape - but also with the excitement of the kill. By the time of his second fishing trip with Boyanowsky in British Columbia in 1987, Hughes commented that he had not shot for twenty years. A day shooting chukar partridges by the Thompson River brought back " "the thrill, the blood lust”" (Boyanowsky 58). Around ten years before his death, a friend invited him to shoot on Exmoor; although Hughes was reluctant to shoot, his friend insisted. 'As soon as I got hold of that gun my heart began to pound. Suddenly I was wildly excited. So I spent that day shooting. And I realized that what I had completely lost since I stopped shooting was that automatic seeing everything in the landscape.' After this glimpse in the 'paradise that I used to live in when I was shooting', he 'relapsed into my desire to shoot no more' (Pero 55). Hughes presents both the shooting of chukars in British Columbia and the shooting of grouse on Exmoor as unique, isolated incidents. They were not. In the interview with Pero, he does not mention his deer stalking with Prince Charles. Clearly, Hughes did not completely lose his interest in shooting game animals - but does his emphasis on the end of his shooting in Poetry and the Making, and in the interview with Pero, suggest that he was somewhat ashamed of it?

Some of Hughes's unease about shooting and hunting-to-hounds undoubtedly came from their class associations. By the late 1980s, he had gone far beyond the working-class trapping, shooting and poaching traditions of his Yorkshire childhood. But that does not mean that he always felt at home among the elite, and his environmentalism provided an innovative way for him to forge links with people from a wide variety of economic backgrounds. In a letter to Gerald, he jokes that he is surprised to meet the very sort of people 'you used to breed your pheasant's [sic] for'. Salmon fishing in Devon was popular with former 'high ranking servicemen', whom Hughes portrays as conservationists: 'without them, I fancy there'd be no Salmon rivers left at all'. He views shooters with greater ambivalence: ' $[t]$ he shooting - in which I seem to have lost all interest - belongs to the Bankers, Landed Rich, \& Company directors - plus a few rich farmers'. The lords and Tory politicians whom he met at parties and on fishing trips knew 'how to enjoy their lives' and were good company, but were nevertheless an 'army of occupation' largely invisible to ordinary people (LTH 526). In a fishing diary that deals with the late 1980s, Hughes recorded a Dorset landowner's 'insolent Restoration manner' and his rudeness towards a local controller of pollution. It was this very manner that Hughes had detested in Cambridge's 'Restoration fop[s]' (LTH 680). But Hughes described the landowner as 'impressive' when their conversation turned to a deer protection bill, which they hoped would be a forerunner of a similar law to protect salmon. 288 It is as if Hughes used environmentalism as a means of transcending class barriers and finding allies: his environmentalist associates ranged from community activists to the Prince of Wales. But important divisions persisted. In 1998, he would describe the struggle between wealthy salmon fishermen and netsmen as 'a social war, a class war', one that also applied to 'grouse shooting and pheasant shooting' (Pero 50). He 
also thought of the movement against hunting-to-hounds as part of 'a very highly politicized class war' (55). By declaring his support for hunting in 1997, Hughes would take his side in that war.

By the late 1980s, Hughes saw the kill as unnecessary for his project to reconnect with the landscape. He wrote in 1987, that this 'ritual' could be performed via poetry and art, rather than through hunting:

The killing and eating of wild creatures, alas, raises the most primitive feelings of the killing and eating of the god. In my boyhood obsession with laying my hands on the prey I was extremely aware of that primitive religious aura. It was something that shifted easily to art, the making of images, embedding them in ritual settings.289

The sense of killing and eating the god is alluded to in Hughes's salmon-poems. He acknowledges that the sacrament can be performed without blood-sacrifice, but he was still (occasionally) shedding the blood of animals.

Curiously, it was not until the 1990s that Hughes began to question his earlier obsession with trapping animals. Hughes recalls in his interview with Pero that 'I had a line of gin traps for stoats, weasels and water rats - for their skins. This went on until I was 14 or 15', when his obsession with fishing took over (54). Hughes's reading of Tarka showed him the suffering that an animal in a leg-hold trap endures (Williamson 90), and these inhumane traps were banned in England and Wales in 1958, only a few years after Hughes had stopped using them. He wrote to Moelwyn Merchant in 1990:

As a sort of ritual - for keeping in touch - my entire boyhood, up to about 18, was spent shooting \& fishing. And trapping, I'm ashamed to day. Am I ashamed? What puzzles me now is how, while I was so obsessed with these creatures, I thought of little but getting my hands on them by killing them - which I did, in vast numbers (LTH 579).

Hughes was nearly sixty when he wrote this. It had been many years since he had trapped animals, and his feelings about them had changed. He admits to being 'puzzled' by his boyhood obsession with killing, but cannot decide whether or not he is ashamed about trapping. It is probable that he felt that trapping prolonged an animal's suffering, and did not provide the 'sporting chance' afforded by other kinds of hunting. He also expressed contradictory opinions about snaring, describing snares as 'horrible' but stating that a fox-cub he caught in a snare remained 'pretty healthy' (705). Legal forms of trapping were also declining in popularity at the time he wrote the letter. Ely notes that 'Trapping (snaring) has virtually died out as a popular practice [...] My peers and I quit snaring largely due to 'cruelty’ concerns'.290 Hughes's uneasy reflections on trapping, and his puzzlement at having

289 Emory MARBL box 56 folder 22 Letter from TH to Natalina 06. 02. 1987.

290 Email from Steve Ely to the present author, 26. 10. 2015. 
once killed vast numbers of animals, paved the way for his moderate, but still contradictory, conservationist defence of hunting later in the 1990s.

When the rural community called upon Hughes to respond to the animal liberation movement in 1995,291 the actions of small, fringe groups of violent animal rights activists raised important questions about the ethical treatment of both animals, and those who own and hunt them. In 1995, Hughes helped the Countryside Movement to redraft its Charter. The conservative philosopher and author Roger Scruton informed Hughes about a new group of intellectuals concerned about rural issues.292 They formed what became the Town and Country Forum. That same year, Hughes went deer stalking with Prince Charles (Bate 2015 483), a fellow conservationist. By 1996, the Countryside Movement had no clear goals; it was necessary to formulate other means of defending country life.293 Scruton urged Hughes to contribute to a book published by the Town and Country Forum: either by expanding upon his views on stag hunting, with which Scruton agreed, or to write about his thoughts on building plans in rural areas.294 Hughes was not able to provide a contribution - by 1998, he was struggling with serious illness and was preoccupied by other publication projects. But he revealed that he had been considering writing 'a collection of bloodsports anecdotes' detailing the way illegally hunted species 'vanish' due to poaching, while hunted species ‘flourish’295 due to game management.

When the Labour Party came to power in 1997, their manifesto promised increased protection for wild creatures. (In 1994, a draft manifesto detailing the Party's support of angling had been welcomed by the Salmon and Trout Association,296 of which Hughes was a member.) However, their measures also included a free vote in Parliament to review hunting with hounds ('Labour Party Manifesto'), provoking demonstrations by country people. 1997 saw Hughes responding to the threat of a ban by publishing an essay in The Guardian on stag and fox hunting, 'The Hart of the Mystery'. His article begins by attempting to re-focus the debate on animals, rather than rural people: 'If hunting is to be banned, what then happens to the deer and the foxes?' Hughes argues that the red deer population on Exmoor increased during times when hunting was permitted (PC 320). A similar situation applied to the fox population: before foxhunting, foxes were almost unknown in North Devon, but the Reverent Jack Russell ensured that a managed population thrived (322). Hughes argues that ' $[t]$ he hunt itself is helpless to protect the deer' and that an unspoken 'agreement among the farmers and country people' means that they 'refrain from killing' the animals. He describes stag hunting

291 BL Add MS 88918/121/2 ‘Countryside Movement: Our Charter’ 4.

292 BL Add MS 88918/121/15, Scruton to TH, 12. 01. 95.

293 BL Add MS 88918/121/15, Scruton to TH, 22. 01. 96.

294 BL Add MS 88918/121/15, Scruton to TH, 07. 01. 98.

295 BL Add MS 88918/121/15, TH to Sophie Scruton, 31. 03. 97.

296 Emory MARBL 664 box 165 folder 3, 'Labour party Policy on Angling: Salmon \& Trout Association Response', 2 unnumbered pages. 
as having 'tribal' origins and the deer as the 'totems of a special way of life' (PC 321): Hughes in primitivist, eco-shamanic mode. He warns that if hunting were banned, 'a new method of control (of the people) and preservation (of the animals)' would have to replace it (322). Otherwise, deer and foxes might be so ruthlessly poached that they would suffer the same fate as 'the bears, the wolves and the beavers' that we have wiped out (321-22). There are several problems with this argument. Firstly, Hughes was dealing with the threat of a nationwide hunting ban; his article extrapolates from the case of foxes and deer in the West Country and applies it to the entire United Kingdom. It is very surprising that he does not acknowledge that foxes thrive in urban parks and gardens, and that red and fallow deer live in suburban areas such as Richmond Park, regardless of whether or not their country cousins are hunted. There was no danger of these animals being poached to extinction. Secondly, when Hughes mentions the bears, wolves and beavers, his article becomes factually inaccurate: historically, these species were treated differently from deer and foxes. Wolves became extinct in Britain due to bounty hunting and deforestation; the wolf was usually considered vermin, and so wolf populations were destroyed rather than managed for hunting (Yalden 168). Bears were extinct by Roman times, due to deforestation and hunting for sport, while beavers became extinct in medieval times (Yalden 165), hunted for their meat and pelts. Hunting did not preserve these species: it contributed to their extermination. Thirdly, Hughes does not mention that there are several factors in the recovery of deer populations after heavy poaching, not just 'a single fragile psychological factor' (321). Deer were once endangered by poaching and deforestation (Yalden 171-72), but later became too numerous in some parts of Britain. Hughes read that the roe deer was a 'forest pest' (Forestry Commission 2) due to the absence of wolves to keep its numbers down (15).297 The red deer of the West Country were also too numerous in the 1990s, and hunting with hounds did not cull sufficient numbers (Langbein and Putman 222-23). Nor did hunting with dogs increase their numbers, but its impact remained 'neutral with regard to conservation of the species' (223). Fourthly, Hughes shows that poaching is inhumane (PC 320), but he does not actually state why hunting with hounds is preferable to other bloodsports that maintain deer and fox populations. He himself participated in deer stalking; culling deer with rifles is the main way that their numbers are controlled on Exmoor (Langbein and Putman 222), although the possibility of a wounded deer escaping means that this is not always a more humane alternative to hunting. Lastly, Hughes advocates hunting a managed population of foxes, which he thinks would otherwise become endangered because they 'interfere with income'. He notes that after Jack Russell's time, farmers established 'artificial dens' and stocked them with foxes; he was heartened to hear of a small wood that 'exploded with foxes' (322) near Russell's home village. Hughes does not raise the question of whether such a high concentration of foxes might endanger rarer predators by competing with them for food, or contemplate whether it might be detrimental to foxes' welfare to keep them with the sole aim of hunting them. In 'The Hart of the Mystery', Hughes fails to marshal the array of scientific evidence that made his defence 
of the Torridge and the Creedy so convincing and impressive. The sort of hunting that Hughes advocates would have been more beneficial to his friends in elite shooting and hunting circles than to animals.

Hughes continued to express contradictory views about hunting to his correspondents. Sagar finds his defence of hunting distinctly 'ambiguous' (2006 147), writing that Hughes's prose 'had nothing to say in favour of hunting except that the future might be even bleaker for deer and foxes without it' (2006 147). He told Hughes that his article left out 'the whole moral and spiritual dimension which characterizes your poems about animals'. Sagar does not wish to live in a society where it is normal to 'torture and kill animals', and finds that 'great changes' in his lifetime have made people 'much better educated about animals' (PC 255). Sagar is referring not only to a potential hunting ban, but to the animal ethics movement - and he is right to point out that Hughes's attitudes had begun to lag behind prevailing currents of thought by the 1990s. Hughes replied that he had been attracted to Devon because of 'the possibility of knocking over the occasional deer - subsistence': contrary to what he argues in his article, he seems to be in favour of accidental poaching here. However, he found the commanding attitude of mounted hunt followers 'awful', likening them to 'King William's barons'. He had 'known for some years what a hunted deer goes through physically. And a hunted fox. And a fish being caught'. He wondered, 'why aren't wild animals simply given the legal status of fellow citizens', in the wake of growing of animal protection (257). He probably put this view forward because Sagar was a critic of blood sports, and it is completely at odds with his distinctly human-centred support of managed animal populations for hunting. Hughes did give different accounts to different readers: Scruton the foxhunting man receives one version of his views; Sagar the animal lover hears another. Whatever his intentions may have been, Hughes makes an extraordinary statement when he wonders why animals are not treated as fellow citizens. For a moment, he expresses a radically green idea that contrasts starkly with his conservative attempts to defend hunting.

In later life, Hughes thought that hunting and shooting preserved a managed population of the hunted creature and deepened the individual human being's connection to the environment. Similarly, he found that fishing brought 'an extension of your whole organism into the whole environment that created you' (Pero 56). Roberts argues that shooting a fox 'marks the end of the enhanced connection with the environment' (2014 8). This does indeed occur in 'A Solstice', but it does not seem to be the case in the interview with Pero: Hughes comments on a heightened awareness of the animals around him, an 'automatic seeing everything in the landscape' (Pero 55). Hughes's reasons for preferring fishing to shooting were various: his boyhood realisation that he was disturbing animals' lives, Plath's influence, and the effect of shingles on his 'best eye' (LTH 705), all played a part. He felt that ours would be a less healthy society without blood sports, 'and less wise, less sensitive to the whole picture or the consequences of our activity on the environment' (Pero 56). This may be so - but here he ignores the fact that establishing artificial grouse moors and fox earths has environmental consequences too. There are also many more humane ways for people to feel immersed in ‘the whole picture’ of ecological interconnection, from birdwatching and wildlife photography to hiking and wild swimming. 


\section{‘The Grouse': Plath’s Influence on Hughes’s Treatment of Prey Animals}

Two primary influences on Hughes's views of animals were the hunters, farmers and poachers of his Yorkshire childhood, and later the Orchard family and the Devon farming community. Yet a third influence - that of Plath - introduced an alternative perspective on animals, and continued to shape his writing right up until his last poems. Hughes's project to memorialise Plath was one of his greatest personal and literary preoccupations. He remembered that he had started writing occasional elegies for her in 1972, perhaps earlier, and by 1997 he had finished Birthday Letters (PC 260). His Silvine Notebook, containing drafts of an early sequence called 'The Sorrows of the Deer', may even date from before 1969 (Bate 2015 511). In Birthday Letters, Hughes mourns the wife to whom the very solar system had joined him. The collection does not contain the sustained ecopoetry of books such as River, since its purpose is to explore human grief. However, repeated images of pursuit and hunting, drawn from Hughes and Plath's shared poetic mythos, show that Hughes wished to redress the image of him as a sadistic hunter that Plath had created in poems such as 'The Rabbit-Catcher'. Yet he also explores the faultlines in their relationship. The two of them had very different views of country ways and the ethical treatment of animals, although this was by no means the most serious source of disagreements between them (Bate 2015 197). Plath did not always comprehend Hughes's killing of animals, and he memorialises her sensitivity to other creatures and her understanding of them. In 'The Owl', he presents her wonder at unfamiliar British wildlife. In 'The Chipmunk' and 'The Fifty-Ninth Bear', Plath has a better understanding of American wildlife than Hughes does. At times, Hughes presents her sympathy for animals as misguided, or indicative of deeper tensions in their relationship. In 'The Rabbit-Catcher', she views snared rabbits as 'baby-eyed | Strangled innocents' (CPH 1138); Hughes is outraged at her desecration of his 'country gods' ( $C P H 1137)$, the 'sanctity of a trapline' and the 'country poverty' that drives people to snare game.298 But it was the early incident involving a grouse that helped Plath to awaken Hughes to a deeper understanding of animal suffering, and which would help to dampen his passion for the kill.

In August 1956, Hughes and Plath hiked across the moors to see the farmhouse that inspired Wuthering Heights. Hughes saw a sick grouse, and put it out of its misery. But the red grouse had been the subject of a story about a 'heather bird' from Plath's childhood:

So, I'd not only killed this helpless thing in front of her, I'd killed the legendary bird. As she went berserk, I felt it go through me like an electric shock. A total transference to me of her feeling.

I realised I didn't want to kill any bird or animal, ever again. And I didn't. I stopped shooting. But I went on fishing. (Pero 55)

After that, Hughes rarely shot game birds, and that day of shooting chukar partridges in British Columbia reminded him of Plath's reaction when he killed the sick grouse. He told Boyanowsky that " "It was like someone throwing water on you and bringing you out of a

298 Plath's rage at Hughes and the snares was partly due to her suspicion that he was attracted to Assia Wevill (Clark 232). 
trance - I suddenly realized how it must have looked from her uninitiated perspective and felt a great dread. I have killed no birds since ... until today”' (59). Plath's 1962 poem 'Pheasant' is, in part, a response to Hughes's killing of the grouse. The poem's speaker begs a hunter to spare a game bird: 'Do not kill it'. It has 'a kingliness, a right'; humans, on the other hand 'trespass stupidly' (CPP 191). In the interview with Pero, Hughes’s sensitive empathy with Plath's outrage at the death of the grouse is an example of his retrospective attempts to reconcile their differing views of killing animals, of hunting, and of their relationship.

Hughes did not publish one particular poem that explores more fully the incident with the grouse and the way it informed his ambivalence towards shooting. This undated draft might have been written during Hughes's late meditations upon his earlier actions, even though the incident it describes occurred in the first year of his marriage to Plath. It is analysed here because of its relationship to the late interview with Pero, and to a late letter ( $\mathrm{LTH} 705$ ). 'The Grouse' is as moving as any of the published Birthday Letters poems. It is even more striking than 'The Rabbit Catcher' in the way Hughes shows the transference of feeling from Plath to him, and the deep identification with the bird that comes of this. The poem exists in several drafts; this one articulates Hughes's change of heart particularly clearly:

I killed it instantly

Crushed its head on a stone with a stone - instant.

Then I had a dead grouse, too thin to eat -

So thin maybe disease \& not shot-pellets

Argued its case. I had a warm dead body

To leave tucked into a safe place to nested life-like

Among roots of heather, the speckled bird unfortunate.

And I had to leave it. I was shocked

By your shock \& outrage. You came at me

From my undefended quarter

And nearly wept - I saw you saw

Something incredible, something inconceivable.

That grouse, for you, died like the Rosenbergs,

Without sense or defence. Was killed

By a stupid machine, a blind habit

A gloating readiness. I saw you see all that 
In my little murder. I was alarmed, and

Something in me awoke up. I had frightened

A suddenly new self. I have forgotten

Everything particular thing about that day

Except the nerve-pain, the monument

Of sensation on the empty moor,

A stone squashing a skull on a stone, squashing

A thumb-soft head. And the a second blow

To make sure. Then the futile corpse. Something

In me spread its wings, \& flew up

[overleaf]

From the grim thing I had been. I too

Left my corpse there, a horrible thing.

Year after year my thoughts fly back over that.

You did that to me, with one cry of pain. 299

This draft articulates Hughes's gratitude to Plath for startling his 'suddenly new self' into being. Birdlike, a newly awakened consciousness of animal suffering takes wing, and circles back to the moor and the grouse many years later. All this is thanks to Plath.

Inside the cover of this notebook and elsewhere, Hughes entitles his collection-in-progress The Sorrows of the Deer, casting himself as stag rather than stag-hunter. When he describes militant feminists raising a 'huge outcry that flushed me from my thicket' (PC 270), he also envisages himself as prey. The fourteenth chapter of The White Goddess is 'The Roebuck in the Thicket' (Bate 2015 511): this is the hounded creature with which Hughes identifies himself. In 'The Dogs Are Eating Your Mother', he warns his children that the 'dogs' that 'Bite the face off her gravestone' - feminist extremists who deface Plath's grave (CPH 1169) - may attack them too: there, he and his family are like foxes on the run from the hunt. Awakened to a new understanding of animal suffering by Plath, then hounded by the likes of Robin Morgan and pursued by prying journalists, Hughes understood what a hunted creature goes through. He clearly did not lack sympathy for hunted animals. This makes his defence of hunting seem all the more convoluted and contradictory.

Defending Fishing

299 BL Add MS 88918/1/6 beige exercise book labelled ‘1. S 18 Rugby St’ by TH, 15 recto and verso. 
Of course, it was Hughes's love of fishing that motivated some of his most prolonged and high-profile environmental campaigns. Two major public campaigns focused on the River Torridge near his home: Hughes's 1985 evidence at the public inquiry into sewage pollution, and a 1997 review of interceptory salmon netting. During his adulthood, Hughes preferred fishing to shooting, and he fiercely defended both fishing and the rivers that he loved to fish. Some of Hughes's fishing-poetry raises complex ethical questions about practices such as killing scarce salmon and live-baiting. Yet between 1994 and 1997, Hughes most clearly articulates the conservationist benefits of fishing.

Hughes's attitude towards certain angling practices changed gradually as his career progressed. His 1964 poem 'Stealing Trout on a May Morning' celebrates the illicit frisson of poaching, although it is unclear whether or not the trout escapes. The poem dates from before Hughes noticed a decline in West Country fish populations. The title poem of Hughes's 1979 collection, 'Earth-Numb,' imagines landing a salmon and envisages its death (CPH 541-2). Yet it is significant that this poem does not describe the actual death of a fish: it is a form of ritual magic to lure salmon, as Gifford has pointed out (1999 150). 'The Live-Bait' (1983), published after River, contains one of Hughes's most lengthy and detailed interrogations of the suffering that fishing might inflict: both the live bait and the larger creature that attempts to devour it undergo horrendous ordeals ( $\mathrm{CPH}$ 686-7). Hughes used live baits on Lake Victoria and in Ireland (LTH 469, Wormald 2014 16). However, Hughes clearly wished to minimise the damage he did to his prey. Carol Hughes recalls that he sometimes used barbless hooks when fishing, to reduce injuries to the fish.300 By the 1990s, Hughes was releasing many of his catches. In the 1993 introduction to River, he favours catch and release fishing. When he fished for steelhead trout in British Columbia, he observed that his fishing companions 'would never dream of killing one of these creatures. "If we killed them," they say, “we'd be like you people in England: we wouldn't have any”' (CPH 1213). In 1994, he only killed a salmon when he wanted to eat it; a few years later, he was arguing that all Torridge salmon should be put back alive.

In 1994, Gifford wrote to ask Hughes about the ethics of fishing, and received a considered response. Hughes does admit that fishing interferes with the fish 'in some cases' (Gifford 1999 152). He then proceeds to refer to accounts by survivors of attacks by predators, some of whom felt no pain: a strangely roundabout and human-centred argument. The next part of the letter is far more scientific, and much more convincing. Hughes writes that when commercially hooked on 'long lines' or 'snagged in gill nets', fish must 'produce the chemicals corresponding to physical pain in human beings,' eventually going into shock and fighting for their last gasp. Hughes had evidently researched this issue, as he had read a paper 'where that was so in a fish that was hooked and let struggle until it began to drown' (152). Hughes later cites incidents where a trout returned to examine a fisherman's fingers once it had been released, and where tagged steelhead trout in British Columbia would be re-caught repeatedly (152-53). These fish were almost certainly not 'hooked on the buzz' of being caught, as Hughes suggests: it is more likely that they were driven by an instinct to feed. As

300 Letter from Carol Hughes to the present author, 23. 01. 2013. 
Gifford points out, 'hunting for food' is the only other justification for fishing when one is not a vegetarian - but industrialised nations do not need to hunt for food. Hughes explained in his letter that he wished to eat fish to remain part of the system of predators and prey, and because he found commercial fishing practices cruel:

When I want to kill and eat a salmon I sink myself up to the fontanelle in evolution's mutual predation system within which every animal cell has been fashioned and tap it on the head knowing that at least it is not - like the vast exterminatory tonnage of fish that feeds the world on fish fingers - dangling for days on a long line or cut to ribbons in a gill net or hauled out en masse to die of suffocation under a heap of its own juveniles. When I'm not going to eat it I put it back.

His awareness of the fate of the 'exterminatory tonnage' is laudable, but there are also more anthropocentric dimensions to his consideration of fishing practices. He frames the desire to fish in Jungian terms. Hughes writes that Jung thought that his patients would be cured if they could reconnect with 'the primitive human animal' (153), and that 'remaking that contact' was vital to human health. This could be done via negative methods such as 'physically violent sport, high-power predatory behaviour in business', or even 'hectic bouts of adultery' and 'petty terrorism'. Hughes found that fishing was an ideal substitute for any other 'aberrant primitive impulse', because it did not 'interfere with the lives of others' (154). This is an admirable idea - but it still problematic, because it favours the sporting pleasure of the 'primitive human animal' over the welfare, and indeed the lives, of other animals.

A few years later, Hughes would refine his arguments about the environmental cost of killing a 'vast exterminatory tonnage' of fish, and about the benefits of catch and release fishing to human beings and to the environment as a whole. Documents from between late 1996 and January 1997 show that Hughes contributed evidence to a public inquiry into the impact of Irish drift nets intercepting breeding Atlantic salmon.301 This declaration of his environmentalist principles that was every bit as public as the evidence he gave at the public inquiry about the Torridge Estuary in 1985. It was distinctive because the decline of the Atlantic salmon was an international problem, spanning an entire ocean, with local consequences for the Torridge: he deploys both his regional and global environmental knowledge. Hughes formulated a defence of rod and line fishing on conservationist and economic grounds, and again criticised large-scale drift net fishing. Here, he constructs a more coherent and convincing argument for the conservationist benefits of rod fishing for salmon, refines his critique of industrial fishing, and argues for fishing as a way for human beings to experience a deep connection to the environment.

At the inquiry, Hughes introduced himself formally as 'Edward James Hughes', a fisherman who had fished Taw and Torridge for thirty-five years. He was a member of the Committee of the River Torridge Fishery Association 'through that period in the eighties when the Torridge salmon became almost extinct', and he took an active part in efforts to 'save and run

301 BL Add MS 88918/121/6 TS 'NET LIMITATIONS AND BYELAW PROPOSALS FOR THE RIVERS TAW AND TORRIDGE PROOF OF EVIDENCE’ 1-12. 
the river'. He was a founder member of the Taw and Torridge Consultative Committee. He stated that the Atlantic salmon had been declining over the past thirty years, due to a combination of several factors. These included 'the development of a specialised High Seas Salmon Fishery, with boats of several nations taking vast tonnages of fish on their feeding grounds and on their migration routes as they return to their home rivers.' Meanwhile, off the coast of Ireland, 'the biggest drift-net fishery in the world' had developed to target salmon returning to Britain.302 Another significant factor was climate change: 'the temperatures and the movements of currents in the North Atlantic are now changing rapidly. One very visible result of this is that the high seas feeding grounds of the salmon are shrinking'. A combination of these factors meant that the salmon catch had declined by eighty per cent in only a decade (3). From 1985, the Environment Agency had implemented important measures to clean the rivers; in the early 1990s, the 'rods initiated a clean-up of the gravels'; but the biggest recovery in salmon populations occurred when the 'nets' (netsmen in the estuary) agreed not to fish for six years, but to accept compensation instead (5). For Hughes, then, rod fishermen are conservationists; commercial fishermen are far more destructive. Changing weather patterns meant that during a drought summer, salmon could not swim up the river, and netsmen might catch all of them (7). Hughes proposes delaying the date when netting can commence (8). Rod fishermen are content with small catches, 'all of which they put back alive'. There could not be a greater contrast between this promotion of catch and release fishing, and Hughes's earlier desire for the kill in 'Earth-Numb'.

But it is when he speaks of the value of unspoiled rivers, and the fisherman's passion for fishing, that Hughes's prose really begins to shine.

There have been many attempts to explain the passion for catching these fish that affects such large numbers of people. Some say it is the memory of those millions of years when our species was evolving as hunters and fishers in the unspoiled wilderness. Salmon and Sea-trout do live in wonderful wild places. We are told that hospital patients recover much more quickly if they can see trees. In the same way fishermen say that a week on a wild river, making physical contact with a wild, mysterious creature, repairs them psychologically. People battered by modern urban life, it is said, need this kind of experience more than ever. It is certain that they seek it more and more, and are willing to pay more and more for it, as life grows more stressful.

Last year, the watershed of the Taw and Torridge were singled out by the CPRE and designated as one of the last three tranquil rural areas in all England. The potential for turning this unspoiled region into a holiday fisherman's paradise lies in the salmon and sea-trout population of the two rivers. It is an immense economic resource, because it

302 BL Add MS 88918/121/6 NET LIMITATION ORDER AND BYELAWY PROPOSALS FOR THE RIVERS TAW AND TORRIDGE PROOF OF EVIDENCE E. J. HUGHES (for the Rod Fishery) 3. Further references are given in parentheses in the text. 
offers what every fisherman is looking for: beautiful, wild rivers in a uniquely beautiful part of $\mathrm{xxx}$ the world.303

Here, Hughes argues in favour of 'making physical contact with a wild, mysterious creature' Gone are the bizarre ideas about fishing standing in for petty terrorism and hectic bouts of adultery. The fish Hughes loves to pursue 'live in wonderful wild places,' 'unspoiled wildernesses': by implication, we need to preserve these wild places. Hughes frames his argument in human-centred terms: fishing is of both economic and psychological benefit. But when his evocation of 'unspoiled' rivers is combined with his presentation of rod fishermen as conservationists who clean gravels and put their salmon back alive, we glimpse ideas that are far more biocentric.

The Public Inquiry of 1997 had encouraging results, including 'restrictions on both the rod and the net fisheries' (Environment Agency 24). Hughes also supported the Icelandic environmentalist and angler Orri Vigfússon's campaigns to protect the Atlantic salmon by writing a high-profile letter to The Times; other well-known signatories of the letter included Jeremy Paxman ('Threat to survival of wild salmon'). At the end of his life, then, Hughes favoured forms of fishing that he felt to be humane and environmentally sustainable. He was even arguing for all salmon caught on the Torridge, a river in which they had nearly become 'extinct', to be put back alive. Yet this leads one to wonder why he had characterised his eating of British salmon as environmentally sustainable, just a few years earlier.

\section{$\underline{\text { Last Environmental Campaigns }}$}

Hughes continued to publish prolifically towards the end of his life, even though he was diagnosed with cancer in April 1997 (PC 154). In his continuing role as 'green Laureate,' Hughes was called upon to lend his support to many campaigns that suggest progressive environmentalist agendas. In 1996, he devised statements of support for the Council for the Protection of Rural England 304 and the RSPB's new biodiversity audit. 305 He had previously refused to be a patron of the Speak a Poem competition because the sponsors were BP, whose 'commercial ethos as regards the environment' caused him concern.306 (He agreed in 1996, once new sponsors backed the competition.)

At a time when his own health was failing, the health of the world's watercourses and British bird populations continued to feature prominently in Hughes's published letters. In August 1998, he told Marina Warner that the nightingale population was dwindling ( $L T H ~ 730$ ). In the last month of his life, he wrote to Nick Gammage that since he had written his famous riverpoem, '[t]he Gulkana has been ruined’ (LTH 736). He was indefatigable in his fight to

303 BL Add MS 88918/121/6, TH’s typescript draft of evidence for Public Inquiry, pages lettered A-D by TH, CD. Handwritten emendations given in italics. Deletions are marked by ' $x$ '.

304 BL Add MS 88918/33. Letter from TH to Council for the Protection of Rural England, 19. 02. 96.

305 BL Add MS 88918/33. Letter from RSPB to TH, 12. 02. 96.

306 BL Add MS 88918/33. Letter from Kate Welbourne to TH, 05. 03. 96. 
preserve the Atlantic salmon: he received an article entitled 'A Glimmer of Hope for Salmon' on the $18^{\text {th }}$ of September, 307 and less than a month before his death, he wrote to the Westcountry Rivers Trust asking for details of the scientists and the scientific papers referenced in the article. Nicholas was researching salmon on the west coast of Canada and the USA, and he was hoping to extend his study to investigate how ocean currents and temperatures affected them. 308 Some of the last poems he published have distinctly ecological strains. He revisits a much earlier fishing trip with his son in 'Some Pike for Nicholas', and expresses his grief at being separated from his brother via the image of a peartree in 'Brother Peartree'. Probably the last poem he wrote, 'The Prophet' (Bate 2015 539), a version of Pushkin, sees the speaker undergo shamanic dismemberment to gain an eaglet's second sight, a wise serpent's tongue, and the ability to hear 'the burgeoning of the earth's vine' ( $\mathrm{CPH}$ 1194). In one of his last published works, Hughes was 'listening deeply', keeping faith with the environment as 'source', hearing the earth's vine grow.

307 BL Add MS 88918/121/6, 18 Sept 1998 - Tom Hills (of Westcountry Rivers Trust) sent TH the Trust’s newsletter.

308 BL Add MS 88918/121/6TH to Tom Hills, $4^{\text {th }}$ Oct 98. 


\section{CONCLUSION}

What emerges from an analysis of Hughes's environmentalism, is how deeply engaged he was in different stages of the environmental movement. His views usually respond to, and occasionally anticipate, the progression of the twentieth century's environmental views except for his problematic support of hunting. He was exceptionally well informed about contemporary developments in environmental politics, science and culture; this enabled him to make his important contributions to the environmental movement as a writer and activist. Hughes's personal mythology casts him as an outsider: a solitary boy with fishing rod and air rifle, a Northern oddity at Cambridge, an Englishman out of place in America, a farmer on the periphery of the literary establishment, a silent man reluctant to discuss Plath, a shamanic Poet Laureate. There is no doubt that his primitivist yearning to return to a time before humankind's supposed divorce from nature would have been seen as distinctly unconventional before the 1960s, and again after the influence of that decade's counterculture decreased. However, his research, reading, writing and activism show how immersed he was in the 'green' intellectual movement; his involvement with campaigns such as the Torridge Action Group demonstrates his commitment to local community activism. Hughes the environmentalist was no lone enraptured nature-writer, no isolated intellectual iconoclast.

Various developments in contemporary history and the conservationist zeitgeist influenced Hughes in ways that were often surprising. 'The Thought-Fox' draws on both Hughes's encounter with a fox at Old Denaby and his watching of 1950s nature films. His interest in the occult and in pre-Christian religion anticipated the 1960s' preoccupation with these issues by over a decade. Yet his epic folk-tale Crow is influenced as much by Ban the Bomb marches, Silent Spring, the Suez crisis and the Vietnam war as by Jung and Radin. He wrote of 'nature as a single organism' as an idea of 'primitive theologies' (WP 132) two years before such ideas would become more mainstream in Lovelock's Gaia hypothesis; but these words appeared in a magazine that presented cutting-edge environmental debates to an international audience. When Hughes decided to go back to the land in 1972, he was not only reviving an old family tradition, but joining a growing number of dissatisfied environmentalists who wished to become more self-sufficient. He and many others reacted to Thatcher's initial unwillingness to address environmental issues by political lobbying, writing protest-poetry, and supporting environmental pressure groups. By the 1980s, his conservation-poems were drawing on cutting-edge environmental science and campaigns; both his research and his environmentalist outputs of the 1990s tackle climate change, the greatest environmental threat of our era. It was only when Hughes continued to acquire the body parts of animals that had become endangered, and when his attempts to defend shooting and hunting with hounds failed to engage adequately with environmental and ethical objections to these practices, that his ideas began to sound outmoded. O'Brien's reading of Hughes as apolitical, and Paulin's view of his sympathy for the political right, begin to look naïve when one considers the extent to which Hughes was influenced by green ideology. Hughes's writing can be demonstrated to betray complex engagements with both left-wing and right-wing discourse. He was not a Laureate of the free market, but a green Laureate. 
Any study that attempts to trace the way Hughes's environmentalism developed, must be flexible in its chronology. Hughes's poetry would keep revisiting the landscapes of his early boyhood in his Cambridge typescript, in Lupercal, in Remains of Elmet, in Wolfwatching and in Elmet: a project to chart a place that spanned nearly four decades. The Crow-project began in the early 1960s, and Hughes was rewriting the prose narrative that was to accompany it well into the 1990s. His British-focused 'green Laureate' activities have different aims from his more 'global' activities, but their chronology overlaps and they are two facets of the same ideological commitment. His published writing about with hunting-to-hounds began with the ambiguous 'An Otter' (1960) and the highly critical 'A Moon Man-Hunt' (1963); it went through several contradictory developments until he openly declared his support for it in 1997.

Hughes's poetry does not simply reward a reading in the light of ecocritical and ecopoetic theory: it suggests new developments for the field. Early ecopoetic theory placed too much emphasis on harmonious ecological interconnection (Skinner 2005), sounding back to the landscape (Skinner 2011), unity with nature (Scigaj 1999, Bate 2000) and ecopoetic form echoing environmentalist sense (Tarlo 2011, Gander and Kinsella). Theorists have accounted for environmental disharmony, disunity and destruction before; Bristow's idea that the Anthropocene lyric dramatises disconnection and breakdown, and Solnick's argument that Hughes's attempts to foreground human beings' animal impulses are matched by a technological rupture, offer important insights. Yet Hughes's poetry of waste in Crow suggests that ecopoetics scholarship needs to pay further attention to the specific literary features that writers use explore the turpitude of pollution, the ugliness of environmental injustice, the pathos of damaged ecologies, the terror of all-out environmental destruction. Our 'remodelling [of] the physical and biological world' at an unprecedented speed is marking future geological strata with rubbish, mines, the fossils of extinct and domesticated species (Vince 4); waste will remain an important preoccupation for authors engaging with the Anthropocene.

Hughes is remembered as a poet, and his poetry is necessarily the primary focus of most research about him. Yet the corpus of his literary outputs shows that he produced far more than just poetry, and his environmentalist outputs were similarly diverse. He was an accomplished writer of environmental fiction, children's stories, letters, reportage, broadcasts, drama and polemic. He also experimented with hybrid forms that defy the boundaries of genre. His Cambridge typescript gives an inkling of this. We see his prose developing from a critique of exploitative uses of animals in the short stories 'Sunday' (1957) and 'The Harvesting' (1959), to a consideration of how poems are like animals in 'Poetry in the Making' (1961) and the ecopsychology of a Yorkshire landscape in his non-fiction essay 'The Rock' (1963). The following year, with the creation of 'Eat Crow,' Hughes begins to articulate his environmental ideas in hybrid form; he had already started the long prosenarratives that accompany the Crow-poems, and at that stage, 'world-repair' seemed a possible goal. By 'The Environmental Revolution' (1970), he was articulating his vision of environmentalism as a modern international movement and a return to the single, sacred idea of 'primitive' peoples. His respect for these peoples and their traditional ways of life were the 
focus of the children's play 'The Tiger's Bones' (1974) and the adults' ghost-story 'The Head' (1978), which sharpen his critique of the environmental cost of western consumerism. Speeches, letters and reviews of the 1980s and 1990s express his growing frustration with political figures who showed a troubling lack of interest in the survival of the human species. If The Iron Woman (1993) concluded with fairytale neatness, his article 'If' (1992) gave a more wide-ranging and realistic appraisal of the global environmental challenges his era faced. Hughes was an important editor of environmental prose, from Your Environment to the Sacred Earth Dramas. His unpublished fishing-diaries, nature-diaries, travelogues and autobiographical prose are some of the most important sources of information about his work and life, and future researchers will glean many insights from these valuable prose documents.

Hughes's legacy as an ecopoet and environmentalist is very visible in Britain today. In the West Country, where he lived for so long, his poetry has become part of the landscape itself. A Ted Hughes Poetry Trail has been set up in the nature reserve at Stover Country Park, South Devon. The poems are designed to resonate with aspects of the park that visitors can see (Joint). In West Yorkshire, the Elmet Trust hosts an annual Ted Hughes Festival; the poem that won the 2014 Elmet Trust Poetry Prize was an elegiac ecopoem about badger baiting by Pat Borthwick. South Yorkshire, too, has its own Ted Hughes network at the University of Huddersfield, a Mexborough Ted Hughes Trail and an annual Ted Hughes Poetry Festival. Hughes would have been happy to find out that Old Denaby Wetland, one of his boyhood shooting paradises, is now a nature reserve. Yet the rivers of the West Country are probably the most significant sign of what Hughes achieved via his environmentalism. The writer Michael Morpurgo describes Hughes as ‘angry’ about water pollution and 'desperate' to improve the state of Britain's rivers, but 'hopeful' that change would happen. Yet fellow campaigner Michael Martin thinks that Hughes was 'less hopeful than I think we might be now', since recent times have seen 'considerable improvements in rivers, and considerable awareness of how easily they're damaged'. These improvements are partly thanks to Hughes's campaigns, and to his continued influence in Devon. In Simon Armitage's words, the healthier rivers are a 'living tribute to his ideas, and his energy, and his commitment' ('Ted Hughes: Eco Warrior'). Hughes's writing proposes no glib resolution to the environmental dilemmas of our time, and with individuals and governments seemingly unwilling to implement 'big, deep change', it would be hubristic to suggest that we can mitigate the impact that we have had on our planet. Yet his writing offers the possibility that our situation is 'not without hope'. 


\section{WORKS CITED}

Abram, David. The Spell of the Sensuous: Perception and Language in a More-Than-Human World. New York: Vintage, 1997. [1996]. Print.

Adams, William M. Against Extinction: The Story of Conservation. London: Earthscan, 2004. Print.

Alberge, Dalya. 'Ted Hughes's schoolboy nonsense sheds light on gloomy poet'. Times $5^{\text {th }}$ June 2003: 8. Print.

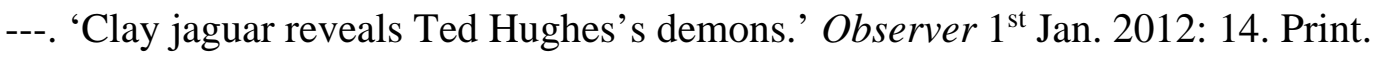

Alderson, Brian. 'Myth with metal fatigue.' Times $16^{\text {th }}$ Aug 1993: 35. Print.

Alvarez, Alfred. Ed. The New Poetry. London: Faber \& Faber 1966 [1962]. Print.

Andersson, Rani-Henrik. The Lakota Ghost Dance of 1890s. Lincoln: Nebraska UP, 2008. Print.

Andrews, Corey. “Work” Poems: Assessing the Georgic Mode of Eighteenth-Century Working-Class Poetry.' In Sandro Jung, ed. Experiments in Genre in Eighteenth-Century Literature. Ghent: Academia Scientific, 2011, pp. 105-133. Print.

Ardrey, Robert. The hunting hypothesis: a personal conclusion concerning the evolutionary nature of man. London: Fontana, 1977. Print.

Arendt, Hannah. The Origins of Totalitarianism. New York: Harcourt: 1966. Print.

Armitage, Simon. 'Ted Hughes - Poet and Eco Warrior.' Guardian 12. 05. 2009: 2.

---. 'Dear Peter: An unpublished Ted Hughes letter, introduced by Simon Armitage.' Granta 119 (26 $6^{\text {th }}$ June 2012). Web. Accessed at http://www.granta.com/New-Writing/DearPeter on 17. 03. 14.

Astley, Neil, ed. Earth Shattering: Ecopoems. Tarset: Bloodaxe 2007. Print.

Baird Callicott, J. ‘Animal Liberation and Environmental Ethics: Back Together Again’. In Eugene C. Hargrove, ed. The Animal Rights/ Environmental Ethics Debate: The Environmental Perspective. Albany: State University of New York Press, 1992. Print.

Barel, C.D.N., R. Dorit, P.H. Greenwood, G. Fryer, N. Hughes, P. B. N. Jackson, H.

Kawanabe, R. H. Lowe-McConnell, M. Nagoshi, A.J. Ribbink, E. Trewavas, F. Witte \& K. Yamakoa 'Destruction of fisheries in Africa’s lakes' in Nature, 6014. 315 (2-8 May 1985): 19-20. Print. 
Barrington, Deborah, Zoë Bennett and Rowland Wymer, "I was in love with both, so they could teach me anything': Ted Hughes, Pauline Mayne and Mexborough.' The Ted Hughes Society Journal 4.1 (2014): 119-128. Print.

Bate, Jonathan. Romantic Ecology. London: Routledge, 1991. Print.

---. The Song of the Earth. London: Picador-Macmillan, 2000. Print.

---. 'Sorrow in a black coat'. Times Literary Supplement 7 Feb 2014: 12-14.

---. Ted Hughes: The Unauthorised Life. London: Collins 2015. Print.

Becket, Fiona. 'Ecological Concerns: A Poetics of Responsibility in D.H. Lawrence.' Etudes lawrenciennes 29 (2004): 23-37.

Bentley, Paul. Ted Hughes, Class and Violence. London: Bloomsbury Academic, 2014. Print. Berger, John. About Looking. New York: Vintage, 1992. Print.

Blake, William. William Blake, ed. by Vivian de Sola Pinto. London: Batsford, 1965. Print.

Boote, Robert. 'European Conservation Year 1970’. Your Environment 1.1 (Winter 1969): 56. Print.

Bowra, C[ecil] M[aurice]. Primitive Song. London: Weidenfeld and Nicholson, 1962. Print.

Boyanowsky, Ehor. Savage Gods, Silver Ghosts: In the Wild with Ted Hughes. (Vancouver: Douglas \& McIntyre, 2010). Print.

Bradbury, Ray. The Martian Chronicles [originally entitled The Silver Locusts]. London: Harper Collins, 1995 [1951]. Print.

Brain, Tracy. The Other Sylvia Plath. Harlow: Pearson Education, 2001. Print.

---. 'Hughes and feminism' in The Cambridge Companion to Ted Hughes, ed by Terry Gifford. Cambridge, Cambridge UP, 2011: 94-106.

Bramwell, Anna. Ecology in the $20^{\text {th }}$ Century: A History. New Haven: Yale UP, 1989. Print.

Brandes, Rand. 'The anthropologist's uses of myth'. In Terry Gifford, ed. The Cambridge Companion to Ted Hughes. Cambridge: Cambridge UP, 2011. Print.

Bright, William. Native American Placenames of the United States. Oklahoma: University of Oklahoma Press, 2004. Print.

Brown, Paul. 'Poet claims lanrels [sic] in clear-water battle.' Guardian 16 ${ }^{\text {th }}$ Apr. 16 1992; 4.

Buell, Lawrence. The Environmental Imagination: Thoreau, Nature Writing and the Formation of American Culture. Cambridge MA: Harvard UP, 1996. Print.

---. 'Toxic Discourse.' Critical Inquiry 24.3 (Spring 1998): 639-665. Print. 
---. Writing for an Endangered World: Literature, Culture, and Environment in the U. S. and beyond. Cambridge MA: Belknap-Harvard, 2001. Print.

---. The Future of Environmental Criticism: Environmental Crisis and Literary Imagination. Malden: Blackwell, 2005. Print.

Caminero-Santangelo, Byron. Different Shades of Green: African Literature, Environmental Justice, and Political Ecology. Charlottesville: Virginia UP 2014. Print.

Carson, Rachel. 'Silent Spring'. The New Yorker, A Reporter at Large sec., $16^{\text {th }}$ June 1962. Web. 23 ${ }^{\text {rd }}$ Nov 2015. http://www.newyorker.com/magazine/1962/06/16/silent-spring.

---. The Edge of the Sea. London: Penguin, 1999 [1955]. Print.

Clanchy, Kate. 'The Nationalisation of Ted Hughes'. Thumbscrew 14 (Autumn 1999): 49-54.

Clark, Heather. The Grief of Influence: Ted Hughes and Sylvia Plath. Oxford: Oxford UP 2010. Print.

Clark, Timothy, ed. The Cambridge Introduction to Literature and the Environment. Cambridge: Cambridge UP, 2011.

---.' Some Climate Change Ironies: Deconstruction, Environmental Politics and the Closure of Ecocriticism.’ The Oxford Literary Review 32.1 (2010): 131-149. Print.

Cramp, Stanley. 'Pesticides: Are We Falling Behind?' Your Environment 1.1 (Winter 1969): 26-27. Print.

Davies, Gareth Huw. 'Return of the otter. Times Spectrum sec., $28^{\text {th }}$ Oct. 1986, no page number. Print.

Davis, William Virgil. R. S. Thomas: Poetry and Theology. Waco: Baylor UP, 2007. Print.

Derrida, Jacques. 'And Say the Animal Responded'. Trans. David Wills. Zoontologies: The Question of the Animal. Ed. Cary Wolfe. Chicago: University of Chicago Press, 2003. 121-46. Print.

Derrida, Jacques. 'The Animal That I Therefore Am (More to Follow). Trans. David Wills. Critical Inquiry 28.2 (2002): 369-218. Print.

Doherty, Gerald. ‘D. H. Lawrence's The Fox: A Question of Species’. D. H. Lawrence Review 37.2 (2012) 1-21. Print.

Dorey, Peter. 'Despair and Disillusion Abound: The Major Premiership in Perspective'. In Peter Dorey, ed. The Major Premiership: Politics and Policies under John Major, 1990-97. Basingstoke: Macmillan, 1999.

Douglas, Ed. 'Portrait of a poet as eco warrior'. Observer $4^{\text {th }}$ Nov. 2007, Features and Reviews sec.: 10. Print. 
Du Bois, Cora. The 1870s Ghost Dance. Lincoln: Nebraska UP, 2007. Print.

Durand, Marcella. ‘The Ecology of Poetry’. ecopoetics 2 (fall 2002) 58-62.

Elkington, John. The Poisoned Womb: Human Reproduction in a Polluted World. London: Penguin, 1986 [1985]. Print.

Eliot, T. S. Collected Poems 1909-1962. London: Faber \& Faber 1963. Print.

Ely, Steve. 'Ted Hughes’s South Yorkshire.' The Ted Hughes Society Journal 3.1 (2013): 2636. Print.

---. Ted Hughes’s South Yorkshire: Made in Mexborough. Basingstoke: Palgrave 2015. Print.

Faas, Ekbert. Ted Hughes: The Unaccommodated Universe. Santa Barbara: Black Sparrow Press, 1980.

Fairhall, John. 'Land Use Feature: Hedges and Trees'. Your Environment 1.3 (Summer 1970): 74-77. Print.

Feder, Helena. 'Ecocriticism, posthumanism and the biological idea of culture'. In Greg Garrard, ed. The Oxford Handbook of Ecocriticism. Oxford: Oxford UP, 2013. Pp. 22540. Print.

Feinstein, Elaine. Ted Hughes: The Life of a Poet. New York: Norton 2001. Print.

Felstiner, John. Can Poetry Save the Earth? A Field Guide to Nature Poems. New Haven: Yale UP, 2009. Print.

Fisher-Wirth, Anne, and Laura-Gray Street, eds. The Ecopoetry Anthology. San Antonio: Trinity UP, 2013. Kindle.

Fletcher, Angus. A New Theory for American Poetry: Democracy, the Environment, and the Future of Imagination. Cambridge, MA: Harvard UP, 2004. Print.

Forestry Commission. ‘The Roe Deer’. Swindon: Her Majesty’s Stationery Office, 1970. Print.

Fortune, R. F. Sorcers of Dobu: The social anthropology of the Dobu islanders of the western Pacific. New York: Dutton, 1932. Print.

Frazer, James. The Golden Bough: A Study in Magic and Religion. Abridged edn. Introd. by George Stocking, Jr. London: Penguin 1992 [1922]. Print.

Gander, Forrest and John Kinsella. Redstart: An Ecological Poetics. Iowa: Iowa UP, 2012. Print.

Garrard, Greg. Ecocriticism. Abingdon: Routledge, 2004. Print.

Gifford, Terry and Neil Roberts. Ted Hughes: A Critical Study. London: Faber \& Faber, 1981. Print.

Gifford, Terry. 'Gods of Mud: Hughes and the Post-Pastoral'. The Challenge of Ted Hughes. 
Ed. Keith Sagar. Basingstoke: Palgrave, 1994. 129-30. Print.

---. “ “Go Fishing:” An Ecocentric or Egocentric imperative?’ In Joanny Moulin, ed. Lire Ted Hughes: New Selected Poems, 1957-1994. Print. 145-56.

---. 'Rivers and Water Quality in the Work of Ted Hughes and Brian Clarke'. Concentric 31, (1 $1^{\text {st }}$ Mar. 2008): 71-91. Print.

---. Ted Hughes. London: Routledge 2009. Print.

---. 'Hughes’s Social Ecology’. The Cambridge Companion to Ted Hughes. Ed. Terry Gifford. Cambridge: Cambridge UP, 2011. 81-93. Print.

---. Green Voices: Understanding Contemporary Nature Poetry. $2^{\text {nd }}$ ed. Nottingham: Critical, Cultural and Communications Press, 2011 [1995]. Print.

---. 'Pastoral, Anti-Pastoral and Post-Pastoral as Reading Strategies'. Critical Insights: Nature and Environment. Ed. Scott Slovic. Ipswich: Salam, 2012. 42-61. Print.

Gilbert, Roger. Review of The Song of the Earth by Jonathan Bate. Modern Philology 100.2 (Nov 2002): 293-7. Print.

Gilcrest, David. Greening the Lyre: Environmental Poetics and Ethics. Reno: Nevada UP, 2002. Print.

Glotfelty, Cheryll and Harold Fromm, eds. The Ecocriticism Reader. Athens: Georgia UP, 1996. Print.

Golden, Amanda. 'Ted Hughes and the Midcentury American Academy.' The Ted Hughes Society Journal 3.1 (2013): 47-52. Print.

Goodby, John. Under the Spelling Wall: the Poetry of Dylan Thomas. Liverpool: Liverpool UP, 2013. Print.

Guardian. Weekend sec. 'Paeons to nature’. Saturday-Sunday February 4-5 1989 17. Print.

Hadley, Edward. The Elegies of Ted Hughes. Basingstoke: Palgrave Macmillan, 2010. Print.

Haig-Brown, Roderick. Return to the River: A Story of the Chinook Run. London: Collins 1942. Print.

---. Panther. London: Cape, 1934. Print.

Hall, Dinah. 'Metallic Moralising.' Sunday Telegraph $9^{\text {th }}$ Sept. 1993. Print.

Hamblin, Jacob Darwin. Arming Mother Nature: The Birth of Catastrophic Environmentalism. Oxford: Oxford UP, 2013. Print.

Hardy, Barbara. Dylan Thomas: An Original Language. Athens, GA: Georgia UP, 2000. Print. 
Haraway, Donna. Simians, Cyborgs and Women: The Reinvention of Nature. Abingdon: Routledge, 1991. Kindle.

---. The Haraway Reader. London and New York: Routledge, 2004. Print.

Hare Preservation Trust, 'Status of the Brown Hare'. 2008-14. Web. $18^{\text {th }}$ Nov. 14. http://www.hare-preservation-trust.co.uk/status.php.

Harrison, Ruth. 'Factory Farming: An Ecological Blunder’. Your Environment 1.4 (Autumn 1970): 137-140. Print.

Harrison, Tony. Collected Poems. London: Penguin, 2007. Print.

Harsent, David. Fire Songs. London: Faber \& Faber, 2014. Kindle.

Heaney, Seamus. Preoccupations: Selected Prose 1968-1978. London: Faber \& Faber 1980. Print.

---, interviewee, and John Haffenden, interviewer. 'Seamus Heaney.' Viewpoints: Poets in Conversation with John Haffenden. London: Faber and Faber, 1981, pp. 57-75. Print.

---. 'Hughes and England.' The Achievement of Ted Hughes. Ed. Keith Sagar. Manchester, Manchester UP, 1983. 14-21.

---. Opened Ground: Poems 1966-1996. London: Faber \& Faber 1998. Print.

---. 'The Trance and the Translation'. Guardian Books sec., 20 $0^{\text {th }}$ Sept 2002.

---. 'Suffering and Decision' in Ted Hughes: From Cambridge to Collected, eds Mark Wormald, Terry Gifford and Neil Roberts. Basingstoke: Palgrave Macmillan 2013 22137.

Heinz, Drue. 'Ted Hughes: The Art of Poetry LXXI’ Paris Review 134 (Spring 1995): 81. Print.

Heise, Ursula K. Sense of Place and Sense of Planet: The Environmental Imagination of the Global. Oxford: Oxford UP, 2008. Print.

Hill, Geoffrey. Mercian Hymns. London: André Deutsch, 1971. Print.

International Union for the Conservation of Nature and Natural Resources, with the United Nations Environment Programme and World Wildlife Fund. 'World Conservation Strategy: Living Resource Conservation for Sustainable Development’. Gland: IUCN, 1980. Print.

Hirschberg, Stuart. Myth in the Poetry of Ted Hughes. Portmarnock: Wolfhound, 1981. Print. Hofmann, Michael and James Lasdun. Eds. After Ovid: New Metamorphoses. London: Faber \& Faber 1994. Print. 
Hogbin, Ian. Experiments in Civilization: The effects of European culture on a native community of the Solomon Islands. London: Routledge 1939. Print.

Hughes, Ted. 'Man and Superbeast.' New Statesman, 13rd Mar. 1962: 420. Print.

---. 'Tarka the Otter by Henry Williamson'. Sunday Times Colour Supplement, $16^{\text {th }}$ Sept. 1962: 18. Print.

---. 'The Rat under the Bowler Hat.' Saturday Night, 10.78 (November 1963): 21-22.

---. 'The Rock.' The Listener 19 ${ }^{\text {th }}$ Sept. 1963: 421-3. Repr. with minor alterations in Worlds: Seven Modern Poets. Ed. Geoffrey Summerfield. Harmondsworth: Penguin 1974.

--- and Daniel Weissbort, editors. Modern Poetry in Translation 1 (1965). Print.

---. Poetry in the Making: A Handbook for Writing and Teaching. London: Faber \& Faber 1967. Print.

---. Eat Crow. London: Rainbow Press, 1971. Print.

---. Letter. 'Children plant trees for tomorrow'. Times Educational Supplement Leaders/Letters sec., $17^{\text {th }}$ Nov. 1972: 2. Print.

---. The Tiger’s Bones and Other Plays for Children. London: Faber \& Faber, 1974. Print.

---. Gaudete. London: Faber \& Faber, 1977. Print.

---, writer and Leonard Baskin, artist. Cave Birds: An Alchemical Cave Drama. London: Faber \& Faber, 1978. Print.

---. 'Address given at the memorial service at St Martin-in-the-Fields, London, at 12 Noon on Thursday, 1 December, 1977'. Henry Williamson, the Man, the Writings: A Symposium. Ed. Brocard Sewell. Padstow: Tabb House, 1980. 159-65. Print.

---, writer and Peter Keen, photographer. River London: Faber \& Faber, 1983. Print.

---. River (American edition). New York: Harper, 1983. Print.

---'A Devon River.' Britain: A World by Itself. Paul Wakefield, ed. and photographer. New York: Barnes \& Noble, 1984. 16. Print.

---, writer and R. J. Lloyd, illustrator. What is the Truth? London: Faber \& Faber, 1984. Print.

---. Letter. 'Putting a value on UK's salmon riches.' Times Letters to the Editor sec., $13^{\text {th }}$ Aug. 1985: 11. Print.

---. 'Baboons and Neanderthals: a rereading of The Inheritors.' William Golding: The Man and his Books. Ed. John Carey. London: Faber and Faber 1987. 161-88. Print.

---. 'Introduction’. In Praise of Trout. Ed. David Profumo. London: Penguin 1989.

---. 'Trout on the Upper Taw.' Taw Fisheries Association News Letter. (Summer 1990): 6. 
Print.

---. 'Dear Premier.' Dear Next Prime Minister: Open Letters to Margaret Thatcher \& Neil Kinnock. Ed. Neil Astley. Newcastle upon Tyne: Bloodaxe, 1990. Print.

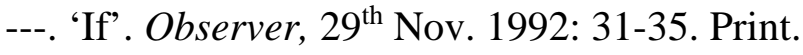

---. Shakespeare and the Goddess of Complete Being. London: Faber \& Faber, [1992] 1993. Print.

---. The Iron Woman. London: Faber \& Faber 1993. Print.

---, writer and Fay Godwin, photographer. Elmet. London: Faber \& Faber 1994. Print.

---. Winter Pollen: Occasional Prose. Ed. William Scammell. London: Faber \& Faber, 1995 [1994]. Print.

---, Tom Barnes, Bill Bewsher, Jack Charlton, Max Hastings, Jean Howman, Mick Lunn, Nickson, Jeremy Paxman and Arlin Rickard. Letter. 'Threat to survival of wild salmon.' Times $30^{\text {th }}$ July 1996: 17 . Print.

---. 'The Hart of the Mystery’ Guardian Features sec., 5th July 1997: 21. Print.

---. The Dreamfighter and Other Creation Tales. London: Faber \& Faber, 2003. Print.

---. Selected Translations. Ed. Daniel Weissbort. London: Faber \& Faber 2006. Print.

---. Collected Poems for Children. London: Faber \& Faber, 2008. Print.

---. A Ted Hughes Bestiary: Poems Selected by Alice Oswald. Introd. Alice Oswald. London: Faber \& Faber 2014. Print.

Hutchings, Kevin. 'Ecocriticism in British Romantic Studies.' Literature Compass 4.1 (2007): 172-202. Print.

Ingelbien, Raphael. 'Mapping the Misreadings: Ted Hughes, Seamus Heaney, and Nationhood’. Contemporary Literature 40.4 (Winter 1999), 627-58. Print.

Intergovernmental Panel on Climate Change. Working Group I. 'Policymakers [sic] Summary’. Geneva: IPCC, 1990. Print.

---. 'IPCC Factsheet’. Geneva: IPCC, 2013. Print.

---. 'Climate Change 2014: Impact, Adaptation, and Vulnerability. Technical Summary'. Geneva: IPCC, 2014. Print.

International Whaling Commission. 'Commercial Whaling', 2016. Web. $7^{\text {th }}$ March 2016. https://iwc.int/commercial.

Jacobsen, Garrett A. ' 'A holiday in a rest home': Ted Hughes as vates in Tales from Ovid.' Ted Hughes and the Classics. Ed. Roger Rees. Oxford: Oxford UP 2009. 156-176. Print. 
Jamie, Kathleen. 'A Lone Enraptured Male.' London Review of Books 30.5 (6 $6^{\text {th }}$ March 2008): 25-7. Print.

Jefferies, Richard. The Gamekeeper at Home; The Amateur Poacher. [Single volume edition; books published in 1878 and 1879 respectively.] Oxford: Oxford UP, 1978. Print.

Joint, Laura. 'Trail with a Rhyme and Reason'. BBC News Devon, 5 ${ }^{\text {th }}$ March 2006. Web. 20. Oct. 2014.

http://www.bbc.co.uk/devon/content/articles/2006/05/03/ted_hughes_poetry_trail_featu re.shtml.

Jones, David. 'Hazards of Enzymes and Detergents'. Your Environment 1.2 (Spring 1970), 54-59. Print.

---. 'Modern Farming and the Soil: Treat It With Respect'. Your Environment II.1 (Spring 1971): 3-5. Print.

Jung, Carl. The Archetypes and the Collective Unconscious. Trans. R. F. C. Hull. Ed. Herbert Read. 19 vols, 2nd edn. Routledge \& Kegan Paul, 1957, 2nd edn 1968-1971. The Collected Works of C. G. Jung, IX, part I (1968-1971). Print.

---. The Collective Unconscious. Trans. R. C. F. Hull. New York: Routledge, 1968. $1^{\text {st }}$ end 1959. Print.

---. The Structure and Dynamics of the Psyche. Trans. R. F. C. Hull. Hove: Routledge, 1960. Kindle.

---. Dreams. Trans. R. F. C. Hull. Abingdon: Routledge, 2002 [first published in 1974]. Print.

Keeling, Arn. "'A Dynamic, Not a Static Conception": The Conservation Thought of Roderick Haig-Brown’. Pacific Historical Review 71. 2 (May 2002): 239-268. Print.

Keery, James. 'The Burning Baby and the Bathwater'. P.N. Review 171, vol. 33:1 (September-October 2006): 56-62. Print.

Kerridge, Richard. 'Ecocritical Readings’. Ted Hughes. Ed. Terry Gifford. Basingstoke: Palgrave Macmillan 2015. 176-190. Print.

King, Angela. 'How To Wipe Out A Species Without Really Trying'. Your Environment 3.3 (Autumn 1972): 112-120; 129-132.

Knickerbocker, Scott. Ecopoetics: The Language of Nature, The Nature of Language. Amherst: Massachusetts UP, 2012. Print.

Krech, Shepard. The Ecological Indian: Myth and History. New York: Norton 1999. Print.

The Labour Party, ‘1997 Labour Party Manifesto’. 1997. Web. 20 $0^{\text {th }}$ Oct 2014. http://www.labour-party.org.uk/manifestos/1997/1997-labour-manifesto.shtml. 
Langbein, Jochen and Rory Putman. 'Studies of English red deer populations subject to hunting-to-hounds'. In Victoria Taylor and Nigel Dunstone, eds. The Exploitation of Mammal Populations. Houten: Springer, 1996. 208-25.

Latour, Bruno. We Have Never Been Modern. Trans. Catherine Porter. Harvard: HarvesterWheatsheaf, 1993. Print.

Lawrence, D. H. The Fox, The Captain's Doll, The Ladybird. Ed. Dieter Mehl. London: Penguin, 1992. Print.

---. The Complete Poems of D. H. Lawrence. Introd. David Ellis. Ware: Wordsworth Editions, 1994. Print.

---. The Woman who Rode Away and Other Stories. Eds Dieter Mehl and Christa Jansohn. Cambridge: Cambridge UP, 2002. Print.

Libby, Anthony. 'God's lioness and the priest of Sycorax: Plath and Hughes.' Contemporary Literature 15. 3 (Summer 1974): 386-405. Print.

Lidström, Susanna. 'Counter and Recovery Poems in the Elmet Collections'. The Ted Hughes Society Journal 1.1 (2011): 50-59. Print.

---. 'Different Shades of Green: a Dark Green Counterculture in Ted Hughes’s Crow.' Ecozon@ 4.1 (2013): 12-29. Print.

--- and Greg Garrard. ‘ “Images adequate to our predicament”: Ecology, Environment and Ecopoetics.’ Environmental Humanities 4 (2014): 35-53. Print.

---. Nature, Environment and Poetry: Ecocriticism and the poetics of Ted Hughes and Seamus Heaney. Oxford: Routledge 2015. Print.

Listener, The. 'Ted Hughes’s Crow.' The Listener. $30^{\text {th }}$ July 1970: 149. Print.

Lister-Kaye, John. Gods of the Morning: A Bird's-Eye View of a Highland Year. Edinburgh: Canongate 2014. Print.

Lopez, Barry. Of Wolves and Men. New York: Scribner 2004 [1978]. Print.

Lovelock, James. Gaia: A New Look at Life on Earth. Oxford: Oxford UP 2000 [1979]. Print.

Macfarlane, Robert. 'Why we need nature-writing'. New Statesman Long Reads sec., $2^{\text {nd }}$ Sept 2015. Web. http://www.newstatesman.com/culture/nature/2015/09/robert-macfarlanewhy-we-need-nature-writing. 7th April 2016.

---. 'Desecration phrasebook: A litany for the Anthropocene.' New Scientist Review sec., 15 Dec 2015. Web. https://www.newscientist.com/article/mg22830523-200-desecrationphrasebook-a-litany-for-the-anthropocene/ $21^{\text {st }}$ Sept 2016. 
---. 'Generation Anthropocene: How humans have altered the planet forever.' Guardian Books sec., $1^{\text {st }}$ April 2016. Web. http://www.theguardian.com/books/2016/apr/01/generationanthropocene-altered-planet-for-ever. 7th April 2016.

Malay, Michael. 'Ted Hughes: Another Look at the Jaguar.' The Ted Hughes Society Journal 4.1 (July 2014): 89-100. Print.

McCormick, John. British Politics and the Environment. London: Earthscan, 1991. Print.

---. The Global Environmental Movement. London: Wiley 1995. $2^{\text {nd }}$ edn. Print.

McGowan, Philip. Review of Ecopoetics: The Language of Nature, the Nature of Language, by Scott Knickerbocker. Modernism/modernity 20.1 (January 2013): 161-63. Print.

McKibben, Bill. The End of Nature. New York: Anchor, 1989. Print.

Merchant, Carolyn. Radical Ecology: The Search for a Livable World. New York: Routledge 1992. Print.

Merchant, W. Moelwyn. R. S. Thomas. Fayetteville: Arkansas UP, 1990. Print.

Middlebrook, Diane. Her Husband: Hughes and Plath - A Marriage. New York: VikingPenguin 2003. Print.

Mies, Maria and Vandana Shiva. Ecofeminism. $2^{\text {nd }}$ edn. London: Zed, 2014. Print.

Miller, Vaughn. 'The 1974-75 UK Renegotiation of EEC Membership and Referendum'. House of Commons Library Briefing Paper 7253, 13 July 2015. Print.

Milman, Oliver. 'EPA head Scott Pruitt denies that carbon dioxide causes global warming.' The Guardian. 9 $9^{\text {th }}$ March 2017. Web. 10 ${ }^{\text {th }}$ April 2017. https://www.theguardian.com/environment/2017/mar/09/epa-scott-pruitt-carbondioxide-global-warming-climate-change

Monbiot, George. 'Meet the conservationists who think that burning is good for wildlife'. The Guardian, 14 ${ }^{\text {th }}$ Jan 2016. Web. $4^{\text {th }}$ April 2016. http://www.theguardian.com/environment/georgemonbiot/2016/jan/14/swaling-iscausing-an-environmental-disaster-on-britains-moors

Morpurgo, Horatio. 'The Table Talk of Ted Hughes'. Arete 6 (Autumn 2001). Web. 24 ${ }^{\text {th }}$ June 2014.

Morrison, Blake. 'Man of Mettle’. Independent Reviews sec., 05. 09. 1993: 32. Print.

Morrison, Susan Signe. The Literature of Waste: Material Ecopoetics and Ethical Matter. Basingstoke: Palgrave Macmillan, 2015. Print.

Morton, Timothy. Shelley and the Revolution in Taste: The Body and the Natural World. Cambridge: Cambridge UP, 1995. Print. 
---. Ecology without Nature: Rethinking Environmental Aesthetics. Cambridge MA: Harvard UP, 2007. Print.

---. 'Writing Ecology.' Originally published as 'Escritura Ecológica'. La Tempestad 10.65 (March 2009), 94-97; pages re-numbered as 1-8.

---. The Ecological Thought. Cambridge MA: Harvard UP, 2010. Print.

---. 'Ecology as Text, Text as Ecology'. The Oxford Literary Review 32.1 (2010): 1-17. Print.

---. 'The Dark Ecology of Elegy'. The Oxford Handbook of the Elegy. Ed. Karen Weisman. Oxford: Oxford UP, 2010. 251-71. Print.

---. Hyperobjects: Philosophy and Ecology after the End of the World. Minneapolis: Minnesota UP, 2013. Print.

Moulin, Joanny. 'The Problem of Biography' in Terry Gifford (ed.), The Cambridge Companion to Ted Hughes. Cambridge: Cambridge UP 2011. Print.

Nye, Robert. 'New Selected Spells by the Royal Witch Doctor.' Literary Review, March 1995: 46-48. Print.

O’Brien, Sean. The Deregulated Muse: Essays on Contemporary British and Irish Poetry. Newcastle: Bloodaxe, 1998. Print.

O’Connor, Daniel. Ted Hughes and Trauma: Burning the Foxes. Basingstoke: Palgrave Macmillan, 2016. Kindle.

Oswald, Alice. ‘Wild Things’ Guardian Reviews sec., 3d Dec. 2005: 21. Print.

---. A Ted Hughes Bestiary: Poems. London: Faber \& Faber, 2014. Print.

Ovid. Metamorphoses. Trans. by Rolfe Humphries. Indianapolis: Indiana UP 1955. Print.

Parham, John. Green Man Hopkins: Poetry and the Victorian Ecological Imagination. Amsterdam: Rodopi, 2010. Print.

Parker, Eric. Predatory Birds of Great Britain. London: W. H. Smith, n.d. (1949?). Print.

Parker, Michael. 'Hughes and the Poets of Eastern Europe.' The Achievement of Ted Hughes. Ed. Keith Sagar. Manchester: Manchester UP 1983. 37-51. Print.

Patterson, Walter C. 'Odourless, Tasteless and Dangerous: Hazards of Radioactive Waste'. Your Environment 1.3 (Summer 1970): 99-104. Print.

---. 'Inadvertent Climate Modification: Report of the Study of Man's Impact on Climate.' Review. Your Environment 3.1 (Spring 1972): 42-3. Print.

Paulin, Tom. Minotaur: Poetry and the Nation State. London: Faber \& Faber, 1992. Print.

Pero, Thomas R. 'So Quickly It’s Over'. Wild Steelhead and Salmon (Winter 1999): 50-57. 
Print.

Phillips, Dana. 'Excremental Ecocriticism and the Global Sanitation Crisis'. In Iovino, Serenella and Serpil Opperman, eds, Material Ecocriticism. Bloomington: Indiana UP, 2014. Print. 172-85.

Plath, Sylvia. The Unabridged Journals of Sylvia Plath, 1950-1962. Ed. Karen V. Kukil. New York: Anchor, 2000. Print.

---. Letters Home. Ed. Aurelia Plath. London: Faber \& Faber 1975. Print.

---. Johnny Panic and the Bible of Dreams. Ed. Ted Hughes. London: Faber \& Faber 1977. Print.

---. Collected Poems. Ed. Ted Hughes. London: Faber \& Faber 1981. Print.

Plumwood, Val. Feminism and the Mastery of Nature. London: Routledge, 1993. Print.

Pogue Harrison, Robert. Forests: The Shadow of Civilization. Chicago: Chicago UP, 1992. Print.

Puckett, Caleb. 'Ecopoetics'. In Kim Kennedy White and Leslie A Duram, eds. America Goes Green: An encyclopedia of Eco-Friendly Culture in the United States. Vol. 1. Santa Barbara: ABC-CLIO, pp. 75-7.

Ramazani, Jehan. Poetry of Mourning: The modern elegy from Hardy to Heaney. Chicago: Chicago UP, 1994. Print.

Reddick, Yvonne. 'Henry Williamson and Ted Hughes: Politics, Nationhood and NatureWriting’. English 63. 338 (Autumn 2013): 353-374. Print.

----. ‘ “Throttle College?” Ted Hughes’s Cambridge Poetry.’ The Cambridge Quarterly 44.3 (2015): 213-232. Print.

Regan, Tom. The Case for Animal Rights. Berkeley: University of California Press, 1983. Print.

Reubold, Todd. 'A Song of Our Warming Planet'. Ensia, 28 ${ }^{\text {th }}$ June 2013. Web. http://ensia.com/videos/a-song-of-our-warming-planet/. 23 ${ }^{\text {rd }}$ Aug 2016

Rigby, Kate. ' “Come forth in to the light of things”: Material Spirit as Negative Ecopoetics.' In Gregory C. Stallings, Manuel Asensi and Carl Good, eds. Material Spirit: Religion and Literature Intranscendent. New York: Fordham UP, 2014, pp. 111-128. Print.

Roberts, Neil. Ted Hughes: A Literary Life. Basingstoke: Palgrave Macmillan 2006. Print.

---. Ted Hughes: New Selected Poems. Penrith: Tirrill Hall, 2007. Ebook.

---. 'Hughes and the Carnivalesque’ in Gifford, ed. Ted Hughes. Basingstoke: Palgrave, 2015. Pp. 70-85. 
Robinson, Craig. 'The Good Shepherd: Moortown Elegies'. The Achievement of Ted Hughes. Ed. Keith Sagar. Manchester: Manchester UP 1983. 257-284. Print.

---. Ted Hughes as Shepherd of Being. Basingstoke: Macmillan, 1989. Print.

Roman Britain.org. 'Nemetostatio'. Web. Accessed on 19 ${ }^{\text {th }}$ Dec 2014. http://www.romanbritain.org/places/nemetostatio.htm

Rome, Adam. “ "Give Earth a Chance”: The Environmental Movement and The Sixties'. The Journal of American History 90.2 (2003): 524-54. Print.

Ross, David, Ted Hughes and Daniel Weissbort, eds. (No author of article specified). 'ECY Review'. Your Environment 1.2 (Spring 1970): 40-41. Print.

RSPB. 'Short-Eared Owl’. N.d. Web. 5 ${ }^{\text {th }}$ April 2016.

https://www.rspb.org.uk/discoverandenjoynature/discoverandlearn/birdguide/name/s/sh ortearedowl/

---. 'Hen Harrier'. N.d. Web. 5 ${ }^{\text {th }}$ April 2016.

http://www.rspb.org.uk/discoverandenjoynature/discoverandlearn/birdguide/name/h/henharri er/index.aspx

Rueckert, William. 'Literature and Ecology: An Experiment in Ecocriticism'. (eds), The Ecocriticism Reader: Landmarks in Literary Ecology. Eds Cheryll Glotfelty and Harold Fromm. Georgia: Georgia UP, 1996. 105-123.

Ryder, Richard. Animal Revolution: Changing attitudes towards speciesism. Oxford: Berg 2000. Print.

Sacks, Peter. The English Elegy: Studies in the Genre from Spenser to Yeats. Baltimore: John Hopkins UP, 1987.

Sacred Earth Drama Trust. Sacred Earth Dramas. Foreword by Ted Hughes. Introd. Toni Arthur. London: Faber \& Faber 1993. Print.

Sandbrook, Dominic. State of Emergency. The Way We Were: Britain, 1970-1974. London: Penguin, 2010.

Sagar, Keith. The Art of Ted Hughes. Cambridge: Cambridge UP, 1978. Print.

---. Ed. The Challenge of Ted Hughes. Basingstoke: Palgrave Macmillan, 1994. Print.

---. The Life of D. H. Lawrence: An Illustrated Biography. London: Chaucer 2011. Print.

---. The Laughter of Foxes: A Study of Ted Hughes. Liverpool: Liverpool UP, 2006. Print.

---. Ted Hughes and Nature: 'Terror and Exultation'. Peterborough: Fastprint Publishing, 2009. Print.

---. 'Ted Hughes and the Classics'. In Ted Hughes and the Classics. Ed. Roger Rees. Oxford: 
Oxford UP, 2009. 1-24. Print.

Salter, Leo. 'Lawrence and the Environment; the Politics of Honesty and Despair.' Etudes lawrenciennes 41 (2010): 175-86. Print.

Sandilands, Catriona. 'Queer Life? Ecocriticism after the fire'. In Greg Garrard, ed. The Oxford Handbook of Ecocriticism. Oxford: Oxford UP 2014, pp. 305-19. Print.

Sassoon, Siegfried. Sherston’s Progress, Vol 3. Garden City: Doubleday Doran, 1936.

Schelling, Andrew. 'A Bioregional Poetry Class at Naropa'. ecopoetics 1 (Winter 2001): 9096. Print.

Schmidt, Christopher. The Poetics of Waste: Queer Excess in Stein, Ashbery, Schuyler, and Goldsmith. New York: Palgrave Macmillan, 2014. Print.

Schumacher, E. F. Small is Beautiful: A Study of Economics as if People Mattered. London: Blond \& Briggs 1973. Print.

Scigaj, Leonard. Ted Hughes: The Unaccommodated Universe. Santa Barbara, CA: Black Sparrow, 1980. Print.

---. 'The Ophiolatry of Ted Hughes’. Twentieth Century Literature 31.4 (Winter 1985): 38098. Print.

---. Ted Hughes. Boston: Twayne, 1991. Print.

---. 'Ted Hughes and Ecology: A Biocentric Vision' in The Challenge of Ted Hughes. Ed. Keith Sagar. Basingstoke: Palgrave Macmillan 1994. 160-181. Print.

---. Sustainable Poetry: Four American Ecopoets. Kentucky: Kentucky UP, 1999. Print.

Scott Bryson, J. The West Side of Any Mountain: Place, Space and Ecopoetry. Iowa: Iowa UP, 2005. Print.

Scruton, Roger. On Hunting. London: Yellow Jersey Press, 1998. Print.

Selby, Nick. 'Ecopoetries in America' in Jennifer Ashton, Ed. The Cambridge Companion to American Poetry Since 1945. Cambridge: Cambridge UP, 2013. Pp.127-42. Print.

Seymour, John. The Complete Book of Self Sufficiency. London: Corgi, 197. Print.

Skea, Ann, transcriber. 'An Interview with Ted Hughes [at the Asia Festival]'. Web. $6^{\text {th }}$ Nov. 2013. http://ann.skea.com/AsiaFestivalInterview.html.

---, transcriber. 'Ted Hughes: Interview and Poetry Reading. Melbourne, Australia. 1976.

Web. 18 March 2016. http://ann.skea.com/Adelaide2.htm

---, transcriber. 'Ted Hughes in an ABC interview, March 1976.' Web. 6 ${ }^{\text {th }}$ Nov. 2013.

http://ann.skea.com/ABC1.htm 
---, transcriber. 'Ted Hughes in an ABC interview, March 1982'. Web. 6 ${ }^{\text {th }}$ Nov. 2013. http://ann.skea.com/ABC2AF.htm.

---, transcriber. 'Ted Hughes at the Adelaide Festival Writers' Week'. Web. $21^{\text {st }}$ May 2014. http://ann.skea.com/Adelaide.htm.

---. 'Ted Hughes and the Goddess' The Ted Hughes Society 2012. Web. 26 ${ }^{\text {th }}$ Nov. 2013. http://www.thetedhughessociety.org/thegoddess.htm.

---. 'Ted Hughes and Crow. 1998. Web. 19'th Dec. 2014. http://ann.skea.com/Trickstr.htm

---. 'Moortown, Elmet and Heptonstall' 2008. Web. 11 Nov 2014.

http://ann.skea.com/NQ8farm.htm.

Skinner, Jonathan 'Statement for “New Nature Writing”', ecopoetics 4/5 (2004-2005): $127-$ 29. Print.

----. 'Dark ecology: In the wolf-songbird complex'. Jacket 2. $14^{\text {th }}$ Sept 2011.

Snyder, Gary. The Real Work: Interviews and Talks, 1964-1979. New York: New Directions, 1980. Print.

Solnick, Sam. Poetry in the Anthropocene. Abingdon: Routledge, 2016. Print.

Stansell, Elizabeth Anderson. " "Somebody else will have to write their poems: Ted Hughes and the evolution of “Skylarks”'. The South Carolina Review 38.2 (Spring 2006): 7297.

Sweeney, Sarah. 'The sounds of nature, as music'. Harvard Gazette. $1^{\text {st }}$ Oct 2012. http://news.harvard.edu/gazette/story/2012/10/the-sounds-of-nature-as-music/. $28^{\text {th }}$ Oct 2015. Web.

Tarlo, Harriet. 'Women and ecopoetics: an introduction in context.' How 23.2 (Summer 2008) 1-24. Print.

---. Ed. The Ground Aslant: An Anthology of Radical Landscape Poetry. Exeter: Shearsman 2011. Print.

Taylor, Brian. 'Shaman of the Tribe? Ted Hughes and Contemporary Animism.' The Ted Hughes Society Journal 4.1 (July 2014): 101-114. Print.

Taylor, Bron. Dark Green Religion: Nature Spirituality and the Planetary Future. Berkeley, CA: California UP, 2010. Print.

The Times, 'The Crow Man as Tribal Poet'. 22 ${ }^{\text {nd }}$ Dec. 1984: 9. Print.

Tuan, Yi-Fu. Space and Place: The Perspective of Experience. Minneapolis: University of Minnesota Press, 1977. Print. 
Vince, Gaia. Adventures in the Anthropocene: A journey to the heart of the planet we made. London: Chatto, 2014. Print.

Virgil. Georgics. Trans. Peter Fallon. Oxford: Oxford UP 2004. Print.

VT Usha and Murali Shivaramakrishnan. 'Postcolonial Indian Readings'. Gifford, ed. Ted Hughes. London: Palgrave, 2015. 145-59.

Wakefield, J. A. 'Clean or Dirty Beaches: Which Do You Prefer?' Your Environment 1.1 (Winter 1969): 29. Print.

Wallis, H. F. 'Uphill All The Way: Long Haul For The Atlantic Salmon'. Your Environment 4.2 (Summer 1973): 102-110. Print.

Weart, Spencer R. The Discovery of Global Warming. Cambridge, MA: Harvard UP, 2008. Print.

Weiser, Matt. 'A guide to the EPA data under threat by the Trump administration'. The Guardian sustainable business sec. $15^{\text {th }}$ March 2017. Web. 10 ${ }^{\text {th }}$ April 2017. https://www.theguardian.com/sustainable-business/2017/mar/15/epa-data-trumpclimate-change

West, Thomas. Ted Hughes. York: Methuen, 1985. Print.

Whale, John. 'The River Cleaners’. Your Environment 1.1 (Winter 1969): 22-25. Print.

Williams, Raymond. The Country and the City. London: Chatto \& Windus, 1973. Print.

Wolfe, Cary. Animal Rites: American Culture, the Discourse of Species, and Posthumanist Theory. Chicago: Chicago UP, 2003. Print.

---. Ed. Zoontologies: The Question of the Animal. Minneapolis: Minnesota UP 2003. Print.

---. What is Posthumanism? Minneapolis: Minnesota UP 2010. Print.

Wormald, Mark. 'Fishing for Ted.' Ted Hughes: From Cambridge to Collected. Ed. Terry Gifford, Neil Roberts and Mark Wormald. Basingstoke: Palgrave Macmillan 2013. 112-129. Print.

---. 'Testing the Waters: Hughes and Irish Pike.' The Ted Hughes Society Journal 4.1 (July 2014): 7-22. Print.

Worster, Donald. Nature's Economy: A History of Ecological Ideas. Cambridge: Cambridge UP, 1994. Print.

Wutz, Michael and Crimmel, Hal. Conversations with W. S. Merwin. Jackson: University Press of Mississippi, 2015. Print.

---. Yalden, Derek. The History of British Mammals. London: Poyser, 1999. Print. 


\section{Unpublished works of scholarly criticism}

Gifford, Terry. 'From Countryside to Environment: Five Stages in the Greening of Ted Hughes'. 2014. Unpublished conference presentation, forthcoming as a book chapter in 2016.

Johnson, Owen. 'Ted Hughes: speaking for the earth.' Durham theses: Durham university. Available online at Durham e-theses: http://etheses.dur.ac.uk/1483/1/1483. Accessed on 01. 07. 14. Web.

Roberts, Neil. 'Ted Hughes’s Paradise’. 2014. Unpublished conference presentation.

\section{$\underline{\text { Scientific publications }}$}

Barel, C.D.N., R. Dorit, P.H. Greenwood, G. Fryer, N. Hughes, P. B. N. Jackson, H. Kawanabe, R. H. Lowe-McConnell, M. Nagoshi, A.J. Ribbink, E. Trewavas, F. Witte \& K. Yamakoa 'Destruction of fisheries in Africa's lakes'. Nature, 6014.315 (2-8 May 1985): 19-20. Print.

Crutzen, Paul J. and Eugene Stoermer. 'The “Anthropocene”'. Global Change Newsletter 41 (2000): 17-18. Print.

Environment Agency. 'River Torridge \& Hartland Streams Consultation Draft September 1998’. Bristol: Environment Agency 1998. Print.

Von der Heydt, Anna and Henk A. Dijkstra, 'Effect of ocean gateways on the global ocean circulation in the late Oligocene and early Miocene'. Palaeoceanography 21.1011: 118. Print.

Koops, Kathelijne, Caspar Schöning, Mina Isaji and Chie Hashimoto. 'Cultural differences in ant-dipping tool length between neighbouring chimpanzee communities at Kalinzu, Uganda.' Scientific Reports, 22 Jul 2015: 1-8. Web. 15 ${ }^{\text {th }}$ June 2016. http://www.nature.com/articles/srep12456

Mazzini, Francesco, Simon W. Townsend, Zsófia Virányi, and Friederike Range. 'Wolf Howling Is Mediated by Relationship Quality Rather Than Underlying Emotional Stress'. Current Biology 23 (September 9 2013): 1677-1680. Print.

\section{$\underline{\text { Audio recordings }}$}

'Ted Hughes and R. S. Thomas Read and Discuss Selections of Their On Poems', Norwich Tapes. The Critical Form, 1978. Audio.

'Two of a Kind: Poets in Partnership'. Interview with Ted Hughes and Sylvia Plath, by Owen Leeming. The Spoken Word: Sylvia Plath. London: British Library, 2010. Audio CD. 
Interview of Ted Hughes by Nigel Forde. 'Bookshelf', BBC Radio 4, $20^{\text {th }}$ March 1992. Audio.

'Ted Hughes: Eco Warrior'. Simon Armitage. BBC Radio 4, 15 ${ }^{\text {th }}$ May 2009. Audio. $\underline{\text { Film }}$

Ted Hughes: Dream Time. Produced by David Cohen. 2015. DVD.

$\underline{\text { Works of reference }}$

The Oxford English Dictionary, digital edn. Oxford: Oxford UP, 2013. Ebook.

A Dictionary of British Place-Names. A. D. Mills. Oxford: Oxford UP, 2003. Print. 